Gabriela BaruQue Villar

\title{
Gênero, cuidado e saúde: estudo entre homens usuários da atenção primária em São Paulo
}

Dissertação apresentada à Faculdade de Medicina da Universidade de São Paulo para obtenção do grau de Mestre em Ciências

Área de concentração: Medicina Preventiva Orientadora: Márcia Thereza Couto Falcão

São Paulo

2007 


\section{GaBRIELA BARUQUe VILLAR}

\section{Gênero, cuidado e saúde: estudo entre homens usuários da atenção primária em São Paulo}

Dissertação apresentada à Faculdade de Medicina da Universidade de São Paulo para obtenção do grau de Mestre em Ciências

Área de concentração: Medicina Preventiva Orientadora: Márcia Thereza Couto Falcão

São Paulo

2007 
Dedico meu trabalho aos meus pais, Evanir e Aníbal, e ao meu irmão, Neto 


\section{Agradecimentos}

É com sinceridade e carinho que presto meus agradecimentos àqueles que vêm me acompanhando na jornada de minha formação, profissional e pessoal, desde o momento em que me conheceram.

Agradeço inicialmente à Carla, que sempre acreditou em mim e despertou em mim o interesse pelo mundo acadêmico.

À Marta, que proporcionou meu contato com o grupo de Pesquisa e Intervenção "Violência e Gênero nas Práticas de Saúde" do Departamento de Medicina Preventiva da Faculdade de Medicina da Universidade de São Paulo (FMUSP), possibilitando o desenvolvimento dessa dissertação.

À Dra. Lilia, pelo interesse e apoio ao tema de meu projeto.

À minha orientadora Márcia Couto, que me direcionou no estudo sobre gênero e homens desde minha residência médica e me recebeu "de braços abertos" como sua primeira mestranda no Departamento de Medicina Preventiva da FMUSP.

À Lílian, por sempre me lembrar das datas e prazos a serem cumpridos no mestrado e por tirar todas as minhas dúvidas, várias vezes, nos momentos finais de meu trabalho.

Aos professores da pós-graduação do Departamento de Medicina Preventiva da FMUSP, por colaborarem em meu aprimoramento científico.

Aos meus professores em minha residência médica em Medicina Preventiva e Social na Faculdade de Ciências Médicas da Santa Casa de São Paulo (FCMSCSP), e aos preceptores no Centro de Saúde Escola Barra Funda "Dr. Alexandre Vranjac" (CSEBF-AV), especialmente à Ana, ao Jota, à Carla, à Vivian e à Rute, pela minha formação integral como sanitarista. À Rute, também, por me inserir na atividade que me direcionou ao tema da presente dissertação.

Aos integrantes do grupo de pesquisa: Adriana, Ana Flávia, Diane, Fábio Américo, Fábio Antônio, Julia, Ligia, Marcelo, Ricardo, Wagner; e aos demais participantes da pesquisa: Márcio, Marcos e Shirlei. Ao Fábio Américo, também, pelo apoio na composição do banco de dados de minha pesquisa. 
À direção do CSEBF-AV, pelo espaço cedido para realização da pesquisa e pela liberação para realização das atividades do mestrado desde seu início. Agradeço à equipe do CSEBF-AV, pela compreensão das minhas ausências, especialmente à Chris, à Inês, à Maura e à Elizete. À equipe do sistema de informações e especialmente à Silvana Ferro, que disponibilizou os dados sobre o CSEBF-AV com todas as especificidades que precisei. À equipe do arquivo, pela ajuda na busca de prontuários e ficha de matrícula dos usuários. Ao Dr. Nivaldo, pela compreensão e disponibilização de mais tempo nos momentos finais para a redação do meu trabalho.

Ao Manoel, pela importante e sincera orientação para o tratamento estatístico dos dados.

Ao Beto, pelo apoio com as infindáveis pesquisas de dados e informações, pelas dicas "de um veterano de mestrado" sobre redação e estruturação da dissertação e por ter ficado ao meu lado nos últimos meses de trabalho, ainda que não nas últimas semanas (que falta você fez!!!) sempre que possível.

Ao meu irmão Neto, pelo auxílio em relação à formatação de figuras e formatação final da dissertação (que não foi nada fácil!!!), pelo apoio e pelo carinho.

À minha "babá" Maura (in memoriam), que nunca faltou com um cafezinho ou um belo lanche ou muita pipoca em todos os meus momentos de estudo, desde sempre.

Aos meus avós, Alice (in memoriam) e Elias (in memoriam), Olinda e Anníbal, que desde sempre participaram do meu processo de formação, apoiando, torcendo e se orgulhando de mim.

Aos meus familiares, também fiéis torcedores do meu desenvolvimento profissional.

Agradeço imensamente aos meus pais, Evanir e Aníbal, por sempre me apoiarem e me orientarem em todas as minhas decisões, profissionais e pessoais, e por estarem presentes e disponíveis sempre que eu preciso. 
I-Juca Pirama

"Tu choraste em presença da morte? Na presença de estranhos choraste? Não descende o cobarde do forte; Pois choraste, meu filho não és! (...)"

"E pois que o acho enfim, qual sempre o tive, Corram livres as lágrimas que choro, Estas lágrimas, sim, que não desonram."

Gonçalves Dias 


\section{Sumário}

LISTA DE TABELAS

LISTA DE FIGURAS

RESUMO

ABSTRACT

APRESENTAÇÃO

CAPÍtUlO 1 - FEMINISMO E GÊNERO 1

\begin{tabular}{lr}
\hline I. FEMINISMO - UM POUCO DE SUA HISTÓRIA & 2
\end{tabular}

$\begin{array}{ll}\text { II. GÊNERO - ALGUMAS CONSIDERAÇÕES } & 12\end{array}$

CAPÍtulo 2 - Masculinidades, HoMens E SAÚde 16

$\begin{array}{lr}\text { I. MASCULINIDADE(S): UM POUCO DE SUA HISTÓRIA } & 17\end{array}$

\begin{tabular}{lr}
\hline II. MASCULINIDADE HEGEMÔNICA & 25
\end{tabular}

III GÊNERO, COMPORTAMENTO DE RISCO E ADOECIMENTO 28

$\begin{array}{ll}\text { IV. SAÚDE DO HOMEM } & 35\end{array}$

\begin{tabular}{lr}
\hline V. O HOMEM CONTEMPORÂNEO & 40
\end{tabular}

CAPÍTULO 3 - OBJETIVOS E MÉTODOS 48

\begin{tabular}{ll}
\hline I. OBJETIVO GERAL & 49
\end{tabular}

$\begin{array}{ll}\text { II. OBJETIVOS ESPECÍFICOS } & 49\end{array}$

\begin{tabular}{ll}
\hline III. DELINEAMENTO DO ESTUDO & 50
\end{tabular}

\begin{tabular}{lr}
\hline IV. SUJEITOS DA INVESTIGAÇÃOO & 51
\end{tabular}

\begin{tabular}{lr}
\hline V. PLANO DE AMOSTRAGEM & 51
\end{tabular}

V.1. Dimensionamento da amostra 51

$\begin{array}{ll}\text { V.2. Desenho da pesquisa } & 52\end{array}$

VI. INSTRUMENTOS DA PESQUISA

VI.1. Elaboração do instrumento questionário $\quad 53$

VI.2. Elaboração do instrumento ficha de leitura dos prontuários $\quad 54$

VI.3. Utilização de dois instrumentos $\quad 55$

$\begin{array}{lr}\text { VII. PESQUISA DE CAMPO } & 55\end{array}$

\begin{tabular}{ll}
\hline VII.1. Seleção e treinamento das equipes & 55
\end{tabular}

VII.2. Logística e implantação da pesquisa de campo $\quad 56$

VII.2.a. Aplicação dos questionários $\quad 56$ 
VII.2b. Leitura dos prontuários médicos

VII.2.c. Controle de qualidade das informações 58

VIII. VARIÁVEIS CONSIDERADAS NO ESTUDO 59

$\begin{array}{ll}\text { IX. ANÁLISE DOS DADOS } & 60\end{array}$

$\begin{array}{ll}\text { IX.1. Codificação dos instrumentos } & 60\end{array}$

IX.2. Constituição do banco de dados $\quad 61$

$\begin{array}{ll}\text { IX.3. Análise estatística } & 61\end{array}$

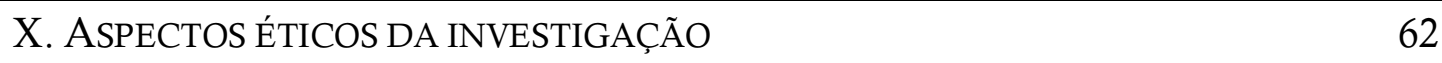

CAPÍTULO 4 CSEBF-AV - CARACTERÍSTICAS DO LÓCUS DA PESQUISA

$\begin{array}{ll}\text { I. SURGIMENTO E CONTEXTUALIZAÇÃO HISTÓRICA } & 65\end{array}$

\begin{tabular}{ll}
\hline II. IMPLANTAÇÃO E OBJETIVOS & 66
\end{tabular}

III. ÁREA ABRANGIDA E POPULAÇÃO ASSISTIDA 68

IV. AS MUDANÇAS: ÁREA, POPULAÇÃO, ORGANIZAÇÃO DO SERVIÇO 69

\begin{tabular}{ll}
\hline V. O CENTRO DE SAÚDE HOJE & 73
\end{tabular}

$\begin{array}{ll}\text { CAPÍtUlO } 5 \text { - RESUltados } & 79\end{array}$

\begin{tabular}{ll}
\hline I. CARACTERIZAÇÃO DA AMOSTRA & 80
\end{tabular}

II. DISTRIBUIÇÃO DOS HOMENS SEGUNDO A PORTA DE ENTRADA NO 81 SERVIÇO

III. CARACTERIZAÇÃO DOS HOMENS USUÁRIOS DO CSEBF-AV 81

III.1. Caracterização sócio-demográfica $\quad 82$

III.2. Caracterização familiar $\quad 86$

$\begin{array}{ll}\text { III.3. Caracterização do perfil sexual e reprodutivo } & 89\end{array}$

III.4. Caracterização das demandas de saúde em geral entre os usuários do $\quad 92$ CSEBF-AV

III.4.1. Saúde sexual: demanda auto-referida e demanda diagnosticada 93

III.4.2. Saúde geral: demanda diagnosticada 96

III.4.3. Hábitos e práticas relacionados à saúde em geral: demanda auto- 109 referida e demanda diagnosticada

$\begin{array}{ll}\text { III.4.3.a. Demanda auto-referida } & 109\end{array}$

$\begin{array}{ll}\text { III.4.3.b. Demanda diagnosticada } & 111\end{array}$

III.5. Caracterização do padrão de uso do CSEBF-AV pelos homens 114 usuários

III.5.1. Padrão de uso auto-referido do CSEBF-AV 
III.5.2. Padrão de uso do CSEBF-AV identificado em prontuário 116 \begin{tabular}{ll} 
CAPÍTULO 6 - DiscUSSÃO & 121 \\
\hline
\end{tabular}

I. HOMENS USUÁRIOS DO CSEBF-AV: QUEM SÃO ELES? 122

II. HOMENS USUÁRIOS DO CSEBF-AV: QUAIS SÃO AS SUAS NECESSIDADES E $\quad 126$ PERCEPÇÕES EM SAÚDE?

II.1. Necessidades e percepções em saúde sexual 125

$\begin{array}{ll}\text { II.2. Necessidades e percepções em saúde geral } & 127\end{array}$

III. HOMENS USUÁRIOS DO CSEBF-AV: COMO INTERAGEM COM OS 132 SERVIÇOS DE SAÚDE?

\begin{tabular}{lr}
\hline III.1. A busca pelos serviços de saúde & 132 \\
\hline III.2. O uso do CSEBF-AV & 132 \\
\hline IV. CONSIDERAÇÕES FINAIS & 135 \\
\hline CAPÍTULO 7 - CONCLUSÃO & 137 \\
\hline ANEXOS & 141 \\
\hline ANEXO A - APROVAÇÃO & 142 \\
\hline ANEXO B - TERMO DE CONSENTIMENTO & 143 \\
\hline ANEXO C - INSTRUMENTOS & 144 \\
\hline ANEXO C.1 - QUESTIONÁRIO & 144 \\
\hline ANEXO C.2 - FICHA DE LEITURA DE PRONTUÁRIOS MÉDICOS & 153 \\
\hline REFERËNCIAS BIBLIOGRÁFICAS & 157 \\
\hline BIBLIOGRAFIA CONSULTADA & 167
\end{tabular}




\section{Lista de tabelas}

Tabela 1: Coeficiente de mortalidade geral e por sexo, por mil habitantes, $\quad 30$ 2000 (20-59 anos)

Tabela 2: Coeficiente de mortalidade por causa, por 100 mil habitantes, cinco primeiras causas de óbito entre homens (CID-10), para homens e mulheres, 2000 (20-59 anos)

Tabela 3: Mortalidade proporcional por causas, cinco primeiras causas de óbito entre homens (CID-10), para homens e mulheres, 2004 (20-59 anos)

Tabela 4: Caracterização sócio-demográfica dos homens entrevistados CSEBF-AV $(\mathrm{N}=237)$

Tabela 5: Caracterização sócio-demográfica dos homens entrevistados -

CSEBF-AV: análise estatística segundo o tipo de matrícula $(\mathrm{N}=237)$

Tabela 6: Caracterização sócio-demográfica dos homens entrevistados CSEBF-AV: análise estatística segundo o tipo de matrícula: excluídos e não-excluídos $(\mathrm{N}=210)$

Tabela 7: Caracterização familiar dos homens entrevistados - CSEBF-AV 88 $(\mathrm{N}=237)$

Tabela 8: Caracterização familiar dos homens entrevistados - CSEBF-

AV: análise estatística segundo o tipo de matrícula $(\mathrm{N}=237)$

Tabela 9: Descrição do perfil sexual e reprodutivo dos homens 91 entrevistados - CSEBF-AV (N=237)

Tabela 10: Descrição do perfil sexual e reprodutivo dos homens 92 entrevistados - CSEBF-AV - relações extraconjugais e uso de preservativo masculino $(\mathrm{N}=237)$

Tabela 11: Demanda diagnosticada entre os homens entrevistados 99 CSEBF-AV, no último ano de uso do serviço $(\mathrm{N}=237)$

Tabela 12: Demanda diagnosticada, por sistema mais acometido, entre 102 os homens entrevistados - CSEBF-AV, no último ano de uso do serviço $(\mathrm{N}=237)$

Tabela 13: Demanda diagnosticada - homens entrevistados - CSEBF- 108 AV: análise estatística segundo o tipo de matrícula $(\mathrm{N}=237)$

Tabela 14: Demanda diagnosticada - homens entrevistados - CSEBF- 108 AV: análise estatística segundo o tipo de matrícula: excluídos e nãoexcluídos $(\mathrm{N}=210)$

Tabela 15: Cuidado com a saúde entre os homens entrevistados - 111 CSEBF-AV $(\mathrm{N}=237)$ 
Tabela 16: Padrão de uso do CSEBF-AV pelos homens entrevistados, usuários do serviço, identificado em prontuário, no último ano: análise estatística segundo o tipo de matrícula $(\mathrm{N}=237)$

Tabela 17: Padrão de uso do CSEBF-AV pelos homens entrevistados, 118 usuários do serviço, identificado em prontuário, no último ano: análise estatística segundo o tipo de matrícula: excluídos e nãoexcluídos $(\mathrm{N}=237)$

Tabela 18: Encaminhamentos registrados em prontuários, último ano de uso do serviço, homens entrevistados - CSEBF-AV: análise estatística segundo o tipo de matrícula $(\mathrm{N}=237)$

Tabela 19: Encaminhamentos registrados em prontuários, último ano de 120 uso do serviço, homens entrevistados - CSEBF-AV: análise estatística segundo o tipo de matrícula: excluídos e não-excluídos $(\mathrm{N}=237)$ 


\section{Lista de figuras}

Figura 1: Município de São Paulo: subprefeituras e distritos - no 74 destaque, subprefeitura Sé, região onde está inserido o CSEBF-AV

Figura 2: Distribuição dos indivíduos cadastrados no CSEBF-AV 76 segundo sexo, outubro/ $2006(\mathrm{~N}=13.794)$

Figura 3: Distribuição dos indivíduos cadastrados no CSEBF-AV 77 segundo porta de entrada e sexo $(\mathrm{N}=13.794)$

Figura 4: Distribuição dos homens entrevistados, segundo o uso do 80 serviço no dia da entrevista $(\mathrm{N}=391)$

Figura 5: Distribuição dos homens entrevistados, segundo a situação de 80 matrícula no serviço $(\mathrm{N}=391)$

Figura 6: Distribuição dos homens entrevistados e matriculados no serviço, segundo a situação do prontuário na ocasião da pesquisa $(\mathrm{N}=316)$

Figura 7: Distribuição dos homens entrevistados e matriculados no 81 serviço segundo a porta de entrada $(\mathrm{N}=237)$

Figura 8: Distribuição da procedência dos homens entrevistados segundo 83 as regiões do Brasil e procedência estrangeira $(\mathrm{N}=237)$

Figura 9: Caracterização familiar dos homens entrevistados - CSEBF-

AV: análise estatística segundo o tipo de matrícula: excluídos e nãoexcluídos $(\mathrm{N}=210)$

Figura 10: Sintomas gênito-urinários, demanda auto-referida pelos 93 homens entrevistados - CSEBF-AV, segundo a porta de entrada $(\mathrm{N}=237)$

Figura 11: Sintomas gênito-urinários, demanda diagnosticada entre os 95 homens entrevistados - CSEBF-AV, segundo a porta de entrada ( $\mathrm{N}=237)$

Figura 12: Sintomas gênito-urinários, comparação entre as demandas 95 auto-referida e diagnosticada entre os homens entrevistados - CSEBF$\mathrm{AV}$, segundo a porta de entrada $(\mathrm{N}=237)$

Figura 13: Demanda diagnosticada entre os homens entrevistados 97 CSEBF-AV, no último ano de uso do serviço $(\mathrm{N}=237)$

Figura 14: Uso de álcool, tabagismo e drogadição entre os homens 112 entrevistados - CSEBF-AV, segundo o tipo de matrícula - demanda diagnosticada ( $\mathrm{N}=237)$

Figura 15: Cuidado com a saúde entre os homens entrevistados, usuários 113 do CSEBF-AV: demanda auto-referida e demanda diagnosticada $(\mathrm{N}=237)$ 
Figura 16: Padrão de uso de serviços de saúde auto-referido pelos

homens entrevistados - CSEBF-AV, no último ano $(\mathrm{N}=237)$

Figura 17: Padrão de uso do CSEBF-AV pelos homens entrevistados, 117 usuários do serviço, identificado em prontuário, no último ano $(\mathrm{N}=237)$

Figura 18: Encaminhamentos registrados em prontuários, último ano de uso do serviço, homens entrevistados - CSEBF-AV (N=237) 


\section{Resumo}

VILLAR GB. Gênero, cuidado e saúde: estudo entre homens usuários da atenção primária em São Paulo [tese]. São Paulo: Faculdade de Medicina, Universidade de São Paulo; 2007. 167p.

A saúde do homem surge como questão de Saúde Pública frente às elevadas taxas de mortalidade masculina quando comparadas às taxas de mortalidade feminina. Há algumas décadas, os estudos sobre homens buscam relacionar essas estatísticas com a questão de gênero, demonstrando que o padrão de comportamento adotado pelos homens, baseado na masculinidade hegemônica, e socialmente imposto, está relacionado ao comportamento do homem em relação ao processo saúde-doença. Este estudo pretende conhecer a população masculina adulta usuária de um serviço de atenção primária à saúde - o Centro de Saúde Escola Barra Funda Dr. Alexandre Vranjac (CSEBF-AV) - e o modo como essa população se relaciona com o serviço: quem são esses homens, quais são as suas demandas e como eles estão inseridos na unidade. A partir do projeto de pesquisa intitulado "Homens, violência e saúde: uma contribuição para a linha de pesquisa e intervenção em gênero, violência doméstica e saúde" selecionou-se amostra de 237 homens usuários do CSEBF-AV. Os homens foram individualmente entrevistados a partir do instrumento questionário e seus prontuários lidos a partir da ficha de leitura de prontuários, buscando-se conhecer aspectos sócio-demográficos, de saúde e de uso do serviço desses homens segundo o tipo de matrícula/ porta de entrada no serviço: moradores e trabalhadores da área de abrangência da unidade, homens em situação de exclusão social e homens cuja entrada no serviço esteve vinculada a condições de saúde-doença relacionadas à vigilância epidemiológica (VE). Os dados coletados foram analisados nos programas STATA v. 9 e Epi Info v. 6.04b. Os homens, em sua maioria, pertenciam ao grupo etário de 35 a 54 anos, tinham 8 a 11 anos de estudo, pertenciam aos estratos sociais $\mathrm{C}$ e D, tinham relacionamento estável, moravam com a família em casa/ apartamento e estavam empregados. Em relação às questões de saúde, a maioria dos homens entrevistados mostrou boa percepção de sinais e sintomas, queixas gerais $(43,5 \%)$ como principal demanda em saúde, uso importante de bebidas alcoólicas $(62,4 \%)$, uso do preservativo masculino para prevenção de infecções sexualmente transmissíveis $(54 \%)$ e opção (do casal) por laqueadura ou pílula anticoncepcional como método contraceptivo $(41,4 \%)$. Em relação ao uso do serviço a maioria dos homens fazia uso de consultas programadas $(70 \%)$ e buscava primeiramente um centro de saúde frente a um problema de saúde $(57,8 \%)$. Observamos que moradores e trabalhadores da área apresentaram padrão de uso do serviço e de demandas semelhantes, enquanto que os homens seguidos pela VE apresentaram padrão específico de uso do serviço e demandas, devido à sua inserção diferenciada no serviço. Os homens em situação de exclusão destacaram-se por apresentar diversas características que os tornam mais vulneráveis às questões de saúde, desde fatores sócio-demográficos a formas de uso dos serviços. Acreditamos que as diferenças observadas entre os quatro grupos de homens poderiam estar relacionadas às questões de gênero, além de outros fatores. Ainda, a maior vulnerabilidade dos homens em situação de exclusão às questões de saúde aponta para a necessidade de uma organização do CSEBF-AV baseada nas relações de gênero, elaborando ações e estratégias que atentem para as necessidades comuns e específicas dos diferentes grupos de homens que fazem uso desse serviço.

Descritores: Saúde dos Homens, Gênero, Atenção Primária à Saúde 


\begin{abstract}
VILLAR GB. Gender, health and care: study among men patients from primary care in São Paulo [these]. São Paulo: "Faculdade de Medicina, Universidade de São Paulo"; 2007. 167p.
\end{abstract}

The men's health has emerged as an important concern to Public Health. It's because of the male death's rates are higher then the women's rates. In last decades, men's studies have been looking for relations between these statistics and gender, and they have demonstrated that the behavior pattern followed by men, based on hegemonic masculinity, and socially expected, it's related to men's behavior and the way they have been taken care of their health. The present study intends to know the adult male patient population from a primary health care - the Centro de Saúde Escola Barra Funda Dr. Alexandre Vranjac (CSEBF-AV) - and how these population have been using the health center: who are those men, which are their health demands and how they are insert in this health center. From the research project "Homens, violência e saúde: uma contribuição para a linha de pesquisa e intervenção em gênero, violência doméstica e saúde" we have selected a source of 237 men patients who are users of this health center. They were individually interwied by researches and a survey was applied to their medical records, intending to know their social aspects, their health and the way they have been using the health center, according to their service's register category: people who resides around the health center, people who works around the health center, people from lower social-economic levels and people that was registered at the service because of some health condition involving epidemiologic surveillance. The data were analyzed by STATA v. 9 and Epi Info v. $6.04 \mathrm{~b}$ programs. Mostly men were aged between 35-54, they had had 8 to 11 year's study, they were from middle class, they were living stable relationships, they were residing in house/ apartment whit their family and they were mostly workers. About health issues, mostly men showed to be able to perceive signs of health problem, general demands appeared being their main health demand $(43,5 \%)$, they were evidence for alcoholic abuse (62,4\%), safe sex practices (54\%), birth control depending on women $(41,4 \%)$. About the use of the health center mostly men were used to come up to their doctor's appointment (70\%), they looked first for health center when they were feeling ill $(57,8 \%)$. Men who resided around the health center and men who worked around the health center had similar use oh the health center, men that were registered at the service because of some health condition involving epidemiologic surveillance had specifics ways in using the health center. Men from lower socio-economic levels showed they were more vulnerable to disease's risk factors. We believe that the differences found among the groups of men could be related to gender, besides other factors. The CSEBF-AV organization based on gender will provide health actions improvement to all different men's groups. 
Apresentação 
A idéia de estudar o homem e como ele se relaciona com sua saúde surgiu ao final do meu primeiro ano de residência médica em Medicina Preventiva e Social. Meu estágio desenvolveu-se no Centro de Saúde Escola Barra Funda "Dr. Alexandre Vranjac" (CSEBF-AV), onde então tive contato com os programas de saúde desenvolvidos em um serviço de atenção primária: saúde da criança, saúde do adulto, saúde da mulher, vigilância epidemiológica, imunização e, no caso do CSEBF-AV, saúde bucal, saúde mental, serviço social e fonoaudiologia. Naquela ocasião, o Programa de Saúde da Família ainda não estava implantado no serviço.

$\mathrm{Na}$ área de saúde da mulher, além das atividades relacionadas às consultas características do programa (pré-natal, ginecologia, papanicolaou e planejamento familiar), tive a oportunidade de acompanhar a implantação de uma nova estratégia de atenção a saúde da mulher: o grupo de climatério. Sob a responsabilidade da Dra. Rute e da Dra. Sueli, ginecologistas da unidade, os grupos aconteciam semanalmente e eram relacionados à consulta das participantes, como uma estratégia para garantir a participação das mulheres no grupo e também reduzir o número de vezes que a usuária teria que se deslocar ao serviço. Os temas desenvolvidos nesse grupo eram iniciados a partir de duas questões: "o que é ser mulher" e "o que é ser mãe". Participei de todos os grupos que aconteceram ao longo do ano e duas questões chamaram minha atenção: a grande maioria das mulheres respondia que "ser mulher" era "ser mãe" e a grande maioria delas apresentava alguma queixa relacionada ao parceiro: a necessidade de cuidar de alguma questão de saúde do parceiro (caso contrário o esposo não se cuidava), a dificuldade em dialogar com seus parceiros (sobre qualquer assunto) e a dificuldade que elas sentiam em lidar com a "depressão" de seus parceiros, geralmente relacionada ao desemprego ou a aposentadoria ou a alguma doença crônica.

A grande maioria daquelas mulheres apresentava um discurso centrado em um modelo predominantemente patriarcal, e manifestavam o desejo de se libertar dessa situação e viver seus "sonhos". Porém muitas dessas mulheres sentiam-se "impossibilitadas" ou "temerosas" em assumir uma mudança tão importante, muitas vezes porque "não é o que se espera da esposa e mãe" ou porque "agora já estou 'velha' para essas coisas". Além das questões que eram então desenvolvidas com aquelas mulheres, as declarações ali expostas chamaram minha atenção para um 
"ator" pertencente às relações sociais dessas mulheres, que não seria totalmente responsável pela situação que surgia a cada grupo mas, muitas vezes, também uma "vítima" do mesmo modelo patriarcal baseado em uma dominação masculina sobre as mulheres: o homem.

Essas questões e esse comportamento que se repetiam a cada grupo despertaram em mim uma curiosidade: “e os homens 'nisso tudo', o que será que eles pensam?". A idéia que me ocorreu, talvez utópica pela sua simplicidade para a "solução do problema", foi "buscar compreender os homens no contexto dessas mesmas relações e, assim, quem sabe, seria possível melhorar a relação e o entendimento entre homens e mulheres, a partir do momento em que os homens pudessem compreender melhor a si próprios e as outras pessoas". Cabe lembrar que nas atividades dos grupos de climatério tais discursos não eram únicos, muitas mulheres já não tinham o modelo patriarcal como referencia e outras referiam maridos que eram parceiros de fato nas questões familiares, o que contribuía muito para o trabalho pretendido pelo grupo.

Iniciei meu segundo ano de residência conhecendo e estudando sobre gênero a fim de desenvolver minha monografia de conclusão da especialização com a temática saúde do homem e gênero. Por intermédio da Dra. Marta Campagnoni, conheci o grupo de estudos "Violência e Gênero nas Práticas de Saúde" do Departamento de Medicina Preventiva da USP, coordenado pela Dra. Lilia Schraiber, e também minha orientadora para a monografia e minha orientadora do presente estudo, Dra. Márcia Thereza Couto. Desde então venho estudando e aprendendo sobre gênero, saúde e homens e, ao longo dessa jornada que se iniciou há cinco anos, compreendi que minha idéia inicial ia mais além do que imaginei naquele momento.

Assim, hoje posso compreender que estudar a saúde do homem com base nas relações de gênero é importante para que os serviços de saúde e, mais especificamente, os serviços de atenção primária a saúde, se organizem de forma a saber "atrair", "receber" e "cuidar" da saúde os homens.

Os estudos sobre homens sob a perspectiva de gênero vêm se desenvolvendo ao longo das últimas décadas pelo mundo e ganharam força no Brasil na última década. Autores como Connell e Kimmel destacam-se nos estudos sobre relações de gênero e masculinidades e, como muitos outros pesquisadores desse assunto, 
apontam que o comportamento socialmente imposto e adotado por grande parte dos homens expõe esse grupo a situações de risco a sua saúde. SILVA SG da, (2000a) assinala que esse comportamento e a necessidade constante dos homens em provar sua masculinidade já vêm de alguns séculos e, concordando com CECCARELLI (1998a), aponta que essa necessidade passou a ser mais veemente a partir do momento em que a sociedade passou por transformações como a Revolução Francesa e a Revolução Industrial. Os autores destacam que nos países onde essas revoluções se iniciaram as mulheres conquistaram mais liberdade e, paradoxalmente, é nesses paises onde se intensificou o "culto à masculinidade" pela necessidade dos homens em provar essa masculinidade a todo instante.

LAURENTI (1998) em seu estudo sobre a saúde dos homens nas Américas aponta elevadas taxas de mortalidade masculina, em relação à população feminina, para doenças cardiovasculares e causas externas, entre outras, e relaciona esses óbitos ao comportamento de risco que os homens assumem a fim de afirmarem sua masculinidade. Os dados obtidos nesse estudo e em estudo posterior do mesmo autor (LAURENTI et al., 2005) apontam uma situação alarmante em relação a mortalidade dos homens que, de certa forma, permite presumir algumas das morbidades que mais acometem a população masculina e, com base nesses dados, notamos que muitas dessas morbidades são passíveis de prevenção. Essas estatísticas destacam a saúde do homem como um problema de Saúde Pública.

Com base na proposta de ConNELL $(1997,2000)$ para o entendimento das várias masculinidades (hegemonia, subordinação, cumplicidade e marginalização) e nas relações de gênero que o autor propõe (de poder, de produção e cathexis) é possível compreender esse comportamento de risco que muitos homens assumem. CONNELL (1997, 2000) sugere uma masculinidade dominante, denominada hegemônica, que seria um ideal a ser alcançado pelos homens. Procurando alcançar esse ideal, muitos homens buscam várias parceiras sexuais, usam de poder e força na relação com a parceira e com filhos, afastam-se de seus sentimentos e percebem-se invulneráveis, entre outras atitudes. A masculinidade hegemônica tende negar tudo o que se relaciona com o feminino e, assim, na busca dessa masculinidade ideal, os homens adotam comportamentos que os afastem de qualquer atributo feminino, entre os quais está a atenção com a própria saúde. 
Para os homens, com base nessa "teoria da negação", assumir um estado de deficiência da saúde é assumir um estado de fraqueza, e a fragilidade é um dos atributos relacionado ao feminino (GIFFIN \& CAVALCANTI, 1999; COURTENAY, 2000; CONNELl, 2000; BANKS, 2004; GRUMBACH, 2004; SCHRAIBER, et al., 2005; COUTO \& SCHRAIBER, 2005; ARILHA, 2005). Além disso, como apontam RowE (2000), BANKS (2004) e FIGUEIREDO (2005), os homens habitualmente relacionam o espaço das unidades básicas de saúde (UBS) com mulheres e crianças, sendo esse um dos motivos que os afasta dos serviços de atenção primária a saúde. De fato, as UBS foram organizadas de forma a desenvolver ações voltadas às mulheres (WoODS et al., 2002; BANKS, 2004; FigueIREDO, 2005), o que ganhou força com a criação do Programa de Atenção Integral à Saúde da Mulher (PAISM), em 1984, como resultado, entre outros, das manifestações do movimento feminista (D'OLIVEIRA \& SENNA, 1996). O programa visava abandonar o entendimento exclusivo da mulher como um binômio materno-infantil e a preocupação única com as boas condições de gestação, parto e puerpério, incorporando a essa tradicional assistência uma resposta organizada dos serviços de saúde. Englobava, portanto, a humanização da assistência, a integralidade e a equidade, abordando a saúde da mulher em todas as fases de seu ciclo vital, considerando as dimensões psicológicas e sociais nessa atenção, e desenvolvendo ações de atenção primária em saúde: educação em saúde, promoção da saúde, prevenção de doenças, tratamento e recuperação de patologias já instaladas (FORMIGA FILHO, 1999).

Dessa forma, os serviços passaram a se organizar, de fato, com a atenção mais voltada às necessidades de saúde das mulheres. Porém, o programa está correlacionado à proposta original do Sistema Único de Saúde (SUS), abrangendo desde a organização dos serviços de saúde até as suas diretrizes: universalidade, integralidade e participação popular (D’OLIVEIRA \& SENNA, 1996). Logo, embora LAURENTI (1998) argumente que não seria efetivo implantar para os homens estratégias e ações em saúde semelhantes àquelas implantadas para as mulheres, é possível partir das ações correlacionadas às propostas do SUS e, ao identificar quais as concepções dos vários homens sobre saúde e doença, organizar os serviços de forma a integrar as ações em saúde do homem e da mulher. 
Assim, ao identificar a população masculina como um grupo que necessita programas de ação em saúde com estratégias efetivas, sem a intenção de espelhar o desenvolvimento da atenção à saúde da mulher, mas também sem deixar de considerar as propostas de integralidade na assistência, ao estudar a saúde dos homens tenho como proposta conhecer o comportamento desses sujeitos dentro de um serviço de atenção primária à saúde. Conhecer, portanto, o uso que fazem desses serviços e observar a relação entre o comportamento por eles adotado e as questões de gênero socialmente impostas, praticadas, esperadas. Nesse sentido, o espaço das unidades básicas de saúde (UBS) apresenta-se como local ideal para o desenvolvimento de ações em saúde voltadas para os homens, uma vez que nas UBS desenvolve-se a atenção primária à saúde, que oferece o acesso aos cuidados e às tecnologias necessárias e adequadas para prevenção de doenças e seguimento das patologias crônicas diagnosticadas, bem como orientações para a promoção da saúde, objetivando-se a atenção integral à saúde (SCHRAIBER \& MENDES-GONÇALVES, 1996). Contudo, é preciso levar em consideração as relações de gênero e abordar, conforme apontado anteriormente, a saúde do homem e a saúde da mulher de forma relacionada e integrada (COURTENAY \& KEELing, 2000; Schofield et al., 2000; Stweart, 2004; Couto \& Schraiber, 2005; Figueiredo, 2005), para que os serviços de saúde e suas equipes estejam preparados para receber esse homem com suas demandas e necessidades específicas.

Compete, ainda, lançar algumas questões: os outros grupos de homens e as mulheres estão preparados para se relacionar com esseS novoS homenS?; com base no conceito de crise segundo CONNELL ${ }^{1}$, a nova masculinidade que será reconstruída, ao fim da atual crise da masculinidade, abandonará a idéia de dominação dos homens sobre as mulheres ou apenas se adaptará à nova realidade mantendo características típicas da hegemonia masculina e mantendo-se única?

\footnotetext{
${ }^{1}$ Connell RW. Masculinities. University of Califórnia Press, Berkeley, Los Angeles; 1995.
} 
Capitulo 1

Feminismo e Gênero 
"Por que a ciência nos é inútil? Porque somos excluídas dos encargos públicos E por que somos excluídas dos cargos públicos? Porque não temos ciência" Nísia Floresta

"And when women do not need to live through their husbands and children, men will not fear the love and strength of women, nor need another's weakness to prove their own masculinity"

Betty Friedan

\section{FEMINISMO - UM POUCO DE SUA HISTÓRIA}

O movimento feminista é um movimento legitimado que busca transformar as relações entre homens e mulheres. Apesar de ter produzido forte impacto sobre as estruturas econômicas, sociais, políticas e culturais e de ter acarretado enormes conquistas em todos os campos, ainda mantém sua luta em busca de mudanças. A cada dia há uma nova luta, uma nova conquista, uma nova demanda, que fazem com que o movimento ganhe, cada vez mais, maior número de adeptas - e adeptos, pois está ainda em plena ebulição (BESSIS, 2000; DuARTE, 2003; RAGO, 2003; COSTA, 2005).

Ao contrário do que prega o senso comum, a história de mulheres reivindicando e lutando por igualdade em relação aos homens é anterior à reconhecida organização das mulheres nas décadas de 60 e 70 e mesmo à demanda pelo direito ao voto do final do século XIX. Datam já do início do século XIX algumas das primeiras manifestações feministas por igualdade (DUARTE, 2003), influenciadas pelas conquistas da Revolução Francesa ao final do século XVIII. Porém, ao se pesquisar sobre história do feminismo encontramos registros de que desde os séculos XV e XVI as mulheres já se reconheciam injustiçadas e que desde o século XVII algumas mulheres, que tiveram a oportunidade e o privilégio de acesso ao estudo e à cultura, já manifestavam em textos e romances a questão da desigualdade entre homens e mulheres (ARANA, 2005; BALLARÍN et al., 1998). ARANA (2005) faz um levantamento histórico da trajetória das mulheres na vida pública diante das desigualdades entre homens e mulheres e aponta, no século XV, 
em relação às artes, por exemplo, que as obras produzidas por mulheres estariam fadadas ao fracasso simplesmente pela autoria feminina. Assim, as obras femininas recebiam autoria masculina, seja com o nome de algum conhecido (pai, irmão, marido) ou sob um pseudônimo masculino ${ }^{2}$.

O final da Idade Média, o Renascimento e a Idade Moderna conheceram mulheres que tiveram a oportunidade de estudar e divulgar as injustiças entre os sexos: nos séculos XIV-XV Christine de Pisan defendeu a educação como ponto essencial para a mudança; nos séculos XVI-XVII Mary de Gournay escreveu "Igualdad de Hombres y Mujeres"; e ainda no século XVII Anna María van Schurman se declarou feminista. No século XVIII, Madame Neci e sua filha Germana de Stael fundaram uma cadeia de periódicos que divulgavam as idéias de um feminismo bastante incipiente (ARANA, 2005) e, conforme assinalam BALLARÍN et al. (1998), algumas das mulheres estudadas, que viveram nesse período, já defendiam que os sexos eram cultural e historicamente construídos e transformados, ou seja, que não era a natureza que determinava as mulheres como inferiores. Essas mulheres já concentravam as discussões sobre as desigualdades entre os sexos sob uma perspectiva que se aproxima do que hoje entendemos por "gênero". Assim, o século XIX presenciou a manifestação de um feminismo mais amplo e organizado, porém ainda incompreendido, ironizado e desacreditado pela "ordem estabelecida" dos homens (ARANA, 2005).

Ao trazer a questão do feminismo para meu trabalho, tenho como proposta resgatar brevemente a história do feminismo e suas conquistas até chegar ao recente paradigma de gênero para tratar as questões relativas aos direitos das mulheres e a inclusão de um novo personagem nessas discussões - o homem, objeto de estudo da minha pesquisa. Tomarei como base o artigo Feminismo e literatura no Brasil (2003), da autora Constância Lima Duarte, que descreve a história do feminismo no Brasil, a partir do século XIX, com base na proposta de Eva Alterman Blay, em quatro principais momentos, ou ondas, pelo característico movimento de fluxo e

\footnotetext{
${ }^{2}$ A desmoralização para com a mulher alcançava uma dimensão tal que um "engenhoso" acróstico do século XV para a palavra "mulher", no caso, "mulier", que inferiorizava a mulher e a relacionava com o que há de "ruim", "mal", "errado", é apontado por ARANA (2005) e, como a autora, não pude deixar de apresentá-lo, estarrecida em conhecer o ilimitado desrespeito com a mulher: M (mal dos males), U (era associado com V, vaidade das vaidades), L (luxúria das luxúrias), I (ira das iras), E ("erinias de las erinias" - fúria das fúrias) e finalmente o $\mathrm{R}$ (ruína dos reinos).
} 
refluxo, isto é, início quase imperceptível e difuso que de repente se avoluma para o clímax e então reflui, numa fase de calmaria para então recomeçar, lembrando o movimento de uma onda. Os quatro períodos apresentados por DUARTE (2003) têm início em: 1830, 1870 (considerados um período - ou uma onda - por Eva A. Blay), 1920 e 1970.

A primeira onda feminista, segundo DuARTE (2003), data do início do século XIX, sendo que a maior demanda feminina na ocasião era por educação, direito até então reservado aos homens e a poucas e privilegiadas mulheres, apesar de que essas recebiam ainda uma educação voltada ao casamento e às prendas domésticas. Mesmo assim, foi uma educação suficiente para que algumas dessas poucas mulheres começassem a refletir e a divulgar as desigualdades entre homens e mulheres e começassem a se manifestar por seus direitos. BESSIS (2000) também aponta a educação como uma das primeiras demandas femininas e que algumas daquelas mulheres que tiveram o privilégio de estudar aproveitaram a "brecha da instrução" para divulgar e lutar por seus direitos. A autora ainda destaca que a demanda por ensino dessas mulheres era conveniente, não só para aperfeiçoar a educação dada aos seus filhos, como para permitir à mulher adentrar o espaço público e exercer sua cidadania.

Data de 1827 a primeira lei brasileira que autorizou escolas públicas femininas. Até então, a educação para as mulheres se dava em conventos ou raras escolas na casa das professoras ou o ensino era individual. DUARTE (2003) aponta que, segundo Nísia Floresta Brasileira Augusta $^{3}$, importante feminista da época, só a educação conscientizaria as mulheres de sua condição imposta de inferioridade. $\mathrm{Na}$ verdade, o simples fato de poder "pensar e refletir" possibilitaria às mulheres pleitearem igualdade, autonomia e emancipação política (DUARTE, 2003). Conforme discute também ARANA (2005), a ofensiva à dignidade das mulheres e a negação ao direito à educação e às ciências era quase que a privação do direito de existir.

A segunda onda feminista ocorreria quase cinqüenta anos mais tarde, quando as mulheres passaram a lutar por mais educação e pelo voto. Sob a lógica de que "a ignorância de seus direitos" era o "grande inimigo" das mulheres, conforme palavras de outra grande feminista da época, também citada por DUARTE (2003), Francisca

\footnotetext{
${ }^{3}$ Foi uma das primeiras mulheres no Brasil a romper os limites do espaço privado e a publicar textos em jornais da chamada "grande imprensa".
} 
Senhorinha da Mota Diniz, as mulheres reivindicavam o direito de estudar em universidades e também de, uma vez diplomadas, exercerem a profissão conquistada. Essas reivindicações, as desigualdades entre homens e mulheres e as conquistas das mulheres pelo mundo passaram a ser escritas por diversas feministas da época (Elisa Diniz Machado Coelho - filha de Senhorinha; Amélia Carolina da Silva Couto; Josefina Álvares de Azevedo, entre tantas outras importantes mulheres contemporâneas) e a circular em jornais e revistas feministas desse período, por meio de artigos, manifestos, romances. Questões como o trabalho remunerado, o direito ao voto, divórcio, dependência econômica levando à subjugação, entre tantas outras questões, estavam sempre presentes nessa "imprensa feminista". Os textos articulavam que o progresso de uma Nação dependia da participação de suas mulheres como cidadãs (BESSIS, 2000; DUARTE, 2003).

Mesmo com a grande divulgação de informações e tantas conquistas os críticos antifeministas argumentavam sobre a impossibilidade de ser mãe, cuidar da casa e trabalhar fora (DUARTE, 2003). Em fins do século XIX ainda se afirmava que a procriação era incompatível com a atividade intelectual e que a cada gestação a mente feminina era deteriorada (ARANA, 2005). Porém, as mulheres pobres trabalhavam fora, em fábricas ou prestando serviços domésticos. Além disso, os antifeministas estereotipavam a mulher feminista como uma mulher feia, mal amada, machona, não feminina (DUARTE, 2003; RAGO, 2003). É interessante notar que a mulher que lutava, pensava, trabalhava, ou seja, a mulher que era ativa como o homem, era identificada com o "não feminino", conforme as expectativas da sociedade, não havendo identificação dessa "mulher ativa" com o "ser mulher" socialmente aceito/ esperado, tradicionalmente, um "ser passivo".

Em relação ao voto feminino, as lutas estavam apenas começando, sobretudo se observarmos que a questão do direito ao voto em nosso país foi bastante dificultada também para os homens, até então detentores de todos os direitos. O direito ao voto foi conquistado no Brasil com a Constituição de 1824, e dado apenas aos homens, maiores de 25 anos (ou maiores de 21 anos se casados ou militares), aos bacharéis e clérigos, e impunha renda mínima para exercer o direito de votar e de ser votado. Apenas em 1889 o ato de votar deixou de depender de uma renda mínima e a idade para o exercício desse direito caiu para 21 anos, mas era permitido apenas aos 
alfabetizados, e ainda apenas aos homens (NiCOLAU, 2002; LEONARDO \& MARMO, 2005; HISTÓRIA DO VOTO, website), o que intensificou ainda mais a demanda das mulheres pelo direito à educação de todas as mulheres.

A terceira onda feminina ocorreu já no início do século XX e trazia como principal demanda a cidadania. Além das manifestações por ampliação do estudo e do campo de trabalho oferecido às mulheres, intensificou-se a demanda pelo direito ao voto. A década de vinte presenciou passeatas barulhentas e pressão junto aos políticos com a campanha pelo voto feminino no Brasil (DUARTE, 2003) e no mundo ${ }^{4}$ (BESSIS, 2000).

No Brasil, em 1927, mais de um século após a outorga do direito ao voto no país, o governador do Rio Grande do Norte aprovou o voto feminino em seu estado, o que intensificou as manifestações das mulheres pelo país. Foi elaborado um manifesto - Declaração de Direito das Mulheres ${ }^{5}$ - que apontava homens e mulheres como equivalentes, detentores de mesmos direitos e deveres e indivíduos que devem ser cooperativos entre si, destacando que a supressão de direitos de um, inevitavelmente acarretaria em prejuízo para o outro e conseqüentemente para a Nação (DUARTE, 2003).

Apenas em 1932, com Getúlio Vargas, as mulheres finalmente receberam o direito ao voto, ainda que conseqüiente também a articulações políticas da época 6 . Assim, Getúlio Vargas, presidente do Governo Provisório, assinou, em 1932, o decreto-lei que incorporou ao novo Código Eleitoral o direito de voto para as mulheres e, em 1934, o decreto foi incorporado à Constituição do mesmo ano.

\footnotetext{
${ }^{4}$ De acordo com LEONARDO \& MARMO (2005) e RiBEIRO (website) o primeiro país do mundo a conceder o direito de voto para as mulheres foi a Nova Zelândia, em 1893, onde as mulheres já exerciam direitos políticos desde 1886, seguido pela Austrália (1902) e Finlândia (1906). Na Europa, a maioria das mulheres passou a ser eleitora entre os anos de 1918 e 1919, como conseqüência da Primeira Guerra Mundial, porém, francesas e italianas só conquistaram esse direito com o fim da Segunda Guerra Mundial. Em países do Oriente como Turquia, Egito, Índia, as mulheres também estavam se organizando e lutando por igualdade de direitos (BESSIS, 2000).

${ }^{5}$ Também chamado Manifesto Feminista, foi assinado por Bertha Lutz, Jerônima Mesquita e Maria Eugênia Celso, entre muitas outras mulheres de importantes famílias políticas, como Clotilde de Mello Vianna, a esposa do Vice-Presidente da República (DUARTE, 2003).

${ }^{6}$ O país vivia naquela ocasião a República do café-com-leite, ou República Velha, que foi destituída por opositores a Washington Luís, entre eles Getúlio Vargas, instalando-se o Governo Provisório (1930-1934), com Vargas como presidente (CHAVES, 2004). Nesse período o país vivia uma ânsia geral por modernização, aguçada pela crise de 1929, e que não dizia respeito apenas à economia, mas também à sociedade, política e cultura, sendo a promessa ao voto feminino um dos pontos elencados por Vargas para a modernização do Estado (o Estado Novo) durante a Revolução de 30 (GADELHA, 2004).
} 
Contudo, foi apenas em 1945 que as mulheres exerceram seu direito de voto, nas eleições que elegeram o presidente Eurico Gaspar Dutra ${ }^{7}$ (NicOLAU, 2002; LEONARDO \& MARMO, 2005; RIBEIRO, website).

Além da demanda por cidadania, novas questões passam a circular. Ainda na segunda década do século XX, na Semana de Arte Moderna, a escritora feminista Ercília Nogueira Cobra lançou um romance, intitulado "Virgindade inútil - novela de uma revoltada". Nessa obra a autora discutia não só a importância da luta das mulheres pelos seus direitos e denunciava a situação de desigualdade vigente como também trazia à luz das discussões, reflexões e reivindicações a exploração sexual e o trabalho das mulheres, dando visibilidade a temas como o direito das mulheres sobre seu próprio corpo, que viriam a eclodir nas décadas de 60 e 70 com a revolução sexual (DUARTE, 2003).

Mais uma vez, passados cinqüenta anos das lutas pelo direito de exercer a cidadania, uma nova onda feminista invadiu o mundo. Nessa ocasião, a principal bandeira levantada pelas feministas defendia o direito sobre o próprio corpo e questionava os papéis historicamente atribuídos às mulheres - e aos homens. Houve também uma transformação nas demandas por igualdade, ficando mais claro que as mulheres, em oposição à masculinidade dominante, não desejavam ser iguais aos homens e sim ter direitos iguais aos dos homens e, para isso, não havia necessidade de deixar de ser mulher (BESSIS, 2000; RAGO, 2003; COSTA, 2005).

A década de 50 se iniciou com o mundo vivendo o fim da Segunda Guerra Mundial e conhecendo a Declaração Universal dos Direitos Humanos, adotada e proclamada pela Organização das Nações Unidas (ONU) (HISTÓRIA DO VOTO, website). O cenário político mundial era a imposição do "american way of life" versus o comunismo soviético, o mundo vivia a Guerra Fria, com as imposições de direita e esquerda sobre as Nações, gerando revolta e insatisfação ao redor do mundo. As décadas de 50, 60 e 70 viveram, diante dessa situação mundial, importante e veloz avanço científico e tecnológico, que foi desde a ida do homem à Lua até a revolucionária pílula anticoncepcional.

\footnotetext{
${ }^{7} \mathrm{O}$ Brasil foi o quarto país das Américas a conceder o direito de voto às mulheres, acompanhando os pioneiros Estados Unidos da América - EUA (1920), Canadá (1916,1917,1918 - onde a conquista foi progressiva) e Equador (1929, primeiro país da América Latina) (EsQUEMA CRONOLÓGICO DO SISTEMA ELEITORAL, website; RIBEIRO, website).
} 
No Brasil, o Golpe Militar em 1964 impôs a ditadura militar de direita no país. As mulheres, nesse cenário, mais uma vez foram às ruas exigir seus direitos, que iam desde seu reconhecimento dentro dos partidos de esquerda até as questões relacionadas ao direito sobre seu corpo: discutiam-se, nessa ocasião, temas como o cuidado com o corpo, a liberdade sexual, o direito da mulher em escolher quando engravidar, o que já passa a remeter a questões como planejamento familiar e controle de natalidade e que, mais tarde, fariam parte de um quadro de reivindicações que incluiria políticas públicas de saúde (Formiga FILHO, 1999; BESSIS, 2000; DuARTE, 2003; RAGO, 2003; Costa, 2005). Era um momento em que, nacional e internacionalmente, vivia-se um processo de transformação sócio-político-cultural que destacava um novo campo de direitos: os direitos reprodutivos (ARILHA, 2005). Jornais e revistas feministas da época discutiam questões polêmicas como a anistia política, a maior participação das mulheres na política, o aborto, a mortalidade materna, o trabalho feminino e a dupla jornada das mulheres, a prostituição e a autonomia e a igualdade na relação afetiva, denunciando as formas de dominação patriarcal (BESSIS, 2000; DUARTE, 2003; RAGO, 2003; COSTA, 2005).

A década de 70 conheceu a força da organização das mulheres pelo mundo (RAGO, 2003), a ONU declarou o ano de 1975 o Ano Internacional da Mulher (Formiga Filho, 1999; Bessis, 2000; DuARTE, 2003; Costa, 2005), que se estendeu pelo decênio 75-85, e oficializou, nesse mesmo ano, o oito de março como Dia Internacional da Mulher ${ }^{8}$. Por essa ocasião, associado ao clima de relativa abertura política no mundo, as mulheres puderam se organizar publicamente e realizar congressos, seminários e encontros, à luz das propostas do "novo" movimento feminista que neste momento se desenvolvia na Europa e Estados Unidos da América (EUA) (Bessis, 2000; DuARTE, 2003; Rago, 2003; CostA, 2005), e mais mulheres se organizaram reivindicando seus direitos e mais visibilidade (DUARTE, 2003).

\footnotetext{
${ }^{8}$ Em 1910, em uma conferência na Dinamarca, o 8 de março foi declarado o Dia Internacional da Mulher, em homenagem às operárias de uma fábrica têxtil de Nova Iorque que, em 8 de março de 1857, entraram em greve reivindicando redução da carga horária (de 16 para 10 horas por dia). Essas operárias, que recebiam menos de um terço do salário dos homens, foram fechadas na fábrica onde, entretanto, se declarara um incêndio, e cerca de 130 mulheres morreram queimadas (http://www.suapesquisa.com/dia_internacional_da_mulher.htm).
} 
Ainda na década de 70 as "minorias sociais" também reivindicavam o "direito à diferença" (RAGO, 2003; COSTA, 2005) ganhando destaque também o movimento de mulheres, sendo que todas essas manifestações acabaram por unir-se ao movimento feminista, adentrando a década seguinte. RAGO (2003) aponta que o movimento de mulheres tinha um caráter mais popular, sendo composto por mulheres das periferias que lutavam por creches, transporte e melhores condições de vida (RAGO, 2003; CostA, 2005). Apesar de não incluírem as mesmas questões da bandeira de luta do movimento feminista, este e o movimento de mulheres e também o movimento das "minorias sociais" se complementaram. Maior número de mulheres foi atingido e as mulheres pobres tiveram a oportunidade de se aproximar de questões como a moral sexual, o direito sobre o corpo e a sexualidade, que dificilmente seriam enunciadas espontaneamente pelo movimento de mulheres (RAGO, 2003).

A década de 80 assistiu à maior participação feminina na política, com destaque para o "lobby do batom", em que as mulheres brasileiras, representadas por diversas feministas e pelas 26 deputadas federais constituintes, garantiram avanços na Constituição Federal de 1988. Foi promulgada uma emenda assegurando igualdade a todos os brasileiros perante a lei, sem distinção de qualquer natureza, e afirmando que homens e mulheres são iguais no Brasil. Além disso, o "lobby do batom" foi o grupo que conseguiu maior número de aprovações dentre suas demandas (Silva SV da, 2000b; DuARTE, 2003; Costa, 2005). Além disso, questões vindas ainda da década de 70 , como a violência contra a mulher, o direito reprodutivo, a sexualidade e a autonomia, tornaram-se mais presentes na pauta dos encontros de mulheres (RAGO, 2003; CosTA, 2005) e questões como estética e saúde entraram em discussão (RAGO, 2003). As feministas perceberam a necessidade e os benefícios de se relacionar com o Estado para garantir políticas que assegurassem as conquistas e os direitos das mulheres (RAGO, 2003; CostA, 2005), e a década de 80 assistiu à elaboração do PAISM (Programa de Atenção Integral à Saúde da Mulher), em 1984, e ao surgimento da primeira Delegacia Especializada da Mulher, em 1985. Conforme assinalado por ANDRADE (2003), com o PAISM a mulher passou a ser entendida como um indivíduo cidadão e sujeito da sociedade. Feministas universitárias também se articularam e institucionalizaram os estudos sobre 
mulheres, como na Europa e nos EUA, e sua legitimação diante dos saberes acadêmicos, com a criação de núcleos de estudo e pesquisa, organização de grupos de trabalho e congressos, proporcionando trocas entre as pesquisadoras ${ }^{9}$ (DUARTE, 2003; RAGO, 2003; SILVA SV da, 2000b).

Nos $\operatorname{anos} 90$ a sociedade convivia com a revolução sexual e as conquistas femininas assimiladas ao seu cotidiano (DUARTE, 2003). Mulheres operárias, moradoras do bairro, trabalhadoras e trabalhadoras rurais continuavam se organizando, caracterizando um feminismo popular. A última década do século XX presenciou a intensificação da participação das mulheres no mercado de trabalho e no cenário político do país e a organização dessas mulheres para garantir a eliminação de todas as formas de discriminação contra a mulher, por parte do governo federal (COSTA, 2005).

O movimento feminista foi além da demanda e da pressão política na defesa de seus interesses, sendo capaz de interagir com o Estado e, ao contrário do que temiam algumas feministas, o movimento permaneceu autônomo. Além disso, com as conquistas alcançadas na defesa dos direitos das mulheres, o movimento feminista expôs seu posicionamento crítico em relação à dominação masculina e rediscutiu os papéis sociais atribuídos a homens e mulheres, estabelecendo assim um processo de reflexão que produziu a categoria analítica de gênero, que será posteriormente discutida (FARIA \& NOBRE, 1997; FonSECA, 1999; SILVA SG da, 2000a; SilVA SV da, 2000b; Korin, 2001; SOIHET, 2003; VILLELA, 2005; COUTO \& SCHRAIBER, 2005; ARILHA, 2005; FERREIRA, 2005).

Sem dúvida, são enormes as conquistas realizadas pelas mulheres em todos os campos da vida social ao longo dessas décadas (RAGO, 2003), mas apesar das mudanças e transformações alcançadas, as mulheres ainda encontram muita resistência cultural e política e mesmo novas pressões machistas e conservadoras. Atualmente, ainda nos deparamos com a desigualdade de salário, a menor proporção

\footnotetext{
${ }^{9}$ O período citado presenciou a criação de grupos e Organizações não governamentais (ONGs) para estudos sobre mulheres: Grupo de Trabalho sobre Estudos da Mulher, da Anpocs; Grupo de Trabalho Mulher na Literatura, da Anpoll; NEM - Núcleo de Estudos sobre a Mulher, da PUC-RJ; NEIM Núcleo de Estudos Interdisciplinares sobre a Mulher, na UFBA; NIELM - Núcleo Interdisciplinar de Estudos da Mulher na Literatura, da UFRJ; NEMGE - Núcleo de Estudos da Mulher e Relações de Gênero, da USP (DUARTE, 2003); Coletivo das Mulheres Negras da Baixada Santista; GELEDÉS Instituto da Mulher Negra e Crioula (defendem a causa das mulheres negras); REDEH - Rede de Desenvolvimento Humano; CFEMEA - Centro Feminista de Estudos e Assessoria; SOF - Sempre Viva Organização Feminista; União das Mulheres, São Paulo, entre outras (RAGO, 2003).
} 
de mulheres em cargos políticos e em cargos de direção, a violência doméstica, a dupla jornada de trabalho, o acirramento da competição no mundo masculino, uma vez que as mulheres são mais exigidas do que os homens nas mesmas funções no mercado de trabalho, entre tantas outras desigualdades que, de certa forma, dão visibilidade a novos fronts para as relações de gênero: profissional e afetivo (DuARTe, 2003; RAGO, 2003; Costa, 2005); e é também por essa razão que as mulheres têm reivindicado cada vez mais seus direitos de cidadania e aberto novas formas e espaços de luta (RAGO, 2003). 
"...el mundo de la mujer es la casa y la casa del hombre es el mundo"

Laura Astúrias

\section{GÊNERO - ALGUMAS CONSIDERAÇÕES}

A década de 70 assistiu a emergência de movimentos sociais ${ }^{10}$ que não só consolidaram novas forças políticas em vários lugares do mundo como também despontaram modificando lugares e mentalidades (SILVA SV da, 2000b). Frente às mobilizações e movimentações da época, muitas pesquisadoras já demonstravam preocupação pela temática feminista e, no Brasil, com o fim da ditadura militar na década de 80 , também se acentuaram as críticas à situação de desigualdade entre homens e mulheres e o poder de dominação dos homens sobre as mulheres. Os papéis sociais atribuídos a esses indivíduos foram rediscutidos e debatidos, surgindo pesquisas que apontavam a necessidade de se estudar as relações sociais entre os sexos a partir de uma nova categoria analítica produzida por essas reflexões: a categoria de gênero (FARIA \& NOBRE, 1997; FonSECA, 1999; SiLVA SG da, 2000a; Silva SV da, 2000b; KorIn, 2001; SOIHET, 2003; VILlela, 2005; CoUTO \& SCHRAIBER, 2005; ARILHA, 2005; FERREIRA, 2005).

Nesse capítulo, pretendo discutir a noção de gênero desde o seu surgimento como categoria de análise das relações sociais, à luz da argumentação de diferentes autores, tomando como base, para o presente estudo, a concepção de gênero segundo CONNELl (1997, 2000).

Inicialmente as discussões sobre gênero referiam-se exclusivamente ou predominantemente a assuntos relacionados com as mulheres (SABO, 1999; COURTENAY, 2000; Korin, 2001; ARILHA, 2005). Sobre essa questão, ARILHA (2005) resume os caminhos de gênero na contemporaneidade em três âmbitos: "gênero usado inadequadamente por ser entendido como sinônimo de 'mulher'; uso do gênero levando a uma perda da dimensão de defesa das necessidades das mulheres (origem da incorporação da dimensão de gênero nos programas e ações das Nações

\footnotetext{
${ }^{10}$ Movimentos sociais anticoloniais, étnicos, raciais, de homossexuais, ecológicos e de mulheres, entre outros (SILVA SV da, 2000b).
} 
Unidas); inclusão não abrangente dos homens e do masculino ao se usar a dimensão de gênero nos debates". O que observamos, de fato, é que a noção de gênero surgiu dentro da movimentação feminista e predominantemente foi usada como sinônimo de mulheres, até o momento em que se compreendeu que essa noção trazia um aspecto relacional e que ele deveria se referir aos homens, às mulheres e às relações entre homens e mulheres (GIFFIN, 2005; ARILHA, 2005), que é a forma que vem sendo proposta para o uso e a compreensão da noção de gênero.

Porém, o que observamos atualmente em muitos artigos científicos é o uso de "gênero" como sinônimo de "sexo", referindo-se à distinção biológica entre homem e mulher (BANDEIRA, 1999; KORIN, 2001). Esta aplicação está gramaticalmente correta, porém observamos estudos que usam o termo gênero como descritor, por exemplo, e aplicam no estudo o sentido é "sexo", causando certa confusão quando realizamos pesquisas. Segundo BANDEIRA (1999), o sexo é um dado de natureza biológica que divide o ser humano em macho e fêmea e que, ainda hoje, é considerado determinante do que é ser homem e do que é ser mulher. A essa perspectiva essencialista sobre ser homem e ser mulher contrapõe-se a noção de gênero, pela qual as representações da diferença sexual (biológica/ anatômica), em termos de masculinidade e feminilidade, podem ser múltiplas. Assim, gênero deixa de lado a visão essencialista de que a desigualdade entre homens e mulheres é resultado das diferenças biologicamente determinadas e procura explicar as relações de poder entre homens e mulheres sob uma perspectiva construcionista (GIFFIN, 1994; HeRnÁNDEZ , 1996; FARIA \& Nobre, 1997; BANDEIRA, 1999; COURTENAY, 2000; DinIZ, 2001; Korin, 2001; SOIHET, 2003; COUTO \& SCHRAIBER, 2005).

Estudiosos do assunto concordam que a noção de gênero é construída histórica, social e culturalmente, de forma dinâmica ao longo dos séculos, variando também segundo região, cultura e estrato social, ainda que em um mesmo momento histórico, e que continua em transformação (HERNÁNDEZ , 1996; FARIA \& NoBRE, 1997; BANDEIRA, 1999; FonseCA, 1999; SABO, 1999; COURTENAY, 2000; Courtenay \& Keeling, 2000; Diniz, 2001; Korin, 2001; Couto \& Schraiber, 2005; MACHADO, 2005).

De fato, Connell (1997) argumenta que, se "ser mulher" e "ser homem" estivesse reduzido somente aos corpos e à reprodução, bastava considerar o aspecto 
biológico. Mas “ser mulher" e "ser homem” inclui relação entre pessoas e entre pessoas e grupos, ou seja, práticas sociais, e as relações de gênero vêm construir uma ponte entre corpos e sociedade, sendo uma das principais estruturas de prática social, que inclui indivíduo, mulher ou homem, com ações masculinas ou femininas, independente de seu sexo biológico. Para Connell (1997), os tipos de conhecimento de gênero estão constantemente em debate político e sujeitos a explicações e pontos de vista conflitantes e, para melhor conhecer a dinâmica da complexa estrutura de gênero, que se estende para além da relação homem e mulher (CONNELL, 1997; GARCIA, 1998; CASTELLS, 2001), CONNELl (1997) propõe um modelo que traz três dimensões de relações - de poder, de produção e cathexis - e que seria o princípio organizador da sociedade (CONNELL, 1997):

1. Relações de poder: constitui a principal linha divisória de poder na ordenação do gênero nas sociedades ocidentais, bem reconhecida na subordinação feminina e dominação masculina.

2. Relações de produção: a ordenação do gênero se dá no trabalho e na alocação de tarefas, com valorização do homem no trabalho (maiores salários, maior ocupação de cargos de chefia).

3. Cathexis: a ordenação do gênero se dá a partir dos desejos sexuais e das práticas sexuais que dão forma e realizam esses desejos, seja de forma consensual ou coercitiva, independente do prazer ser obtido mutuamente ou não pelo objeto desejante (homem, posição de dominação) e pelo objeto desejado (mulher, posição de subordinação).

Gênero representaria, portanto, um conceito relacional que busca diferenciar a construção social do masculino e do feminino do sexo biológico (FARIA \& NOBRE, 1997; BANDEIRA, 1999). Conforme DiNIZ (2001), trata-se de um construto social e cultural que estabelece valores diferenciados para homens e mulheres e para as formas como esses indivíduos se relacionam na sociedade, estabelecendo diferenças entre os atributos de homens e mulheres no acesso aos recursos produtivos e na autoridade para tomar decisões. Sobre o caráter relacional de gênero, COUTO (2002), SOIHET (2003) e GOMES et al. (2005) assinalam a dificuldade em se compreender adequadamente homens e mulheres através de um estudo que os considere totalmente 
em separado e que, conforme assinalam GiFFIN \& CAVALCANTI (1999), não considere as semelhanças e diferenças nas relações de gênero.

Dessa forma, gênero seria pertinente às relações entre homens, entre mulheres e entre homens e mulheres (CONNELl, 1997; SCHOFIELD et al., 2000; COUTO \& SCHRAIBER, 2005), construindo assim as identidades masculina e feminina com base no que é determinado biologicamente e com base nas ações que homens e mulheres deveriam praticar, segundo os atributos sociais que a sociedade espera desses indivíduos, isto é, mulheres com atitudes femininas e homens com atitudes masculinas (FARIA \& NOBRE, 1997; BANDEIRA, 1999; COURTENAY, 2000; SCHOFIELD et al., 2000; DinIZ, 2001; KORIN, 2001). FARIA \& NOBRE (1997) e COURTENAY (2000) argumentam que esses padrões de feminilidade e de masculinidade esperados das mulheres e dos homens, respectivamente, são socialmente impostos e "naturalmente" adotados pelos indivíduos em geral. Além disso, são padrões dicotômicos que diferenciam mulheres e homens pelo "ser" e pelo "não ser". Assim, das mulheres espera-se que sejam delicadas, passivas, maternais, frágeis e que se realizem no espaço privado, no lar; enquanto que dos homens espera-se exatamente o contrário, que sejam agressivos, ativos, objetivos e racionais e que se realizem no espaço público (FARIA \& NOBRE, 1997; BANDEIRA, 1999; KORIN, 2001).

Gênero, portanto, representaria os atributos sociais desempenhados por homens e mulheres, mas sem impor que atitude cada um deveria ter. Conforme CONNELl (1997), gênero é uma das principais estruturas das práticas sociais e vai além das relações entre indivíduos, sendo uma estrutura complexa, com várias lógicas, e que funciona como um ordenador da prática social. Gênero estabeleceria, assim, as relações de poder e hierarquia não apenas entre indivíduos e grupos mas também entre instituições (CONNELl, 1997; Couto \& SchraIBER, 2005; ARILHA, 2005), associando-se também à estrato social, à raça e etnia, à nacionalidade e à posição na ordem mundial, sendo organizador das relações entre homens, entre mulheres, entre homens e mulheres e também entre os cidadãos e o governo (CONNELl, 1997; SOIHET, 2003; COUTO \& SCHRAIBER, 2005). 
Capítulo 2

Masculinidades, Homem e Saúde 
"A proporção em que masculinidade e feminilidade se misturam num indivíduo, está sujeita a flutuações muito amplas (...) e aquilo que constitui a masculinidade ou a feminilidade é uma característica desconhecida que foge do alcance da anatomia"

Sigmund Freud

\section{MASCULINIDADE(S): UM POUCO DE SUA HISTÓRIA}

Ao estudar sobre masculinidades procurei conhecer de que forma esse tema surgiu como interesse para o debate acadêmico Psicologia, nas Ciências Sociais e especialmente na Saúde Coletiva.

SiLVA (SILVA SG da, 2000a) aponta que a discussão sobre masculinidade vem desde a era vitoriana e tem, em sua origem, relação com a discussão sobre sexualidade. Apesar de não haver um vocabulário que exprimisse a sexualidade de homens e mulheres, no século XVIII, a explicação "do modelo de sexualidade humana" estabeleceu-se a partir de normas da diferença sexual entre ambos. A concepção dominante até então era a do one-sex-model ou monismo sexual, pelo qual a mulher era entendida como um homem invertido ${ }^{11}$, naturalmente inferior ao modelo anátomo-fisiológico de perfeição masculino. FONSECA (1999) relaciona o peso da anatomia na definição das essências masculina e feminina à teoria do essencialismo, influenciada pela teoria de Darwin e que ressurgiu com as teorias sociobiológicas, que justificavam os comportamentos humanos em termos de hereditariedade genética e de funcionamento fisiológico (FONSECA, 1999; COUTO \& SCHRAIBER, 2005).

Na transição para o século XIX, acompanhando as transformações políticosociais desse período ${ }^{12}$, surgiu a concepção do two-sex-model para explicar as diferenças entre homens e mulheres. Nessa ocasião estabeleceu-se na Europa uma

\footnotetext{
${ }^{11}$ Por essa concepção, o útero seria o escroto feminino, os ovários seriam os testículos, a vulva seria o prepúcio e a vagina seria um pênis (SILVA SG da, 2000a).

12 O final do século XVIII viveu a Revolução Francesa, que bradava por liberdade, igualdade e fraternidade; a Revolução Industrial, que ocasionou uma desordem no papel social do homem da época; e as Guerras de Independência na América (SILVA SG da, 2000a). Tais transformações sociais exigiriam mudanças no comportamento dos homens (CONNELL, 1997, 2000; SCHRAIBER et al., 2005; ARILHA, 2005), mudanças essas que estremeceram a identidade masculina até então tão bem definida (GifFIN \& CAVAlCANTI, 1999; GifFIN, 2000; Silva SG da, 2000a; MACHADO, 2005).
} 
nova sociedade burguesa (capitalista, individualista, moralista, imperialista, colonialista e nacionalista) que impôs uma diferença moral para definir o padrão de comportamento para homens e mulheres. As mulheres passaram a ser entendidas como complementares aos homens e ainda eram consideradas inferiores, devido às conseqüências morais delas advindas (SILVA SG da, 2000a).

Assim, para a explicação das diferenças entre os sexos, o século XIX assistiu à mudança da concepção biológica para uma concepção política-econômica-social que consolidou ainda mais a supremacia masculina. A norma natural dos sexos ditava as regras, tudo era entendido a partir da diferença sexual entre homens e mulheres e o risco de ser parecido com aquilo que era identificado como feminino ou de ser considerado um homem invertido, como eram chamados os homossexuais na ocasião, tornou-se uma presença constante. $\mathrm{O}$ medo da feminilidade teve como consequiência o aumento do culto à masculinidade que, associado aos eventos revolucionários $^{13}$ vindos do final do século XVIII e suas repercussões, consolidou uma masculinidade hegemônica que deveria ser comum a todos os homens (CONNELl, 2000; ARILHA, 2005). O homem dessa época passou a vivenciar mais intensamente a necessidade de ter que provar, constantemente, "ser macho", e o "ser homem" passou a ser entendido como "não ser mulher" (HERNÁNDEZ , 1996; Connell, 1997; Ceccarelli, 1998a ; Garcia, 1998; FonseCA, 1999; SABO, 1999; SILVA SG da, 2000a; 2000; GIFFIN, 2005). Esse processo caracterizou a primeira crise da identidade masculina (SILVA SG da, 2000a), tão debatida atualmente, que foi mais percebida em regiões onde as mulheres desfrutavam de mais liberdade (CECCARELLI, 1998a, 1998b; SILVA SG da, 2000a).

No século XIX o comportamento de homens e de mulheres esteve, portanto, mais associado aos papéis sociais impostos e esperados de cada sexo, com base na identidade sexual biológica (FONSECA, 1999; SILVA SG da, 2000a; SCHRAIBER et al., 2005; COUTO \& SchraIBER, 2005). FonSECA (1999), ao discutir a teoria dos "papéis sexuais", aponta que a mesma rejeita o argumento da diferença biológica em favor da diferença estrutural e da distinção entre liderança instrumental e expressiva, o que a autora relaciona com o papel da mãe e do pai dentro da composição familiar, ou seja,

${ }^{13}$ Vide nota 11. 
de garantia de funcionamento da família e de autoridade, respectivamente. Assim, variações nesse modelo eram vistas como desvios ou falhas na socialização.

$\mathrm{O}$ século XX assistiu à crescente organização das mulheres em defesa de seus direitos e, nas décadas de 60 e 70, as reivindicações dos movimentos feministas e das minorias sociais, como o movimento homossexual (SABO, 1999; GIFFIN, 2005; MACHADO, 2005) e as críticas feministas à dominação masculina proporcionaram o surgimento dos estudos sobre os homens (GARCIA, 1998; GIFFIN, 2005). Conforme argumentam SCHRAIBER et al. (2005) e GOMES \& NASCIMENTO (2006), a década de 70 foi o marco inicial norte americano para os estudos sobre os homens. Os EUA e a Europa eram as regiões onde predominavam as mulheres com mais liberdade e, conseqüentemente, nesses locais era mais visível a perda da identidade masculina em relação aos padrões tradicionalmente impostos e esperados pela sociedade (CECCARElli, 1998a, 1998b; SiLva SG da, 2000a) sendo, pois, esperado que os estudos sobre os homens sob uma perspectiva de gênero surgissem inicialmente nas regiões mencionadas. Apesar de apresentarem um caráter exploratório nessa época, os estudos sobre homens já se organizavam sob o conceito de que a masculinidade socialmente imposta levava ao déficit de saúde dos homens (PITTMAn, 1999; SABO, 1999; Connell, 2000; Courtenay, 2000; Davies et al., 2000; GifFin, 2005; SCHRAIBER et al., 2005; COUTO \& SCHRAIBER, 2005; ARILHA, 2005) e também das mulheres (SABO, 1999; ConNELl, 2000) e, alguns homens da época já percebiam essa situação e refletiam também sobre a posição de dominação masculina em relação às mulheres e às minorias sociais (HERNÁNDEZ , 1996; FONSECA, 1999; GIFFIN \& CavalCANTI, 1999; PitTMan, 1999; GiFfin, 2005).

Dentre as reivindicações femininas nos anos 70 destacaram-se as lutas pela igualdade de direitos, pelo direito sobre o próprio corpo, pelos direitos reprodutivos e pela liberdade sexual (Formiga FiLho, 1999; Bessis, 2000; DuARTe, 2003; RAGO, 2003; Costa, 2005) e que, associados ao advento da pílula anticoncepcional, propiciaram o surgimento de novas questões como o planejamento familiar e as infecções sexualmente transmissíveis (ISTs), colocando em foco a saúde reprodutiva e sexual (GIFFIN, 2005; COUTO \& SCHRAIBER, 2005). Essa nova questão apontou para a necessidade de estudos relacionais de gênero que ampliassem o espectro da análise 
em direção aos homens (GARCIA, 1998; GIFFIN, 2005; SCHRAIBER et al., 2005; VILLELA, 2005; COUTO \& SCHRAIBER , 2005; ARILHA, 2005).

Apesar dos homens estarem sempre presentes em estudos e pesquisas, até há poucas décadas o conceito de homem era relacionado ao genérico ser humano (FonseCA, 1999; MEDRADO et al., website). Há inúmeros estudos sobre "os homens" que abordam presença ou ausência de morbidades e taxas de mortalidade por sexo, por grupo étnico, por estrato social, por grupo etário e por causa, mas que se preocupam, predominantemente, com o aspecto biológico relacionado às patologias, discutindo a saúde do homem em contraste com a saúde da mulher (COURTENAY \& KEELING, 2000; SCHOFIELD et al., 2000; JONES, 2004). Apenas mais recentemente, e como conseqüência das transformações decorridas desde o início do século $\mathrm{XX}$, e mais especificamente das décadas de 60 e 70, que os homens passaram a ser vistos como indivíduos, do sexo masculino, com necessidades, demandas e comportamentos específicos (CONNELL, 2000; SILVA SG da, 2000a; GIFFIN, 2005; SCHRAIBER et al., 2005; COUTO \& SCHRAIBER, 2005; ARILHA, 2005).

SCHRAIBER et al. (2005) e MEDRADO et al. (website) apontam que a novidade nos estudos atuais com homens é justamente essa percepção de que os homens são também orientados por um modelo ideal e estão também inseridos em relações sociais hierárquicas (CONNELL, 2000; GIFFIN, 2005; ARILHA, 2005) e, na tentativa de alcançar o modelo ideal (CONNELL, 2000; ARILHA, 2005) socialmente esperado acabam vivendo uma situação opressora e prejudicial, em última instância, à sua saúde (PitTman, 1999; SABo, 1999; Connell, 2000; Courtenay, 2000; Davies et al., 2000; GIFFIN, 2005; SCHRAIBER et al., 2005; COUTO \& SCHRAIBER, 2005; ARILHA, 2005).

Na década de 80 os estudos sobre homens ganharam uma nova terminologia, estudo sobre masculinidadeS (COURTENAY, 2000; SCHRAIBER et al., 2005; COUTO \& SCHRAIBER, 2005), mais condizente com a percepção dos vários homens e seus modos de vida, inaugurando a entrada da perspectiva relacional de gênero nos estudos sobre os homens e suas masculinidades. No Brasil e na América Latina os estudos sobre homens ganharam força no final da década de 80 , seguindo a tendência do que vinha sendo produzido nos EUA e na Europa (SCHRAIBER et al., 2005). 
Nos anos 90 o enfoque feminista de gênero se estabeleceu e a noção de que as relações entre os indivíduos são histórica e culturalmente construídas tornou-se referência dos estudos sobre mulheres e homens (COUTO \& SCHRAIBER, 2005). Foi nesse período também que se consolidou a abordagem de aspectos como poder, desigualdade e iniqüidade de gênero na maioria dos estudos sobre homens e saúde (SCHRAIBER et al., 2005).

Ao mesmo tempo, os órgãos internacionais passaram a discutir a presença dos homens nas questões relacionadas à saúde. Em 1994, na Conferência Internacional de População e Desenvolvimento, realizada no Cairo (Conferência do Cairo), os textos oficiais ressaltaram a importância da inclusão dos homens para as discussões sobre saúde reprodutiva e sexual. Segundo ArILHA (2005), os textos oficias da Organização das Nações Unidas (ONU) relacionavam o homem a um papel de responsabilidade ou irresponsabilidade na parceria com as mulheres, identificando os mesmos como um instrumento de apoio ou de dificuldade para a conquista das necessidades das mulheres (SCHRAIBER et al., 2005; COUTO \& SCHRAIBER, 2005; ARILHA, 2005). As autoras concordam ao apontar a existência de discursos que se preocupam com a população masculina como detentora de direitos e que deve ser incluída em projetos, programas e ações, particularmente voltados à saúde, que considerem sua especificidade de gênero. Entretanto, independentemente de haver ou não uma visão do homem como sujeito de direitos, pelo menos naquele momento em que a população masculina começou a ganhar destaque e tornar-se alvo de preocupação, no que diz respeito à saúde dos homens e também à saúde das mulheres, a presença do indivíduo do sexo masculino em textos oficiais internacionais como objeto de atenção implementou sobremaneira a necessidade de atenção a essa população. De fato, a década de 90 assistiu a produção de muitos trabalhos voltados à população masculina sob a perspectiva de gênero (SABO, 1999; CONNELl, 2000; SCHRAIBER et al., 2005; COUTO \& SCHRAIBER, 2005; ARILHA, 2005; MACHADO, 2005), como o estudo de LAURENTI (1998), na América Latina, e como as discussões sobre masculinidade e masculinidades que têm em Robert W. Connell e Michael S. Kimmel nomes de destaque (SCHRAIBER et al., 2005). Nessa ocasião, estabeleceu-se "essa nova tendência" de se estudar os homens e as mulheres sob a perspectiva de gênero e o melhor entendimento desta noção como relacional entre 
homens e mulheres e não mais como sinônimo de mulher (SCHRAIBER et al., 2005; GOMES \& NASCIMENTO, 2006).

Além disso, o advento da epidemia da AIDS, que tomou corpo na década de 90 e adentrou o novo século com uma mudança de seu perfil epidemiológico, ou seja, a maior freqüência de casos entre homens homossexuais dando lugar ao aumento do número de casos entre mulheres heterossexuais e o aumento da transmissão por via heterossexual, também foi marco importante na incorporação da perspectiva de gênero para o entendimento do aspecto relacional da conjugalidadeafetividade. Conseqüentemente, houve reconhecimento e valorização da necessidade de se enfocar os homens na área da saúde sexual e reprodutiva, surgindo estudos que abordavam a dimensão do poder nas relações entre homens e mulheres, demonstrando a dificuldade destas em negociar o uso de preservativo ou de se recusar a manter relação sexual, e estudos que abordavam os referenciais masculinos de invulnerabilidade, que contribui para a manutenção de práticas sexuais de risco (GARCIA, 1998; SCHRAIBER et al., 2005; VILLELA, 2005; COUTO \& SCHRAIBER, 2005). Além disso, a Organização Mundial da Saúde (OMS) apresentou publicações (2000, 2001) voltadas para as especificidades da saúde masculina e o seu comprometimento em diferentes fases da vida, alertando para a necessidade de investigações e estudos em geral acerca da posição social específica dos homens e as repercussões em termos de determinantes da saúde masculina (GOMES \& NASCIMENTO, 2006).

Assim, o início do século XXI vem assistindo ao surgimento de periódicos, eventos e organizações voltados especificamente ao estudo dos homens sob a perspectiva relacional de gênero:

No âmbito internacional podemos mencionar:

A. Congressos:

1. Annual Conference on Men and Masculinities (AMSA I - Nova Iorque, 1993), realizado anualmente;

2. 1st World Congress on Men's Health \& Gender (Viena, 2001), realizado anualmente por três anos e então passou a ser bienal;

3. I Coloquio Internacional sobre Género y Masculinidades (México, 2004); 
4. Coloquio Internacional de Estudios sobre varones y masculinidades (México, 2006).

B. Organizações:

1. American Men Studies Association (AMSA);

2. International Society for Men's Health \& Gender - ISMH;

3. Men's Health Forum UK - fundado em 1994, com o objetivo de incluir temas sobre saúde do homem nas políticas públicas de saúde na Europa;

4. European Men's Health Forum - lançado em 2001, no 1st World Congress on Men's Health \& Gender, em Viena, pelo Men's Health Forum UK;

5. Men's studies press: editora que publica literatura que aborda o homem.

C. Periódicos:

1. Internacional Journal of Men's Health, publicado três vezes por ano (2003: ano da primeira publicação);

2. Fathering: A Journal of Theory and Research about Men as Parents, publicado três vezes por ano;

3. Thymos: Journal of Boyhood Studies, será publicado duas vezes por ano (2007: ano previsto para lançamento);

4. The Journal of Men's Studies (AMSA), publicado três vezes por ano;

5. The Journal of Men's Health \& Gender (ISMH), publicado duas vezes por ano (2003: ano da primeira publicação, lançado no $3 r d$ World Congress on Men's Health \& Gender);

6. Men's Health Journal, publicação do Men's Health Forum UK e do European Men's Health Fórum (2001: ano da primeira publicação, publicado quatro vezes por ano).

No âmbito nacional podemos mencionar: 
A. Eventos

1. $1^{\mathrm{o}}$. Workshop do Programa de Capacitação para Organizações da Sociedade Civil Regional N, NE e CO - Brasil Engajando Homens Jovens na Promoção da Saúde e Equidade de gênero (Recife, 2003);

2. Seminário Internacional e Nacional Homens, sexualidade e reprodução (São Paulo, 1998; Recife, 2003, 2005, 2006).

B. Organizações:

1. GESMAP - Grupo de estudos sobre sexualidade masculina e paternidade, fundado em 1995;

2. PAPAI - organização civil fundada em 1997 (ações voltadas para homens jovens em situação de pobreza e produção científica);

3. ECOS - Estudos e Comunicação em Sexualidade e Reprodução Humana - organização não-governamental fundada em 1989, atualmente inclui em suas práticas educativas e de comunicação a ótica de jovens e adultos do sexo masculino.

C. Publicações:

1. Ciência \& Saúde Coletiva - Saúde do homem: alerta e relevância, em 2005, número especial da revista publicada pela ABRASCO (Associação Brasileira de Pós-Graduação em Saúde Coletiva) com a temática Saúde do Homem;

2. Homens e masculinidades - outras palavras, livro publicado pela ECOS/EDITORA 34, em 1998 (org. Arilha, M; Ridenti, S.G.U.; Medrado, B.);

3. Antropologia, Gênero e Masculinidade - primeira página na internet brasileira dedicada ao estudo da masculinidade, criada em 1997. 
Toda a produção que vem ocorrendo desde a década de 90 também ilustra o interesse crescente que vem incidindo na área da saúde em relação às especificidades de gênero para a abordagem da saúde masculina, o que demonstra a importância desse novo e crescente campo para os estudos acadêmicos e para os serviços de saúde.

\section{MASCUlinidade HegeMôNiCA}

A partir da década de 90, portanto, os estudos sobre homens e masculinidades passam a realizar desenvolvimentos teóricos próprios consistentes (SABO, 1999; CONNELl, 2000; SCHRAIBER et al., 2005; COUTO \& SCHRAIBER, 2005; ARILHA, 2005; MACHADO, 2005). Destaca-se nessa ocasião o trabalho desenvolvido por Robert W. Connel (1997) a respeito do referencial para o estudo das masculinidades. Para esse autor o conceito de masculinidade é relacional e só existe em contraste com a feminilidade, definindo-se em quatro principais enfoques:

1. Essencialista: a masculinidade exige que o homem seja um ser ativo.

2. Positivista: a masculinidade como aquilo que os homens realmente são e, para tal, há de se considerar: definição de masculinidade com base nos estudos sobre gênero, depende de homens e mulheres já estarem divididos entre homens e mulheres, o que os homens são não tem a ver com ser homem ou mulher mas com ações masculinas e femininas.

3. Normativo: a masculinidade define aquilo que os homens devem ser, com base em imagens masculinas da mídia e nos "papéis" sexuais socialmente esperados.

4. Semiótico: a masculinidade definida com base no lugar masculino (lugar da autoridade - o falo) e no lugar feminino (feminilidade como carência).

Portanto, a masculinidade seria a posição nas relações de gênero, ou seja, as práticas pelas quais homens e mulheres se comprometem com o lugar masculino e o lugar feminino na sociedade e os efeitos dessas práticas na experiência corporal, na personalidade e na cultura (CONNELL, 1997). Para esse autor, as relações de gênero vão além da relação entre homens e mulheres, sendo também a base para a 
compreensão das várias masculinidades e das relações entre elas, isto é, das relações de gênero entre os homens. Assim, para o entendimento das relações entre as diferentes masculinidades, o autor propõe uma análise dinâmica das posições que essas masculinidades ocupam na sociedade, de acordo com as práticas e relações que constroem os principais padrões de ordenação de gênero nas sociedades ocidentais: hegemonia, subordinação, cumplicidade e marginalização:

1. Hegemonia: dominação cultural na sociedade. Um grupo sustenta posição de liderança, seria uma forma de masculinidade exaltada sobre as outras. Assim, teríamos a masculinidade hegemônica, pela qual seria legitimado o patriarcado, garantindo ao homem posição de liderança, autoridade e dominação sobre as mulheres. A masculinidade hegemônica representaria o ideal de masculinidade, que deve ser alcançado por todos os homens.

2. Subordinação: seria a dominação da masculinidade hegemônica sobre as outras masculinidades, caracterizando uma relação de hierarquia e subordinação entre os diferentes grupos de homens (homossexuais, negros, baixo estrato social, idosos, etc.).

3. Cumplicidade: seria a contrapartida pelo exercício do poder garantido pela masculinidade hegemônica: o dever do homem em cumprir com as responsabilidades assumidas (matrimônio e paternidade - função de provedor e protetor).

4. Marginalização: seria a relação entre a masculinidade hegemônica e a "outra" masculinidade. O ideal de masculinidade representado por indivíduo que, por algum motivo, não preenche todos os "requisitos" da masculinidade hegemônica, como por exemplo um esportista negro e famoso, que povoa o imaginário fantasioso do homem branco sobre "ser homem". Apesar de ser rico e famoso, por ser negro, esse esportista não será aceito no grupo, não poderá gozar de autoridade social. A masculinidade hegemônica determina as masculinidades que serão marginalizadas ou não.

Essa ordenação é mutável e dinâmica segundo as situações vividas (GARCIA, 1998), porém, apesar das transformações que a construção da identidade masculina vem sofrendo ao longo dos séculos, o processo histórico e cultural da construção do 
que é "ser homem" apresenta ainda tendência em manter a posição de dominação e poder dos homens sobre as mulheres. Dessa forma, a população masculina continuaria assumindo a função de provedor, o que garantiria aos homens autoridade moral e honra na casa e controle da sexualidade da sua mulher, permitindo o uso de força e violência; e o desempenho profissional e sexual esperado pela sociedade continuaria sendo exigido (CONNELl, 1997, 2000; CECCARELli, 1998b; GARCIA, 1998; GifFin \& Cavalcanti, 1999; PitTMan, 1999; Sabo, 1999; GifFin, 2005; VILLELA, 2005; MACHADO, 2005). Assim, o homem manteria a necessidade de mostrar independência, autocuidado, habilidade para desenvolver e manter relacionamentos, mostrar virilidade (o que inclui força, poder, agressividade, sexualidade incontrolável) e independência (DAVIES et al., 2000; RowE, 2000; TAYLOR, 2003; WHITE \& CASH, 2004; GOMES et al., 2005). Observamos então que as relações de gênero vivenciadas pela sociedade atual e já debatidas na academia trazem bem definidos os padrões de masculinidade e de feminilidade que, segundo a expectativa da sociedade, são respectivamente atribuídos aos homens e às mulheres. Segundo ConNELl (2000), esse padrão ideal de masculinidade seria uma forma de masculinidade culturalmente dominante, denominada masculinidade hegemônica. Para melhor compreensão da masculinidade hegemônica, GARCIA (1998) apresenta algumas características básicas que Brannon e David ${ }^{14}$ estabeleceram:

1. Desvalorização do feminino (no sissy stuff)

2. Masculinidade associada a poder, riqueza, sucesso (be a big wheel)

3. Distanciamento emocional (be a strucky oak)

4. Agressividade e comportamento de risco (give'em hell)

Dessa forma, a masculinidade definir-se-ia como o "não ser": não ser pacífico, não ser conciliador, não ser não conquistador sexual, não ser emotivo, não ser submisso e, assim, só existe masculinidade em contraste com a feminilidade, ou seja, não ser feminino e/ou não ter qualquer atributo que sugira feminilidade (CONNEll, 1997; CeCCARelli, 1998a; GarCia, 1998; FonSECA, 1999; Silva SG da, 2000a; GIFFIN, 2005).

\footnotetext{
${ }^{14}$ Brannon, R., David, D. The Forty-nine percent majority. Reading. MA: Addison-Wesley, 1976.
} 


\section{GÊNERO, COMPORTAMENTO DE RISCO E ADOECIMENTO}

A perspectiva relacional de gênero, com enfoque feminista, se estabeleceu nos campos de estudos sobre homens e saúde na década de 90 (GOMES et al., 2005; COUTO \& SCHRAIBER, 2005; ARILHA, 2005). O foco dos estudos voltou-se para as relações de poder dos homens entre si e entre homens e mulheres; e a articulação de gênero com outras categorias como raça/cor, etnia, orientação sexual, religião, estrato social, geração, entre outros, permitiu compreender melhor os processos de saúde e de doença nos diferentes segmentos de homens (SOIHET, 2003; CoUTO \& SCHRAIBER, 2005).

A partir dos estudos de gênero voltados para as mulheres consolidou-se a noção de dois sexos opostos que se relacionam entre si segundo os conceitos sociais de feminilidade e de masculinidade (COURTEnAy, 2000; GifFin; 2005). Assim, podemos entender que a noção de gênero proporcionou o rompimento das dicotomias público-privado, produção-reprodução, razão-emoção, natural-cultural, socialbiológico, ativo-passivo, entre outros (FARIA \& NOBRE, 1997; GIFFIN, 2005) uma vez que procura compreender como as relações de gênero estruturam as práticas sociais (CONNELl, 1997; FARIA \& NOBRE, 1997; COUTO \& SCHRAIBER, 2005). A compreensão do caráter relacional de gênero que estrutura os atributos sociais de homens e mulheres possibilita uma nova perspectiva para entendermos a forma como os homens se relacionam com sua saúde (PITTMAn, 1999; Courtenay, 2000; SCHOFIELD et al., 2000; COURTENAY \& KEELING, 2000; STEWART, 2004).

De fato, ao estudarmos homens a partir da perspectiva de gênero, observamos que a busca do modelo ideal do "ser masculino" (CONNELL, 2000; ARILHA, 2005) acarreta alguns prejuízos sobre a saúde da população masculina (PITTMAN, 1999; SABO, 1999; CONNEll, 2000; Courtenay, 2000; DAVIES et al., 2000; GIFFIN, 2005; SCHRAIBER et al., 2005; COUTO \& SCHRAIBER, 2005; ARILHA, 2005).

SCHRAIBER et al. (2005) sugerem três principais eixos temáticos para a discussão sobre saúde do homem e que, para melhor entendimento e sucesso das investigações e ações, devem ser debatidos sob o enfoque de gênero: o primeiro diz respeito às questões relativas à saúde reprodutiva e sexual, lançadas já na década de 70; o segundo refere-se à violência doméstica, obstáculo para as práticas de 
prevenção no que toca a saúde sexual e reprodutiva e importante nas questões referentes à saúde da mulher em geral, sexual e reprodutiva; e o terceiro eixo, que inaugura a preocupação mais "exclusiva" com os homens, a temática da morbimortalidade masculina.

Uma grande dificuldade para abordar a saúde do homem sob o aspecto de gênero é o fato de que pesquisas e estudos sobre saúde da população masculina sempre abordaram as diferenças entre homens e mulheres sob o aspecto biológico relacionado às patologias. Conforme apontado anteriormente na presente discussão, as pesquisas e estudos abordam as patologias mais freqüentes por sexo, por faixa etária, por estrato social, por raça/ cor e discutem a saúde do homem em contraste com saúde da mulher (COURTENAY \& KEELING, 2000; SCHOFIELD et al., 2000; JONES, 2004). Dessa forma, a atenção à saúde do homem acaba sendo reduzida à prevenção do câncer de próstata, uma vez que o carro chefe do programa da saúde da mulher é a prevenção dos cânceres de mama e de colo de útero.

Ao compararmos taxas de morbidade feminina e masculina observamos que elas são mais elevadas entre a população feminina, desviando assim a atenção em relação à saúde do homem (LAURENTI, 1998; PitTMAN, 1999; SCHOFIELD et al., 2000). Porém, quando observamos essas taxas com mais cautela, notamos que seus elevados valores para a população feminina em contraposição à população masculina se devem ao fato de que as mulheres, quando necessitam, buscam mais assistência à saúde (Laurenti, 1998; PitTMan, 1999; Courtenay, 2000; PinHeiro, et al., 2002; LAURENTI et al., 2005). De fato, ao observarmos as taxas de hospitalização entre homens e mulheres, bem como as taxas de morbidade entre homens e mulheres idosos, nota-se como são próximas (LAURENTI, 1998; PINHEIRO, et al., 2002) . Além disso, há maior morbidade masculina em relação às doenças de notificação compulsória (DNC) e àquelas associadas ao trabalho. Por fim, as elevadas taxas de mortalidade e a menor expectativa de vida encontradas entre os homens somam-se às argumentações sobre a necessidade de se voltar a atenção à saúde do homem (LAURENTI, 1998).

Análise de dados obtidos do Ministério da Saúde (DATASUs) e do IBGE (SIDRA, CENSO 2000) permite uma noção da situação geral de saúde dos homens no país. Ao observarmos o coeficiente de mortalidade dos homens em relação às 
mulheres, entre 20 e 59 anos, no Brasil, observamos uma sobretaxa de mortalidade entre os homens. Observamos ainda que o número de óbitos de homens na população masculina, para o mesmo grupo etário, é também maior do que o número de óbitos de todos os indivíduos na população geral, à exceção do Estado de São Paulo. A tabela 1 apresenta os coeficientes de mortalidade geral e de mortalidade por sexo no Brasil, Estado e Município de São Paulo, para indivíduos de 20 a 59 anos, para o ano de 2000. Como o lócus do presente estudo pertence à área central do município de São Paulo e responde suas atividades aos órgãos municipais de saúde da Subprefeitura Sé, a tabela 1 também apresenta os coeficientes dessa região, permitindo uma noção do que ocorre no espaço onde está inserido o CSEBF-AV.

Tabela 1: Coeficiente de mortalidade geral e por sexo, por mil habitantes, 2000 (20-59 anos)

\begin{tabular}{lccc}
\hline \multicolumn{1}{c}{ REGIÃO } & $\begin{array}{c}\text { Coeficiente de mortalidade } \\
\text { por sexo por mil habitantes }\end{array}$ & $\begin{array}{c}\text { Coeficiente de mortalidade } \\
\text { geral por mil habitantes }\end{array}$ \\
\cline { 2 - 3 } & Homens & Mulheres & \\
\hline \hline Brasil & 5 & 2 & 4 \\
Estado de São Paulo & 3 & 2 & 8 \\
Município de São Paulo & 6 & 2 & 4 \\
Subprefeitura Sé & 5 & 2 & 3 \\
\hline Fonte: DATASUS; IBGE (SIDRA, CENSO 2000); TABNET DE MORTALIDADE (Município de São Paulo - MSP)
\end{tabular}

LAURENTI et al. (2005) destacam as cinco primeiras causas de óbito entre homens, para todas as faixas etárias, no Brasil em 2001: doenças do aparelho circulatório $(28,7 \%)$, causas externas $(21 \%)$, neoplasias $(13,9 \%)$, doenças do aparelho respiratório $(10,3 \%)$ e doenças do aparelho digestivo $(6,0 \%)$.

O coeficiente de mortalidade por causa, para homens e para mulheres, permite conhecer de que doença os homens morrem mais, na população masculina, e de que doenças as mulheres morrem mais, na população feminina. A tabela 2 mostra os coeficientes de mortalidade por causa, para homens e mulheres entre 20 e 59 anos, das cinco primeiras causas de óbito em homens, segundo o CID-10, para o ano de 2000 no Brasil, Estado e Município de São Paulo e Subprefeitura Sé. Observamos que em todas as regiões pesquisadas a maioria dos coeficientes masculinos é superior aos coeficientes femininos, chamando a atenção o fato de que o coeficiente de 
mortalidade por neoplasias para as mulheres é o que mais se aproxima do mesmo coeficiente para os homens, chegando a ser superior no Estado de São Paulo e na região da Subprefeitura Sé. O Estado de São Paulo também chama a atenção por apresentar maior coeficiente de mortalidade por doenças circulatórias para as mulheres.

Tabela 2: Coeficiente de mortalidade por causa, por 100 mil habitantes, cinco primeiras causas de óbito entre homens (CID-10), para homens e mulheres, 2000 (20-59 anos)

\begin{tabular}{|c|c|c|c|c|c|c|c|c|}
\hline \multirow{3}{*}{$\begin{array}{c}\text { Causas por } \\
\text { capítulo CID-10 }\end{array}$} & \multicolumn{8}{|c|}{ Coeficiente de Mortalidade por causa (por 100 mil habitantes) } \\
\hline & \multicolumn{2}{|c|}{ Brasil } & \multicolumn{2}{|c|}{ Estado SP } & \multicolumn{2}{|c|}{ Município. SP } & \multicolumn{2}{|c|}{ Subpref. Sé } \\
\hline & $\mathbf{H}$ & $\mathbf{M}$ & $\mathbf{H}$ & $\mathbf{M}$ & $\mathbf{H}$ & $\mathbf{M}$ & $\mathbf{H}$ & $\mathbf{M}$ \\
\hline D. infec. e parasitárias & - & - & 23,1 & 20,0 & 53,6 & 20,2 & 94,2 & 22,5 \\
\hline Neoplasias & 48,5 & 46,6 & 30,4 & 55,3 & 64,8 & 58,7 & 61,6 & 62,7 \\
\hline D. circulatórias & 93,0 & 58,3 & 56,1 & 68,7 & 123,3 & 70,0 & 109,1 & 57,1 \\
\hline D. digestivas & 37,0 & 10,1 & 24,5 & 13,1 & 45,0 & 10,7 & 39,2 & 11,3 \\
\hline Alt. Exames & 54,3 & 27,3 & - & - & - & - & - & - \\
\hline Causas externas & 168,4 & 20,8 & 104,3 & 24,2 & 240,5 & 23,1 & 135,3 & 20,1 \\
\hline
\end{tabular}

Os dados sobre morbidade masculina em serviços de atenção primária à saúde ainda são poucos, ou porque os homens freqüentam pouco esse tipo de serviço de saúde (onde podemos obter a prevalência das morbidades na população), ou porque são poucos os estudos com esse enfoque, ou ambas as situações. Assim, para termos uma idéia de quais seriam as doenças mais prevalentes na população masculina podemos fazer uso das estatísticas de mortalidade, que apontam, entre todas as causas de óbitos na população masculina, de qual causa os homens morrem mais. As estatísticas de mortalidade são muito úteis para fornecer uma noção de quais doenças são mais prevalentes em uma região ou população estudadas, porém não permitem apontar todas as morbidades presentes na população, como aquelas que têm alta prevalência e baixa letalidade. Assim, a partir de dados mais recentes do Ministério da Saúde (DATASUS) procuramos conhecer a mortalidade proporcional por causas, das cinco primeiras causas de óbitos em homens, segundo o CID-10, para o ano de 2004, para homens e mulheres entre 20 e 59 anos, no Brasil, Estado e Município de São Paulo e Subprefeitura Sé (Tabela 3). Podemos observar a maior proporção de 
óbitos de homens em relação às mulheres para todas as causas, com exceção das neoplasias, que apresentam proporções bastante próximas para homens e mulheres. Estas informações mostram que, na região da Subprefeitura Sé, por exemplo, ainda há importante prevalência de doenças infecciosas e parasitárias na população masculina, apontando a necessidade de uma ação mais efetiva na região para o combate dessas doenças que são, em sua maioria, evitáveis. Porém, não podemos deixar de considerar que a síndrome da imunodeficiência adquirida (AIDS), segundo o CID-10, está no grupo de doenças infecciosas e parasitárias, e apenas um estudo detalhado entre as causas nesse grupo de doenças poderia esclarecer quais seriam as doenças infecciosas e parasitárias mais freqüentes nas estatísticas de mortalidade.

Tabela 3: Mortalidade proporcional por causas, cinco primeiras causas de óbito entre homens (CID-10), para homens e mulheres, 2004 (20-59 anos)

\begin{tabular}{|c|c|c|c|c|c|c|c|c|}
\hline \multirow{3}{*}{$\begin{array}{c}\text { Causas por } \\
\text { capítulo CID-10 }\end{array}$} & \multicolumn{8}{|c|}{ Mortalidade proporcional por causas ( $\%$ ) } \\
\hline & \multicolumn{2}{|c|}{ Brasil } & \multicolumn{2}{|c|}{ Estado SP } & \multicolumn{2}{|c|}{ Município. SP } & \multicolumn{2}{|c|}{ Subpref. Sc } \\
\hline & $\mathbf{H}$ & $\mathbf{M}$ & $\mathbf{H}$ & $\mathbf{M}$ & $\mathbf{H}$ & $\mathbf{M}$ & $\mathbf{H}$ & $\mathbf{M}$ \\
\hline D. infec. e parasitárias & - & - & - & - & 5,5 & 2,5 & 8,3 & 3,8 \\
\hline Neoplasias & 7,3 & 7,3 & 8,6 & 7,9 & 8,9 & 8,8 & 10,8 & 11,6 \\
\hline D. circulatórias & 12,6 & 8,1 & 14,0 & 8,4 & 15,3 & 9,1 & 14,9 & 8,3 \\
\hline D. digestivas & 5,1 & 1,5 & 6,3 & 1,6 & 5,9 & 2,3 & 2,6 & 1,5 \\
\hline Alt. Exames & 6,8 & 3,3 & 4,5 & 1,7 & - & - & - & - \\
\hline Causas externas & 23,6 & 3,0 & 22,7 & 2,9 & 23,3 & 2,7 & 18,8 & 2,6 \\
\hline
\end{tabular}

Taxas de mortalidade masculina mais elevadas que as taxas de mortalidade feminina e taxas de morbidade feminina mais elevadas que as taxas de morbidade masculina evidenciam que não seriam apenas os fatores biológicos que interfeririam nas questões de saúde de homens e mulheres mas também os atributos de gênero socialmente construídos teriam efeito sobre as práticas sociais dos indivíduos (PitTMAn, 1999; Gomes et al., 2005; COUTO \& SchraiBer, 2005), além de sua situação socioeconômica e outros fatores sociais, como acrescentam LAURENTI (1998), Rowe (2000), PinHEIRO et al. (2002), WoOds et al. (2002) e LAURENTI et al.(2005). Como aborda COURTENAY (2000), as práticas sociais de homens e mulheres levam esses indivíduos a crenças e comportamentos em relação à saúde baseados também em gênero. 
Partindo-se da noção de masculinidade hegemônica como um modelo ideal a ser alcançado pelos homens (CONNELL, 1997) é possível perceber os prejuízos que os homens vivenciam nessa busca. Assim, se a sociedade espera que os homens sejam fortes e independentes eles não se permitem perceber sinal ou sintoma de perturbação da saúde como um problema e que eles precisam de ajuda, ou seja, eles não se permitem manifestar "essa fraqueza" (GIFFIN \& CAVALCANTI, 1999; Courtenay, 2000; CONNELl, 2000; BANKS, 2004; GRUMBACH, 2004; SCHRAIBER, et al., 2005; COUTO \& SCHRAIBER, 2005; ARILHA, 2005).

Uma das características da masculinidade hegemônica (CONNELL, 1997) é a percepção de invulnerabilidade, que faz o homem não perceber que adota padrões de comportamento considerados de risco para sua saúde (GIFFIN, 1994; HEISE, 1994; Connell, 1997; Garcia, 1998; Giffin \& Cavalcanti, 1999; Courtenay, 2000; Courtenay \& KeEling, 2000; Schofield et al., 2000; GifFIn, 2002). Esses padrões de comportamento expõem o homem a situações de vulnerabilidade emocional, biológica e social: arriscar-se a contrair infecções sexualmente transmissíveis (ISTs/ AIDS) ou a uma gestação indesejada quando se recusa a usar preservativos e mantém grande número de parceiras (exercendo seu poder, seu comportamento de risco e sua sexualidade incontrolável e/ou insaciável); usar da violência e da força para obter encontro sexual; não envolvimento emocional para não perder seu poder (GIFFIN, 1994; Heise, 1994; Connell, 1997; Garcia, 1998; LAURenti, 1998; GifFin \& Cavalcanti, 1999; Pittman, 1999; Courtenay, 2000; Schofield et al., 2000; Courtenay \& Keeling, 2000; Davies et al., 2000; Diniz, 2001; Arilha, 2005; COUTO \& SCHRAIBER, 2005; LAURENTI et al., 2005; SCHRAIBER et al., 2005; VILLELA, 2005), entre outras situações, que levam a consequiências prejudiciais à sua saúde e à saúde das pessoas com quem se relaciona.

O estilo de vida imposto à população masculina gera estresse, sedentarismo, má alimentação e prática de comportamentos não saudáveis e de risco, como o hábito de fumar, o uso de bebida alcoólica e, às vezes, a associação deste hábito com a condução de veículos motorizados, não usar cinto de segurança, entre outros, propiciando tanto o desenvolvimento de doenças (cardiovasculares, neoplasias malignas - câncer gástrico, câncer de pulmão) como de situações que aumentam as taxas de mortalidade por acidentes e violência, principalmente entre os homens 
jovens (Laurenti, 1998; Courtenay, 2000; Courtenay \& KeEling, 2000; Davies et al., 2000; Rowe, 2000; TAYLOR, 2003; White \& CASH, 2004; Couto \& SCHRAIBER, 2005).

Assim, as práticas sociais de gênero tenderiam a inibir o homem de cuidar de sua saúde, deixando ele de perceber ou de valorizar qualquer sinal de patologia e de freqüentar serviços de atenção primária à saúde (lócus identificado como feminino) (CourtenAy, 2000; RutZ, 2004; GifFin, 2005; Couto \& SChraiber, 2005), o que o faz recorrer, muitas vezes, a prontos socorros e hospitais quando sua doença já está em fases de complicações e de mais difícil reversão. Este comportamento de negação, associado ao comportamento de exposição aos fatores de risco acima mencionados, e que responde a desafios (LAURENTI, 1998; SCHOFIELD et al., 2000), contribui para a elevação das taxas de mortalidade masculina (LAURENTI, 1998; Courtenay, 2000; Courtenay \& KeEling, 2000; Davies et al., 2000; Rowe, 2000; SCHOFIELD et al., 2000; TAYLOR, 2003; WHITE \& CASH, 2004; COUTO \& SCHRAIBER, 2005) e, conforme abordam PITTMAN (1999) e LAURENTI et al. (2005), é um comportamento esperado e considerado "normal" pela sociedade.

Laurenti (1998), Courtenay (2000), Courtenay \& KeEling (2000) e DAVIES et al. (2000) relacionam o comportamento masculino ao desenvolvimento de algumas patologias ao observarem a menor taxa de mortalidade feminina por câncer de pulmão, conseqüente ao tabagismo, e o aumento das taxas de doenças cardiovasculares e de mortalidade por causas externas na população feminina conseqüente ao novo estilo de vida adotado pelas mulheres e sua maior exposição ao espaço público (semelhante aos homens).

A influência de comportamentos específicos adotados por homens e mulheres, que variam cultural, histórica e socialmente, é hoje entendida como importante fator de risco para o adoecimento dos homens. Dessa forma, olhar a saúde sob a perspectiva de gênero e aprimorar esse olhar permitem compreender como o comportamento de gênero interfere na saúde de homens e mulheres e possibilita pensar e organizar os serviços de saúde com ações voltadas à saúde dos homens, de forma integral (SCHOFIELD et al., 2000; BANKS, 2004), procurando-se garantir que essas ações possam interagir com aquelas já desenvolvidas na saúde da mulher, mantendo-se o caráter relacional de gênero também no desenvolvimento de ações de 
saúde em geral dos indivíduos (COURTEnAy \& KEELing, 2000; SCHOField et al., 2000; STWEART, 2004; COUTO \& SCHRAIBER, 2005; FIGUEIREDO, 2005).

\section{IV.SAÚDE DO HOMEM}

Conforme discutido até aqui, a masculinidade hegemônica seria uma forma de masculinidade culturalmente dominante pela qual "ser homem" é "não ser feminino": não ser pacífico, não ser conciliador, não ser não conquistador sexual, não ser emotivo, não ser submisso, não ser fraco/ não admitir fraqueza, ou seja, não ter qualquer atributo que sugira feminilidade (CONNELl, 1997; CECCARELLI, 1998a; GARCIA, 1998; FonSECA, 1999; DAVIES et al., 2000; SILVA SG da, 2000a; White \& CASH, 2004; GIFFIN, 2005).

A fim de responder a essas exigências o homem assume um comportamento considerado de risco que seria não só a sua exposição a fatores considerados de risco para o adoecimento como também a conduta que esse homem adota frente a algum prejuízo à sua saúde (CONNEL, 1997; SABO, 1999; COURTENAY, 2000; ADDIS \& MAHALIK, 2003).

Partindo-se da idéia de que estar doente sugere "fraqueza" e de que fragilidade é sinônimo de feminilidade, é "natural" o hábito que os homens têm de não valorizar sua saúde nem a presença de sinais ou sintomas, buscando ajuda médica apenas em casos extremos (muitas vezes apenas frente à impossibilidade de trabalhar), conforme achados de WoOds et al. (2002) e de WHITE \& CASH (2004), com o que concordam COURTENAY (2000), ROWE (2000), BANKS (2004) e Figueiredo (2005). Dessa forma, como aponta FigueIREDO (2005), os homens tenderiam a buscar serviços de saúde que os recebessem a qualquer hora, solucionando seu problema imediato, ou seja, pronto-socorros e serviços de prontoatendimento, conforme encontrado por PINHEIRO et al. (2002) e por WoOds et al. (2002), e teriam mais dificuldade em fazer um acompanhamento de seus problemas de saúde. Ainda, Wood et al. (2002) assinalam que os homens predominam nesse tipo de serviço em relação às mulheres, que predominantemente freqüentam as UBS. No entanto, essa diferença no uso de serviços de saúde entre homens e mulheres não ocorre ou é muito pequena quando observamos as taxas de internação para homens e 
mulheres, conforme apontam LAURENTTI (1998) e PINHEIRO et al. (2002), cujos achados apontaram ainda que a aproximação dessas taxas aumenta conforme se eleva a idade de homens e mulheres.

Ainda, conforme apresentamos anteriormente, os dados epidemiológicos sobre saúde para homens e mulheres no Brasil mostram a maior mortalidade masculina, geral e por quase todas as causas específicas, em relação às mulheres (LAURENTI, 1998; LAURENTI et al., 2005). Além disso, a mortalidade proporcional nos indica que morbidades relacionadas ao sistema cardiovascular, as quais podem ser evitadas e/ ou controladas, bem como suas complicações, estão presentes de forma importante na população masculina. Esse dado, associado às estatísticas de outras patologias, indica uma situação de saúde desfavorável para os homens e levanta a necessidade de uma melhor abordagem a essa população nos serviços de atenção primária à saúde (FIGUEIREDO, 2005).

Porém, o homem é tradicionalmente visto fora das unidades básicas de saúde, tanto pela própria população masculina como pelos serviços de saúde e suas equipes e também pela sociedade, como conseqüência do padrão sócio-cultural dominante em nossa sociedade.

De fato, alguns autores abordam algumas razões que poderiam contribuir para afastar os homens dos serviços de atenção primária à saúde:

1. Dificuldade de acesso: BANKS (2004) aponta a distância da UBS ao local de trabalho e o horário coincidente da consulta e do trabalho como possíveis fatores de dificuldade; conforme os achados de WoODs et al. (2002), RowE (2000) concorda que a demora na espera para a consulta também é um problema para os homens.

2. Tempo reduzido de consulta: Woods et al. (2002) mostraram que profissionais de saúde da atenção primária à saúde dedicam menos tempo de consulta e menos informações sobre a patologia e sobre orientações para comportamentos saudáveis para os homens do que para as mulheres, situação que Rowe (2000) e BANKS (2004) apontam como queixa dos homens.

3. Padrões culturais e sociais: os homens costumam identificar a doença com "fraqueza" (COURTENAY, 2000; Rowe, 2000; BAnKS, 2004; FigueIREDO, 2005) deixando o problema de lado o quanto for possível; além disso, os homens acham 
que "fariam o médico perder tempo", já que não apresentam problemas (BANKS, 2004).

4. Noções equivocadas: Rowe (2000), BANKS (2004) e FiguEIREdo (2005) apontam que os homens identificam o espaço da UBS como local destinado às mulheres e crianças.

5. Desinteresse dos homens: o aparente desinteresse dos homens com sua própria saúde leva os serviços e profissionais de saúde a acharem que qualquer esforço para atrair os homens às UBS seria em vão (BANKS, 2004).

6. Masculinidade hegemônica: DAVIES et al. (2000) e WoODs et al. (2002) identificaram, corroborando o que é apontado por outros autores, que a noção de invulnerabilidade do ideal de masculinidade e a necessidade de mostrar independência faz os homens evitarem a busca por ajuda (ameaça à masculinidade) e não perceberem alguns de seus comportamentos como fatores de risco à sua saúde (Heise, 1994;; Rowe, 2000; AdDis \& MAHALiK, 2003; BANKS, 2004; White \& CASH, 2004; FigUEIREDO, 2005).

Além disso, cultural e socialmente a mulher sempre foi identificada como aquela que cuida: do marido, do filho, do pai, do irmão (cuidar de $=$ feminino) (Courtenay, 2000; Woods et al., 2002; Figueiredo, 2005), o que faz com que os homens, na hora que precisam buscar ajuda médica, não saibam aonde ir exatamente, já que não têm o hábito de freqüentar serviços de saúde (Rowe, 2000), o que concorda com os achados de DAVIES et al. (2000) e de WooDs et al. (2002), e não saibam também expressar o que sentem, o problema que apresentam, uma vez que são pouco comunicativos e têm dificuldade para falar de si mesmos (DAVIES et al., 2000; Rowe, 2000; WoOds et al. 2002, FigueIREDO, 2005). Essas são atitudes esperadas de um indivíduo que é educado para não sentir dor, não pedir ajuda, não falar sobre seus sentimentos.

Os autores pesquisados assinalam ainda uma outra questão que contribuiria para afastar o homem das UBS: as próprias UBS e suas equipes. Conforme apontado anteriormente, o tempo reduzido de consulta, a pouca explicação sobre a patologia do paciente e as poucas orientações sobre mudança de hábitos de vida considerados de risco para a saúde podem afastar os homens das UBS. São situações que podem contribuir para que eles se sintam menos aceitos naquele espaço (com o qual já não 
se identificam), achem que estão desperdiçando o seu tempo e o do médico. Isso acontece porque os próprios profissionais estão pouco preparados para lidar com o homem, por influência, entre outros, da masculinidade hegemônica, que faz o profissional aceitar/ acreditar que os homens não teriam "grandes" problemas de saúde e que eles realmente não iriam seguir as orientações feitas (RowE, 2000; BANKS, 2004; FigUEIREDO, 2005).

De fato, em seu estudo com profissionais de serviços de atenção primária a saúde, WoODS et al.(2002) não só identificaram essa situação como observaram que as consultas com as médicas são mais demoradas, pois elas exploram não só as queixas clínicas como também as relações sociais que o paciente vivencia, com o que concorda Rowe (2000). Poderíamos dizer que as mulheres não teriam "preconceito" em identificar fraquezas ou sofrimentos nos homens e por isso investigariam essas questões, enquanto que os médicos homens, respondendo à masculinidade hegemônica, evitariam identificar essas fraquezas e sofrimentos em seus pares, não ampliando assim a investigação. Em relação ao paciente, poderíamos dizer que frente à sua médica, ele cederia aos seus sentimentos entendendo que não estaria diante de uma "mulher" mas sim de uma "doutora" que estaria ali para ajudá-lo. Em relação ao médico do sexo masculino, o homem poderia adotar o mesmo raciocínio, porém se o médico não questiona o paciente também não fala. Essas idéias são apenas conjecturas que levantam mais questões para se pensar e investigar. ConNELL (1997) e SCHOFIELD et al. (2000) ainda apontam a identificação da relação médico-paciente com uma relação de hierarquia na qual o médico tem o poder (ele diagnostica e prescreve o tratamento que deve ser seguido) e o paciente se submete a esse poder de resolução. Essa situação poderia também contribuir para afastar os homens dos serviços de saúde.

Além disso, as unidades básicas de saúde (UBS) foram tradicionalmente desenvolvidas para atender às mulheres e às crianças (WOODS et al., 2002; BANKS, 2004; FIGUEIREDO, 2005), justificando a identificação que os homens fazem das UBS como sendo um espaço "feminilizado", além de o ambiente, inevitavelmente, tornarse mais receptivo às mulheres do que aos homens (desde as revistas em sala de espera até os cartazes informativos sobre saúde e atividades desenvolvidas) (DAVIES et al., 2000; Rowe, 2000; WoODS et al., 2002; BANKS, 2004; FIGUEIREDO, 2005). 
Dessa forma, como apontam BANKS (2004) e FIGUEIREDO (2005) e conforme identificado por Woods et al. (2002), torna-se clara a necessidade da abordagem de gênero e da compreensão das masculinidades para o estudo da saúde do homem e a necessidade de espaços para se discutir esse tema com os profissionais de saúde, sensibilizando-os para o atendimento dos homens. A partir disso, é possível identificarmos onde podemos atuar, como profissionais de saúde e planejadores de ações e sob a perspectiva de organização dos serviços de saúde.

Como sugerem FigUEIREDO (2005) e BANKS (2004), uma estratégia seria transformar o ambiente da UBS em um espaço atrativo para os homens oferecendo revistas de interesse masculino nas salas de espera, cartazes e folhetos informativos com questões de saúde específicas dos homens e, a depender da unidade de saúde, flexibilidade de horários ${ }^{15}$. DAVIES et al. (2000) observaram que os homens mostraram-se receptivos a atividades como palestras e grupos com temas de saúde de seu interesse, conforme foi sugerido nos estudos de WoODS et al. (2002). Rowe (2000) e FIGUEIREDO (2005) concordam com esses achados e apontam ainda que ações de promoção à saúde e de informação e educação em saúde poderiam ser desenvolvidas nos ambientes freqüentados pelos homens, incluindo o local de trabalho. Alguns dos temas sabidamente procurados pelos homens incluem questões como disfunção erétil, ejaculação precoce, ISTs/ AIDS, câncer de próstata, planejamento familiar e paternidade. GARCIA (1998) ainda assinala que o exercício da paternidade, que inclui os cuidados corporais e as necessidades afetivas dos filhos, permitiria não só trabalhar as dificuldades que os homens têm para expressar afeto e ternura como também seria uma estratégia para começarmos a trazer os homens para as UBS.

É preciso lembrar que não são todos os homens que apresentam as atitudes aqui discutidas em relação à saúde e nem todas elas em conjunto. Entendemos hoje que existem diversas masculinidades e, como conseqüência, alguns homens não têm

\footnotetext{
${ }^{15}$ A discussão de que os homens não freqüentam UBS porque as consultas coincidem com o horário de trabalho gera algumas discussões, a partir do momento que as mulheres que trabalham fora também o fazem no horário de funcionamento das UBS. O que se observa é, mais uma vez, a questão da masculinidade hegemônica: os chefes parecem menos resistentes em liberar as mulheres para consultas médicas (o que inclui papanicolaou e pré-natal, no caso das gestantes, e acompanhamento dos filhos ao pediatra), enquanto que para os homens, o próprio trabalhador procura rejeitar que "precisa ir ao médico", evitando ser considerado "doente" por isso e assim perder o emprego, uma vez que o chefe se mostra mais resistente a aceitar essa necessidade do funcionário.
} 
mais receio/medo de demonstrar características associadas ao feminino. Assim, esses homens preocupam-se com seus filhos, dividem a tarefa doméstica com suas parceiras, demonstram seus sentimentos e também valorizam a própria saúde (GIFFIN \& Cavalcanti, 1999; Pittman, 1999; Davies et al.,2000; Silva SG da, 2000a; KorIN, 2001; GIFFIN, 2002; WoOdS et al., 2002; ADDIS \& MAHALIK, 2003; FigUEIREDO, 2005).

WoODS et al. (2002) também advertem que os dados sobre a saúde desfavorável dos homens são dados gerais e não devem ser atribuídos exclusivamente à masculinidade hegemônica. É preciso considerar que os dados estatísticos não incluem fatores que também interferem no tipo de atenção que um indivíduo, seja homem ou mulher, tem com sua saúde, como baixa condição socioeconômica e pouca escolaridade, com o que concordam LAURENTI (1998), ROWE (2000) e LAURENTI et al. (2005) e conforme foi observado por PINHEIRO et al. (2002). Esses autores assinalam que os indivíduos vivendo nessas situações são a grande maioria da população geral. FIGUEIREDO (2005) concorda que a situação de saúde desfavorável dos homens não deve ser unicamente pensada como uma falta de responsabilidade dos homens com sua saúde e aponta que tal situação também não deve ser atribuída a uma falha na organização dos modelos de atenção primária à saúde. De fato, conforme discutimos até aqui, os motivos que afastam os homens dos serviços de atenção primária à saúde são múltiplos e há muito a ser pesquisado e estudado para muito também ser desenvolvido.

\section{O HOMEM CONTEMPORÂNEO}

Conforme discutido até aqui, observamos que existe um padrão de masculinidade hegemônica, histórica e culturalmente construído, passível, portanto, de transformações, e que é socialmente imposto aos homens (HERNÁNDEZ, 1996; Couto \& Schraiber, 2005). Porém, o exercício desse modelo "ideal" do "ser homem" (CONNELl, 2000; ARILHA, 2005), ao qual GifFIn \& CAVALCANTI (1999) denominam "velho padrão" de masculinidade, não é fácil de ser alcançado pelos homens (CONNELL, 2000). Ao tentar aproximar-se da masculinidade hegemônica o homem se expõe, e também aqueles que lhe são próximos, a riscos de saúde em geral 
(Garcia, 1998; Pittman, 1999; Sabo, 1999; Connell, 2000; Courtenay, 2000; DAVIES et al., 2000; GIFFIN, 2002, 2005; MERYN, 2004; SCHRAIBER et al., 2005; COUTO \& SCHRAIBER, 2005; ARILHA, 2005). Assim, o homem se expõe a situações de risco ao exercer a sexualidade incontrolável, conforme exposto anteriormente, ou quando procura responder a desafios e demonstrar poder, envolvendo-se muitas vezes em situações de violência que podem terminar de forma fatal ou com prejuízos graves. A fim de não ser identificado com qualquer atributo feminino, distancia-se emocionalmente em seus relacionamentos (familiares, parceira, filhos), ou deixa de dar atenção adequada à sua saúde, não percebendo - ou não aceitando - qualquer forma de adoecimento, afastando assim qualquer forma de identificação com fragilidade (Giffin \& CAVAlCANTI, 1999; Courtenay, 2000; Connell, 2000; BANKS, 2004; GrumbaCH, 2004; SCHRAIBER, et al., 2005; COUTO \& SCHRAIBER, 2005; ARILHA, 2005). A busca dessas práticas e a impossibilidade ou dificuldade para alcançá-las (CONNELL, 2000) gera também estresse psicossocial a esse homem, uma vez que ele não consegue responder ao que a sociedade espera dele, o que pode leválo à prática de violência ou ao uso de bebida alcoólica como forma de "continuar" exercendo ou de "não perder" seu poder.

Mas será que os homens estão a todo instante desejando viver essas situações, ou seja, reproduzir o padrão hegemônico de masculinidade que a sociedade lhes impõe? Em nenhum momento se cansam, adoecem, precisam expor seus sentimentos e frustrações? GIFFIN \& CAVALCANTI (1999) trazem essas questões ao abordarem a insatisfação que alguns homens têm expressado com esse velho padrão de comportamento que os torna prisioneiros de seu próprio poder de dominação (HERNÁNDEZ, 1996; GifFin \& CAVAlCANTI, 1999; FonSECA, 1999; GifFIN, 2005). GIFFIN \& CAVALCANTI (1999) assinalam que a situação vivida pelas mulheres na década de 70 quando rejeitaram a identificação do feminino com o espaço privado e buscaram sua consolidação no espaço público está sendo vivida atualmente por parcela dos homens de maneira inversa: alguns rejeitam sua identificação apenas com o espaço público e reivindicam um lugar no espaço privado. Essas autoras ainda identificam um "novo padrão" de masculinidade que responderia às novas demandas de alguns homens. 
A existência de um "velho" e de um "novo" padrão de masculinidade, divergentes em muitos aspectos, possibilita maior visibilidade ao que alguns autores (HERNÁNDEZ, 1996; FONSECA, 1999, SILVA SG da, 2000a; GIFFIN, 2005) denominam "crise da masculinidade" ou "crise da identidade masculina". O debate atual em torno da identidade masculina tem apontado para uma verdadeira crise da masculinidade, mas, segundo Silva (SILVA SG da, 2000a), esta discussão é antiga, havendo ecos dela desde o período vitoriano, como discutido anteriormente.

As transformações socioeconômicas e culturais exigiram mudanças no comportamento dos homens (CONNELL, 1997, 2000; SCHRAIBER et al., 2005; ARILHA, 2005), mudanças essas que ocasionaram uma certa desordem no papel do homem ao longo dos tempos (GIFFIN \& CAVALCANTI, 1999; GIFFIN, 2000; SILVA SG da, 2000a; MACHADO, 2005), que se viu diante da obrigatoriedade de cultivar e provar sua masculinidade e sua virilidade constantemente, o que consolidou a necessidade de cultuar uma masculinidade hegemônica comum a todos os homens (CONNELL, 2000; SILVA SG da, 2000a).

FONSECA (1999) aponta a conceituação de Connell ${ }^{16}$ sobre crise, de que esta pressupõe a destruição de um sistema, de alguma forma coerente, e a sua posterior restauração. Em relação à masculinidade, o autor considera que a crise da masculinidade seria um processo de transformação para sua posterior restauração, ou seja, restauração da hegemonia e dominação masculina. FONSECA (1999) e CASTELLS (2001) resgatam as três estruturas das relações de gênero definidas por CoNNELL (1997) e observam, em cada uma delas, as transformações que vêm acontecendo e proporcionando a crise da masculinidade. FonSECA (1999) aponta que as relações de poder implicam na tendência mais visível da crise, com o colapso histórico da legitimidade patriarcal. Quanto às relações de produção, a autora destaca o aumento de postos de trabalho ocupados por mulheres e, sobre as relações de cathexis, a autora menciona a estabilização da sexualidade de homossexuais que passa a ser uma alternativa pública dentro da ordem heterossexual. De fato, essas transformações vão exatamente de encontro ao que é o oposto das características atribuídas à masculinidade hegemônica (CONNELL, 1997, 2000).

\footnotetext{
${ }^{16}$ Connell RW. Masculinities. University of Califórnia Press, Berkeley, Los Angeles; 1995.
} 
As transformações apontadas indicam a necessidade dos homens em adotar um "novo padrão" de masculinidade. Assim, frente ao crescente desemprego e à maior facilidade das mulheres em se adaptarem a trabalhos relacionados a atividades domésticas, os homens passam a ficar mais tempo em casa enquanto as mulheres estão fora. Então, cabe a esses homens cuidar dos filhos, levá-los à escola, ao médico, para atividades de lazer; preparar as refeições para a família e cuidar da casa, isto é, desempenhar as tarefas domésticas tão associadas com o feminino. Essa situação, que rouba do homem a função de provedor e lhe impõe a necessidade de executar tarefas do âmbito doméstico, demonstra uma ruptura na estrutura patriarcal tradicional. Esta seria a primeira tendência de crise da masculinidade apontada por FONSECA (1999), além de ser o cenário clássico que muitas vezes gera situação de violência doméstica e alcoolismo dos homens para aqueles que ainda buscam desempenhar o modelo ideal de masculinidade e não aceitam perder o poder atribuído a eles.

Outra situação que exige um novo comportamento por parte dos homens resulta das conquistas do movimento feminista e do movimento das minorias sociais (como os homossexuais) decorridas década de 70. A anticoncepção e a liberação sexual, permitindo à mulher controle sobre o próprio corpo e liberdade para a busca de prazer, mudou os relacionamentos entre homens e mulheres, sendo que o homem não é mais o único que inicia a aproximação que objetiva o encontro sexual e passa, assim, a dividir com a mulher a ação de conquista sexual. Além disso, algumas mulheres já se sentem mais seguras para exigir seus direitos como o uso de preservativos na relação sexual, tomando o poder anteriormente detido pelos homens. Os homossexuais conquistaram o direito de expressar sua orientação sexual publicamente, impondo uma nova ordem para a relação binária heterossexual homem-mulher, apontando a terceira tendência de crise da masculinidade referida por FONSECA (1999). A presença da mulher no mercado de trabalho, segunda tendência de crise da masculinidade apresentada pela autora, transforma não só as relações familiares baseadas no padrão patriarcal, desde a mulher como única provedora até a necessidade da divisão das tarefas domésticas, incluindo o cuidado com os filhos, quando o casal trabalha fora; como também altera a dinâmica cotidiana nos locais de trabalho, onde surge uma nova "competição", uma vez que as 
mulheres são ainda inferiorizadas pela sociedade em geral e perder, por exemplo, um cargo importante em uma empresa para uma mulher é, para o homem que segue o velho padrão de masculinidade, uma verdadeira derrota.

Além disso, muitos homens contemporâneos demonstram maior preocupação com a própria saúde e buscam assistência médica não apenas para controle de doenças já instaladas como também para prevenção de doenças em geral (GIFFIN \& Cavalcanti, 1999; PitTMAn, 1999; Davies et al.,2000; Silva SG da, 2000a; Korin, 2001; GIFFIN, 2002; WoOds et al., 2002; AdDIS \& MAHALIK, 2003; FIGUEIREDO, 2005).

Não podemos deixar de mencionar a valorização que existe atualmente para a aparência física do homem, que vai desde estar bem vestido até tratamentos estéticos, reconhecidamente associados ao sexo feminino. Revistas renomadas, como Veja ${ }^{17} \mathrm{e}$ Época $^{18}$, já publicaram matérias especiais sobre homens abordando também essas questões. A Revista Veja, inclusive, já publicou mais de uma vez encarte especial ${ }^{19}$ sobre homens, abordando temas como vaidade, alimentação saudável, prática esportiva, trabalho, paternidade, saúde, doença e prevenção. Também a Revista da Folha $^{20}$ (encarte semanal adjunto ao jornal Folha de São Paulo) já colocou o homem no foco de suas publicações. Atualmente, há várias revistas ${ }^{21}$ dedicadas especialmente aos homens, diferentes daquelas que apresentam algumas matérias informativas e entrevistas mas têm como "tema de capa" a nudez feminina. Essas novas revistas preocupam-se com o homem e discutem suas matérias abordando assuntos ditos estereotipados (FARIA \& NOBRE, 1997) em revistas femininas, como

\footnotetext{
${ }^{17}$ Veja - O novo homem - outubro, 2003, matéria de capa (abordou afetividade, paternidade e vaidade).

${ }^{18}$ Época - Eternamente jovem - setembro, 2003, matéria de capa (abordou saúde, doença e envelhecimento).

${ }_{19}^{19}$ Veja - edição especial: Homem - outubro, 2003 (além de abordar questões como saúde e doença, envelhecimento e vaidade, enfocou homens solteiros e casados, sexo e acrescentou assuntos como homossexualidade, hobbies e "dicas" para conquistar as mulheres. Ainda levantou questões sobre a esposa que trabalha fora e o marido não e a disputa de poder entre homens e mulheres no local de trabalho); Veja - edição especial: Homem: O homem em seu novo papel - agosto, 2004 (acrescentou temas como moda masculina e família, quando esta não apresenta a composição tradicional).

${ }^{20}$ Revista da Folha - Especial saúde do homem: Papo de homem - julho, 2003, encarte especial (abordou saúde e doença, vaidade e questões de grande interesse dos homens: disfunção erétil e próstata); Revista da Folha - Homens apaixonados - agosto, 2003, matéria de capa (ressaltou homens que expressam sua afetividade).

${ }^{21}$ Vogue Homem (Carta Editorial), deixou de ser encarte da Vogue em 2004, sendo publicada duas vezes ao ano; Men's Health (editora Abril), primeira edição em maio de 2006. É curioso observar que, enquanto a Men's Health traz um modelo do sexo masculino em sua capa, a Revista Vogue Homem continua trazendo modelos atraentes do sexo feminino.
} 
moda, beleza, culinária, saúde e forma física, cuidado com os filhos, trabalho, decoração e "truques infalíveis" tanto para conquistar as mulheres como para ter/ manter melhor desempenho sexual.

Alguns autores assinalam que alguns homens atualmente já se mostram dispostos a exercer algumas das características desse novo padrão de masculinidade sem o receio de se aproximarem do feminino, pois esses homens já percebem a necessidade e os benefícios próprios em adotar esse novo comportamento. Assim, muitos homens desejam e têm prazer em participar do cuidado com os filhos, desde o planejamento com a parceira a respeito da gravidez até os cuidados com a criança, incluindo passear com os filhos, brincar com os filhos, levá-los à escola e acompanhá-los ao médico. Em relação à liberdade sexual e às ISTs/AIDS, muitos homens têm a percepção dos riscos que impõem à sua saúde ao exercer a sexualidade incontrolada. Além de não ser uma necessidade hegemônica para todos os homens, eles compreenderam que diminuir o número de parceiras e adotar métodos de proteção para as relações sexuais ajudam a diminuir o risco de contraírem alguma doença sexualmente transmissível e também de engravidarem a parceira sem planejamento. Com essa percepção, muitos homens têm valorizado o relacionamento afetivo com as parceiras fixas, o que muitas vezes colabora para a redução de parceiras eventuais e para a conscientização a respeito do uso do preservativo. Esses homens deixaram de pensar apenas em si e passaram a pensar no casal e na família. Os autores ainda destacam que muitos homens estão, hoje em dia, encontrando prazer e satisfação em ficar mais tempo no ambiente doméstico, com a família, e em dividir as tarefas da casa com a esposa, o que acaba sendo mais uma forma de aproximar afetivamente esse homem da sua família e de seu próprio lar (GIFFIN \& CAVAlCANTI, 1999; PitTMAN, 1999; DAVIES et al.,2000; Silva SG da, 2000a; Korin, 2001; GIFFIN, 2002; WoOds et al., 2002; AdDIS \& MAHALIK, 2003; FIGUEIREDO, 2005).

Frente ao exposto, torna-se compreensível a situação de grande conflito que o homem contemporâneo vive entre exercer o velho ou o novo padrão de masculinidade, uma vez que esse novo padrão exige do homem ações "femininas" e a aceitação do exercício de ações "masculinas" pelas mulheres. Essa insegurança em assumir um comportamento com características femininas, por ser ele rejeitado pela 
masculinidade hegemônica, leva à tão debatida crise da masculinidade (HERNÁNDEZ, 1996; GifFin \& CAVAlCANTI, 1999; FonSECA, 1999; Silva SG da, 2000a; GiFFIn, 2005) e, considerando o que foi discutido até aqui, compreendemos o por quê desse debate ser tão visível na atualidade. FonSECA (1999) e Silva (SILVA SG da, 2000a) apontam que a crise da masculinidade advém justamente da tentativa do homem em seguir a hegemonia masculina, ou seja, enquanto se espera e se exige dos homens que exerçam um modelo único de masculinidade, seja ele o velho padrão, o novo padrão ou um outro padrão a ser "definido" ainda, a crise da identidade masculina continuará presente. Os autores apontam que existem vários grupos de homens, e para cada grupo existe uma masculinidade mais compatível com a realidade, cultura e história de cada um (HERNÁNDEZ , 1996; CONNELl, 1997, 2000; FonSECA, 1999; Silva SG da, 2000a; Couto \& SchraIBER, 2005; ARILHA, 2005). Talvez a solução para a crise da identidade masculina esteja justamente vinculada à aceitação social (ou maior e melhor aceitação social) das diversas masculinidades.

Portanto, devemos compreender que ser homem não é ter ações só masculinas e que ser mulher não é ter ações só femininas. Há necessidade de abandonarmos de vez a teoria essencialista sobre homens e mulheres e assumirmos cada vez mais que homens e mulheres são sujeitos que interagem entre si com base nas relações de gênero (CONNELL, 1997). Segundo esse autor, a masculinidade não pode ser definida como um objeto mas como sendo a posição nas relações de gênero, as práticas pelas quais homens e mulheres se comprometem com essa posição de gênero e os efeitos dessas práticas na experiência corporal, na personalidade e na cultura. Ou seja, os indivíduos não estão ordenados apenas em grupos de homens e mulheres mas sim em feminino e masculino segundo suas ações, pois esses termos vão além da diferença entre sexos para como homens diferem entre si e mulheres diferem entre si em matéria de gênero (GIFFIN, 1994; HERNÁNDEZ ，1996; FARIA \& NOBRE，1997; BAndeIRA, 1999; Courtenay, 2000; Diniz，2001; Korin, 2001; SoIHET, 2003; LAURENTI et al., 2005; COUTO \& SCHRAIBER, 2005).

Assim, ao pensar o novo padrão de masculinidade a que GIFFIN \& CAVALCANTI (1999) se referem, podemos acrescentar a idéia de ações masculinas e ações femininas que podem ser exercidas, segundo a estrutura de gênero, por 
indivíduos homens ou por indivíduos mulheres, desvinculando a relação de exclusividade masculinidade-homem e feminilidade-mulher.

Esses conceitos assim transformados e interpretados permitem que a sociedade passe por uma transformação cultural e assim mude suas exigências a homens e mulheres, possibilitando aos homens exporem seus sentimentos e suas carências, suas necessidades, facilitando, assim, estratégias no campo da saúde para beneficiá-los. 
Capítulo 3

\section{Objetivos e Métodos}




\section{OBJETIVO GERAL}

Conhecer a população masculina adulta (18 a 60 anos) usuária de um serviço de atenção primária à saúde - o Centro de Saúde Escola Barra Funda "Dr. Alexandre Vranjac" (CSEBF-AV) - e o modo como essa população se insere no serviço.

\section{OBJETIVOS ESPECÍFICOS}

1. Conhecer quem são os homens que freqüentam o CSEBF-AV a partir da caracterização desse grupo quanto às categorias de condição de matrícula/ porta de entrada no serviço (morador da área de abrangência, trabalhador da área de abrangência, homens em situação de exclusão e homens com necessidade de seguimento/tratamento por doenças de notificação compulsória);

2. Identificar as demandas auto-referidas e diagnosticadas de saúde em geral e saúde sexual e reprodutiva desses homens segundo as categorias de condição de matrícula/ porta de entrada no serviço;

3. Caracterizar o uso do serviço auto-referido e registrado em prontuário dos usuários segundo as categorias de condição de matrícula/ porta de entrada no serviço.

4. Comparar em caráter exploratório a demanda diagnosticada e o uso do serviço para homens em situação de exclusão e homens moradores e trabalhadores da área de abrangência.. 


\section{DELINEAMENTO DO ESTUDO}

O presente estudo faz parte de um projeto de pesquisa mais amplo intitulado "Homens, violência e saúde: uma contribuição para a linha de pesquisa e intervenção em gênero, violência doméstica e saúde", desenvolvido junto à linha de Pesquisa e Intervenção "Violência e Gênero nas Práticas de Saúde", do Departamento de Medicina Preventiva da Faculdade de Medicina da USP, entre 2002-2004, pela então pesquisadora em pós-doutoramento Márcia Thereza Couto, sob supervisão de Lilia Blima Schraiber, com financiamento da Fapesp.

A investigação do projeto mais amplo ocorreu no âmbito de dois serviços de atenção primária à saúde do Município de São Paulo: o Centro de Saúde Escola Samuel B. Pessoa (CSE Butantã), ligado à Faculdade de Medicina da Universidade de São Paulo, e o Centro de Saúde Escola Barra Funda "Dr. Alexandre Vranjac" (CSEBF-AV), ligado à Faculdade de Ciências Médicas da Santa Casa de São Paulo. Estes serviços foram selecionados durante a elaboração do projeto porque responderam aos critérios estabelecidos de entrada na pesquisa, a saber:

1. Estrutura assistencial apropriada e qualidade de organização, apresentando corpo de profissionais com adequado desempenho de trabalho em equipe, além da qualidade dos registros médicos;

2. Significativos volumes de demanda por homens usuários e acompanhantes, o que permite adequada logística à aplicação das entrevistas em tempos compatíveis com a pesquisa;

3. Presença de profissionais da equipe multiprofissional de saúde que possam acolher casos ativados pela pesquisa;

4. Serviços com qualidade de funcionamento capazes de serem referências em suas regiões para um primeiro atendimento aos homens entrevistados que vivenciam situações de violência nos espaços público e privado/doméstico;

5. Condições de instalação e outras infra-estruturas de apoio logístico à pesquisa de campo;

6. Sensibilidade e disponibilidade da chefia e das equipes ao problema violência como necessidade de saúde. 
A presente pesquisa apresenta um estudo de caso no Centro de Saúde Escola Barra Funda "Dr. Alexandre Vranjac" (CSEBF-AV). Para sua execução, tomamos parte do projeto mais amplo e selecionamos os aspectos sócio-demográficos e familiares, características de saúde geral e de saúde sexual e reprodutiva, autoreferidas e diagnosticadas, e características de uso do serviço, no último ano, de homens usuários do CSEBF-AV, entrevistados na condição de usuários ou acompanhantes, desde que matriculados no serviço.

\section{SUJEITOS DA INVESTIGAÇÃO}

A população de estudo desta pesquisa foi composta por homens entre 18 e 60 anos, usuários do Centro de Saúde Escola Barra Funda "Dr. Alexandre Vranjac" (CSEBF-AV), cuja forma de acesso à unidade de saúde tenha ocorrido espontaneamente, estimulada pelo serviço ou ainda na forma de acompanhantes de usuário(a)s da unidade.

Cabe relembrar que o CSEBF-AV é um serviço de atenção primária à saúde, localizado em área central do Município de São Paulo, cuja parcela da população é constituída por indivíduos em situação de exclusão social: moradores de rua, de cortiços, de albergues e de favelas; destacando-se o fato de que entre moradores de rua e de albergues é maior a população masculina (VIEIRA et al., 1992), objeto de estudo da presente pesquisa. Além dos moradores da área, o CSEBF-AV tem também porta de entrada aos trabalhadores da área, bastante presentes na área que concentra diversos estabelecimentos comerciais.

\section{Plano de amostragem}

V.1. Dimensionamento da amostra

O cálculo do tamanho da amostra do projeto mais amplo necessário para atingir os objetivos de tal projeto, que versava sobre violência, foi baseado em dados de duas pesquisas: Ocorrência de casos de violência doméstica e sexual nos serviços de saúde em São Paulo e desenvolvimento de tecnologia de atendimento para o 
programa de saúde da mulher (SCHRAIBER, 2002) e WHO Multi-Country Study on Women's Health and Domestic Violence Against Women (SCHRAIBER \& D' OLIVEIRA, 2002).

A primeira pesquisa aconteceu em unidades básicas de saúde do Município de São Paulo e de Municípios da Grande São Paulo e a segunda, populacional, foi realizada no Município de São Paulo. A partir dos dados obtidos em ambas as pesquisas, com foco no objeto do projeto mais amplo - violência contra a mulher perpetrada por homens - observou-se as freqüências do tipo de violência ocorrida (física por parceiro íntimo, sexual por parceiro íntimo e física ou sexual por parceiro íntimo, na vida) bem como observou-se as frequiências das principais variáveis relacionadas ao homem agressor (desemprego, etilismo, história de violência da mãe pelo parceiro e história de violência física sofrida na família) e, a partir dessas observações, com diferentes amostragens, optou-se pela variável com maior amostragem. Assim, o projeto mais amplo chegou a uma amostra de 786 usuários, que permitiria obter: 1. estimativas de prevalência de diferentes formas de violência conjugal atual e, conseqüentemente, a identificação da porcentagem de potenciais “agressores" e suas características sócio-demográficas, sob uma precisão de 5\% entre a prevalência estimada e o verdadeiro valor populacional e com 95\% de confiança; 2 . estimativas de razão de prevalência mínimas, as quais seriam alcançadas com um poder do teste de $80 \%$, ou seja, com uma chance de $80 \%$ de detectar diferenças entre usuários "agressores" e "não- agressores" a um nível de significância de 5\%, quanto aos potenciais fatores de risco que estariam sujeitos.

Dessa forma, da amostra necessária de 786 homens (usuários e acompanhantes-usuários), para um estudo de prevalência de violência contra mulheres em serviços de atenção primária; 395 homens foram entrevistados no CSE Butantã e 391 homens foram entrevistados no CSEBF-AV. A presente pesquisa busca caracterizar a população masculina usuária de uma unidade básica de saúde e, para tal finalidade, a amostra de 391 homens se mostra adequada para compor a população de estudo da pesquisa atual.

V.2. Desenho da pesquisa 
Quanto ao desenho da pesquisa, o projeto mais amplo utilizou-se da triangulação de técnicas de pesquisas qualitativas - Observação de tipo etnográfico e Grupos Focais - e quantitativas - Questionário e Ficha de Leitura de Prontuários sendo as técnicas quantitativas utilizadas na pesquisa atual para a obtenção dos dados.

\section{INSTRUMENTOS DA PESQUISA}

VI.1. Elaboração do instrumento questionário

A estrutura do instrumento questionário (Anexo C.1) seguiu a orientação do estudo realizado por SCHRAIBER (1999) com usuárias de serviços de atenção primária e foi adaptada à pesquisa com população masculina para o projeto mais amplo. $\mathrm{O}$ questionário foi composto por 3 partes, sendo que para a pesquisa atual utilizamos as questões da primeira e, especialmente, da segunda parte:

1. A primeira parte coletou informações relativas à identificação do serviço e do usuário e aos aspectos sócio-demográficos e familiar. A questão sobre escolaridade permitiu identificar se o nível de estudo interferia na auto-identificação de demandas em saúde e no uso de serviços de saúde; a questão sobre cor da pele abordou a auto-percepção dos usuários; as questões sobre local de nascimento e tempo em São Paulo permitiram observar se existia relação entre migração e inserção e seguimento no serviço de saúde em questão. Em relação ao estrato sócioeconômico, adotou-se o critério $^{22}$ de classificação da Associação Brasileira de Institutos de Pesquisa e de Mercado (ABIPEME, 2001), composta por cinco classes sócio-econômicas - A, B, C, D, E. Além disso, nessa primeira parte do questionário buscou-se conhecer se os homens entrevistados tinham ou não alguma relação afetiva no momento da entrevista e qual o tipo de relação que mantinham (casado/amigados, solteiros namorando, solteiros sozinhos, etc.) bem como conhecer características da (o) parceira (o).

${ }^{22}$ Esse critério baseia-se na somatória de pontos relativos à posse de bens de consumo duráveis (eletrodomésticos e eletroeletrônicos) e de serviços (empregada doméstica) e da escolaridade do chefe da família. 
2. A segunda parte identificou aspectos de saúde em geral e sexual e reprodutiva, abordando questões como idade na primeira relação sexual e tipo de parceira (amiga, namorada, profissional do sexo, etc.), número de filhos, métodos contraceptivos, presença de sintomas relativos ao aparelho gênito-urinário e tipo de conduta frente a uma necessidade em saúde, desde o tipo de local procurado para resolver uma questão de saúde até a presença ou não de dificuldades para acessar um serviço de saúde. Além disso, essa parte permitiu conhecer comportamentos que os homens adotam em relação ao tabagismo, etilismo, uso de drogas ilícitas e prática de atividade física.

3. A terceira parte abordou questões sobre violência psicológica, física e sexual sofrida e perpetrada pelos usuários. Como essa parte não faz parte do presente estudo, não será particularizada.

Com esse instrumento procuramos abordar as queixas e sintomas autoreferidos pelos usuários e a atitude que referem adotar diante dessas demandas referidas (demandas e condutas referidas).

Para o projeto mais amplo o instrumento questionário foi aplicado no CSE Butantã e no CSEBF-AV. Neste último, lócus da presente pesquisa, 391 homens foram entrevistados e compuseram a amostra inicial deste estudo.

VI.2. Elaboração do instrumento ficha de leitura dos prontuários

A estrutura do instrumento ficha de leitura dos prontuários (Anexo C.2) também seguiu a orientação do estudo realizado por SCHRAIBER (1999), sendo então adaptada à pesquisa com população masculina para o projeto mais amplo. $\mathrm{O}$ instrumento ficha de leitura dos prontuários foi composto por duas fichas. A primeira procurou conhecer as atividades freqüentadas pelos homens no último ano e na vida de usuário do serviço, bem como o número de vezes que o usuário esteve no serviço de saúde. A segunda ficha abordou, de forma detalhada, o uso do serviço de saúde no último ano, identificando o tipo de atividade freqüentada, o profissional que realizou atendimento, todas as queixas/sintomas assinaladas, diagnósticos registrados e, também, a existência ou não de condutas e encaminhamentos realizados, internos 
e/ou externos ao serviço (demanda diagnosticada e condutas registradas). Assim, para cada atendimento realizado ao usuário, no último ano, uma nova segunda ficha era preenchida.

A segunda ficha do instrumento ficha de leitura dos prontuários, para identificação de queixas e sintomas diagnosticados/ registrados em prontuário, foi construída com a perspectiva de abordar cada sistema fisiológico. Dessa forma, foram especificados sintomas mais freqüentes relativos a cada sistema, com base em levantamento exploratório realizado no Centro de Saúde Escola Samuel B (CSE Butantã), com amostra de 100 prontuários médicos analisados por médicos residentes de Medicina Preventiva e Social da Faculdade de Medicina de São Paulo, no ano de 2001.

Dos 391 homens entrevistados no CSEBF-AV, 237 tiveram seus prontuários localizados e lidos, constituindo a amostra final do presente estudo.

VI.3. Utilização de dois instrumentos

A utilização do instrumento questionário e do instrumento ficha de leitura dos prontuários objetivou conhecer demandas sentidas/ percebidas pelos usuários que são auto-referidas (dado obtido com o instrumento questionário) e aquelas que são diagnosticadas, isto é, registradas nos prontuários dos usuários conforme anamnese realizada nas atividades por eles freqüentadas (dado obtido com o instrumento ficha de leitura dos prontuários). Além disso, os instrumentos permitiram conhecer as condutas adotadas (referidas e registradas) frente a cada demanda. Assim, a partir da composição dos dois instrumentos procuramos conhecer semelhanças e diferenças, dentre as variáveis abordadas em ambos os instrumentos, entre informação autoreferida e informação diagnosticada/ registrada.

\section{Pesquisa de CAMPo}

VII.1. Seleção e treinamento das equipes 
A seleção e o treinamento das equipes foram fundamentais para o bom andamento da pesquisa e controle de qualidade das informações coletadas. Para a composição da equipe que atuou na aplicação dos questionários aos usuários, priorizou-se entrevistadores do sexo masculino, acreditando-se que assim os usuários se sentiriam mais à vontade para responder às perguntas constantes do questionário da pesquisa mais ampla. Foram selecionados estudantes de graduação dos cursos de Medicina e Ciências Sociais da USP.

Os entrevistadores contaram com um supervisor de campo em cada serviço pesquisado para a realização das entrevistas e, para a leitura de prontuários, a equipe contou com o apoio de profissionais que atuam como médicos clínicos nos serviços estudados.

No CSEBF-AV, cujos usuários entrevistados compuseram a população de estudo da presente pesquisa, eu tive a oportunidade de atuar no apoio para interpretação dos registros médicos da fase de leitura de prontuários; uma vez que na ocasião da pesquisa eu atuava na unidade há 2 anos; e auxiliar a equipe em dúvidas sobre os registros encontrados nos prontuários, tomando, assim, contato com os achados prévios desse momento do projeto mais amplo.

VII.2. Logística e implantação da pesquisa de campo

\section{VII.2.a. Aplicação dos questionários}

A aplicação dos questionários aos usuários do CSEBF-AV foi realizada no período de fevereiro a abril de 2003, perfazendo 391 questionários. Para realização das entrevistas o CSEBF-AV disponibilizou salas de consultórios privativos e espaço de apoio para o trabalho de supervisão de campo e conferência dos questionários aplicados.

O trabalho de campo contou com uma equipe de 5 pesquisadores, 1 codificadora e 1 supervisora de campo. Os pesquisadores foram divididos em grupos segundo uma escala que permitiu a presença de 3 pesquisadores no período de maior fluxo - manhã - e, no período de menor fluxo - tarde -, a presença de 2 pesquisadores.

Este plano de trabalho possibilitou a coleta de dados de forma consistente e 
sistemática, não havendo nenhum viés de seleção dos entrevistados, na medida em que havia compatibilização entre fluxo de usuários por períodos e dias da semana e a presença de pesquisadores.

Durante a coleta de dados, os pesquisadores foram orientados a verificar a presença de homens elegíveis em todas as atividades/programas existentes no serviço, seja na condição de usuário ou acompanhante. Sendo o serviço unidade básica de saúde, as portas de entrada preferenciais de homens elegíveis na categoria usuário eram as atividades desenvolvidas na Saúde do Adulto (consultas de clínica geral, atividades de enfermagem - como controle de pressão arterial, medicação e curativo -, atividades de grupos - diabetes, hipertensão), Saúde Mental (consultas de psiquiatria e de psicologia e grupos de triagem da saúde mental), Serviço Social e uso da farmácia e laboratório. Em relação aos homens elegíveis na categoria acompanhante o leque de possibilidades ainda incluía atividades na Saúde da Criança (consulta pediátrica, odontológica, de fonoaudiologia e de psicologia infantil) e na Saúde da Mulher (consultas de pré-natal e ginecológicas e grupo de planejamento familiar). $\mathrm{O}$ direcionamento para a realização das entrevistas visou a não interferência nas atividades dos profissionais, visto que a duração da entrevista era de apenas 30 minutos e esta era realizada durante o período de espera do paciente para ser atendido, evitando-se que o usuário perdesse sua vez de entrada na consulta médica ou em qualquer outra atividade assistencial.

Merece comentário a disponibilidade de profissionais responsáveis pelos sistemas de informação do serviço no auxílio à busca dos números de prontuários de usuários e acompanhantes que tinham matrícula no serviço. Esta ajuda se mostrou importante tendo em vista que muitos usuários não sabiam seu número de matrícula e esqueciam o cartão durante a ida ao serviço. Com isso, foi possível a boa realização da etapa futura de pesquisa, a leitura dos prontuários médicos de amostra dos homens entrevistados e que eram matriculados no serviço.

\section{VII.2.b. Leitura dos prontuários médicos}

O campo de leitura dos prontuários no CSEBF-AV ocorreu entre os meses de março e maio de 2003. A equipe responsável por essa atividade foi composta por 
uma supervisora de campo, uma supervisora de escritório, quatro alunos de iniciação científica, duas pesquisadoras de campo contratadas para essa atividade e um médico da unidade, disponível para o apoio na interpretação dos registros médicos, atividade que eu exerci no CSEBF-AV, cujo campo compôs a amostra da presente pesquisa. Os horários de leitura foram agendados de forma a garantir a presença do maior número de pesquisadores, estratégia que possibilitou maior integração da equipe de leitura e a concordância unânime quando do surgimento de dúvidas durante a leitura dos prontuários, o que elevou a produtividade do trabalho de campo.

A seleção de prontuários a serem lidos ocorreu segundo os seguintes critérios: 1. O homem entrevistado ser matriculado no serviço;

2. O homem entrevistado e matriculado no serviço ter feito uso do centro de saúde no último ano. Assim, dos 391 usuários entrevistados no CSEBF-AV, 316 eram matriculados no serviço. Destes, pudemos estudar 237 casos, uma vez que usuários que não haviam feito uso do serviço no último ano e usuários cujos prontuários não foram localizados foram excluídos. O motivo para não se encontrar todos os prontuários justifica-se pelo funcionamento do próprio serviço: quando o usuário não comparece ao serviço há mais de dois anos, como trabalhador da região, e há mais de três anos, como morador da área adscrita do serviço, seu prontuário é inativado. Para esses prontuários o serviço possuía um arquivo-morto separado, porém, mesmo com a busca efetivada no arquivo-morto, tais prontuários não puderam ser localizados pelos profissionais do serviço.

\section{VII.2.c. Controle de qualidade das informações}

À supervisão de campo coube a tarefa de verificação atenta dos questionários aplicados após o término da entrevista, o que se mostrou fundamental uma vez que, a partir dessa verificação, foi possível corrigir pequenos erros de preenchimento das questões por parte dos entrevistadores e, assim, garantir a qualidade e a consistência dos dados coletados.

Além disso, também foi responsabilidade da equipe de supervisão de campo: 1. Preparação do material de pesquisa (questionários, planilhas de controle de campo, consentimentos informados); 
2. Encontrar e disponibilizar salas para o desenvolvimento das atividades da equipe de trabalho bem como a distribuição dos pesquisadores (entrevistas, leitura de prontuários, verificação dos questionários, etc.); 3. Garantir que o homem entrevistado não perdesse o chamado para o atendimento enquanto estivesse em entrevista e, no caso dos acompanhantes, verificar se os pacientes que estes acompanhavam acabavam a consulta, a fim de não causar nenhum transtorno para o serviço e para o usuário. Quando os homens entrevistados eram acompanhantes de crianças, as mesmas brincavam de desenhar com a supervisora de campo enquanto o homem respondia a entrevista, sendo disponibilizado lápis de cor e papel para a atividade.

\section{VARIÁVEIS CONSIDERADAS NO ESTUDO}

O CSEBF-AV, no processo de matrícula de seus usuários, apresenta, na ficha de cadastramento utilizada nesse processo, um item relacionado ao tipo de entrada que o paciente tem no serviço, ou seja, que característica o paciente apresenta que justifica sua matrícula na unidade, uma vez que a inserção de indivíduos nas unidades de saúde deve respeitar a área adscrita do serviço. No caso do CSEBF-AV o paciente pode ser matriculado na unidade quando:

1. É morador da área adscrita;

2. É trabalhador na área adscrita;

3. Entra no serviço para atenção a qualquer condição de saúde-doença relacionada às doenças de notificação compulsória ou infecções sexualmente transmissíveis (entrada pela vigilância epidemiológica);

4. É indivíduo que vive em situação de exclusão social (moradores de rua, profissionais do sexo, moradores de favela, moradores de cortiço, albergados);

5. Tem vínculo familiar com usuário morador da área, trabalhador da área, matriculado para seguimento relacionado à vigilância epidemiológica ou que vive em situação de exclusão social.

Devido a essa característica do CSEBF-AV, especialmente a discriminação positiva para entrada no serviço, para o presente estudo criamos uma nova variável, 
"porta de entrada", como uma variável dependente para ser analisada segundo as condições sócio-demográficas e os aspectos de saúde geral e sexual e reprodutiva e o uso de serviços de saúde. Com a nova variável pudemos conhecer quem são os homens usuários do CSEBF-AV e se diferentes situações de matrícula implicam diferentes auto-referências à saúde e ao uso do serviço entre esses homens. Assim, para a variável "porta de entrada", consideramos quatro tipos de matrícula:

1. Morador da área adscrita: aqui incluídos moradores da área de assistência do serviço, moradores da área do PSF da unidade e indivíduos com vínculo familiar com esses usuários (serão denominados ao longo do estudo como moradores);

2. Trabalhadores da área adscrita e indivíduos com vínculo familiar com esses usuários (serão denominados ao longo do estudo como trabalhadores);

3. Entrada no serviço pela vigilância epidemiológica e indivíduos com vínculo familiar com esses usuários (serão denominados ao longo do estudo como vigilância);

4. Indivíduos em situação de exclusão social e indivíduos com vínculo familiar com esses usuários (serão denominados ao longo do estudo como exclusão).

\section{ANÁLISE DOS DADOS}

IX.1. Codificação dos instrumentos

A codificação dos questionários e das fichas de leitura dos prontuários aplicados no projeto mais amplo ocorreu de forma paralela à aplicação e supervisão em campo. A codificação e a supervisão do preenchimento dos instrumentos, de forma simultânea, possibilitaram uma diminuição significativa de perdas de informação, assim como facultou uma avaliação seqüencial das atividades dos pesquisadores. As dúvidas surgidas durante a codificação dos questionários foram remetidas à Pesquisadora Responsável, a fim de que o questionário chegasse sem nenhuma lacuna ou dúvida nas mãos das duas digitadoras contratadas. Com isto, ampliou-se a qualidade do dado e a agilidade na etapa subseqüente: a dupla digitação. 
IX.2. Constituição do banco de dados

A entrada dos dados coletados ocorreu em dois bancos, um para os questionários e outro para as fichas de leitura dos prontuários. A constituição dos bancos se deu por meio de uma dupla digitação, por pessoas diferentes, de cada questionário e de cada ficha de leitura previamente supervisionados e codificados. Ressalte-se ainda que, devido ao cuidado nesta etapa da pesquisa, não tivemos problemas significativos na fase de validação dos dois bancos. Os dados foram digitados no programa STATA versão 9.

\section{IX.3. Análise estatística}

A análise estatística dos bancos de dados da presente pesquisa foi realizada nos programas STATA v. 9 e Epi Info v. 6.04b.

Primeiramente, a partir do número de matrícula dos usuários do serviço, realizamos a fusão do banco de dados dos questionários com o banco de dados das fichas de leitura de prontuários e criamos a nova variável "porta de entrada" no serviço. O novo banco de dados permitiu a caracterização sócio-demográfica da população estudada, a identificação das demandas auto-referidas e diagnosticadas de saúde em geral e saúde sexual e reprodutiva dos usuários, e permitiu caracterizar o padrão de uso do serviço, auto-referido e registrado em prontuário, pelos homens estudados, segundo as categorias de condição de matrícula/ porta de entrada.

Posteriormente, procuramos observar a relação das demandas diagnosticadas e do uso do serviço com o tipo de entrada do usuário no serviço. Para esse momento da análise fizemos o recorte com vistas aos homens em situação de exclusão, população atendida pelo CSEBF-AV de forma diferenciada, e comparamos as demandas desses usuários e a forma como eles utilizam o serviço com as demandas dos moradores e trabalhadores da área do CSEBF-AV e o uso do serviço feito por esses dois grupos. Optamos por unir moradores e trabalhadores devido à semelhança apresentada por eles em relação ao uso dos serviços e também pelo reduzido tamanho da amostra se adotada a divisão de quatro grupos segundo a "porta de entrada". Além disso, a exclusão dos homens seguidos pela vigilância 
epidemiológica se fez necessária tanto pela sua característica especial de entrada na unidade, não caracterizando, necessariamente, a população adscrita ao CSEBF-AV, como pelo uso diferenciado do serviço: muitos freqüentam a unidade por determinado período de tempo, relacionado geralmente ao tempo de tratamento da patologia que causou sua inclusão no serviço e, justamente por terem essa entrada na unidade, fazem uso diferenciado das consultas assistenciais, freqüentando muitas vezes o pronto atendimento por terem sido convocados, e não por necessidade sentida, e freqüentando as consultas programadas para seguimento da patologia em tratamento e vigilância, e não por uma atenção voltada espontaneamente à sua saúde em geral.

A análise estatística foi realizada no programa Epi Info v. 6.04b, empregando-se o teste estatístico do Qui-quadrado, Qui-quadrado com correção de Yates e teste Exato de Fisher (quando esse se fez necessário). Foi estabelecido um alfa de 0,05 e foram também calculados intervalos de confiança de $95 \%$ para as estimativas produzidas.

\section{ASPECTOS ÉTICOS DA INVESTIGAÇÃO}

O projeto mais amplo, do qual o presente estudo faz parte, seguiu os trâmites junto à Comissão de Ética Para Análise de Projeto de Pesquisa (CAPPesq) da Faculdade de Medicina da USP e ao Comitê de Ética da Faculdade de Ciências Médicas da Santa Casa de São Paulo. Também foi enviado às respectivas direções dos serviços de saúde onde a pesquisa ocorreu: Centro de Saúde Escola Samuel B. Pessoa (CSEB) e Centro de Saúde Escola Barra Funda "Dr. Alexandre Vranjac" (CSEBF-AV), sendo alvo de estudo e aprovação (Anexo A).

Em termos operacionais de pesquisa, atenção especial foi dada aos procedimentos de natureza ética uma vez que o estudo mais amplo tinha como tema a violência doméstica conjugal e suas consequiências para a saúde. Dessa forma foram praticadas as seguintes medidas:

1. Elaboração de um consentimento pós-informação com cuidados éticos e informativos, em linguagem clara e acessível, que garantia participação dos informantes de modo consciente e seguro (Anexo B); 
2. Garantia de privacidade durante a entrevista (os serviços de saúde disponibilizaram salas/ consultórios que ficaram à disposição das equipes entrevistadoras);

3. Suporte de caráter assistencial, psicológico, social e médico aos casos identificados de homens que vivenciam situações de violência e que desejassem essa atenção;

4. Suporte de natureza psicológica e ética aos pesquisadores de campo (em termos de treinamento específico, supervisão técnica e apoio psicoemocional). 
Capítulo 4 CSEBF-AV - Caracteristicas do lócus da pesquisa 
O Centro de Saúde Escola Barra Funda "Dr. Alexandre Vranjac" (CSEBFAV) é o local onde conclui minha residência médica em Medicina Preventiva e Social e onde, desde então, tenho o privilégio de atuar como médica sanitarista. No CSEBF-AV conheci muitos bons profissionais com os quais, até hoje, aprendo muito sobre a saúde: políticas, organização, assistência, diversidades. Foram dois anos de especialização e, atualmente, quatro anos como profissional. Pesquisar e discorrer sobre a história do CSEBF-AV e encontrar em trabalhos e artigos elaborados sobre o local e seu modo de organização muito daquilo que sempre ouvi dos funcionários de longa data da unidade foi uma atividade que permitiu apresentar o lócus do meu trabalho, contextualizando seu processo de desenvolvimento até suas atuais características. Além disso, pesquisar sobre o CSEBF-AV também me aproximou mais um pouco da importância dessa unidade para todos que por ela passaram, desde funcionários, fundadores, professores e alunos até os usuários, muitos dos quais hoje trazem seus filhos para serem atendidos pelos pediatras que tiveram quando crianças.

\section{SURGIMENTO E CONTEXTUALIZAÇÃO HISTÓRICA}

O Centro de Saúde Escola Barra Funda "Dr. Alexandre Vranjac" (CSEBFAV) nasceu como fruto de um convênio estabelecido entre três entidades: Fundação Arnaldo Vieira de Carvalho (FAVC), Irmandade da Santa Casa de Misericórdia de São Paulo (ISCM-SP) e Secretaria de Estado da Saúde de São Paulo (SES-SP). Esse convênio foi assinado em janeiro de 1967 e deu origem ao então denominado Centro de Saúde Experimental da Barra Funda e Bom Retiro (CSE BF-BR) (SILveIRA, 1999).

O CSE BF-BR foi um dos primeiros centros de saúde escola criados no Estado de São Paulo (ANDRADE, 2003) e sua formação esteve intimamente relacionada a novas concepções sobre o processo saúde-doença, a novas práticas de organização dos serviços de saúde e novos modelos de ensino que despontavam na década de 60, momento de profunda transformação no plano administrativo da Saúde Pública na SES-SP 23 (SILVEIRA, 1999).

\footnotetext{
${ }^{23}$ Reforma Leser, Decreto n ${ }^{\circ} .48040$ de $1^{\circ}$. de junho de 1967 (SILVEIRA, 1999).
} 
A transformação e renovação que ocorriam na época trouxeram importantes conceitos para a prática em saúde: integralidade - dos serviços de saúde em nível local; descentralização executiva - com autonomia das unidades de saúde; centralização normativa - uniformidade na execução e supervisão dos serviços; e sistemas permanentes de planejamento - envolvendo a produção de conhecimentos em epidemiologia, estatísticas de saúde e treinamento de pessoal.

Além da transformação no cenário político, mudanças também ocorreram no Estado de São Paulo, havendo um intenso desenvolvimento urbano e industrial que conseqüentemente transformou a demanda social, com novas reivindicações e necessidades em saúde.

\section{IMPLANTAÇÃO E OBJETIVOS}

Todo esse processo de transformação político-administrativa e sóciodemográfica influenciou o surgimento do CSE BF-BR, cuja inauguração se deu em 16 de abril de 1969, apesar de já funcionar desde 1968.

Assim, o modelo de assistência médica individual na rede de centros de saúde, que dominava o cenário da assistência à saúde até meados da década de 60 , tomava um novo rumo: o trabalho voltado à comunidade, base do projeto de formação do CSE BF-BR, cujos objetivos, em seus primórdios, abrangiam:

1. Promoção, proteção e recuperação da saúde da população moradora da área abrangida pela unidade, através da assistência médica sanitária e ações educativas com a população;

2. Ensino de Saúde Pública para alunos de Medicina, Enfermagem e outros profissionais de saúde;

3. Treinamento de pessoal em serviço;

4. Realização de pesquisas operacionais aplicadas à Saúde Pública (MerCADANTE, 1970; SimON, 1970), com desenvolvimento de técnicas e métodos que pudessem ser estendidos à rede de unidades sanitárias do Estado de São Paulo (experimentação de novas tecnologias). 
Dessa forma, para se obter um diagnóstico das condições de vida e saúde da população residente, na busca de instrumentos para o entendimento e a organização de um modelo assistencial a ser operacionalizado (ANDRADE, 2003), além de buscar uma concepção sobre o processo saúde-doença que incluísse o conhecimento sobre a doença e fatores psicossociais que pudessem influenciar no processo saúde-doença (SiLVEIRA, 1999), em junho de 1968 foi realizado um censo da área. Assim, a área de 2,53 $\mathrm{Km}^{2}$ foi percorrida para um reconhecimento de suas características gerais e, para tal, contou com a participação de líderes da comunidade no preparo junto à população para a aceitação dos recenseadores (SIMON, 1970; CARNEIRO JUNIOR \& SILVEIRA, 2003).

O levantamento cadastral e o recenseamento foram idealizados e realizados por profissionais do Departamento de Medicina Social da Faculdade de Ciências Médicas da Santa Casa de São Paulo (FCMSC-SP). Com essa atividade foram obtidas características sócio-demográficas, econômicas e culturais da população bem como informações sobre suas condições de vida, o que permitiu a elaboração de estratégias para a implantação da unidade sanitária, seus programas e atividades. Apesar de já haver uma definição prévia dos programas de saúde (mulher, criança, adulto, mental, bucal) a atividade de recenseamento permitiu a implantação desses programas de forma adaptada à realidade local identificada.

Tratava-se de novas práticas de ação em saúde, da experimentação, o que viabilizou também novas formas de preparar profissionais para o trabalho em saúde, além de cumprir sua finalidade com relação ao ensino (SILVEIRA, 1999). A experimentação e a formação de profissionais de saúde com base na novidade e com o olhar voltado para a comunidade como um todo eram e ainda são a linha mestra do CSEBF-AV, o que o torna local privilegiado para a realização do presente estudo.

Como aponta SilveIRA (1999), foram muitas as inovações que atingiram a formação da unidade sanitária, incluindo o convênio entre instituição de ensino privada com o setor público, os trabalhos preliminares com a formação de equipe de pesquisa que realizaram o censo na região, com participação de alunos da graduação, a especificidade de uma carreira de médico sanitarista e a formação de uma equipe técnica atuando em conjunto com o médico sanitarista chefe da unidade. Foi um processo de experimentação que atingiu questões conceituais, com a reflexão a 
respeito das questões práticas de organização da assistência, do ensino e da pesquisa, envolvendo ainda experimentação em administração (SILVEIRA, 1999).

Assim, na história de formação do centro de saúde destacam-se a autonomia administrativa e a liberdade para testar novos modelos de atenção à saúde, de ensino e de pesquisa e para a formação de recursos humanos para a saúde, destacando-se a qualidade do centro de saúde em ser escola e ter um caráter experimental, funcionando como um laboratório, tanto para a organização do serviço como para orientar o ensino. O centro de saúde traz também a inovação do ensino do profissional de saúde fora do ambiente hospitalar e, mais especificamente, próximo da comunidade. Essa inovação traz à tona a realidade social da população, focando o olhar do profissional de saúde para a população atendida como um todo, e não apenas para o indivíduo, e sobre como ela se organiza, o que permite perceber e entender de que maneiras essa organização pode ou não interferir no processo saúdedoença da comunidade (SILVEIRA, 1999).

Portanto, ensino e assistência estavam conjugados em uma mesma organização, que buscava manter o equilíbrio entre as necessidades da comunidade, de ensino e de treinamento (MERCADANTE, 1970), mantendo-se o foco na população assistida pelo serviço.

O treinamento em serviço de pessoal para atuar em saúde foi outra inovação do CSE BF-BR que era, assim, local de prática e treinamento para profissionais de saúde do próprio centro de saúde, de outras unidades, além dos alunos de graduação em Medicina, Enfermagem e Fonoaudiologia. Em relação à unidade buscou-se criar um corpo homogêneo de funcionários ${ }^{24}$ para um trabalho coordenado, focando-se a noção de Saúde Pública como ciência que desenvolve a promoção, proteção e recuperação da saúde e a motivação da população quanto aos cuidados com a saúde (SILVEIRA, 1999).

\section{III. ÁREA ABRANGIDA E POPULAÇão ASSISTIDA}

Na ocasião de sua fundação em 1969, o centro de saúde prestava assistência aos moradores da área dos subdistritos da Barra Funda e do Bom Retiro, na época

\footnotetext{
${ }^{24}$ Entre eles estavam incluídos, além dos profissionais de saúde, auxiliares administrativos, serventes, equipe de limpeza e as visitadoras de saúde.
} 
com uma população de 26.500 habitantes ocupando um espaço geográfico de 2,53 $\mathrm{Km}^{2}$ (SILVEIRA, 1999). Na ocasião, a maior parte dessa população era moradora de uma grande favela local, "Ordem e Progresso", que foi cadastrada na unidade através de prontuários "ficha família". A matrícula no serviço garantia acesso aos programas de saúde da mulher, da criança, do adulto, mental e bucal, além de ações de vigilância epidemiológica, grupos de orientação e consultas programadas e "extras" (ANDRADE, 2003; CARNEIRO JUNIOR \& SILVEIRA, 2003). Já nessa ocasião o centro de saúde procurava desenvolver atividades de promoção à saúde e de educação e orientação em saúde, tanto individual, na forma das pré e pós-consultas com a equipe de enfermagem (atividade desenvolvida até hoje) como orientações em grupos. (MERCADANTE, 1970).

Um aspecto importante da formação do centro de saúde e que foi fundamental para a aproximação da equipe de saúde com a comunidade foi a constituição de uma equipe de visitadoras de saúde, que possibilitava canais de comunicação com associações do bairro ou com outros grupos representantes da população (SILVEIRA, 1999), facilitando a divulgação de informação em saúde na comunidade e estabelecendo o vínculo entre comunidade e serviço de saúde, atividade que nos remete, hoje, às atividades dos agentes comunitários de saúde (ACS) das equipes de programa de saúde da família (PSF).

\section{AS MUDANÇAS: ÁREA, POPULAÇÃO, ORGANIZAÇÃO DO SERVIÇO}

Ao final dos anos 70, mudanças na área de abrangência do centro de saúde, como a remoção da favela "Ordem e Progresso", maior contingente de usuários da unidade, abrem uma crise de identidade no serviço, associada a sucessivas crises financeiras, o que concentrou o trabalho do centro de saúde dentro da unidade. Com isso, perderam-se as atividades de orientação da população fora do espaço da unidade e também da percepção, pelas visitadoras, da realidade e dinâmica da população, importante para se pensar ações em saúde adaptadas à comunidade (SILVEIRA, 1999).

A crise desencadeada pelos processos de mudança ao redor do centro de saúde e dentro dele coincidiu com a entrada de um novo diretor, Dr. Alexandre Vranjac (que hoje empresta o nome à unidade), que resgatou a tradição e um dos 
objetivos primeiros do serviço: entender, viver e trabalhar o centro de saúde como um espaço de novas experimentações. Houve mudanças no plano administrativo da unidade, com descentralização interna da gestão do serviço, uma concepção inovadora naquele momento (SILVEIRA, 1999). Esse processo de inovações frente às crises correntes injetou nova perspectiva ao centro de saúde.

Ao longo dos anos 80, o centro de saúde voltou a viver crises financeiras, administrativas e, conseqüentemente, de identidade, o que levou o serviço e a equipe a viver um período extremamente conturbado (SILVEIRA, 1999). Nessa década, a região do centro de saúde sofreu novas mudanças, houve um processo de reorientação urbana, a organização de um crescente setor empresarial, constituído principalmente por pequenas empresas de comércio, que ocuparam antigas moradias da região. Além disso, houve a instalação do Sistema Metroviário de Transporte e do Memorial da América Latina, junto à antiga linha do trem, o que trouxe ao bairro características de área urbana central. Essa transformação urbana mudou a população assistida pelo centro de saúde, antes constituída apenas por moradores, o que obrigou o serviço a se reorganizar para atender uma nova demanda populacional: trabalhadores da região. O centro de saúde realizou levantamento censitário dos estabelecimentos comerciais e criou a "ficha empresa" para o cadastro desses trabalhadores na unidade (ANDRADE, 2003; CARNEIRO JUNIOR \& SILVEIRA, 2003).

Durante os anos 90 as mudanças regionais continuaram, com a chegada de hipermercados e mudança do Fórum Criminal (maior da América Latina) para a Barra Funda, além do Fórum Trabalhista, o que engrossou as características urbanas e propiciou importante aumento do trabalho informal, atraído pelo aumento da circulação de pessoas nessa área, conseqüente a essas novas instalações na região.

A urbanização dessa parte da área central do município trouxe para a região novas relações de comércio e trabalho e novas oportunidades, o que atraiu diversos grupos populacionais como moradores de rua, profissionais do sexo, trabalhadores informais, novas favelas e migrantes em situação irregular no país, que vivem relação de trabalho quase escravo no setor das confecções (ANDRADE, 2003). Essas populações encontram em uma região como a que a Barra Funda se transformou várias formas de sobrevivência, fato que os mantêm por perto dessas oportunidades e, consequientemente, cria uma nova demanda para o serviço de saúde. Trata-se de 
grupos com formas específicas de uso do serviço, que não se enquadram na ação programática tradicionalmente proposta, criando, mais uma vez para a unidade, a necessidade de se reorganizar tecnologicamente a fim de responder às crescentes e específicas demandas, preocupando-se em garantir acesso a esses grupos populacionais de desigual inserção na sociedade (SILVEIRA, 1999; ANDRADE, 2003).

Todo esse processo de transformação externa e interna ao centro de saúde fez com que a nova direção recuperasse novamente os propósitos originais do serviço: a experimentação de novas práticas em saúde associada ao aprimoramento do ensino em graduação e pós-graduação dos profissionais de saúde em formação (SILVEIRA, 1999; ANDRADE, 2003).

Entre as mudanças ocorridas nessa reestruturação do serviço, o prontuário família passou a ser individual, porém mantendo, em sua numeração, uma seqüência que identificava como sendo membros da "mesma família" os indivíduos que vivem sob o mesmo teto (SILVEIRA, 1999). Tal estratégia permitiu, por exemplo, que dois membros da mesma família pudessem fazer uso do serviço simultaneamente, sem perder a facilidade que os profissionais tinham de localizar rapidamente prontuários de indivíduos da mesma família frente à necessidade de discussão de um caso, por exemplo.

A organização interna do serviço sofreu também outra mudança, conseqüente à presença de novos grupos populacionais, emergentes na região, mencionados anteriormente. Esses grupos são constituídos por indivíduos que vivem à margem da sociedade e fazem uso irregular do serviço, sendo que o centro de saúde estabeleceu a necessidade de se reorganizar de forma a dar maior visibilidade e acesso a essa população quando esses procurassem o serviço. Nasceu assim no centro de saúde uma política de discriminação positiva, que procura facilitar o acesso desses indivíduos ao serviço. Dessa forma, a partir de uma proposta inicial de tratamento e/ ou cuidado torna-se "mais fácil" vincular esses grupos à unidade e, a partir disso, eles passaram, de certa forma, a fazer uso das ações propostas dentro do fluxo de organização estabelecido na unidade (SILVEIRA, 1999; ANDRADE, 2003; CARNEIRO JUNIOR \& SILVEIRA, 2003).

Em 2001, duas equipes do Programa de Saúde da Família (PSF) passaram a integrar o quadro de funcionários do centro de saúde. Sua entrada no serviço exigiu 
nova reorganização interna, uma vez que a área adscrita das equipes era coincidente com a área de abrangência do centro de saúde. Com isso, pacientes antigos do serviço se viram diante de novos médicos, o que, inicialmente, criou uma situação delicada mas que, com a presença de novos membros pertencentes à equipe do PSF, como os agentes comunitários de saúde (ACS), cuja função em muito se assemelha à função das antigas visitadoras do serviço, a população gradualmente aceitou e se acostumou com a mudança.

Além disso, novas instituições instalaram-se na região do centro de saúde, como o albergue Projeto Boracea e a Casa de Cuidados. O Projeto Boracea alberga moradores de rua e, como se encontra na área do PSF, há um ACS responsável por matricular no serviço todo novo usuário cadastrado no albergue, o que aumentou de forma considerável a demanda desse grupo populacional na unidade e, conseqüentemente, aumentou a demanda de homens ao serviço, comprovadamente maioria entre população de rua (VIEIRA et al., 1992). Tal acontecimento justifica a organização de uma assistência voltada ao público masculino e suas particularidades, tanto em necessidades em saúde e sociais como na prática de cuidado com a saúde. É curioso observar que, mesmo quando esses usuários deixam o albergue, aqueles que criaram vínculo com o serviço e iniciaram uma proposta de seguimento e cuidado com a saúde continuam frequientando a unidade, o que demonstra que a discriminação positiva auxilia de maneira importante na inserção desse tipo de usuário na atenção primária, promovendo a universalidade e a eqüidade propostas pelo Sistema Único de Saúde (SUS). A Casa de Cuidados recebe população de exclusão que tem alta hospitalar, geralmente pós-operatória, e que não terá cuidados pós-operatórios adequados morando na rua. O centro de saúde envia, semanalmente, um médico ou uma enfermeira e uma auxiliar de enfermagem para avaliação clínica desses pacientes, cuidado e tratamento de outras queixas presentes, buscando-se também vincular o indivíduo ao centro de saúde quando de sua alta da Casa de Cuidados. 


\section{O CENTRO DE SAÚDE HOJE}

O antigo Centro de Saúde Experimental da Barra Funda e Bom Retiro (CSE BF-BR), atualmente denominado Centro de Saúde Escola Barra Funda "Dr. Alexandre Vranjac" (CSEBF-AV), opera hoje com muitas mudanças decorrentes das transformações socioeconômicas, culturais e políticas ocorridas em sua área de abrangência desde a sua fundação, mas mantém muito de suas raízes para o desenvolvimento de suas ações frente às constantes modificações vivenciadas.

Uma importante alteração foi a mudança da gestão da unidade, anteriormente de responsabilidade da Fundação Arnaldo Vieira de Carvalho (FAVC), para a Irmandade da Santa Casa de Misericórdia de São Paulo (ISCM-SP). Essa alteração de gestão trouxe mudanças positivas e negativas: otimizou a participação do centro de saúde como formador de profissionais de saúde da graduação e pós-graduação ${ }^{25}$ da Faculdade de Ciências Médicas da Santa Casa de São Paulo (FCMSCSP) em atenção primária à saúde, porém houve mudança no quadro de funcionários além de sua redução, o que retrocedeu, de certa forma, todo um trabalho que vinha sendo desenvolvido com a equipe da unidade como um todo. Assim, novos treinamentos mostram-se necessários, contudo, a maior demanda atual, a reduzida equipe e também a maior demanda para as atividades de ensino têm atrasado esse processo de treinamento dos novos funcionários.

Atualmente o CSEBF-AV situa-se no limite entre as Subprefeituras da Lapa e da Sé e responde suas atividades a esta última. A Subprefeitura da Sé compreende oito Distritos Administrativos: Bela Vista, Bom Retiro, Cambuci, Consolação, Liberdade, República, Santa Cecília e Sé (CARNEIRO JunIOR et al., 2004; TABNET DE MORTALIDADE, $\mathrm{MSP}^{26}$ ). A área de abrangência do CSEBF-AV estende-se por um território que passa pelos distritos administrativos da Barra Funda, parte do Bom Retiro e parte da Santa Cecília, cobrindo uma população de aproximadamente 32 mil

\footnotetext{
25 Atualmente, o CSEBF-AV recebe alunos da graduação em Medicina $\left(1^{\circ}, 3^{\circ}\right.$ e $5^{\circ}$ anos), em Enfermagem e em Fonoaudiologia; e recebe residentes da Clínica Médica $\left(1^{\circ}\right.$ e $2^{\circ}$ anos $)$, Pediatria $\left(1^{\circ}\right.$ ano), Programa de Saúde da Família ( $1^{\circ}$ e $2^{\circ}$ anos) e Psiquiatria $\left(1^{\circ}\right.$ ano). Para o ano de 2007 , há uma proposta de inserção dos alunos de graduação em Medicina do $2^{\circ}$ ano e de estagiários das áreas de Psicologia e Serviço Social.

${ }^{26}$ Município de São Paulo.
} 
habitantes em 2000 (CARNEIRO JUNIOR \& SilveIRA, 2003; CARNEIRO JuniOR et al., 2004) (Figura 1).

Figura 1: Município de São Paulo: subprefeituras e distritos - no destaque, subprefeitura Sé, região onde está inserido o CSEBF-AV

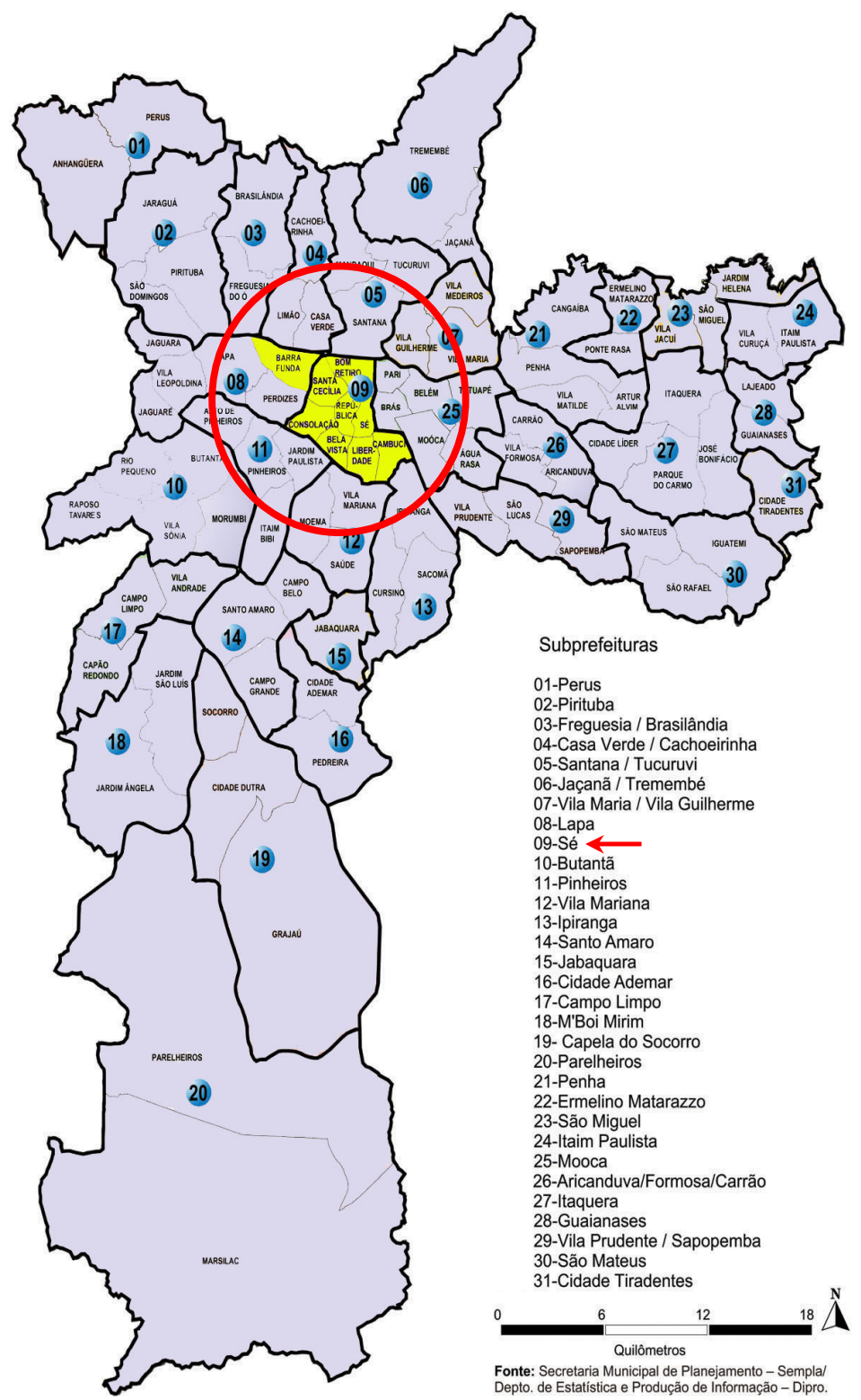


Considerando-se a população com 18 anos ou mais, residente no Distrito da Barra Funda, encontramos uma população de 4.329 homens $(42,4 \%)$ e 5.891 mulheres (57,6\%). Entre 18 e 60 anos, faixa etária dos homens estudados na presente pesquisa, encontramos um total de 8.005 indivíduos, com 55,4\% de mulheres e 44,6\% de homens. Em relação ao grupo etário, homens e mulheres concentram-se entre 25 e 44 anos (49,5\% e 49,6\%, respectivamente) e, para os grupos etários a partir de 35 anos, há predomínio do sexo feminino (IBGE - SIDRA, CENSO 2000).

A população com 18 anos ou mais cadastrada atualmente no serviço é de $16.011^{27}$ indivíduos, dos quais $59,2 \%$ são do sexo feminino e $40,8 \%$ são do sexo masculino, sendo esse predomínio feminino esperado em uma unidade de atenção básica de saúde e, de certa forma, reflete a distribuição de homens e mulheres na população residente no Distrito da Barra Funda (Figura 2). Entre 18 e 60 anos encontramos um total de 13.794 indivíduos com 59,2\% de mulheres e 40,8\% de homens, sendo que em relação ao grupo etário, homens e mulheres concentram-se entre 25 e 44 anos $(54,1 \%$ e 56,4\%, respectivamente) e, para todos os grupos etários, há predomínio do sexo feminino. Cabe observar que a população masculina e feminina, com 18 anos ou mais, residente nos Distritos do Bom Retiro e da Santa Cecília é, respectivamente: $53,8 \%$ mulheres e 46,2\% homens; 56,6\% mulheres e 43,4\% homens. Em ambos os distritos há o predomínio de mulheres a partir dos 35 anos, como no distrito da Barra Funda, o que nos mostra que na área abrangida pelo CSEBF-AV os homens são maioria no grupo etário entre 18 e 35 anos em relação às mulheres, ao contrário do que observamos entre os usuários da unidade, como apontado acima, assinalando a necessidade do desenvolvimento de ações que atraiam esses homens jovens ao serviço.

\footnotetext{
${ }^{27}$ Dados obtidos a partir do sistema de informações do CSEBF-AV (outubro, 2006).
} 
Figura 2: Distribuição dos indivíduos cadastrados no CSEBF-AV segundo o sexo, outubro/ $2006(\mathrm{~N}=13.794)$

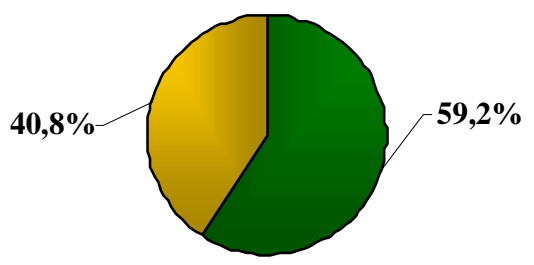

$\square$ Mulheres $\quad \square$ Homens

Os indivíduos cadastrados no CSEBF-AV estão assim distribuídos segundo a porta de entrada: $68,8 \%$ moradores da área, dos quais 40,7\% são do sexo masculino; 10,9\% trabalhadores da área, dos quais $34,2 \%$ são do sexo masculino; 5,2\% são indivíduos que vivem em situação de exclusão social, dos quais $45,1 \%$ são do sexo masculino e $1,7 \%$ são indivíduos matriculados por situação de vigilância epidemiológica, dos quais $65,2 \%$ são do sexo masculino. Os 13,4\% restantes enquadram-se entre os indivíduos que são matriculados por "outras situações",28 (Figura 3). Cabe observar que entre os indivíduos cadastrados como situação de exclusão social estão incluídas as profissionais do sexo, que correspondem a 30,3\% dos indivíduos em situação de exclusão social $(n=717)$, ou seja, se esse grupo for retirado, observamos, para o novo total de indivíduos em situação de exclusão ( $\mathrm{n}=500)$, o predomínio de homens vivendo em situação de exclusão social $(64,6 \%$ homens e 35,4\% mulheres), conforme é apontado na literatura (VIEIRA et al., 1992).

\footnotetext{
${ }^{28}$ Inclui: indivíduos matriculados como estudante, indivíduos matriculados por intermédio do agente de rua ou indivíduos encaminhados de outras UBSs para especialidades existentes o CSEBF-AV, como saúde mental (psiquiatria e psicologia), saúde bucal, fonoaudiologia e saúde da mulher.
} 
Figura 3: Distribuição dos indivíduos cadastrados no CSEBF-AV segundo a porta de entrada e sexo $(\mathrm{N}=13.794)$

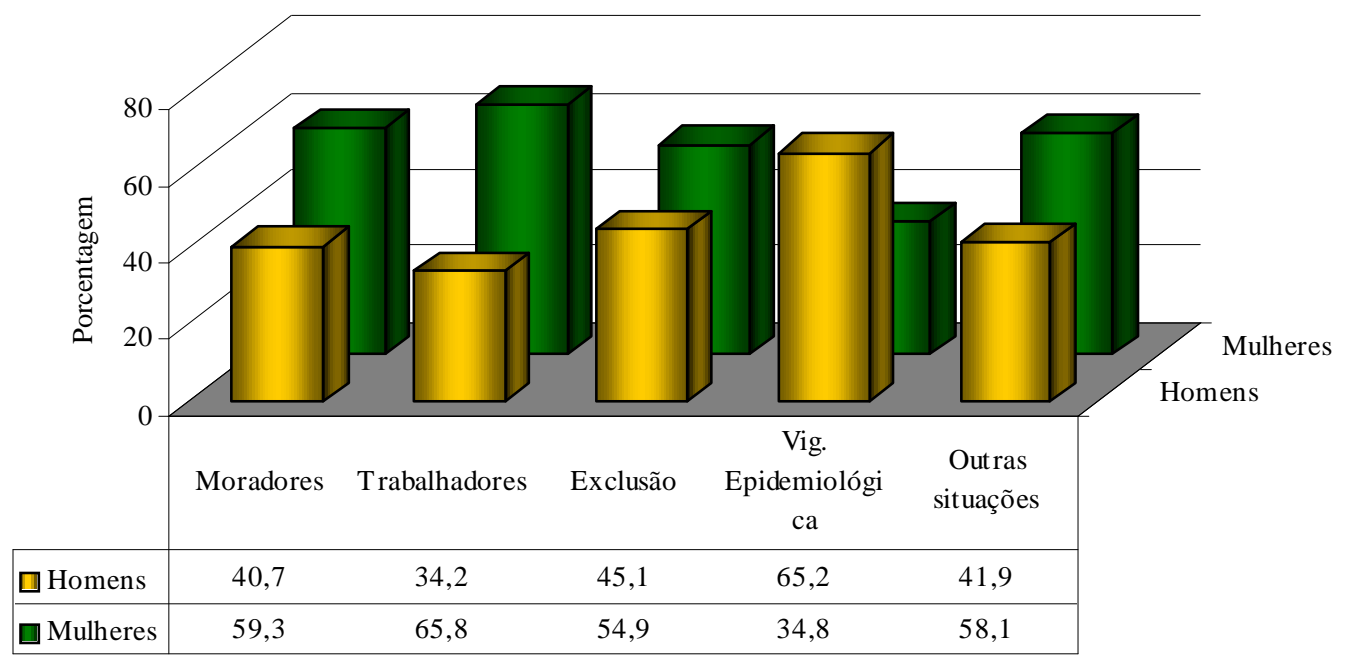

O CSEBF-AV oferece atualmente aos seus usuários assistência à Saúde da Criança (pediatria - puericultura e adolescentes, assistência ao recém nascido, imunização, saúde bucal, fonoaudiologia, psicologia, serviço social); à Saúde da Mulher (assistência ao pré-natal e ao puerpério e grupo de gestantes, grupo de planejamento familiar, grupos de coleta e de resultado de papanicolaou, assistência ginecológica e grupo de climatério, além de atenção nas áreas de Saúde Mental psiquiatria e psicologia, Saúde Bucal para as gestantes, imunização, serviço social); à Saúde do Adulto (consulta médica individual, grupo de cuidados, assistência domiciliar, além de atenção nas áreas de Saúde Mental - psiquiatria e psicologia, imunização, serviço social e Saúde Bucal em casos de urgência). Além disso, o serviço conta com assistência para curativos e pequenos ferimentos, com um laboratório para coleta de exames, com uma farmácia para o fornecimento de medicamentos aos usuários, com o serviço da vigilância epidemiológica e com uma equipe especializada em atendimento de casos de violência doméstica. Há também duas equipes de PSF que, além das atividades assistenciais individuais (consulta médica e de enfermeira) desenvolvem ações de promoção à saúde na comunidade com intermédio dos ACS e realizam visitas periódicas às suas famílias. Todas essas atividades contam com a participação dos profissionais de saúde em formação 
anteriormente mencionados ${ }^{29}$. Além dos profissionais de saúde a equipe do CSEBFAV conta com equipe administrativa que atua desde o processo de agendamento, passando pela secretaria e equipe de limpeza, até o processamento das informações das atividades desenvolvidas pela unidade e equipe de vigias.

Os homens, objeto de meu estudo, estão contemplados dentro das atividades de planejamento familiar e Saúde do Adulto como um todo. Alguns poucos homens acompanham suas esposas nas consultas de pré-natal ou seus filhos nas atividades de saúde da criança. Não há na unidade uma atenção especial voltada aos usuários do sexo masculino, cuja demanda nessa unidade vem aumentando consideravelmente nesses últimos anos, conforme discutido, e por isso acredito merecer atenção especial para que sejam garantidos a esses homens: acesso ao serviço, adesão ao seguimento que venha a ser proposto, participação em atividades de promoção à saúde e prevenção, atentando também para temas que mais despertam a curiosidade masculina (câncer de próstata, impotência, ejaculação precoce, infertilidade, infecções sexualmente transmissíveis e AIDS, etilismo, práticas esportivas e seus riscos e benefícios e planejamento familiar), assegurando a esse grupo atenção integral à saúde.

29 Alunos da graduação em Medicina ( $1^{\circ}, 3^{\circ}$ e $5^{\circ}$ anos), em Enfermagem e em Fonoaudiologia; residentes da Clínica Médica ( $1^{\circ}$ e $2^{\circ}$ anos), Pediatria ( $1^{\circ}$ ano), Programa de Saúde da Família $\left(1^{\circ}\right.$ e $2^{\circ}$ anos) e Psiquiatria ( $1^{\circ}$ ano). 


\section{Capitulo 5 \\ Resultados}




\section{CARACTERIZAÇÃo dA AMOSTRA}

A população de estudo foi composta por 391 homens, dos quais 231 (59\%) estavam no serviço como usuários no momento da entrevista e 160 (41\%) estavam no serviço como acompanhantes (Figura 4). Entre os 160 acompanhantes, 53\% (85 homens) possuíam matrícula no serviço e 47\% (75 homens) não eram matriculados. Assim, dos 391 homens entrevistados 81\% (316 homens) possuíam matrícula no serviço (Figura 5). Destes, 10,5\% (33 homens) foram excluídos pois os respectivos prontuários não foram encontrados e 14,5\% (46 homens) não tiveram seus prontuários lidos pois não haviam feito uso do serviço no último ano, sendo também excluídos em virtude do recorte do estudo que fez a caracterização dos homens enquanto usuários do serviço (Figura 6). Dessa forma, a descrição dos resultados contemplará os $237(60,6 \%)$ homens entrevistados e matriculados e que fizeram uso do serviço no último ano.

Figura 4: Distribuição dos homens entrevistados, segundo o uso do serviço no dia da entrevista $(\mathrm{N}=391)$

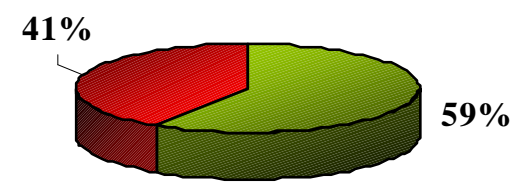

$\square$ usuários
Figura 5: Distribuição dos homens entrevistados, segundo a situação de matrícula no serviço $(\mathrm{N}=391)$

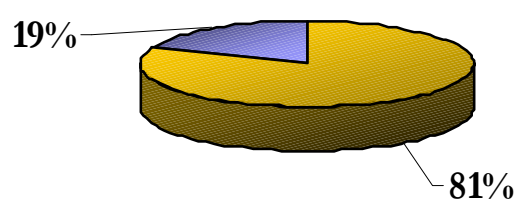

$\square$ matriculados

Figura 6: Distribuição dos homens entrevistados e matriculados no serviço, segundo a situação do prontuário na ocasião da pesquisa $(\mathrm{N}=316)$

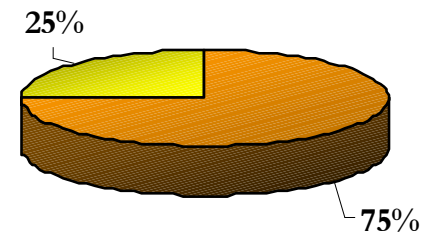

$\square$ matriculados com prontuários

$\square$ matriculados sem prontuário 


\section{DistribuiçÃo dos hOMEnS SEgundo a PORTA DE ENTRAdA No SERVIÇO}

A partir da categorização da população de estudo segundo a variável "porta de entrada" buscamos conhecer quem eram os homens que faziam uso do CSEBFAV. Assim, dos 237 homens que compuseram a amostra final do presente estudo (homens entrevistados que possuíam prontuário no serviço e fizeram uso do mesmo no último ano), 73,4\% (n=174; IC: 67,2-78,8) eram moradores da área de abrangência do centro de saúde (moradores), 6,3\% ( $\mathrm{n}=15$; IC: 3,7-10,4) eram usuários que vivem em situação de exclusão social (exclusão), 15,2\% (n=36; IC: 11,0-20,5) eram trabalhadores da área de abrangência do serviço (trabalhadores) e 5,1\% ( $\mathrm{n}=12$; IC: 2,8-8,9) eram matriculados no serviço para acompanhamento da vigilância epidemiológica (vigilância) (Figura 7).

Figura 7: Distribuição dos homens entrevistados e matriculados no serviço segundo a porta de entrada $(\mathrm{N}=237)$

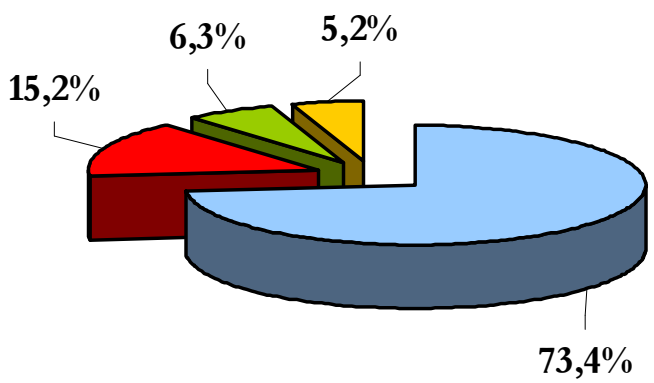

口Moradores

Trabalhadores

口Exclusão social

$\square$ Vig. Epidemiológica

\section{CARACTERIZAÇão DOS HOMENS USUÁRIOS DO CSEBF-AV}

Os resultados a seguir serão descritos em categorias: sócio-demográficas, familiares, saúde reprodutiva e sexual, demandas auto-referidas e demandas diagnosticadas de saúde em geral e padrão de uso dos serviços. Para cada categoria, apresentaremos, primeiramente, a descrição dos resultados observados segundo a porta de entrada dos homens no serviço; num segundo momento apresentaremos a 
significância estatística dos resultados obtidos segundo as quatro portas de entrada dos homens entrevistados: moradores, exclusão, trabalhadores e vigilância epidemiológica e, finalmente, apresentaremos a significância estatística dos resultados obtidos a partir do recorte com vistas aos homens em situação de exclusão social. Assim, dois grupos de análise foram constituídos: excluídos (inclui os homens entrevistados em situação de exclusão social) e não-excluídos (inclui os homens entrevistados moradores e trabalhadores da área de abrangência do CSEBF-AV), conforme apresentado na metodologia.

\section{III.1. Caracterização sócio-demográfica}

A idade média da amostra de 237 homens usuários do CSEBF-AV foi de 39,6 anos, havendo uma concentração na faixa etária de 35 a 54 anos entre moradores $(55,1 \%)$, trabalhadores $(58,3 \%)$ e homens em situação de exclusão $(53,4 \%)$ e um predomínio de homens em seguimento pela vigilância epidemiológica (VE) $(83,4 \%)$ em grupo etário mais jovem (18 a 34 anos). Eram procedentes de São Paulo 40,1\% dos homens entrevistados, seguidos por $13,1 \%$ procedentes da Bahia e 10,5\% procedentes de Pernambuco, sendo que 63,7\% referiram terem nascido em área urbana. Nos quatro grupos de homens também a maioria era procedente de São Paulo. Ao observarmos a procedência mais freqüente em segundo lugar, por porta de entrada no serviço, identificamos que, na amostra entrevistada, moradores e homens seguidos pela VE eram procedentes da Bahia (14,4\% e 25\%, respectivamente), trabalhadores eram procedentes de Minas Gerais $(16,7 \%)$ e homens que vivem em situação de exclusão eram procedentes do Rio de Janeiro (13,3\%). A figura 8 ilustra a distribuição da procedência dos homens entrevistados segundo as regiões do país e procedência estrangeira. Entre os homens nascidos no Estado de São Paulo ( $n=94)$, 69,1\% referiram ter nascido na capital do Estado, 6,4\% na Grande São Paulo e 24,5\% em outras regiões do Estado. Perguntamos aos homens há quanto tempo viviam em São Paulo e, desconsiderados 71 homens que referiram nunca terem saído da Grande São Paulo, 26\% do restante referiu viver em São Paulo há 11-20 anos e 26\% há 21-30 anos. Ao observarmos, por porta de entrada, o tempo que os homens entrevistados viviam em São Paulo, excluindo aqueles que nunca saíram da Grande 
São Paulo, identificamos que moradores e homens em situação de exclusão estavam em São Paulo, em sua maioria, há 11-20 anos (27,3\% em ambos os casos), enquanto que trabalhadores e homens seguidos pela VE estavam há 21-30 anos (38,5\% e $37,5 \%$, respectivamente).

Figura 8: Distribuição da procedência dos homens entrevistados segundo as regiões do Brasil e procedência estrangeira $(\mathrm{N}=237)$

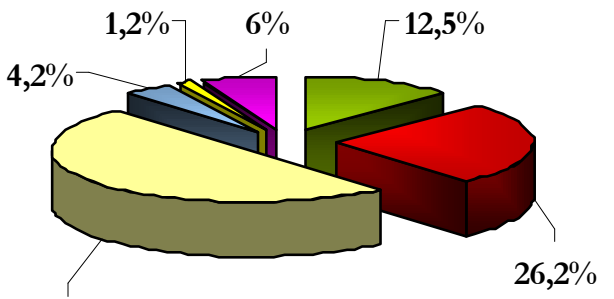

$49,8 \%$

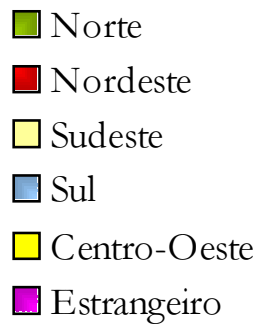

Estrangeiro

Em relação à cor da pele auto-referida, houve predomínio da cor parda/ mulata nos quatro grupos de homens. Em relação à escolaridade, 62,9\% dos homens tinham entre 5 e 11 anos de estudo, sobre a situação ocupacional, com exceção do grupo de homens em situação de exclusão, que se agruparam em autônomos e desempregados (33,3\% para cada), os outros três grupos de homens concentraram-se entre trabalhadores de empresa, ou seja, trabalhavam com carteira assinada. Entre os moradores cabe ressaltar que parcela considerável era autônoma. Os homens moradores e trabalhadores da área do CSEBF-AV e aqueles em seguimento pela VE pertenciam predominantemente aos estratos sociais $\mathrm{C}$ e $\mathrm{D}$, enquanto que os homens em situação de exclusão pertenciam, em sua maioria, ao estrato social E $(53,3 \%)$. Quanto à moradia, todos os grupos de homens responderam, em sua maioria, que viviam em casa/ apartamento. Apesar de $40 \%$ dos homens em situação de exclusão terem referido esse tipo de moradia, observamos que 53,3\% deles referiram morar em barraco ou na rua ou em outros locais, como, por exemplo, albergues. A tabela 4 ilustra os dados apresentados acima. 
Tabela 4: Caracterização sócio-demográfica dos homens entrevistados - CSEBF-AV ( $N=237)$

\begin{tabular}{|c|c|c|c|c|c|}
\hline \multicolumn{2}{|c|}{ Variáveis pesquisadas } & $\begin{array}{l}\text { Moradores } \\
\mathbf{n}=174(\%)\end{array}$ & $\begin{array}{l}\text { Exclusão } \\
\mathrm{n}=15(\%)\end{array}$ & $\begin{array}{c}\text { Trabalhadores } \\
\text { n=36 }(\%)\end{array}$ & $\begin{array}{c}\text { Vigilância } \\
n=12(\%)\end{array}$ \\
\hline \multirow{5}{*}{ Grupo etário } & 18-24 anos & 13,8 & 20,0 & 111,1 & 18 16,7 \\
\hline & 25-34 anos & 23,6 & 26,7 & 16,7 & 50,0 \\
\hline & 35-44 anos & 26,4 & 26,7 & 19,4 & 16,7 \\
\hline & 45-54 anos & 28,7 & 26,7 & 38,9 & 8,3 \\
\hline & 55-60 anos & 7,5 & $\ldots$ & 13,9 & 8,3 \\
\hline \multirow{5}{*}{ Cor da pele } & Branco & 39,1 & 6,7 & 33,3 & 33,3 \\
\hline & Negro & 6,3 & 20,0 & 11,1 & $\ldots$ \\
\hline & Amarelo & 0,6 & $\ldots$ & $\ldots$ & $\ldots$ \\
\hline & Pardo/ mulato & 51,7 & 73,3 & 55,7 & 66,7 \\
\hline & Outros mestiços & 2,3 & $\ldots$ & $\ldots$ & $\ldots$ \\
\hline \multirow{5}{*}{ Escolaridade } & $0 \mathrm{ou}<1$ ano & 2,3 & 6,7 & 8,3 & 8,3 \\
\hline & 1 a 4 anos & 25,4 & 53,3 & 27,8 & 25,0 \\
\hline & 5 a 8 anos & 29,8 & 33,4 & 27,8 & 41,6 \\
\hline & 9 a 11 anos & 36,2 & 6,7 & 30,6 & 16,6 \\
\hline & $>11$ anos & 6,4 & $\ldots$ & 5,6 & 8,3 \\
\hline \multirow{7}{*}{ Ocupação } & Estudante & 1,7 & 6,7 & $\ldots$ & $\ldots$ \\
\hline & Trabalhador empresa & 45,4 & $\ldots$ & 77,8 & 58,3 \\
\hline & Autônomo & 36,8 & 33,3 & 13,9 & 8,3 \\
\hline & Esporádica & 1,2 & 6,7 & $\ldots$ & $\ldots$ \\
\hline & Desempregado & 9,8 & 33,3 & 2,8 & 16,7 \\
\hline & $\begin{array}{l}\text { Aposentado/pensionist } \\
\mathrm{a}\end{array}$ & 4,6 & 6,7 & 2,8 & 16,7 \\
\hline & Outros & 0,6 & 13,3 & 2,8 & $\ldots$ \\
\hline \multirow{5}{*}{ Estrato social } & Estrato B & 9,8 & $\ldots$ & 8,3 & $\ldots$ \\
\hline & Estrato C & 26,4 & 20,0 & 55,6 & 58,3 \\
\hline & Estrato D & 47,1 & 26,7 & 30,6 & 33,3 \\
\hline & Estrato E & 16,1 & 53,3 & 5,6 & 8,3 \\
\hline & Sem resposta & 0,6 & $\ldots$ & $\ldots$ & $\ldots$ \\
\hline \multirow{6}{*}{ Moradia } & Casa/apartamento & 81,0 & 40,0 & 88,9 & 100,0 \\
\hline & Quintal/ cortiço & 1,2 & $\ldots$ & $\ldots$ & $\ldots$ \\
\hline & Pensão/ quarto & 10,9 & 6,7 & $\ldots$ & $\ldots$ \\
\hline & Barraco & 4,0 & 13,3 & 2,8 & $\ldots$ \\
\hline & Morador de rua & $\ldots$ & 13,3 & $\ldots$ & $\ldots$ \\
\hline & Outros & 2,9 & 26,7 & 8,3 & $\ldots$ \\
\hline
\end{tabular}


Ao analisarmos $^{30}$ as características sócio-demográficas dos homens entrevistados, comparando o grupo dos homens em situação de exclusão (excluídos) com os outros três grupos, observamos: em relação à ocupação, os excluídos predominaram na situação "atualmente não trabalhando"; em relação ao estrato social, os excluídos predominaram nas classes "D e E". A análise estatística desses resultados mostrou que os mesmos foram estatisticamente significantes $(\mathrm{p}<0,05,3$ graus de liberdade - 3gl) (Tabela 5). A análise estatística para as outras variáveis sócio-demográficas não apresentou significância $(\mathrm{p}>0,05)$.

Tabela 5: Caracterização sócio-demográfica dos homens entrevistados - CSEBF-AV: análise estatística segundo o tipo de matrícula $(\mathrm{N}=237)$

\begin{tabular}{|c|c|c|c|c|c|c|c|c|c|}
\hline \multirow{3}{*}{ Variáveis } & \multicolumn{8}{|c|}{ Tipo de Matrícula } & \multirow{3}{*}{$\begin{array}{c}\text { Teste estatístico } \\
\text { Qui-quadrado } \\
x^{2}\end{array}$} \\
\hline & \multicolumn{2}{|c|}{$\begin{array}{l}\text { Moradores } \\
(\mathrm{n}=174)\end{array}$} & \multicolumn{2}{|c|}{$\begin{array}{c}\text { Exclusão } \\
(\mathbf{n}=15)\end{array}$} & \multicolumn{2}{|c|}{$\begin{array}{c}\text { Trabalhadores } \\
\quad(n=36)\end{array}$} & \multicolumn{2}{|c|}{$\begin{array}{c}\text { Vigilância } \\
(\mathrm{n}=12)\end{array}$} & \\
\hline & $\mathbf{n}$ & $\%$ & $\mathbf{n}$ & $\%$ & $\mathbf{n}$ & $\%$ & $\mathbf{n}$ & $\%$ & \\
\hline $\begin{array}{l}\text { Atualmente não } \\
\text { trabalhando }\end{array}$ & 17 & 10,0 & 5 & 41,0 & 1 & 3,0 & 2 & 20,0 & $\begin{aligned} \mathbf{x}^{2} & =11,14 \\
\boldsymbol{p} & =\mathbf{0 , 0 1 0}\end{aligned}$ \\
\hline $\begin{array}{l}\text { Estrato social } \\
\text { D e E }\end{array}$ & 110 & 63,6 & 12 & 80,0 & 13 & 36,1 & 5 & 41,7 & $\begin{array}{l}\mathbf{x}^{2}=13,31 \\
\boldsymbol{p}=\mathbf{0 , 0 0 4}\end{array}$ \\
\hline
\end{tabular}

Ao realizarmos o mesmo teste estatístico considerando dois grupos de análise, excluídos e não-excluídos, observamos: em relação à cor da pele, os excluídos predominaram entre os "não-brancos" (negros, pardos/ mulatos, outras); em relação à escolaridade, os excluídos predominaram entre os que estudaram até quatro anos; em relação à ocupação, os excluídos predominaram na situação "atualmente não trabalhando"; em relação à moradia, os excluídos predominaram no tipo de moradia considerada nessa pesquisa "com risco social". O teste do qui-quadrado para esses resultados também foi estatisticamente significante $(\mathrm{p}<0,05)$ (Tabela 6). A análise estatística para as outras variáveis sócio-demográficas, considerando dois grupos de análise, não apresentaram significância $(\mathrm{p}>0,05)$.

\footnotetext{
${ }^{30}$ Para essa análise, consideramos dois tipos de resposta para as variáveis pesquisadas. Assim: grupo etário, 18-34 anos e 34-60 anos; cor da pele, branco e "não-branco"; escolaridade, até 4 anos de estudo e mais de 4 anos de estudo; ocupação, trabalhando e não trabalhando atualmente; estrato social B-C e D-E; moradia, com risco social (quintal ou cortiço, barraco, morador de rua, outros) ou sem risco social (casa/ apartamento, pensão).
} 
Tabela 6: Caracterização sócio-demográfica dos homens entrevistados - CSEBF-AV: análise estatística segundo o tipo de matrícula: excluídos e não-excluídos $(\mathrm{N}=210)$

\begin{tabular}{|c|c|c|c|c|c|}
\hline \multirow{3}{*}{ Variáveis } & \multicolumn{4}{|c|}{ Tipo de Matrícula } & \multirow{3}{*}{$\begin{array}{c}\text { Teste estatístico } \\
\text { Qui-quadrado } \\
x^{2}\end{array}$} \\
\hline & \multicolumn{2}{|c|}{ Exclusão $(n=15)$} & \multicolumn{2}{|c|}{ Não-exclusão (n=210) } & \\
\hline & $\mathbf{n}$ & $\%$ & $\mathbf{n}$ & $\%$ & \\
\hline $\begin{array}{l}\text { Cor da pele "não- } \\
\text { branca" }\end{array}$ & 14 & 93,3 & 130 & 62,0 & $\begin{array}{l}\boldsymbol{x}^{2}=6,00 \\
\boldsymbol{p}=\mathbf{0 , 0 1 4}\end{array}$ \\
\hline Até 4 anos de estudo & 9 & 60,0 & 61 & 29,0 & $\begin{array}{c}\mathbf{x}^{2}=4,90 \\
\boldsymbol{p}=\mathbf{0 , 0 2 6} *\end{array}$ \\
\hline $\begin{array}{l}\text { Atualmente não } \\
\text { trabalhando }\end{array}$ & 5 & 41,0 & 18 & 9,0 & $\begin{array}{c}\boldsymbol{x}^{2}=6,85 \\
\boldsymbol{p}=\boldsymbol{0 , 0 0 8 ^ { * }}\end{array}$ \\
\hline $\begin{array}{l}\text { Moradia com risco } \\
\text { social }\end{array}$ & 8 & 53,3 & 18 & 9,0 & $\begin{array}{l}\boldsymbol{x}^{2}=23,24 \\
\boldsymbol{p}<0,001^{*}\end{array}$ \\
\hline
\end{tabular}

*com correção de Yates

III.2. Caracterização familiar

A respeito da composição familiar dos homens entrevistados observamos que os homens em situação de exclusão eram, em sua maioria, solteiros e viviam sozinhos (60\%), enquanto que para os outros três grupos de homens a maioria deles era casada/ amigada e vivia na tradicional composição familiar "casal com filhos". Entre os moradores e trabalhadores que referiram relacionamento atual a maioria estava naquela relação há mais de 10 anos, inclusive os homens em situação de exclusão que referiram ter companheira, enquanto que os homens seguidos pela VE concentraram-se na categoria de relacionamento 2 a 5 anos. A maioria dos homens entrevistados, nos quatro grupos, tinham filhos, predominando de dois a três. Por sua vez, os homens seguidos pela VE tinham predominantemente apenas um filho (Tabela 7).

Em relação à companheira dos homens entrevistados, a idade média delas foi 34 anos, com predomínio de mulheres entre 25 e 44 anos para os grupos de moradores, trabalhadores e homens em situação de exclusão. As companheiras dos homens seguidos pela VE, mais jovens, eram igualmente mais jovens (18 a 34 anos). Em relação à escolaridade das companheiras dos homens entrevistados $40 \%$ delas tinham de 9 a 11 anos de estudo (excluídos 23 casos em que os homens não 
souberam referir a escolaridade da companheira) (Tabela 7). Cabe ressaltar que na amostra de 391 homens entrevistados apenas um referiu parceria homossexual.

Ao analisarmos $^{31}$ as características familiares dos homens entrevistados, comparando o grupo dos homens em situação de exclusão com os outros três grupos, observamos significância estatística para a variável situação conjugal, com os excluídos predominando entre aqueles que não tinham parceira $(\mathrm{p}=0,001,3 \mathrm{gl}), \mathrm{o}$ mesmo ocorrendo quando consideramos dois grupos de analise (excluídos e nãoexcluídos) $(\mathrm{p}<0,001)$. Os homens em situacao de exclusão também predominaram entre os que moravam sozinhos e para a variável "com quem mora", considerando os quatro grupos de análise $(\mathrm{p}=0,012,3 \mathrm{gl})$ e os dois grupos de analise $(\mathrm{p}=0,004)$ (Tabela 8, Figura 9).

Em relação às características das parceiras e o tempo de relacionamento não houve significância estatística para as variáveis pesquisadas ( $\mathrm{p}>0,05)$.

31 Para essa análise, consideramos dois tipos de resposta para as variáveis pesquisadas. Assim: situação conjugal, com parceira e sem parceira; com quem mora, com familiares e sozinho; tempo do atual relacionamento, até 10 anos e mais de 10 anos. 
Tabela 7: Caracterização familiar dos homens entrevistados - CSEBF-AV (N=237)

\begin{tabular}{|c|c|c|c|c|c|c|c|c|c|}
\hline \multicolumn{3}{|c|}{ Variáveis pesquisadas } & $\begin{array}{l}\text { Moradores } \\
\mathrm{n}=174(\%)\end{array}$ & & $\begin{array}{l}\text { Exclusão } \\
\text { n=15 (\%) }\end{array}$ & $\begin{array}{c}\begin{array}{c}\text { Trabalhadorc } \\
\mathrm{n}=36(\%)\end{array} \\
\end{array}$ & & $\begin{array}{l}\text { Vigilância } \\
n=12(\%)\end{array}$ & \\
\hline \multicolumn{3}{|c|}{ Casado/ amigado } & 67,8 & & 40,0 & 72,2 & & 50,0 & \\
\hline \multirow{3}{*}{ Situação conjugal ${ }^{1}$} & \multicolumn{2}{|c|}{ Tem parceira, s/ rel sexual } & 1,2 & & $\ldots$ & 16,7 & & 8,3 & \\
\hline & \multicolumn{2}{|c|}{ Tem parceira, c/ rel sexual } & 9,2 & & $\ldots$ & $\ldots$ & & 8,3 & \\
\hline & \multicolumn{2}{|c|}{ Solteiro, sem parceira/o } & 21,3 & & 60,0 & 11,1 & & 33,4 & \\
\hline \multirow{10}{*}{ Com quem mora } & \multicolumn{2}{|l|}{ Casal } & 8,0 & & $\ldots$ & 2,8 & & 16,7 & \\
\hline & \multicolumn{2}{|c|}{ Casal com filhos } & 43,7 & & 33,3 & 55,6 & & 25,0 & \\
\hline & \multicolumn{2}{|c|}{ Casal com parentes } & 2,3 & & $\ldots$ & & & $\ldots$ & \\
\hline & \multicolumn{2}{|c|}{ Casal com filhos e parentes } & 17,8 & & 6,7 & 13,9 & & 25,0 & \\
\hline & \multicolumn{2}{|c|}{ Chefe com filhos } & 8,0 & & $\ldots$ & 8,3 & & & \\
\hline & \multicolumn{2}{|c|}{ Chefe c/ filhos e parentes } & 2,3 & & $\ldots$ & & & 8,3 & \\
\hline & \multicolumn{2}{|c|}{ Chefe e parentes } & 4,6 & & $\ldots$ & 5,6 & & 16,7 & \\
\hline & \multicolumn{2}{|l|}{ Pessoa sozinha } & 10,9 & & 40,0 & 11,1 & & 8,3 & \\
\hline & \multicolumn{2}{|l|}{ Com amigos } & 1,2 & & 6,7 & 2,8 & & $\ldots$ & \\
\hline & \multicolumn{2}{|l|}{ Outros } & 1,2 & & 6,7 & $\ldots$ & & $\ldots$ & \\
\hline \multirow{4}{*}{$\begin{array}{l}\text { Tempo do atual } \\
\text { relacionamento }^{2}\end{array}$} & \multicolumn{2}{|l|}{2 anos ou menos } & 17,5 & & 16,7 & 9,4 & & 25,0 & \\
\hline & \multicolumn{2}{|l|}{2 a 5 anos } & 14,6 & & 16,7 & 9,4 & & 37,5 & \\
\hline & \multicolumn{2}{|l|}{5 a 10 anos } & 24,0 & & 33,3 & 18,8 & & 25,0 & \\
\hline & \multicolumn{2}{|l|}{ mais de 10 anos } & 43,8 & & 33,3 & 62,5 & & 12,5 & \\
\hline & Sim & & 75,3 & & 60,0 & 69,4 & & 50,0 & \\
\hline & Não & & 24,7 & & 40,0 & 30,6 & & 50,0 & \\
\hline Filhos $^{3}$ & 1 filho & & 29,8 & & 13,3 & 22,2 & & 66,7 & \\
\hline & 2 a 3 filhos & & 59,5 & & 26,7 & 38,9 & & 16,7 & \\
\hline & mais de 3 filhos & & 10,7 & & 20,0 & 8,3 & & 16,7 & \\
\hline & & 18-24 anos & 19,7 & & 33,3 & 15,6 & & 25,0 & \\
\hline & & 25-34 anos & 29,9 & & 33,3 & 21,9 & & 37,5 & \\
\hline & & 35-44 anos & 29,9 & & 33,3 & 34,4 & & 12,5 & \\
\hline & Grupo etano & 45-54 anos & 18,2 & & $\ldots$ & 18,8 & & $\ldots$ & \\
\hline & & $55-60$ anos & 2,2 & & $\ldots$ & 6,3 & & $250^{\circ}$ & \\
\hline & & Não sabe & $\ldots$ & & $\ldots$ & 3,1 & & 25,0 & \\
\hline & & 0 ou $<1$ ano & 3,3 & & 400 & 7,7 & & $\ldots$ & \\
\hline & Escolaridade $^{4}$ & 1 a 4 anos & 28,5 & & $\begin{array}{l}\mathbf{4 0 , 0} \\
20,0\end{array}$ & 19,2 & & $\ldots$ & \\
\hline & (anos de & 5 a 8 anos & 20,3 & & 40,0 & 38,5 & 50,0 & & \\
\hline & estudos) & 9 a 11 anos & 42,3 & & & 30,8 & & 33,3 & \\
\hline $\begin{array}{c}\text { Caracteristicas da } \\
\text { companheira }\end{array}$ & & $>11$ anos & 5,6 & & $\ldots$ & 3,8 & & 16,7 & \\
\hline & & Estudante & 2,3 & & $\ldots$ & 3,1 & & $\ldots$ & \\
\hline & & Do lar & 27,0 & & 66,7 & 46,9 & & $\ldots$ & \\
\hline & & Doméstica & $13,2)$ & & $\ldots$ & $9,4)$ & & 37,5 & \\
\hline & & Trab empresa & 24,1 & & 16,7 & 31,3 & & 25,0 & \\
\hline & Ocupacão & Autônoma & 8,0 & $47,6 \%$ & 16,7 & $3,1\}$ & $50,0 \%$ & 12,5 & $87,5 \%$ \\
\hline & cupaça & Esporádica & 0,6 & & $\ldots$ & 3,1 & & $\ldots$ & \\
\hline & & Desempregada & 1,7 & & $\ldots$ & $3,1)$ & & 12,5 & \\
\hline & & Apos/ pensio & 1,2 & & $\ldots$ & $\ldots$ & & $\ldots$ & \\
\hline & & Outros & 0,6 & & $\ldots$ & & & $\ldots$ & \\
\hline & & Não sabe & $\ldots$ & & $\ldots$ & $\ldots$ & & 12,5 & \\
\hline
\end{tabular}

${ }^{1}: \mathrm{n}$ (moradores $)=173 ;{ }^{2}: \mathrm{n}$ (moradores $)=137 ; \mathrm{n}$ (exclusão $)=6 ; \mathrm{n}$ (trabalhadores $)=32 ; \mathrm{n}$ (vigilância $)=8$

${ }^{3}$ : n (moradores $)=131 ; n$ (exclusão) $=9 ;$ n (trabalhadores $)=25 ;$ n (vigilância $)=6$

${ }^{4}: \mathrm{n}$ (moradores $)=123 ; \mathrm{n}$ (exclusão) $=5 ; \mathrm{n}$ (trabalhadores $)=26 ; \mathrm{n}$ (vigilância $)=8$ 
Tabela 8: Caracterização familiar dos homens entrevistados - CSEBF-AV: análise estatística segundo o tipo de matrícula $(\mathrm{N}=237)$

\begin{tabular}{|c|c|c|c|c|c|c|c|c|c|}
\hline \multirow{3}{*}{ Variáveis } & \multicolumn{8}{|c|}{ Tipo de Matrícula } & \multirow{3}{*}{$\begin{array}{c}\text { Teste } \\
\text { estatístice } \\
\text { Qui- } \\
\text { quadrado } \\
x^{2}\end{array}$} \\
\hline & \multicolumn{2}{|c|}{$\begin{array}{c}\text { Moradores } \\
(\mathrm{n}=174)\end{array}$} & \multicolumn{2}{|c|}{$\begin{array}{c}\text { Exclusão } \\
(n=15)\end{array}$} & \multicolumn{2}{|c|}{$\begin{array}{c}\text { Trabalhadores } \\
(\mathbf{n}=36)\end{array}$} & \multicolumn{2}{|c|}{$\begin{array}{l}\text { Vigilância } \\
\quad(n=12)\end{array}$} & \\
\hline & $\mathbf{n}$ & $\%$ & $\mathbf{n}$ & $\%$ & $\mathbf{n}$ & $\%$ & $\mathbf{n}$ & $\%$ & \\
\hline $\begin{array}{l}\text { Situação } \\
\text { conjugal s/ } \\
\text { parceira }\end{array}$ & 37 & 21,3 & 9 & 60,0 & 4 & 11,1 & 4 & 33,3 & $\begin{aligned} \mathbf{x}^{2} & =15,58 \\
\boldsymbol{p} & =\mathbf{0 , 0 0 1}\end{aligned}$ \\
\hline $\begin{array}{l}\text { Mora } \\
\text { sozinho }\end{array}$ & 19 & 11,0 & 6 & 40,0 & 4 & 11,1 & 1 & 8,3 & $\begin{aligned} \boldsymbol{x}^{2} & =10,90 \\
\boldsymbol{p} & =\mathbf{0 , 0 1 2}\end{aligned}$ \\
\hline
\end{tabular}

Figura 9: Caracterização familiar dos homens entrevistados - CSEBF-AV: análise estatística segundo o tipo de matrícula: excluídos e não-excluídos $(\mathrm{N}=210)$

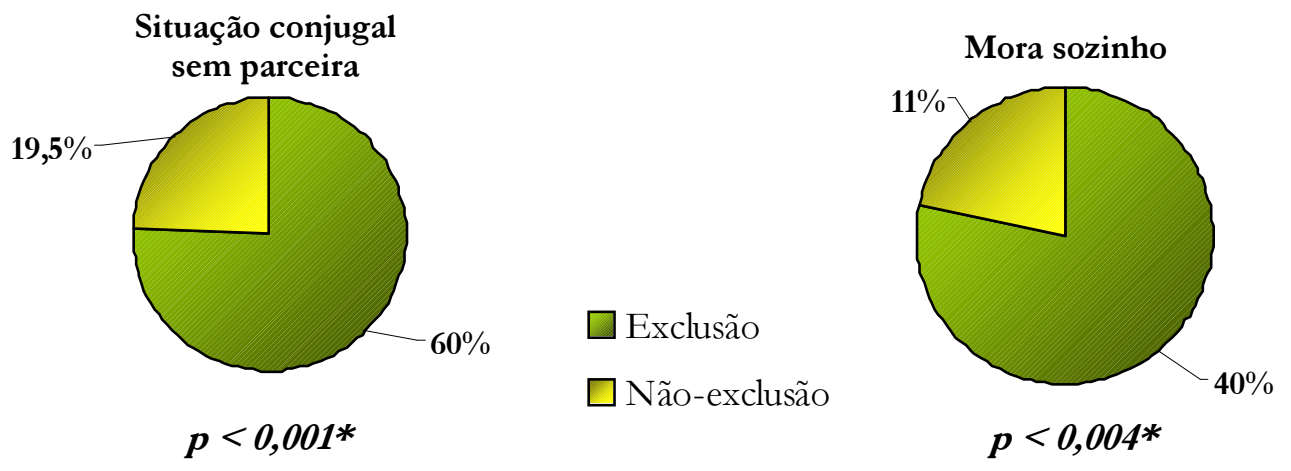

* com correção de yates

III.3. Caracterização do perfil sexual e reprodutivo

Praticamente $90 \%$ dos homens entrevistados, nos quatro grupos, tiveram sua primeira relação sexual na faixa etária de 10 a 20 anos, com os homens seguidos pela VE concentrando-se na faixa etária de 15 a 20 anos, chamando a atenção o fato de que $75 \%(n=12)$ dos homens seguidos pela VE, mais jovens, tiveram sua primeira relação sexual mais tardiamente, isto é, entre 15 e 20 anos. Em relação à primeira parceira sexual, os quatro grupos de homens referiram, predominantemente, ter sido uma amiga/ conhecida. Em relação ao método anticoncepcional (MAC) adotado pelos homens entrevistados, excluímos os homens sem parceira no momento da 
entrevista $^{32}$ e, além dos dados apresentados na tabela 9, optamos também por excluir os usuários que referiram: não uso de MAC, métodos naturais ${ }^{33}$, parceira na menopausa ou histerectomizada, desconhece se parceira usa MAC, não sabe o que usa, outros (gravidez, amamentação) para analisarmos o uso de métodos mais dependentes e menos dependentes de uma atitude do homem. Dessa forma, observamos que entre moradores e trabalhadores houve predomínio de laqueadura ( $31 \%, n=100$ e $42 \%, n=24$, respectivamente), entre os homens que vivem em situação de exclusão predominou o uso de anticoncepcional oral $(50 \%, n=4)$ e entre os homens seguidos pela VE houve o predomínio do uso de preservativo masculino $(66,7 \%, n=6)$. Analisamos ainda quais MAC apareceram como segunda opção: métodos naturais (especialmente por homens que vivem em situação de exclusão), preservativo masculino (moradores e trabalhadores).

Investigamos também o desejo pelo último filho e observamos que, com exceção dos trabalhadores, os outros grupos de homens desejaram, em sua maioria, o filho (Tabela 9). Questionamos os homens a respeito de relações extraconjugais no último ano e apenas moradores e trabalhadores responderam positivamente à questão (19,7\% e 21,9\%, respectivamente), sendo que $69,2 \%$ e $50 \%$, respectivamente, referiram ser poucas vezes. Em relação ao uso de preservativo masculino para prevenção de alguma infecção sexualmente transmissível (IST), recentemente/ atualmente, a maioria dos homens trabalhadores e seguidos pela VE e pouco mais da metade dos homens moradores da área respondeu já ter feito uso do mesmo com essa finalidade, sendo que pouco mais da metade dos homens que vivem em situação de exclusão referiram o não uso de preservativo masculino com essa finalidade e, entre $13 \%$ e $17 \%$ dos homens entrevistados referiram que já recusaram usar o preservativo frente a solicitação da parceira (Tabela 10).

\footnotetext{
${ }^{32} \mathrm{O}$ questionário abordou o uso de MAC com a parceira atual.

${ }^{33}$ Incluia tabelinha, coito interrompido, lavagem, ducha, abstinência sexual.
} 
Tabela 9: Descrição do perfil sexual e reprodutivo dos homens entrevistados - CSEBF-AV ( $\mathrm{N}=237)$

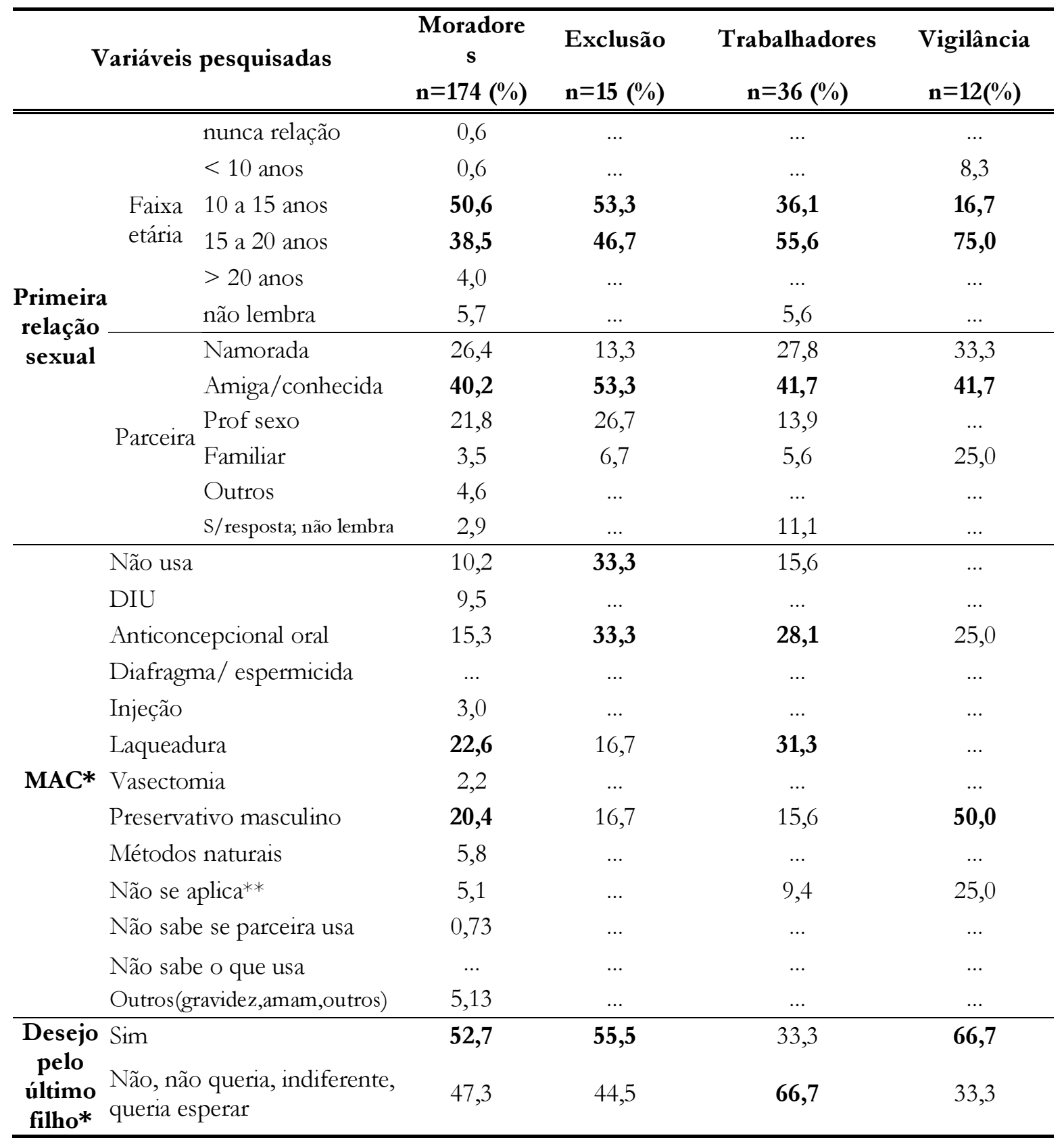

${ }^{*} \mathbf{N}$ exclui homens solteiros (n solteiros): $\mathbf{n}$ (moradores) $=37 ; \mathbf{n}$ (exclusão) $=9 ; \mathbf{n}$ (trabalhadores) $=4 ; \mathbf{n}$ (vigilância) $=4$ **mulheres na menopausa ou histerectomizadas

MAC: método anticoncepcional 
Tabela 10: Descrição do perfil sexual e reprodutivo dos homens entrevistados - CSEBF$\mathrm{AV}$ - relações extraconjugais e uso de preservativo masculino $(\mathrm{N}=237)$

\begin{tabular}{llcccc}
\hline \multicolumn{2}{c}{ Variáveis pesquisadas } & $\begin{array}{c}\text { Moradores } \\
\mathbf{n = 1 7 4} \mathbf{( \% )}\end{array}$ & $\begin{array}{c}\text { Exclusão } \\
\mathbf{n}=\mathbf{1 5} \mathbf{( \% )}\end{array}$ & $\begin{array}{c}\text { Trabalhadores } \\
\mathbf{n = 3 6} \mathbf{( \% )}\end{array}$ & $\begin{array}{c}\text { Vigilância } \\
\mathbf{n = 1 2 ( \% )}\end{array}$ \\
\hline \hline & Sim & 19,7 & - & 21,9 & - \\
Relações extraconjugais & Não & 80,3 & 100,0 & 78,1 & 100,0 \\
\cline { 2 - 6 } no último ano & Freqüência* & & & & \\
& Muitas vezes & 11,5 & - & 16,7 & - \\
& Poucas vezes & $\mathbf{6 9 , 2}$ & - & $\mathbf{5 0 , 0}$ & - \\
\hline Uso de preservativo & Raras vezes & 19,3 & - & 33,3 & - \\
masculino contra IST & Sim & $\mathbf{5 1 , 5}$ & 46,7 & $\mathbf{6 3 , 9}$ & $\mathbf{6 6 , 7}$ \\
Recusa ao preservativo & & 48,5 & $\mathbf{5 3 , 3}$ & 36,1 & 33,3 \\
masculino frente a & Sim & & & & \\
solicitação da parceira & Não & 13,2 & 13,3 & 5,6 & 16,7 \\
\hline
\end{tabular}

*N exclui homens que não tiveram relação extraconjugal; IST: infecção sexualmente transmissível

Ao analisarmos ${ }^{34}$ as características do perfil sexual e reprodutivo dos homens entrevistados, comparando o grupo dos homens em situação de exclusão com os outros três grupos e considerando dois grupos de analise, observamos que não houve significância estatística para as variáveis analisadas nas tabelas 3 e 4 ( $p>0,05)$.

III.4. Caracterização das demandas de saúde em geral entre os usuários do CSEBF-AV

A caracterização aqui proposta visa apresentar: 1. as demandas de saúde referidas pelos homens na entrevista aplicada com o instrumento questionário (as informações assim obtidas foram designadas demanda auto-referida); 2. as demandas de saúde registradas nos respectivos prontuários médicos e obtidas a partir do instrumento ficha de leitura dos prontuários - ficha 2 (as informações assim obtidas foram designadas demanda diagnosticada).

\footnotetext{
34 Para essa análise, consideramos dois tipos de resposta para as variáveis pesquisadas. Assim: primeira relação sexual: idade, até 15 anos e mais de 15 anos; parceira, com profissional do sexo ou não; método anticoncepcional, depende exclusivamente da mulher e não depende exclusivamente da mulher (preservativo masculino e vasectomia); uso e não uso de preservativo masculino contra IST; recusa ou não ao preservativo masculino frente a solicitação da parceira.
} 


\section{III.4.1. Saúde sexual: demanda auto-referida e demanda diagnosticada}

$\mathrm{O}$ instrumento questionário, em relação à demanda em saúde, abordou aspectos relacionados ao sistema gênito-urinário no último ano, tomando como referência os últimos doze meses a fim de minimizar um possível viés de memória. Entre homens moradores da área de abrangência do CSEBF-AV que referiram algum sintoma gênito-urinário observamos um predomínio de secreção uretral e entre os trabalhadores quase 20\% referiram disúria. Entre os homens seguidos pela VE, observamos que houve predomínio de queixas como secreção uretral e ferida ou verruga na região genital. O grupo de homens em situação de exclusão social, em relação a essa pergunta, negou qualquer tipo de sintomatologia do sistema gênitourinário no último ano (Figura 10).

Figura 10: Sintomas gênito-urinários, demanda auto-referida pelos homens entrevistados - CSEBF-AV, segundo a porta de entrada $(\mathrm{N}=237)$

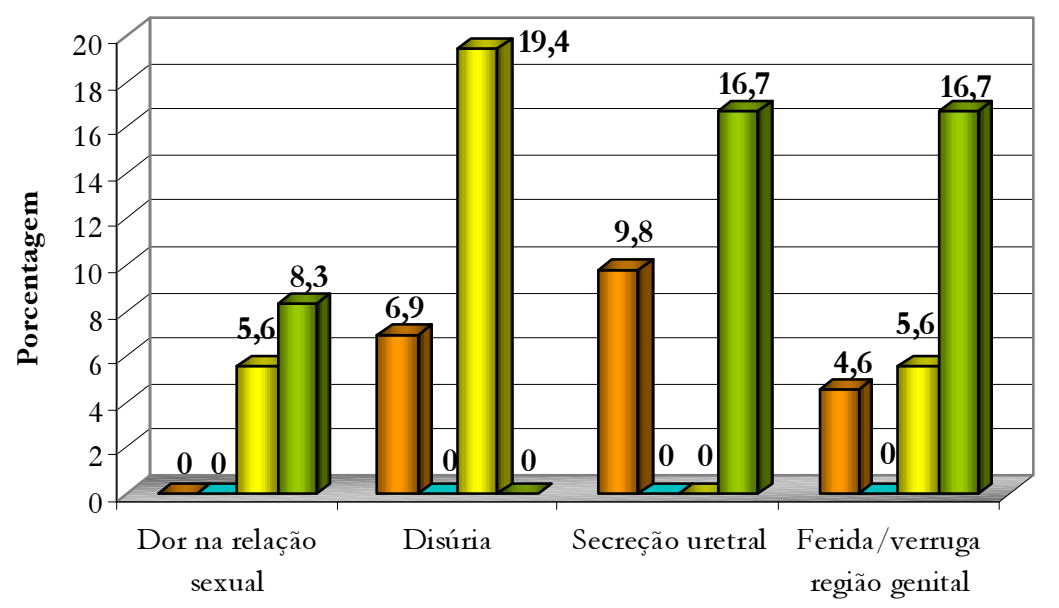

$\square$ Moradores $\square$ Exclusão $\square$ Trabalhadores $\quad \square$ Vigilância

Ao observarmos os registros em prontuário dos homens entrevistados, obtidos a partir do instrumento ficha de leitura dos prontuários - ficha 2, no último ano de uso do serviço, em relação ao sistema gênito-urinário, observamos, em relação aos dados investigados pelo instrumento questionário (dor na relação, disúria, secreção uretral e ferida ou verruga na região genital) que os homens dos quatro grupos apresentavam percepção em relação aos sintomas (demanda auto-referida) diferente 
do que estava registrado em prontuários (demanda diagnosticada). Os homens moradores e trabalhadores da área, segundo o questionário aplicado, apresentaram uma percepção aumentada de problemas de saúde gênito-urinário em relação ao que foi encontrado em seus prontuários para a maioria dos sintomas investigados. Os homens seguidos pela VE destacaram-se por apresentar maior congruência entre demanda auto-referida e demanda diagnosticada, apesar de não referirem no questionário disúria, sintoma encontrado no prontuário. Já os trabalhadores, em relação ao mesmo sintoma, destacaram-se por referirem disúria mais do que o registrado em prontuário. Porém, o grupo que mais chamou a atenção foi o de homens em situação de exclusão, pois apesar de negarem qualquer sintoma gênitourinário quando investigados pelo instrumento questionário, apresentaram registro desse tipo de sintoma em seus respectivos prontuários.

A figura 11 ilustra a demanda diagnosticada para sintomas gênito-urinários entre os homens entrevistados e a figura 12 ilustra a comparação descrita. Nesse caso, o esperado seria "zero" para todos os sintomas, o que indicaria coincidência entre demandas auto-referida e diagnosticada (ou ausência do sintoma). A presença de diferença implica discordância entre as demandas, sendo que valores positivos implicam percepção aumentada em relação ao sintoma e valores negativos implicam percepção diminuída em relação ao sintoma, ou seja, a demanda auto-referida pelos homens entrevistados. 
Figura 11: Sintomas gênito-urinários, demanda diagnosticada entre os homens entrevistados - CSEBF-AV, segundo a porta de entrada $(\mathbf{N}=237)$

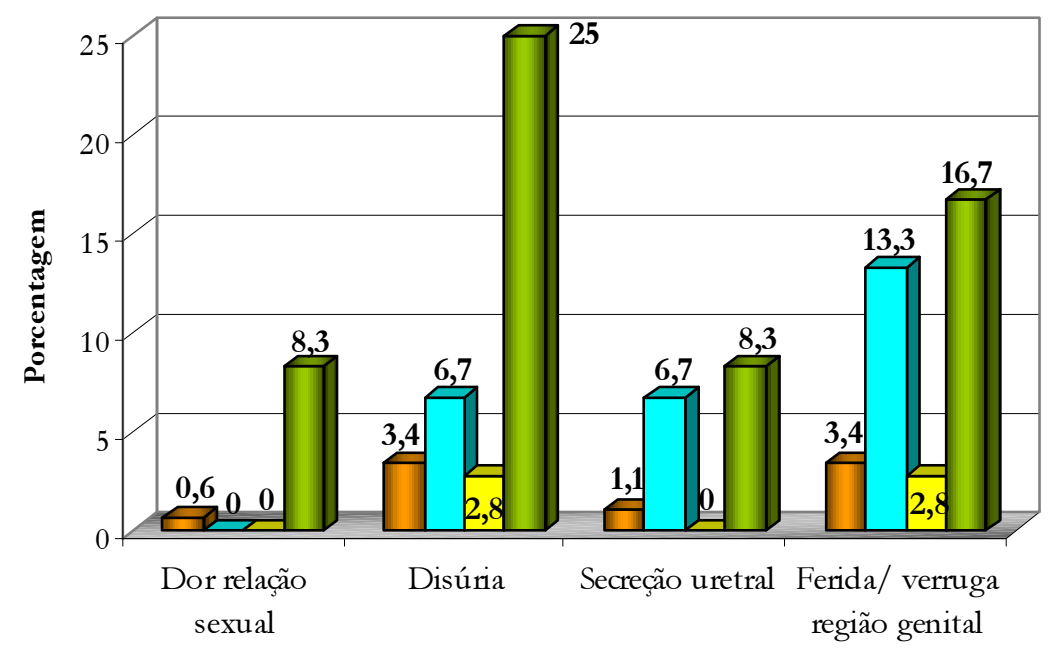

$\square$ Moradores $\square$ Exclusão $\quad \square$ Trabalhadores $\quad \square$ Vigilância

Figura 12: Sintomas gênito-urinários, comparação entre as demandas auto-referida e diagnosticada entre os homens entrevistados - CSEBF-AV, segundo a porta de entrada $(\mathrm{N}=237)$

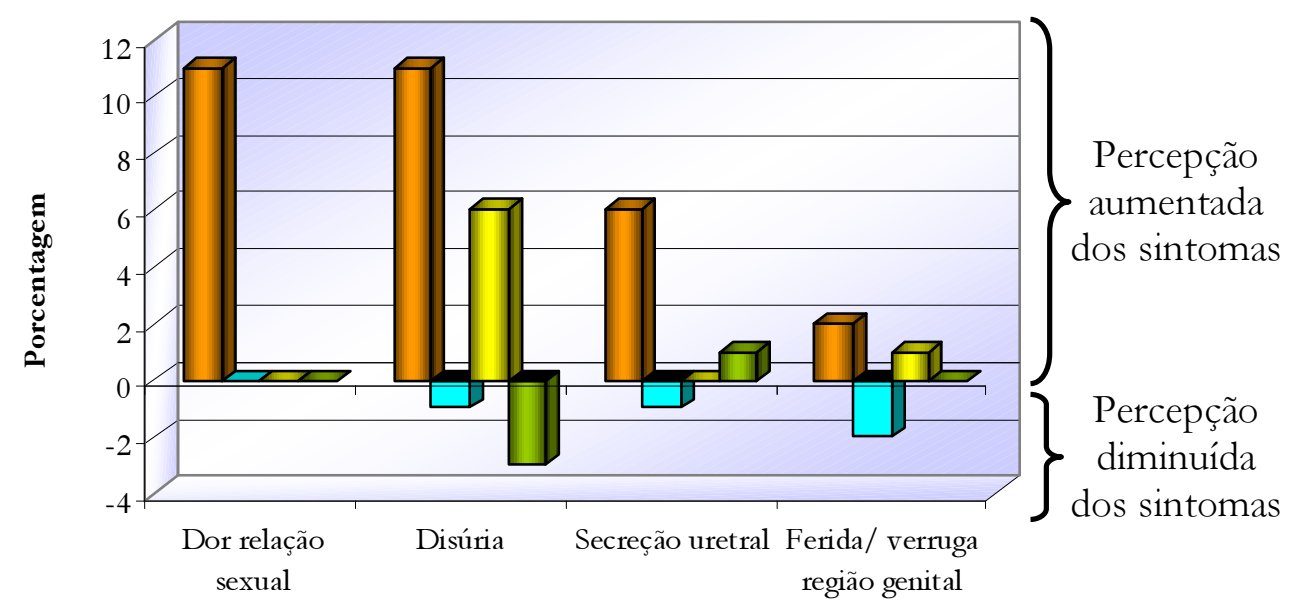

$\square$ Moradores $\square$ Exclusão $\square$ Trabalhadores $\square$ Vigilância

A análise estatística dos sintomas gênito-urinário obtidos tanto pelo instrumento questionário (demanda auto-referida) como pelo instrumento ficha de leitura dos prontuários - ficha 2 (demanda diagnosticada), não mostrou significância (Teste Exato de Fisher, p > 0,05). 
III.4.2. Saúde geral: demanda diagnosticada

Investigamos também, a partir do instrumento ficha de leitura dos prontuários - ficha 2, a demanda diagnosticada dos homens entrevistados para todos os sistemas fisiológicos: sintomas gerais, sistema osteomuscular (SOM), sistema digestivo (SD), sistema cardiovascular (SCV), sistema respiratório (SR), sistema nervoso (SN), sistema metabólico (SM) e queixas relativas aos anexos olhos, ouvidos e pele, além de queixas de ordem social e psicológica.

A fim de conhecer o perfil de demandas diagnosticadas dos homens entrevistados optamos por considerar como demanda mais frequiente aquela que apareceu pelo menos uma vez no prontuário do usuário, ao longo do último ano. Assim, em relação às queixas registradas em prontuários, as queixas/ diagnósticos que apareceram, pelo menos uma vez ao longo do último ano, segundo a porta de entrada dos homens entrevistados foram (Tabela 11, Figura 13):

1. Moradores: sintomas gerais $(42,5 \%)$, seguido por queixas do sistema digestivo $(36,2 \%)$ e do sistema osteomuscular $(32,8 \%)$.

2. Exclusão: sintomas gerais $(53,4 \%)$, seguido por queixas do sistema respiratório $(53,3 \%)$ e por problemas sociais $(40 \%)$.

3. Trabalhadores: sistema digestivo $(47,3 \%)$, seguido por sintomas gerais $(44 \%)$ e por queixas do sistema respiratório $(41,7 \%)$.

4. Vigilância epidemiológica: sistema gênito-urinário (75\%), seguido por queixas psicológicas $(50 \%)$, por queixas do sistema osteomuscular $(41,7 \%)$ e por sintomas gerais $(41,6 \%)$. 
Figura 13: Demanda diagnosticada* entre os homens entrevistados - CSEBF-AV, no último ano de uso do serviço (N=237)

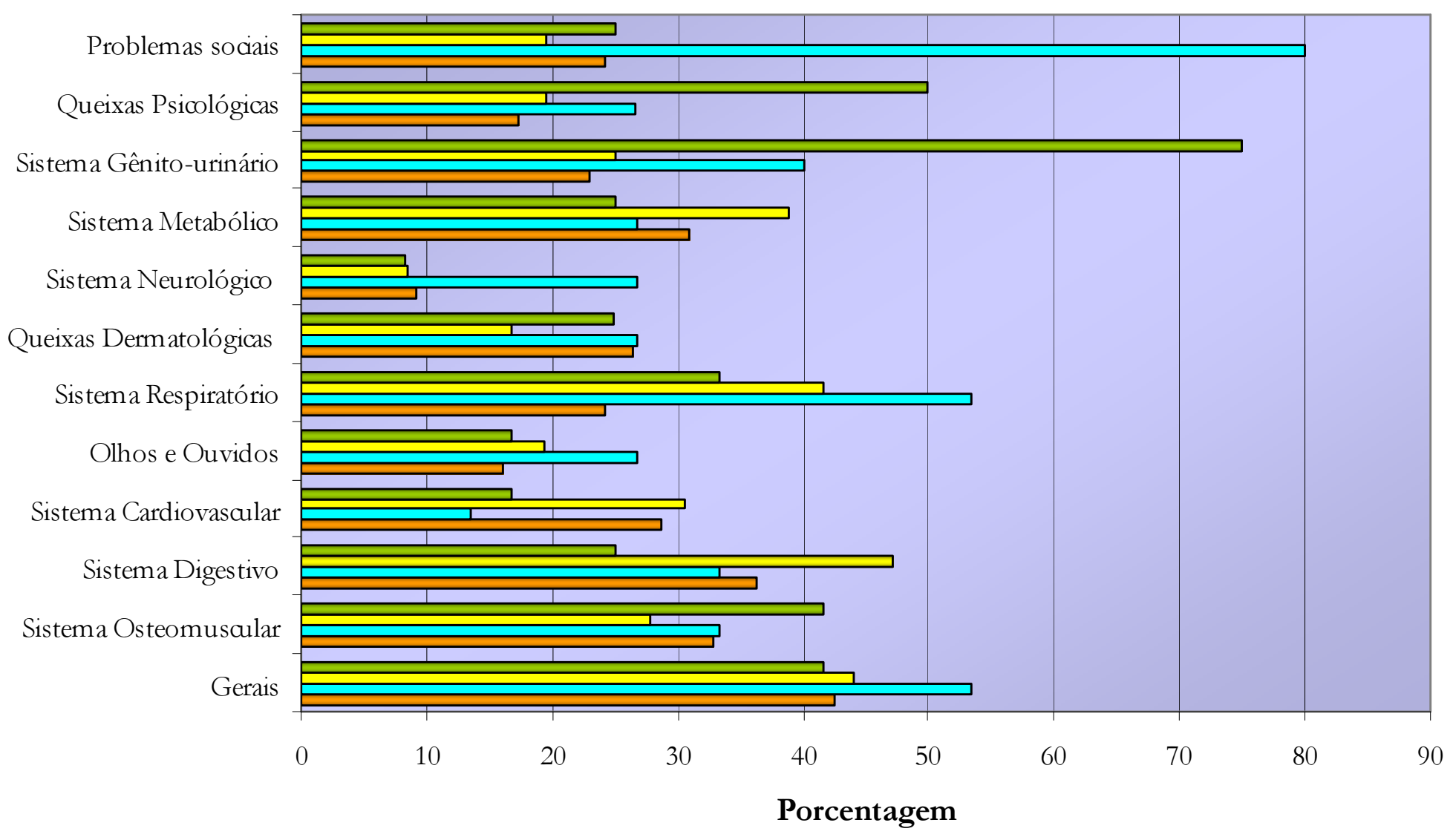

$\square$ Moradores $\quad \square$ Exclusão $\quad \square$ Trabalhadores $\quad \square$ Vigilância

* Pelo menos 1 vez: inclui todos que apresentaram a queixa pelo menos uma vez no último ano 
Além das queixas mais freqüentes observadas, procuramos conhecer quais demandas diagnosticadas mais se repetiram nos prontuários dos usuários, ao longo do último ano. Consideramos para tal aquelas que apareceram registradas três vezes ou mais, no último ano. Assim, as queixas/ diagnósticos que mais apareceram registradas, segundo a porta de entrada dos homens entrevistados foram (Tabela 11):

1. Moradores: queixas dos sistemas cardiovascular e metabólico $(15,6 \%$ e $15,5 \%$, respectivamente).

2. Exclusão: queixas do sistema cardiovascular e queixas relacionadas a olhos e ouvidos (13,4\% cada).

3. Trabalhadores: queixas do sistema cardiovascular $(19,4 \%)$ e queixas do sistema osteomuscular $(13,9 \%)$.

4. Vigilância epidemiológica: queixas gerais (25\%) e queixas do sistema respiratório $(25 \%)$. 
Tabela 11: Demanda diagnosticada entre os homens entrevistados - CSEBF-AV, no último ano de uso do serviço (N=237)

\begin{tabular}{|c|c|c|c|c|c|c|c|c|c|c|c|c|}
\hline \multirow{3}{*}{ Queixas/ diagnósticos } & \multicolumn{12}{|c|}{ Freqüência de registro no prontuário ( $\%$ casos) } \\
\hline & \multicolumn{3}{|c|}{$\begin{array}{c}\text { Moradores } \\
(\mathbf{n}=174)\end{array}$} & \multicolumn{3}{|c|}{$\begin{array}{c}\text { Exclusão } \\
(n=15)\end{array}$} & \multicolumn{3}{|c|}{$\begin{array}{c}\text { Trabalhadores } \\
(\mathrm{n}=36)\end{array}$} & \multicolumn{3}{|c|}{$\begin{array}{c}\text { Vigilância } \\
(\mathrm{n}=12)\end{array}$} \\
\hline & $\begin{array}{l}\text { Só } \\
1 \text { vez }\end{array}$ & $\begin{array}{l}3 \text { vezes } \\
\text { ou mais }{ }^{1}\end{array}$ & $\begin{array}{c}\text { Pelo } \\
\text { menos } \\
1 \text { vez }\end{array}$ & $\begin{array}{c}\text { Só } \\
1 \text { vez }\end{array}$ & $\begin{array}{l}3 \text { vezes } \\
\text { ou mais }\end{array}$ & $\begin{array}{c}\text { Pelo } \\
\text { menos } \\
1 \text { vez }\end{array}$ & $\begin{array}{c}\text { Só } \\
1 \text { vez }\end{array}$ & $\begin{array}{l}3 \text { vezes } \\
\text { ou mais }\end{array}$ & $\begin{array}{c}\text { Pelo } \\
\text { menos } \\
1 \text { vez }\end{array}$ & $\begin{array}{c}\text { Só } \\
1 \text { vez }\end{array}$ & $\begin{array}{l}3 \text { vezes } \\
\text { ou mais }\end{array}$ & $\begin{array}{c}\text { Pelo } \\
\text { menos } \\
1 \text { vez }\end{array}$ \\
\hline Gerais & 28,7 & 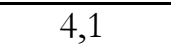 & 42,5 & 40,0 & 6,7 & $\overline{53,4}$ & 13,5 & 13,8 & 44,0 & 8,3 & 25,0 & 41,6 \\
\hline Sistema Osteomuscular & 21,3 & 2,3 & 32,8 & 13,3 & $\ldots$ & 33,3 & 11,1 & 13,9 & 27,8 & 16,7 & 16,7 & 41,7 \\
\hline Sistema Digestivo & 21,8 & 8,1 & 36,2 & 26,7 & $\ldots$ & 33,4 & 30,5 & 8,4 & 47,2 & $\ldots$ & 8,3 & 25,0 \\
\hline Sistema Cardiovascular & 10,3 & 15,6 & 28,7 & $\ldots$ & 13,4 & 13,4 & 8,3 & 19,4 & 30,5 & $\ldots$ & 16,7 & 16,7 \\
\hline Olhos e Ouvidos & 11,5 & 1,7 & 16,0 & 13,3 & 13,4 & 26,7 & 11,1 & $\ldots$ & 19,4 & 16,7 & $\ldots$ & 16,7 \\
\hline Sistema Respiratório & 16,7 & 4,1 & 24,2 & 33,3 & 13,3 & 53,3 & 16,7 & 11,1 & 41,7 & 8,3 & 25,0 & 33,3 \\
\hline Queixas Dermatológicas & 20,1 & 2,3 & 26,4 & 20,0 & 6,7 & 26,7 & 11,1 & 2,8 & 16,7 & 8,3 & 16,6 & 24,9 \\
\hline Sistema Neurológico & 6,9 & 1,2 & 9,2 & 6,7 & 13,3 & 26,7 & 2,8 & 2,8 & 8,4 & $\ldots$ & 8,3 & 8,3 \\
\hline Sistema Metabólico & 8,1 & 15,5 & 31,0 & 13,3 & 6,7 & 26,7 & 13,9 & 11,1 & 38,9 & 16,7 & 8,3 & 25,0 \\
\hline Sistema Gênito-urinário & 15,5 & 2,8 & 22,9 & 20,0 & $\ldots$ & 40,0 & 13,9 & 5,6 & 25,1 & 50,0 & 8,3 & 75,0 \\
\hline Queixas Psicológicas & 10,9 & 2,9 & 17,2 & 13,3 & 6,6 & 26,6 & 13,9 & 2,8 & 19,5 & 33,3 & 16,7 & 50,0 \\
\hline Problemas sociais & 12,1 & 6,4 & 24,2 & 60,0 & 13,3 & 80,0 & 11,1 & 5,6 & 19,5 & 16,7 & 8,3 & 25,0 \\
\hline
\end{tabular}

13 vezes ou mais: queixa que mais se repete; ${ }^{2}$ Pelo menos 1 vez: inclui todos que apresentaram a queixa pelo menos uma vez no último ano 
Frente aos dados obtidos observamos o tipo de queixa mais freqüente (queixas que apareceram registradas pelo menos uma vez nos prontuários) em cada

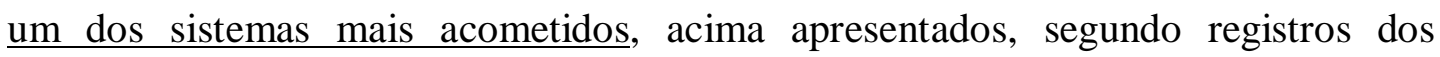
prontuários no último ano. Assim, as queixas/ diagnósticos que apareceram registradas pelo menos uma vez ao longo do último ano, segundo a porta de entrada dos homens entrevistados foram (Tabela 12):

1. Moradores:cefaléia $(16,1 \%)$ e tontura $(13,2 \%)$ entre queixas gerais, dor em membros inferiores $(12,7 \%)$ e dor nas costas/ ombros $(11,5 \%)$ entre queixas do sistema osteomuscular, epigastralgia $(14,9 \%)$ e outras queixas $(12,7 \%)$ entre queixas do sistema digestivo, hipertensão arterial $(21,8 \%)$ entre queixas cardiovasculares, obesidade/ sobrepeso $(16,7 \%)$ e dislipidemias (12\%) entre as queixas metabólicas.

2. Exclusão: inapetência/ perda de peso e fraqueza ( $20 \%$ cada) entre as queixas gerais, tabagismo $(33,3 \%)$ e problemas familiares e com álcool (26,7\% cada) entre os problemas sociais, tosse $(26,7 \%)$ entre as queixas do sistema respiratório, hipertensão arterial $(13,4 \%)$ entre as queixas do sistema cardiovascular, otalgia $(26,7 \%)$ entre as queixas relacionadas a olhos e ouvidos.

3. Trabalhadores: epigastralgia e outras queixas (16,7\% cada) entre as queixas do sistema digestivo, hipertensão arterial $(22,2 \%)$ entra as queixas cardiovasculares, tosse $(27,7 \%)$ entre as queixas do sistema respiratório, cefaléia $(36,2 \%)$ entre as queixas gerais e dor nas costas ou ombros $(19,5 \%)$ entre as queixas do sistema osteomuscular.

4. Vigilância epidemiológica: tontura/ desmaio entre as queixas gerais $(25 \%)$, disúria $(25 \%)$ e outras queixas $(50 \%)$ entre as queixas do sistema gênitourinário, tosse $(25 \%)$ entre as queixas do sistema respiratório, dor em membros inferiores $(41,6 \%)$ entre as queixas do sistema osteomuscular, ansiedade (50\%) entre as queixas psicológicas.

Em relação ao tipo de queixa mais freqüente, em cada um dos sistemas mais acometidos, observamos também as queixas/ diagnósticos que mais se repetiram no prontuário, ou seja, três vezes ou mais, ao longo do último ano, segundo a porta de entrada dos homens entrevistados (Tabela 12): 
1. Moradores:cefaléia $(8,1 \%)$ entre queixas gerais, epigastralgia $(1,7 \%)$ e outras queixas $(1,8 \%)$ entre queixas do sistema digestivo, hipertensão arterial $(13,1 \%)$ entre queixas cardiovasculares, diabetes mellitus $(6,9 \%)$ entre as queixas metabólicas. Em relação ao sistema osteomuscular não houve queixa registrada três vezes ou mais no último ano.

2. Exclusão: fraqueza $(6,7 \%$ cada) entre as queixas gerais, asma $(6,7 \%)$ entre as queixas do sistema respiratório, hipertensão arterial $(13,4 \%)$ entre as queixas do sistema cardiovascular, otalgia $(13,4 \%)$ entre as queixas relacionadas a olhos e ouvidos. Em relação aos problemas sociais não houve queixa registrada três vezes ou mais no último ano.

3. Trabalhadores: dor abdominal, epigastralgia e outras queixas (2,8\% cada) entre as queixas do sistema digestivo, hipertensão arterial $(16,6 \%)$ entre as queixas cardiovasculares, tosse $(2,8 \%)$ entre as queixas do sistema respiratório, cefaléia $(8,4 \%)$ entre as queixas gerais e dor nas costas/ ombros $(8,4 \%)$ entre as queixas do sistema osteomuscular.

4. Vigilância epidemiológica: urgência urinária $(8,3 \%)$ entre as queixas do sistema gênito-urinário, tuberculose $(16,7 \%)$ entre as queixas do sistema respiratório, dor em membros inferiores $(8,3 \%)$ entre as queixas do sistema osteomuscular. Em relação às queixas psicológicas e aos sintomas gerais não houve queixa registrada três vezes ou mais no último ano. 
Tabela 12: Demanda diagnosticada, por sistema mais acometido, entre os homens entrevistados - CSEBF-AV, no último ano de uso do serviço $(\mathrm{N}=237)$

\begin{tabular}{|c|c|c|c|c|c|c|c|c|c|c|c|c|}
\hline \multirow{3}{*}{ Queixas/ diagnósticos } & \multicolumn{12}{|c|}{ Freqüência de registro no prontuário ( $\%$ casos) } \\
\hline & \multicolumn{3}{|c|}{$\begin{array}{c}\text { Moradores } \\
(\mathbf{n}=174)\end{array}$} & \multicolumn{3}{|c|}{$\begin{array}{c}\text { Exclusão } \\
(\mathrm{n}=15)\end{array}$} & \multicolumn{3}{|c|}{$\begin{array}{c}\text { Trabalhadores } \\
(\mathrm{n}=36)\end{array}$} & \multicolumn{3}{|c|}{$\begin{array}{l}\text { Vigilância } \\
\quad(n=12)\end{array}$} \\
\hline & $\begin{array}{c}\text { Só } \\
1 \text { vez }\end{array}$ & $\begin{array}{l}3 \text { vezes } \\
\text { ou mais }{ }^{1}\end{array}$ & $\begin{array}{c}\text { Pelo } \\
\text { menos }^{1} \text { vez }^{2} \\
\end{array}$ & $\begin{array}{c}\text { Só } \\
1 \text { vez }\end{array}$ & $\begin{array}{l}3 \text { vezes } \\
\text { ou mais }\end{array}$ & $\begin{array}{c}\text { Pelo } \\
\text { menos } \\
1 \text { vez } \\
\end{array}$ & $\begin{array}{c}\text { Só } \\
1 \text { vez }\end{array}$ & $\begin{array}{l}3 \text { vezes } \\
\text { ou mais }\end{array}$ & $\begin{array}{c}\text { Pelo } \\
\text { menos } \\
1 \text { vez } \\
\end{array}$ & $\begin{array}{c}\text { Só } \\
1 \text { vez }\end{array}$ & $\begin{array}{l}3 \text { vezes } \\
\text { ou mais }\end{array}$ & $\begin{array}{c}\text { Pelo } \\
\text { menos } \\
1 \text { vez } \\
\end{array}$ \\
\hline Queixas Gerais & 28,7 & 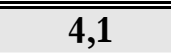 & 42,5 & 40 & 6,7 & 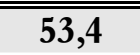 & $1 \overline{13,5}$ & 13,8 & 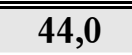 & 8,3 & 25,0 & 41,6 \\
\hline Dor inespecífica & 1,7 & $\ldots$ & 1,7 & $\ldots$ & $\ldots$ & $\ldots$ & $\ldots$ & $\ldots$ & $\ldots$ & $\ldots$ & $\ldots$ & $\ldots$ \\
\hline Calafrios & $\ldots$ & $\ldots$ & $\ldots$ & 6,7 & $\ldots$ & 6,7 & $\ldots$ & $\ldots$ & $\ldots$ & $\ldots$ & $\ldots$ & $\ldots$ \\
\hline Sudorese & 3,5 & $\ldots$ & 3,5 & 6,7 & $\ldots$ & 13,4 & 2,8 & $\ldots$ & 5,6 & 8,3 & 8,3 & 8,3 \\
\hline Febre & 6,9 & 0,6 & 7,5 & 6,7 & & 6,7 & 13,9 & $\ldots$ & 19,5 & 8,3 & $\ldots$ & 8,3 \\
\hline Fraqueza & 6,9 & $\ldots$ & 8,6 & 13,3 & 6,7 & 20,0 & 8,3 & $\ldots$ & 11,1 & 8,3 & $\ldots$ & 8,3 \\
\hline Dor no peito & 6,3 & $\ldots$ & 6,3 & 6,7 & $\ldots$ & 13,4 & 5,6 & $\ldots$ & 8,4 & 8,3 & $\ldots$ & 16,6 \\
\hline Queixas vagas & 2,9 & 0,6 & 4,1 & 6,7 & $\ldots$ & 6,7 & 2,8 & $\ldots$ & 2,8 & 8,3 & $\ldots$ & 8,3 \\
\hline Cefaléia & 12,6 & 8,1 & 16,1 & $\ldots$ & $\ldots$ & $\ldots$ & 16,7 & 8,4 & 36,2 & 8,3 & $\ldots$ & 16,6 \\
\hline Tontura/desmaio & 10,9 & 1,1 & 13,2 & $\ldots$ & $\ldots$ & $\ldots$ & $\ldots$ & $\ldots$ & $\ldots$ & 16,7 & $\ldots$ & 25,0 \\
\hline Edema & 5,2 & $\ldots$ & 5,2 & $\ldots$ & $\ldots$ & $\ldots$ & 2,8 & $\ldots$ & 2,8 & 8,3 & $\ldots$ & 8,3 \\
\hline Inapetência/ perda de peso & 4,0 & 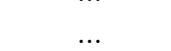 & 5,2 & 13,3 & $\ldots$ & 20,0 & 2,8 & & 2,8 & 16,7 & & 16,7 \\
\hline Sistema Osteomuscular & 21,3 & 2,3 & 32,8 & 13,3 & $\ldots$ & 33,3 & 11,1 & 13,9 & 27,8 & 16,7 & 16,7 & 41,7 \\
\hline Dor nas costas / ombros & 9,8 & $\ldots$ & 11,5 & & & & 8,3 & 8,4 & 19,5 & & $\ldots$ & 8,3 \\
\hline Dor em membros superiores & 5,2 & $\ldots$ & 5,8 & & & & 8,3 & $\ldots$ & 11,1 & 8,3 & $\ldots$ & 16,6 \\
\hline Dor em membros inferiores & 9,8 & $\ldots$ & 12,7 & NR & NR & NR & 8,3 & 2,8 & 13,9 & 33,3 & 8,3 & 41,6 \\
\hline Mialgias & 1,7 & & 2,3 & & & & 2,8 & & 2,8 & 8,3 & $\ldots$ & 16,6 \\
\hline Outras queixas & 5,2 & $\ldots$ & 6,4 & & & & 2,8 & 2,8 & 8,4 & 8,3 & $\ldots$ & 8,3 \\
\hline
\end{tabular}


Tabela 12: Demanda diagnosticada, por sistema mais acometido, entre os homens entrevistados - CSEBF-AV, no último ano de uso do serviço $(\mathrm{N}=237)$

\begin{tabular}{|c|c|c|c|c|c|c|c|c|c|c|c|c|}
\hline \multirow{3}{*}{ Queixas/ diagnósticos } & \multicolumn{12}{|c|}{ Freqüência de registro no prontuário (\% casos) } \\
\hline & \multicolumn{3}{|c|}{$\begin{array}{c}\text { Moradores } \\
\quad(\mathbf{n}=174)\end{array}$} & \multicolumn{3}{|c|}{$\begin{array}{c}\text { Exclusão } \\
(\mathbf{n}=15)\end{array}$} & \multicolumn{3}{|c|}{$\begin{array}{l}\text { Trabalhadores } \\
\quad(\mathbf{n}=36)\end{array}$} & \multicolumn{3}{|c|}{$\begin{array}{l}\text { Vigilância } \\
\quad(n=12)\end{array}$} \\
\hline & $\begin{array}{l}\text { Só } \\
1 \text { vez }\end{array}$ & $\begin{array}{l}3 \text { vezes } \\
\text { ou mais }{ }^{1}\end{array}$ & $\begin{array}{c}\text { Pelo } \\
\text { menos } \\
1 \text { vez }^{2}\end{array}$ & $\begin{array}{c}\text { Só } \\
1 \text { vez }\end{array}$ & $\begin{array}{l}3 \text { vezes } \\
\text { ou mais }\end{array}$ & $\begin{array}{c}\text { Pelo } \\
\text { menos } \\
1 \text { vez }\end{array}$ & $\begin{array}{l}\text { Só } \\
1 \text { vez }\end{array}$ & $\begin{array}{l}3 \text { vezes } \\
\text { ou mais }\end{array}$ & $\begin{array}{c}\text { Pelo } \\
\text { menos } \\
1 \text { vez }\end{array}$ & $\begin{array}{c}\text { Só } \\
1 \text { vez }\end{array}$ & $\begin{array}{l}3 \text { vezes } \\
\text { ou mais }\end{array}$ & $\begin{array}{c}\text { Pelo } \\
\text { menos } \\
1 \text { vez }\end{array}$ \\
\hline Sistema Digestivo & 21,8 & 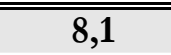 & 36,2 & 26,7 & ב... & 33,4 & 30,5 & 8,4 & 47,2 & ב... & 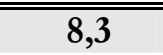 & 25,0 \\
\hline Dor abdominal & 7,5 & $\ldots$ & 8,1 & & & & 5,6 & 2,8 & 8,4 & & & \\
\hline Epigastralgia & 10,9 & 1,7 & 14,9 & & & & 11,1 & 2,8 & 16,7 & & & \\
\hline Dispepsia & 6,3 & $\ldots$ & 8,6 & & & & 2,8 & $\ldots$ & 2,8 & & & \\
\hline Náusea & 4,6 & 0,6 & 5,2 & & & & 5,6 & $\ldots$ & 8,4 & & & \\
\hline Vômito & 1,7 & $\ldots$ & 1,7 & & & & 2,8 & $\ldots$ & 2,8 & & & \\
\hline Diarréia & 2,3 & 0,6 & 2,9 & & & & 5,6 & $\ldots$ & 5,6 & & & \\
\hline Obstipação intestinal & 1,7 & 0,6 & 2,9 & NR & NR & NR & 5,6 & $\ldots$ & 5,6 & NR & NR & NR \\
\hline Sangramento retal & 1,2 & $\ldots$ & 1,8 & & & & 2,8 & $\ldots$ & 2,8 & & & \\
\hline Disfagia & 0,6 & $\ldots$ & 0,6 & & & & $\ldots$ & $\ldots$ & $\ldots$ & & & \\
\hline Massas abdominais & 0,6 & $\ldots$ & 0,6 & & & & $\ldots$ & $\ldots$ & $\ldots$ & & & \\
\hline Verminose & 1,2 & $\ldots$ & 1,8 & & & & $\ldots$ & $\ldots$ & 2,8 & & & \\
\hline Distensão abdominal & $\ldots$ & $\ldots$ & $\ldots$ & & & & $\ldots$ & $\ldots$ & $\ldots$ & & & \\
\hline Outras queixas & 9,2 & 1,8 & 12,7 & & & & 11,1 & 2,8 & 16,7 & & & \\
\hline Sistema Cardiovascular & 10,3 & 15,6 & 28,7 & $\ldots$ & 13,4 & 13,4 & 8,3 & 19,4 & 30,5 & $\ldots$ & 16,7 & 16,7 \\
\hline Precordialgia & 2,9 & $\ldots$ & 4,1 & $\ldots$ & $\ldots$ & $\ldots$ & $\ldots$ & $\ldots$ & $\ldots$ & & & \\
\hline Hipertensão arterial & 7,5 & 13,1 & 21,8 & $\ldots$ & 13,4 & 13,4 & 2,8 & 16,6 & 22,2 & & & \\
\hline Varizes & 0,6 & 0,6 & 1,8 & & $\ldots$ & $\ldots$ & $\ldots$ & 2,8 & 5,6 & $\mathrm{NR}$ & $\mathrm{NR}$ & $\mathrm{NR}$ \\
\hline Outras queixas & 3,5 & 1,7 & 6,4 & $\ldots$ & $\ldots$ & $\ldots$ & 8,3 & $\ldots$ & 11,1 & & & \\
\hline
\end{tabular}


Tabela 12: Demanda diagnosticada, por sistema mais acometido, entre os homens entrevistados - CSEBF-AV, no último ano de uso do serviço $(\mathrm{N}=237)$

\begin{tabular}{|c|c|c|c|c|c|c|c|c|c|c|c|c|}
\hline \multirow{3}{*}{ Queixas/ diagnósticos } & \multicolumn{12}{|c|}{ Freqüência de registro no prontuário (\% casos) } \\
\hline & \multicolumn{3}{|c|}{$\begin{array}{c}\text { Moradores } \\
(\mathrm{n}=174)\end{array}$} & \multicolumn{3}{|c|}{$\begin{array}{c}\text { Exclusão } \\
(\mathbf{n}=15)\end{array}$} & \multicolumn{3}{|c|}{$\begin{array}{c}\text { Trabalhadores } \\
(\mathbf{n}=36)\end{array}$} & \multicolumn{3}{|c|}{$\begin{array}{l}\text { Vigilância } \\
(\mathbf{n}=12)\end{array}$} \\
\hline & $\begin{array}{l}\text { Só } \\
1 \text { vez }\end{array}$ & $\begin{array}{l}3 \text { vezes } \\
\text { ou mais }{ }^{1}\end{array}$ & $\begin{array}{c}\text { Pelo } \\
\text { menos }^{2} \\
1 \text { vez }^{2}\end{array}$ & $\begin{array}{c}\text { Só } \\
1 \text { vez }\end{array}$ & $\begin{array}{l}3 \text { vezes } \\
\text { ou mais }\end{array}$ & $\begin{array}{c}\text { Pelo } \\
\text { menos } \\
1 \text { vez }\end{array}$ & $\begin{array}{l}\text { Só } \\
1 \text { vez }\end{array}$ & $\begin{array}{l}3 \text { vezes } \\
\text { ou mais }\end{array}$ & $\begin{array}{c}\text { Pelo } \\
\text { menos } \\
1 \text { vez }\end{array}$ & $\begin{array}{c}\text { Só } \\
1 \text { vez }\end{array}$ & $\begin{array}{l}3 \text { vezes } \\
\text { ou mais }\end{array}$ & $\begin{array}{c}\text { Pelo } \\
\text { menos } \\
1 \text { vez }\end{array}$ \\
\hline Sistema Metabólico & 8,1 & 15,5 & 31,0 & 13,3 & 6,7 & 26,7 & 13,9 & 11,1 & 38,9 & 18,7 & 8,3 & 25,0 \\
\hline Obesidade/ sobrepeso & 8,6 & 4,1 & 16,7 & & & & & & & & & \\
\hline $\begin{array}{l}\text { Dislipidemias } \\
\text { Diabetes mellitus }\end{array}$ & $\begin{array}{l}4,6 \\
1,7\end{array}$ & $\begin{array}{l}2,8 \\
\mathbf{6 , 9}\end{array}$ & $\begin{array}{c}12,0 \\
8,6\end{array}$ & NR & NR & NR & NR & NR & NR & NR & NR & NR \\
\hline Outros distúrbios metabólicos & 5,2 & 2,2 & 8,6 & & & & & & & & & \\
\hline Sistema Respiratório & 16,7 & 4,1 & 24,2 & 33,3 & 13,3 & 53,3 & 16,7 & 11,1 & 41,7 & 8,3 & 25,0 & 33,3 \\
\hline Dispnéia & \multirow{8}{*}{ NR } & \multirow{8}{*}{ NR } & \multirow{8}{*}{ NR } & 13,3 & $\ldots$ & 13,3 & 8,3 & $\ldots$ & 16,6 & 16,7 & 16,7 & $\ldots$ \\
\hline Tosse & & & & 20,0 & $\ldots$ & 26,7 & 19,4 & & 27,7 & 8,3 & 25,0 & 8,4 \\
\hline Gripe/ sinusite & & & & 20,0 & $\ldots$ & 20,0 & 2,8 & 2,8 & 8,4 & $\ldots$ & $\ldots$ & $\ldots$ \\
\hline Dor de garganta & & & & 13,3 & & 13,3 & 2,8 & $\ldots$ & 5,6 & $\ldots$ & $\ldots$ & $\ldots$ \\
\hline Asma/ bronquite & & & & 6,7 & 6,7 & 20,1 & 2,8 & $\ldots$ & 8,4 & $\ldots$ & $\ldots$ & $\ldots$ \\
\hline Pneumonia & & & & $\ldots$ & $\ldots$ & 6,7 & 8,3 & $\ldots$ & 8,3 & $\ldots$ & $\ldots$ & $\ldots$ \\
\hline Tuberculose & & & & $\ldots$ & $\ldots$ & $\ldots$ & 2,8 & $\ldots$ & 2,8 & $\ldots$ & 16,7 & 16,7 \\
\hline Outras queixas & & & & 6,7 & & 13,4 & 5,6 & & 5,6 & 8,3 & 16,6 & $\ldots$ \\
\hline Queixas psicológicas & 10,9 & 2,9 & 17,2 & 13,3 & 6,6 & 26,6 & 13,9 & 2,8 & 19,5 & 33,3 & 16,7 & 50,0 \\
\hline Depressão & \multirow{6}{*}{ NR } & \multirow{6}{*}{ NR } & \multirow{6}{*}{ NR } & \multirow{6}{*}{ NR } & \multirow{6}{*}{ NR } & \multirow{6}{*}{ NR } & \multirow{6}{*}{ NR } & \multirow{6}{*}{ NR } & \multirow{6}{*}{ NR } & $\ldots$ & $\ldots$ & $\ldots$ \\
\hline Raiva & & & & & & & & & & & $\ldots$ & $\ldots$ \\
\hline Ansiedade & & & & & & & & & & 41,7 & $\ldots$ & 50,0 \\
\hline Insônia & & & & & & & & & & $\ldots$ & $\ldots$ & $\ldots$ \\
\hline Tentativa de suicídio & & & & & & & & & & $\ldots$ & $\ldots$ & $\ldots$ \\
\hline Problemas de memória & & & & & & & & & & 8,3 & $\ldots$ & 8,3 \\
\hline
\end{tabular}


Tabela 12: Demanda diagnosticada, por sistema mais acometido, entre os homens entrevistados - CSEBF-AV, no último ano de uso do serviço $(\mathrm{N}=237)$

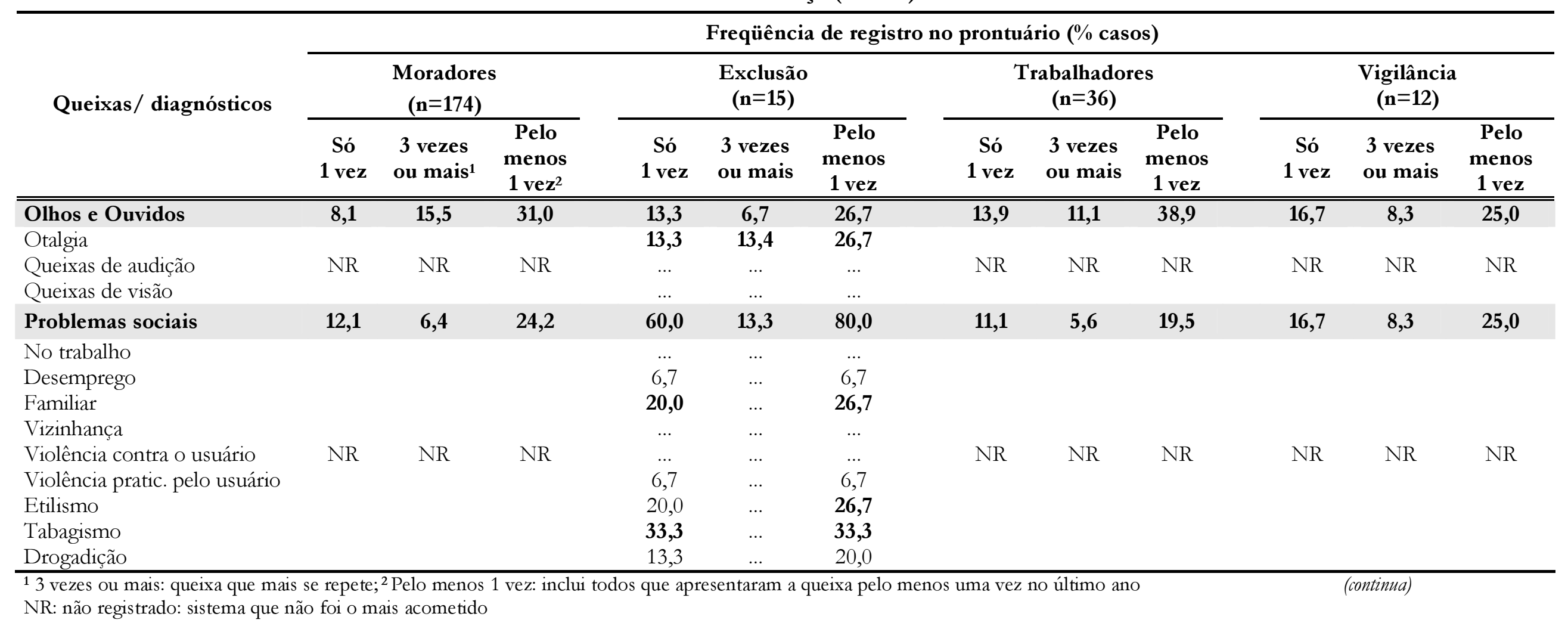


Tabela 12: Demanda diagnosticada, por sistema mais acometido, entre os homens entrevistados - CSEBF-AV, no último ano de uso do serviço $(\mathrm{N}=237)$

\begin{tabular}{|c|c|c|c|c|c|c|c|c|c|c|c|c|}
\hline \multirow{3}{*}{ Queixas/ diagnósticos } & \multicolumn{12}{|c|}{ Freqüência de registro no prontuário (\% casos) } \\
\hline & \multicolumn{3}{|c|}{$\begin{array}{c}\text { Moradores } \\
(\mathrm{n}=174)\end{array}$} & \multicolumn{3}{|c|}{$\begin{array}{c}\text { Exclusão } \\
(\mathrm{n}=15)\end{array}$} & \multicolumn{3}{|c|}{$\begin{array}{c}\text { Trabalhadores } \\
(\mathbf{n}=36)\end{array}$} & \multicolumn{3}{|c|}{$\begin{array}{c}\text { Vigilância } \\
(\mathbf{n}=12)\end{array}$} \\
\hline & $\begin{array}{l}\text { Só } \\
1 \text { vez }\end{array}$ & $\begin{array}{l}3 \text { vezes } \\
\text { ou mais }{ }^{1}\end{array}$ & $\begin{array}{c}\text { Pelo } \\
\text { menos } \\
1 \text { vez }^{2}\end{array}$ & $\begin{array}{c}\text { Só } \\
1 \text { vez }\end{array}$ & $\begin{array}{l}3 \text { vezes } \\
\text { ou mais }\end{array}$ & $\begin{array}{c}\text { Pelo } \\
\text { menos } \\
1 \mathrm{vez}\end{array}$ & $\begin{array}{l}\text { Só } \\
1 \text { vez }\end{array}$ & $\begin{array}{l}3 \text { vezes } \\
\text { ou mais }\end{array}$ & $\begin{array}{c}\text { Pelo } \\
\text { menos } \\
1 \text { vez }\end{array}$ & $\begin{array}{c}\text { Só } \\
1 \text { vez }\end{array}$ & $\begin{array}{l}3 \text { vezes } \\
\text { ou mais }\end{array}$ & $\begin{array}{c}\text { Pelo } \\
\text { menos } \\
1 \text { vez }\end{array}$ \\
\hline Sistema gênito-urinário & 10 & 2,9 & 17,2 & 13,3 & 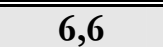 & 26,6 & 1813,9 & 2,8 & 19,5 & 33,3 & 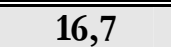 & $\begin{array}{l}50,0 \\
\end{array}$ \\
\hline Disúria & & & & & & & & & & 25,0 & $\ldots$ & 25,0 \\
\hline Urgência urinária & & & & & & & & & & 8,3 & 8,3 & 16,6 \\
\hline Incontinência urinária & & & & & & & & & & $\ldots$ & $\ldots$ & $\ldots$ \\
\hline Uretrite & & & & & & & & & & 8,3 & $\ldots$ & 8,3 \\
\hline Impotência & NR & NR & NR & NR & NR & NR & NR & NR & NR & $\ldots$ & $\cdots$ & $\ldots$ \\
\hline Ejaculação precoce & & & & & & & & & & $\ldots$ & $\ldots$ & $\ldots$ \\
\hline Ferida/lesão/prurido no pênis & & & & & & & & & & 16,7 & $\ldots$ & 16,7 \\
\hline Dor na relação sexual & & & & & & & & & & 8,3 & $\ldots$ & \\
\hline Outras queixas & & & & & & & & & & 33,3 & $\ldots$ & 50,0 \\
\hline
\end{tabular}

13 vezes ou mais: queixa que mais se repete; ${ }^{2}$ Pelo menos 1 vez: inclui todos que apresentaram a queixa pelo menos uma vez no último ano

NR: não registrado: sistema que não foi o mais acometido 
A fim de explorar os sintomas registrados nos prontuários dos homens entrevistados por tipo de entrada no serviço realizamos algumas análises estatísticas.

Em relação aos sintomas gerais e aos sistemas osteomuscular, cardiovascular, metabólico e digestivo e em relação aos anexos olhos, ouvidos e pele, comparando o grupo dos homens em situação de exclusão com os outros três grupos de homens, não observamos significância estatística quanto aos dados encontrados (Teste do quiquadrado, $\mathrm{p}>0,05)$.

Ao analisarmos as queixas referentes ao sistema respiratório, comparando o grupo dos homens em situação de exclusão com os outros três grupos e o grupo excluídos com o grupo não-excluídos, observamos que o predomínio desse tipo de queixa entre os homens em situação de exclusão foi estatisticamente significante nos dois tipos de análise ( $\mathrm{p}<0,05,3 \mathrm{gl} ; \mathrm{p}<0,05$, respectivamente) (Tabelas 13 e 14). Como a população em situação de exclusão está mais exposta ao risco de contrair tuberculose (CARBone, 2000 ) e a região central do Município de São Paulo, onde está inserido o CSEBF-AV, é a que apresenta maior incidência da doença no município (123,5 casos por 100 mil habitantes, 2003, região da Santa Cecília/ Sé) (SMS-CCD), investigamos se foi significativa a presença mais freqüente de sintomas considerados sugestivos da tuberculose (sudorese/ calafrio, fraqueza, perda de peso/ inapetência, tosse) entre os homens entrevistados em situação de exclusão. Observamos que o predomínio de sudorese/ calafrio e perda de peso/ inapetência no grupo excluídos em relação ao grupo não-excluídos foi estatisticamente significante (Teste exato de Fisher, $p=0,028$; Teste exato de Fisher, $p=0,045$, respectivamente).

Em relação ao sistema nervoso, observamos que houve indício de que o predomínio de sintomas no grupo excluídos, quando consideramos dois grupos de análise, excluídos e não-excluídos, poderia ser estatisticamente significativo (Teste exato de Fisher, $\mathrm{p}=0,053$ ) (Tabela 14).

Ao analisarmos as queixas relacionadas a questões sociais, comparando o grupo dos homens em situação de exclusão com os outros três grupos e o grupo excluídos com o grupo não-excluídos, observamos que o predomínio desse tipo de queixa entre os homens em situação de exclusão foi estatisticamente significante nos dois tipos de análise ( $\mathrm{p}<0,001,3 \mathrm{gl} ; \mathrm{p}<0,001$, respectivamente) (Tabelas 13 e 14). 
Em relação ao sistema gênito-urinário observamos que o predomínio de queixas relacionadas a esse sistema ocorreu no grupo de homens seguidos pela vigilância epidemiológica de forma estatisticamente significativa $(\mathrm{p}<0,001,3 \mathrm{gl})$ (Tabela 13). Da mesma forma, o grupo de homens seguidos pela vigilância epidemiológica apresentou predomínio de queixas de ordem psicológica de forma estatisticamente significativa ( $<<0,05,3 \mathrm{gl})$ (Tabela 13).

Tabela 13: Demanda diagnosticada - homens entrevistados - CSEBF-AV: análise estatística segundo o tipo de matrícula $(\mathrm{N}=237)$

\begin{tabular}{|c|c|c|c|c|c|c|c|c|c|}
\hline \multirow{3}{*}{ Queixas } & \multicolumn{8}{|c|}{ Tipo de Matrícula } & \multirow{3}{*}{$\begin{array}{c}\text { Teste } \\
\text { estatístico } \\
\text { Qui-quadrado } \\
x^{2}\end{array}$} \\
\hline & \multicolumn{2}{|c|}{$\begin{array}{l}\text { Moradores } \\
(\mathbf{n}=174)\end{array}$} & \multicolumn{2}{|c|}{$\begin{array}{c}\text { Exclusão } \\
(n=15)\end{array}$} & \multicolumn{2}{|c|}{$\begin{array}{c}\text { Trabalhadores } \\
\quad(n=36)\end{array}$} & \multicolumn{2}{|c|}{$\begin{array}{l}\text { Vigilância } \\
\qquad(\mathrm{n}=12)\end{array}$} & \\
\hline & $\mathbf{n}$ & $\%$ & $\mathbf{n}$ & $\%$ & $\mathbf{n}$ & $\%$ & $\mathbf{n}$ & $\%$ & \\
\hline Respiratórias & 42 & 24,1 & 8 & 53,3 & 15 & 41,7 & 4 & 33,3 & $\begin{array}{l}\boldsymbol{x}^{2}=9,20 \\
p=0,026\end{array}$ \\
\hline $\begin{array}{l}\text { Gênito- } \\
\text { urinárias }\end{array}$ & 40 & 23,0 & 6 & 40,0 & 9 & 25,0 & 9 & 75,0 & $\begin{aligned} x^{2} & =16,81 \\
p & <0,001\end{aligned}$ \\
\hline Sociais & 42 & 24,1 & 12 & 80,0 & 7 & 19,4 & 3 & 25,0 & $\begin{array}{l}\mathbf{x}^{2}=23,12 \\
\boldsymbol{p}<0,001\end{array}$ \\
\hline Psicológicas & 30 & 17,2 & 4 & 26,7 & 7 & 19,4 & 6 & 50,0 & $\begin{array}{l}\boldsymbol{x}^{2}=8,05 \\
p=\mathbf{0 , 0 4 5}\end{array}$ \\
\hline
\end{tabular}

Tabela 14: Demanda diagnosticada - homens entrevistados - CSEBF-AV: análise estatística segundo o tipo de matrícula: excluídos e não-excluídos $(\mathrm{N}=210)$

\begin{tabular}{|c|c|c|c|c|c|}
\hline \multirow{3}{*}{ Queixas } & \multicolumn{4}{|c|}{ Tipo de Matrícula } & \multirow{3}{*}{ Teste estatístico } \\
\hline & \multicolumn{2}{|c|}{ Exclusão (n=15) } & \multicolumn{2}{|c|}{ Não-exclusão $(n=210)$} & \\
\hline & $\mathbf{n}$ & $\%$ & $\mathbf{n}$ & $\%$ & \\
\hline Respiratórias & 8 & 53,3 & 57 & 27,1 & $\begin{array}{c}\text { Fisher } \\
p=0,040\end{array}$ \\
\hline Neurológicas & 4 & 26,7 & 19 & 9,0 & $\begin{array}{c}\text { Fisher } \\
\boldsymbol{p}=\mathbf{0 , 0 5 3}\end{array}$ \\
\hline Sociais & 12 & 80,0 & 49 & 23,3 & $\begin{array}{l}\mathbf{x}^{2}=19,97 \\
\boldsymbol{p}<\mathbf{0 , 0 0 1 *}\end{array}$ \\
\hline
\end{tabular}

*com correção de Yates 
III.4.3. Hábitos e práticas relacionados à saúde em geral: demanda auto-referida e demanda diagnosticada

\section{III.4.3.a. Demanda auto-referida}

Em relação ao hábito de fumar e ao uso de drogas ilícitas observamos que os homens, predominantemente, não faziam uso dessas substâncias na ocasião da entrevista $(70,5 \%$ e $98,3 \%$, respectivamente, $\mathrm{N}=237)$. Por outro lado, em relação ao uso de bebida alcoólica, observamos que a maioria dos homens fazia algum tipo de uso (diário, ocasional) $(62,4 \%, \mathrm{~N}=237)$. Observando os homens segundo a porta de entrada no serviço identificamos que a maioria dos homens em situação de exclusão $(\mathrm{n}=15)$ fazia algum tipo de uso do cigarro comum $(53,4 \%)$, em relação à bebida alcoólica a maioria negou seu uso $(60 \%)$ e dois deles $(13,3 \%)$ referiram uso de drogas ilícitas diariamente. Em relação aos moradores da área de abrangência ( $n=174)$, identificamos que 64,9\% faziam algum tipo de uso de bebida alcoólica, dos quais $40 \%$ ( $n=113)$ faziam uso de 1 a 2 vezes por semana; quanto aos trabalhadores da área $(n=36)$ e aos homens seguidos pela VE $(n=12)$, observamos a mesma situação, sendo que $61,1 \%$ e $66,7 \%$, respectivamente, faziam algum tipo de uso de bebida alcoólica, dos quais $36,4 \%$ para os dois grupos de homens (trabalhadores $\mathrm{n}=22$, vigilância $\mathrm{n}=8$ ), faziam uso de 1 a 2 vezes por semana de bebida alcoólica (Tabela 15). A maioria dos homens moradores, dos trabalhadores e dos homens em seguimento pela VE negou o hábito de fumar. Entre trabalhadores e homens seguidos pela VE, $100 \%$ negaram o uso de drogas ilícitas, enquanto que entre os moradores apenas dois referiram algum tipo de uso de drogas ilícitas (Tabela 15).

Ao analisarmos os hábitos dos homens entrevistados, relacionados ao tabagismo, comparando o grupo dos homens em situação de exclusão com os outros três grupos, observamos que o predomínio desse hábito entre os excluídos foi estatisticamente significativo $\left(\boldsymbol{x}^{2}=14,70, \mathrm{p}=0,002,3 \mathrm{gl}\right)$. Quando analisamos segundo os grupos excluídos e não-excluídos observamos que não houve significância estatística para predomínio de tabagistas no grupo excluídos ( $\mathrm{p}>0,05)$.

Em relação ao uso de álcool também não houve significância estatística pra o predomínio de usuários de álcool entre moradores, trabalhadores e homens seguidos 
pela vigilância ( $\mathrm{p}>0,05,3 \mathrm{gl})$. Ao analisarmos o uso de álcool segundo dois grupos, excluídos e não-excluídos, observamos que houve significância estatística para o predomínio de usuários de álcool entre os não-excluídos $\left(\boldsymbol{x}^{2}=6,31, \mathrm{p}=0,011\right)$. Quanto ao uso de drogas ilícitas observamos significância estatística para o predomínio do uso de drogas no grupo excluídos em relação ao grupo não-excluídos (Teste exato de Fisher, $\mathrm{p}=0,023$ ).

Sob o aspecto da prática atual de atividade física observamos que os quatro grupos de homens predominantemente praticavam atividade física diariamente ou de 1 a 2 vezes por semana, porém o grupo de trabalhadores se destacou, pois foram os que mais apareceram no grupo daqueles que nunca praticavam atividade física $(44,4 \%)$ (Tabela 15).

Em relação à prática de atividade física não observamos significância estatística em relação aos dados encontrados quando consideramos o critério "prática" ou "não prática" de atividade física. Ao analisarmos essa variável com um novo critério, "prática de atividade física até duas vezes por semana" ou "prática de atividade física menos que duas vezes por semana/ não prática de atividade”, também observamos que não houve significância estatística $(\mathrm{p}>0,05)$, ao analisarmos os quatro grupos de homens ou ao considerarmos os grupos excluídos e não-excluídos. 
Tabela 15: Cuidado com a saúde entre os homens entrevistados - CSEBF-AV ( $N=237)$

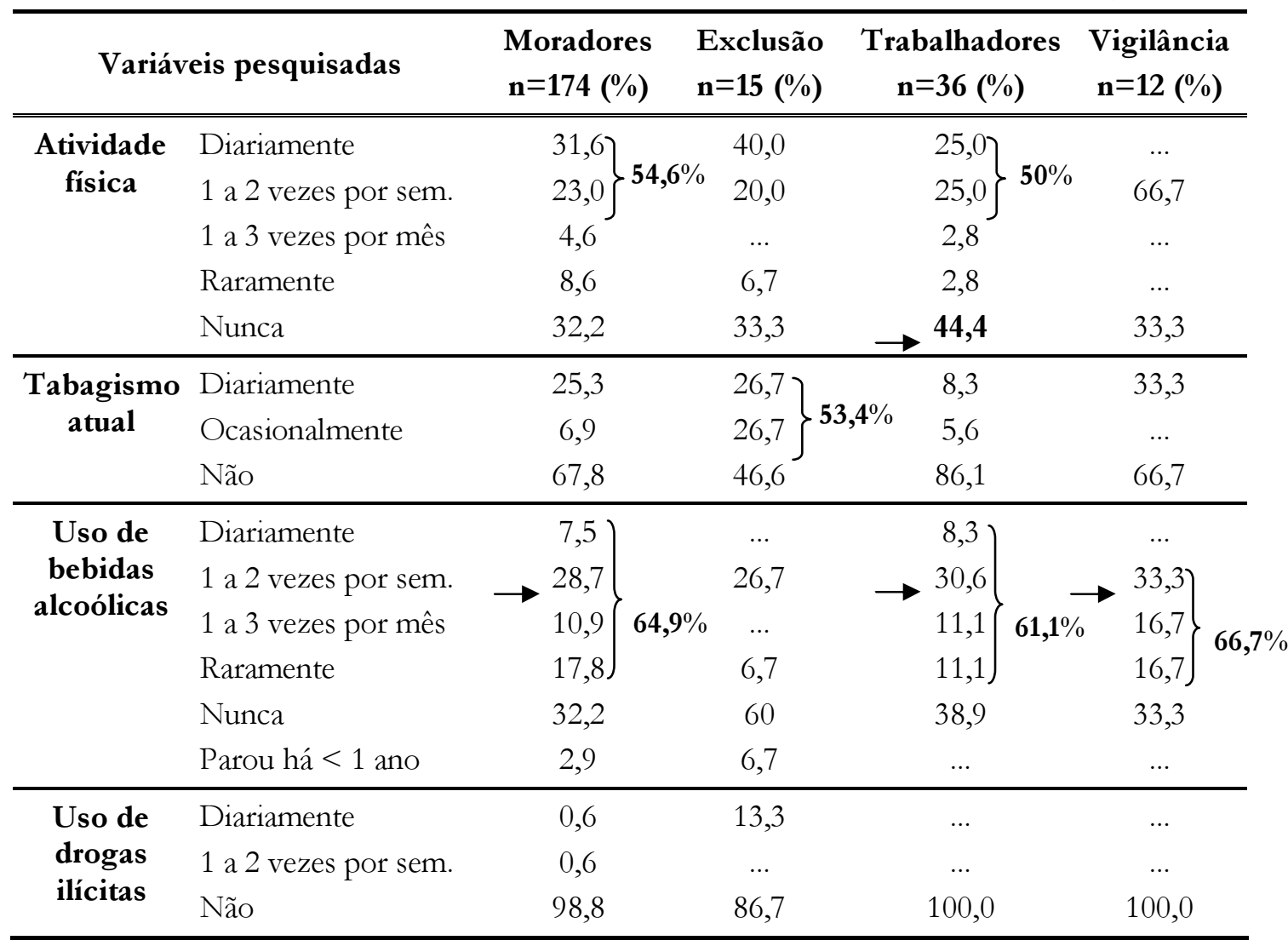

III.4.3.b. Demanda diagnosticada

A partir do instrumento ficha de leitura de prontuários - ficha 2 observamos o registro, pelo menos uma vez no último ano, dos aspectos relacionados ao uso de álcool, tabagismo e drogas ilícitas e identificamos que os homens em situação de exclusão usavam, predominantemente em relação aos outros três grupos de homens, os três tipos de substâncias (Figura 14). Em relação à prática de atividade física, apesar desse item constar dos prontuários do CSEBF-AV, infelizmente é um dado pouco preenchido pelos profissionais e, além disso, o instrumento ficha de leitura dos prontuários não investigou essa questão. 
Figura 14: Uso de álcool, tabagismo e drogadição entre os homens entrevistados CSEBF-AV, segundo o tipo de matrícula - demanda diagnosticada $(\mathrm{N}=237)$

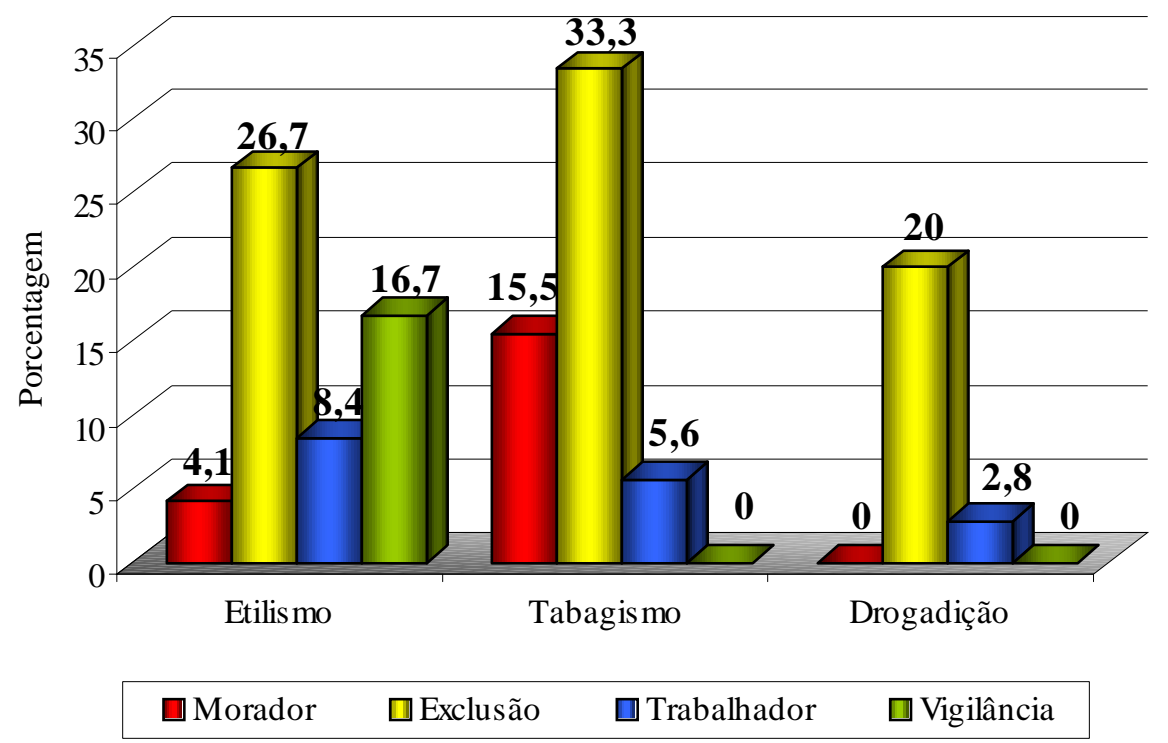

Realizamos a análise estatística dos resultados obtidos em relação à demanda diagnosticada sobre uso de álcool, tabagismo e drogas ilícitas. Observamos significância estatística para o predomínio de tabagismo entre os homens entrevistados em situação de exclusão ao considerarmos quatro e dois grupos de análise $\left(\boldsymbol{x}^{2}=19,26, \mathrm{p}<0,001,3 \mathrm{gl}\right.$; Teste exato de Fisher, $\mathrm{p}=0,008$, respectivamente). Não houve significância estatística para o predomínio do uso de álcool entre os homens entrevistados em situação de exclusão ( $p>0,05$ ), mas observamos uma tendência de significância quando utilizamos o teste exato de Fisher ( $\mathrm{p}=0,056)$ para dois grupos de análise (excluídos e não-excluídos). Em relação ao uso de drogas houve significância estatística para o maior uso desse tipo de substancia entre o grupo excluídos (Teste exato de Fisher, $\mathrm{p}<0,001$ ).

Ao observarmos a demanda auto-referida em comparação à demanda diagnosticada em relação ao uso de álcool, drogas ilícitas e ao tabagismo observamos importante discordância entre os dois tipos de demanda, principalmente referente ao tabagismo e ao uso de álcool, que aparecem mais na demanda auto-referida, para os quatro grupos de homens (com exceção dos homens em situação de exclusão em relação ao uso de álcool)(Figura 15). 
Figura 15: Cuidado com a saúde entre os homens entrevistados, usuários do CSEBF-AV: demanda auto-referida e demanda diagnosticada $(\mathrm{N}=237)$
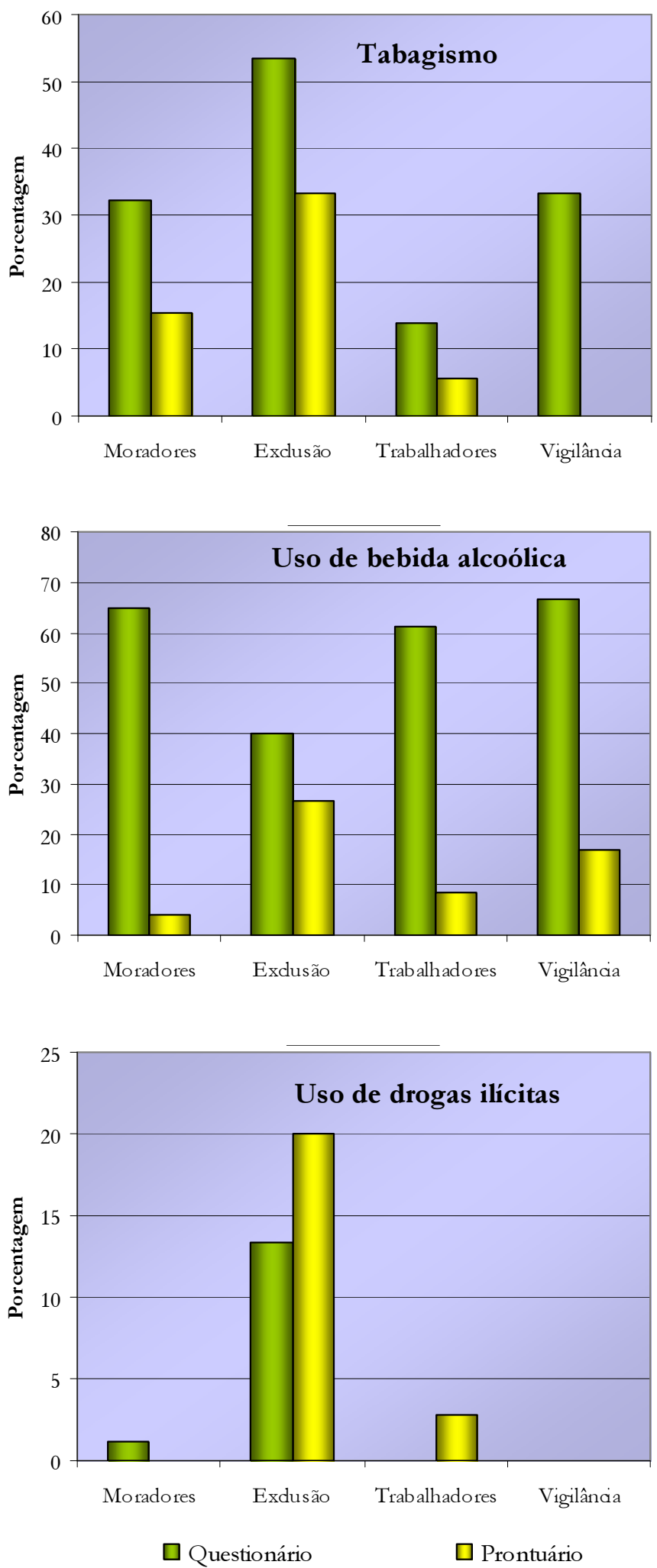
III.5. Caracterização do padrão de uso do CSEBF-AV pelos homens usuários

\section{III.5.1. Padrão de uso auto-referido do CSEBF-AV}

O instrumento questionário, em relação ao uso do CSEBF-AV pelos homens, investigou a atitude que os homens adotavam frente a um problema de saúde e se existia algum tipo de dificuldade para tal. Observamos que, nos quatro grupos, a maioria dos homens procurou, primeiramente, o centro de saúde ${ }^{35}$ mais próximo, com destaque para os homens seguidos pela vigilância, porém esse resultado não foi estatisticamente significativo, mesmo utilizando-se dois grupos de análise (excluídos e não-excluídos) ( $\mathrm{p}>0,05)$. Ainda em relação à atitude que os homens adotavam frente a um problema de saúde investigamos qual era a segunda opção ${ }^{36}$ na procura de serviços de saúde e observamos que moradores, homens em situação de exclusão e homens seguidos pela VE procuraram, predominantemente, um pronto-socorro público $^{37}$, com destaque para os homens em situação de exclusão, mas esse resultado também não apresentou significância estatística, mesmo utilizando-se dois grupos de análise $(\mathrm{p}>0,05)$. Ao analisarmos a segunda opção mais procurada pelos homens entrevistados considerando "procura a farmácia" e "outras opções”38 observamos que o predomínio dos trabalhadores $(45 \%, \mathrm{n}=11)$ para essa opção foi estatisticamente significante $^{39}\left(\boldsymbol{x}^{2}=7,44, \mathrm{p}=0,024,2 \mathrm{gl}\right)$, porém não houve significância ao utilizarmos dois grupos de análise. Em relação a alguma dificuldade encontrada pelos homens entrevistados para acessar qualquer serviço de saúde, da última vez que tentaram, observamos o predomínio dos homens seguidos pela vigilância $(66,7 \%, n=12)$, sendo que esse resultado foi estatisticamente significante $\left(\boldsymbol{x}^{2}=9,71, \mathrm{p}\right.$ $=0,021,3 \mathrm{gl})$.

\footnotetext{
${ }^{35}$ Para essa análise consideramos: procura o centro de saúde mais próximo e outras opções (não faz nada, usa remédios caseiros ou procura: pronto socorro, convênio, farmácia e outros).

${ }^{36}$ Para essa análise não consideramos os indivíduos que não apresentaram uma segunda opção.

37 Para essa análise consideramos: procura o pronto-socorro e outras opções (não faz nada, usa remédios caseiros ou procura: convênio, farmácia e outros).

${ }^{38}$ Não faz nada, usa remédios caseiros ou procura: pronto socorro, convênio e outros.

39 Para essa análise os homens seguidos pela vigilância foram excluídos por não apresentarem "farmácia" como opção.
} 
Figura 16: Padrão de uso de serviços de saúde auto-referido pelos homens entrevistados - CSEBF-AV, no último ano (N=237)

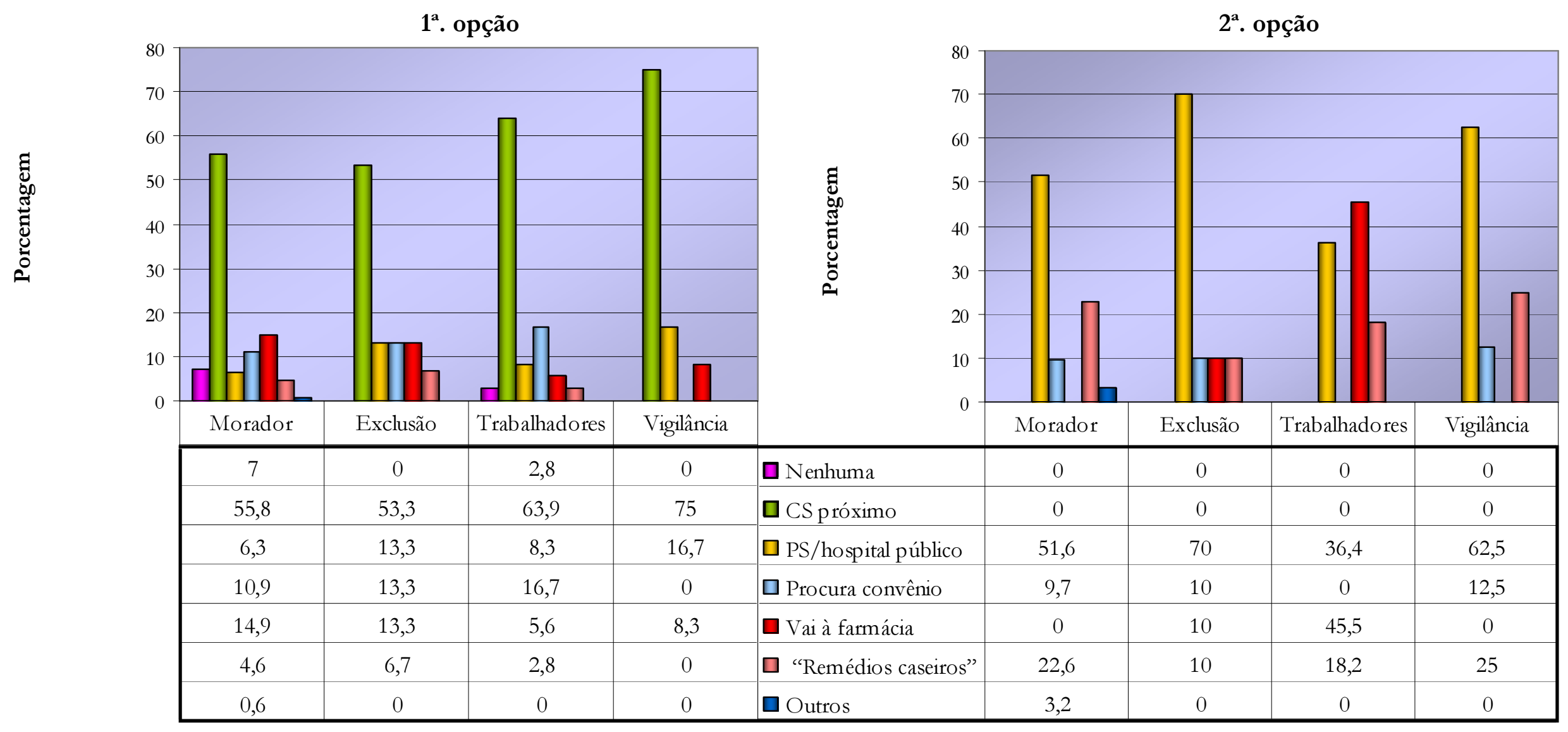


As queixas registradas em relação às dificuldades encontradas foram relacionadas à falta de vagas (moradores, trabalhadores e homens seguidos pela VE) e demora em ser atendido (homens que vivem em situação de exclusão). A figura 16 ilustra a distribuição dos homens em relação ao uso auto-referido de serviços de saúde.

\section{III.5.2. Padrão de uso do CSEBF-AV identificado em prontuário}

Ao observarmos os registros em prontuário dos homens entrevistados, no último ano de uso do serviço, a partir do instrumento ficha de leitura dos prontuários - ficha 2, observamos que moradores e trabalhadores usaram predominantemente consultas agendadas $(71,4 \%$ e $72,2 \%$, respectivamente) e menos as consultas de pronto atendimento $(45,9 \%$ e $44,4 \%$, respectivamente), enquanto os homens em situação de exclusão usaram, de forma inversamente proporcional, mais as consultas de pronto atendimento que as consultas agendadas $(73,3 \%$ e $46,7 \%$, respectivamente). Os homens seguidos pela VE freqüentaram igualmente consultas agendadas e de pronto atendimento.

Em relação às outras atividades assistenciais, destacou-se o importante uso do atendimento de enfermagem por moradores, trabalhadores e homens em situação de exclusão. Esse último grupo de homens, em relação aos três grupos de homens mencionados, chamou ainda a atenção pelo uso mais freqüente das atividades em Saúde Mental e, conforme esperado, do Serviço Social. Destacou-se, na amostra estudada, o uso predominante do Serviço Social pelos homens seguidos pela VE, superando inclusive o uso por homens em situação de exclusão (50\% e 26,7\%, respectivamente). É ainda importante observar que os homens fizeram pouco uso de atividades em grupo, no caso do CSEBF-AV, voltados para hipertensão arterial e diabetes mellitus, além do grupo de triagem da saúde mental. Os três grupos não mais existem e, atualmente, estão sendo repensados pelas equipes responsáveis do serviço, apresentando-se, pois, primoroso momento para voltarmos a atenção também às necessidades e dificuldades dos homens para esse tipo de atividade. A figura 17 ilustra os dados apresentados acima. 
Figura 17: Padrão de uso do CSEBF-AV pelos homens entrevistados, usuários do serviço, identificado em prontuário, no último ano $(\mathrm{N}=237)$

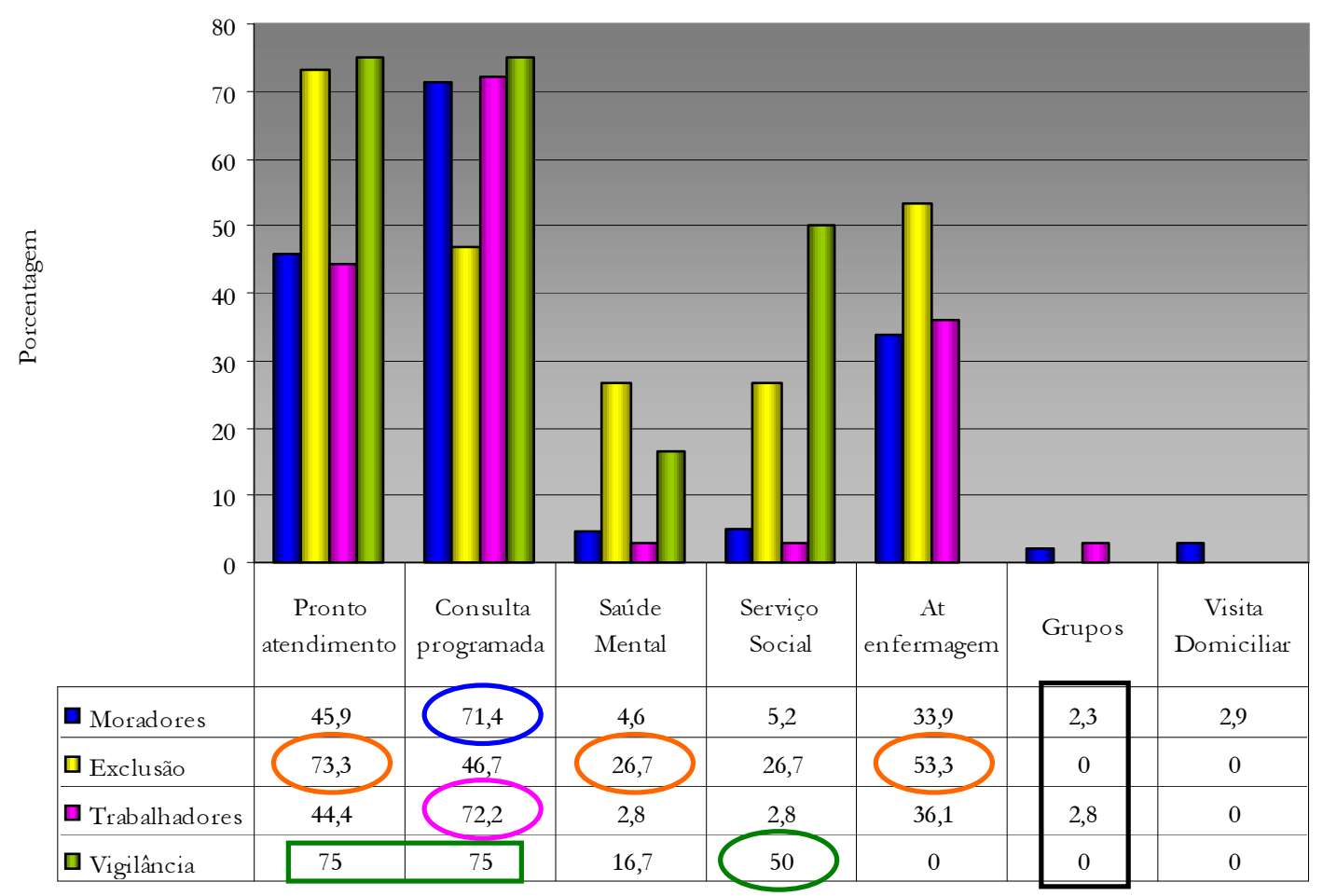

Ao analisarmos os dados acima apresentados observamos que o uso de pronto atendimento predominantemente pelos homens seguidos pela vigilância foi estatisticamente significante ( $\mathrm{p}<0,05,3 \mathrm{gl}$ ) enquanto que ao analisarmos o uso do pronto atendimento considerando os grupos excluídos e não-excluídos observamos que o predomínio do grupo excluídos nessa assistência apresentou indício importante de significância estatística $(\mathrm{p}=0,051)$. Em relação ao uso de consultas programadas não observamos significância estatística em relação ao menor uso dessa assistência pelos homens em situação de exclusão social considerando dois grupos de análise (p $<0,05)$, bem como não houve significância pelo maior uso dos homens seguidos pela VE em relação aos outros três grupos $(\mathrm{p}<0,05,3 \mathrm{gl})$. O uso do serviço social predominou de forma significativa entre os homens em situação de exclusão, quando consideramos dois grupos de análise $(\mathrm{p}=0,008)$, o que também foi observado em relação ao uso da assistência em saúde mental por esse grupo de homens, quando consideramos dois grupos de análise $(p=0,006)$. Em relação ao uso predominante do atendimento de enfermagem pelos homens em situação de exclusão não observamos 
significância estatística ( $p>0,05$ ). As tabelas 16 e 17 ilustram os resultados apresentados acima.

Tabela 16: Padrão de uso do CSEBF-AV pelos homens entrevistados, usuários do serviço, identificado em prontuário, no último ano: análise estatística segundo o tipo de matrícula $(\mathrm{N}=237)$

\begin{tabular}{|c|c|c|c|c|c|c|c|c|c|}
\hline \multirow{3}{*}{$\begin{array}{c}\text { Assistência } \\
\text { utilizada }\end{array}$} & \multicolumn{8}{|c|}{ Tipo de Matrícula } & \multirow{3}{*}{$\begin{array}{c}\text { Teste estatísticc } \\
\text { Qui-quadrado } \\
x^{2}\end{array}$} \\
\hline & \multicolumn{2}{|c|}{$\begin{array}{l}\text { Moradores } \\
(\mathrm{n}=174)\end{array}$} & \multicolumn{2}{|c|}{$\begin{array}{c}\text { Exclusão } \\
(\mathbf{n}=15)\end{array}$} & \multicolumn{2}{|c|}{$\begin{array}{c}\text { Trabalhadores } \\
(\mathbf{n}=36)\end{array}$} & \multicolumn{2}{|c|}{$\begin{array}{l}\text { Vigilância } \\
\qquad(\mathrm{n}=12)\end{array}$} & \\
\hline & $\mathbf{n}$ & $\%$ & $\mathbf{n}$ & $\%$ & $\mathbf{n}$ & $\%$ & $\mathbf{n}$ & $\%$ & \\
\hline $\begin{array}{l}\text { Pronto } \\
\text { Atendimento }\end{array}$ & 80 & 45,9 & 11 & 73,3 & 16 & 44,4 & 9 & 75,0 & $\begin{array}{l}\mathbf{x}^{2}=4,28 \\
\boldsymbol{p}=\mathbf{0 , 0 3 8}\end{array}$ \\
\hline Programada & 124 & 71,4 & 7 & 46,7 & 26 & 72,2 & 9 & 75,0 & $\begin{array}{l}\boldsymbol{x}^{2}=4,25 \\
\boldsymbol{p}>\mathbf{0 , 0 0 5}\end{array}$ \\
\hline
\end{tabular}

Tabela 17: Padrão de uso do CSEBF-AV pelos homens entrevistados, usuários do serviço, identificado em prontuário, no último ano: análise estatística segundo o tipo de matrícula: excluídos e não-excluídos $(\mathrm{N}=237)$

\begin{tabular}{|c|c|c|c|c|c|}
\hline \multirow{3}{*}{$\begin{array}{l}\text { Assistência } \\
\text { utilizada }\end{array}$} & \multicolumn{4}{|c|}{ Tipo de Matrícula } & \multirow{3}{*}{ Teste estatístico } \\
\hline & \multicolumn{2}{|c|}{ Exclusão (n=15) } & \multicolumn{2}{|c|}{ Não-exclusão $(n=210)$} & \\
\hline & $\mathbf{n}$ & $\%$ & $\mathbf{n}$ & $\%$ & \\
\hline $\begin{array}{l}\text { Pronto } \\
\text { Atendimento }\end{array}$ & 11 & 73,3 & 96 & 27,1 & $\begin{array}{l}\boldsymbol{x}^{2}=7,78 \\
\boldsymbol{p}=\mathbf{0 , 0 5 1}\end{array}$ \\
\hline Programada & 7 & 46,7 & 150 & 86,2 & $\begin{array}{c}\mathbf{x}^{2}=2,98 \\
\boldsymbol{p}=\mathbf{0 , 0 8 4 *}\end{array}$ \\
\hline $\begin{array}{l}\text { Atendimento de } \\
\text { enfermagem }\end{array}$ & 8 & 53,3 & 72 & 34,3 & $\begin{array}{c}\boldsymbol{x}^{2}=2,22 \\
\boldsymbol{p}>\mathbf{0 , 0 5}\end{array}$ \\
\hline Saúde mental & 4 & 26,7 & 9 & 4,30 & $\begin{array}{c}\text { Fisher } \\
\boldsymbol{p}=\mathbf{0 , 0 0 6}\end{array}$ \\
\hline Serviço social & 4 & 26,7 & 10 & 4,8 & $\begin{array}{c}\text { Fisher } \\
p=0,008\end{array}$ \\
\hline
\end{tabular}

*com correção de Yates

A ficha de leitura de prontuários - ficha 2 forneceu ainda informações sobre a conduta adotada pelos profissionais do serviço ao final de cada atendimento ao usuário, ao longo do último ano. Em relação às solicitações realizadas, ou seja, exames, retornos e orientações, os homens que vivem em situação de exclusão e 
aqueles seguidos pela VE foram os que mais apresentaram pelo menos uma solicitação ao longo do último ano. Quanto aos encaminhamentos realizados (Figura 18), observamos que para moradores, trabalhadores e homens seguidos pela VE destacou-se o encaminhamento externo (encaminhamentos às especialidades, atendimentos em pronto socorro e em centros de referência), porém esse resultado não foi estatisticamente significante ( $p>0,05)$ (Tabela 18). Já os homens que vivem em situação de exclusão utilizaram igualmente encaminhamentos externos e encaminhamentos internos (trânsito do usuário nos serviços de saúde mental e/ou serviço social e/ou atendimento de enfermagem), porém predominando o uso do encaminhamento interno em relação aos outros três grupos de homens. Esse resultado foi estatisticamente significativo considerando quatro e dois grupos de análise ( $\mathrm{p}=0,004,3 \mathrm{gl} ; \mathrm{p}=0,001)$ (Tabelas 18 e 19).

Figura 18: Encaminhamentos registrados em prontuários, último ano de uso do serviço, homens entrevistados - CSEBF-AV $(\mathrm{N}=237)$

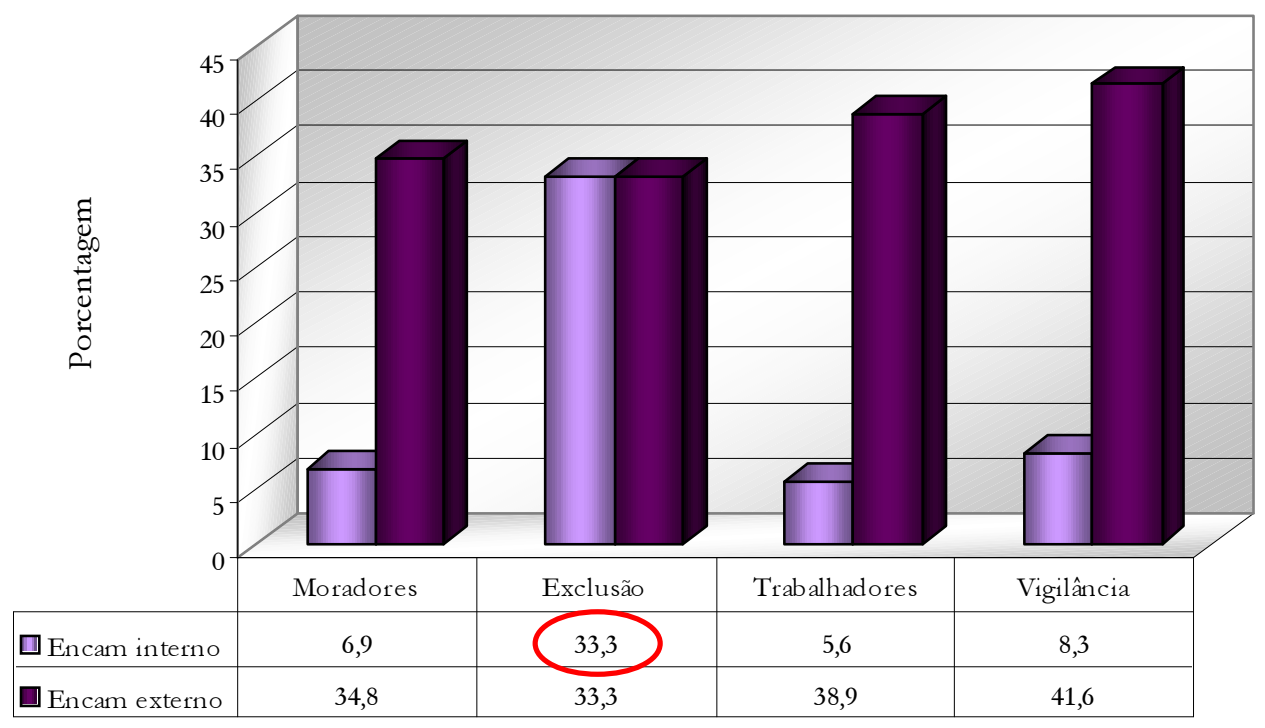


Tabela 18: Encaminhamentos registrados em prontuários, último ano de uso do serviço, homens entrevistados - CSEBF-AV: análise estatística segundo o tipo de matrícula $(\mathrm{N}=237)$

\begin{tabular}{|c|c|c|c|c|c|c|c|c|c|}
\hline \multirow{3}{*}{ TE } & \multicolumn{8}{|c|}{ Tipo de Matrícula } & \multirow{3}{*}{$\begin{array}{c}\text { Teste } \\
\text { estatístico } \\
\text { Qui-quadrado } \\
x^{2}\end{array}$} \\
\hline & \multicolumn{2}{|c|}{$\begin{array}{c}\text { Moradores } \\
(\mathrm{n}=174)\end{array}$} & \multicolumn{2}{|c|}{$\begin{array}{c}\text { Exclusão } \\
(\mathbf{n}=15)\end{array}$} & \multicolumn{2}{|c|}{$\begin{array}{c}\text { Trabalhadores } \\
(\mathrm{n}=36)\end{array}$} & \multicolumn{2}{|c|}{$\begin{array}{l}\text { Vigilância } \\
(\mathbf{n}=12)\end{array}$} & \\
\hline & $\mathbf{n}$ & $\%$ & $\mathbf{n}$ & $\%$ & $\mathbf{n}$ & $\%$ & $\mathbf{n}$ & $\%$ & \\
\hline Interno & 12 & 6,9 & 5 & 33,3 & 2 & 5,6 & 1 & 8,3 & $\begin{array}{l}\boldsymbol{x}^{2}=12,95 \\
\boldsymbol{p}=\mathbf{0 , 0 0 4}\end{array}$ \\
\hline Externo & 60 & 34,8 & 5 & 33,3 & 14 & 38,9 & 5 & 41,6 & $\begin{array}{l}\mathbf{x}^{2}=0,49 \\
\boldsymbol{p}>\mathbf{0 , 0 0 5}\end{array}$ \\
\hline
\end{tabular}

TE:tipo de encaminhamento

Tabela 19: Encaminhamentos registrados em prontuários, último ano de uso do serviço, homens entrevistados - CSEBF-AV: análise estatística segundo o tipo de matrícula: excluídos e não-excluídos $(\mathrm{N}=237)$

\begin{tabular}{|c|c|c|c|c|c|}
\hline \multirow{3}{*}{$\begin{array}{c}\text { Tipo de } \\
\text { encaminhamento }\end{array}$} & \multicolumn{4}{|c|}{ Tipo de Matrícula } & \multirow{3}{*}{$\begin{array}{c}\text { Teste estatístico } \\
\text { Qui-quadrado } \\
x^{2}\end{array}$} \\
\hline & \multicolumn{2}{|c|}{ Exclusão (n=15) } & \multicolumn{2}{|c|}{ Não-exclusão $(n=210)$} & \\
\hline & $\mathbf{n}$ & $\%$ & $\mathbf{n}$ & $\%$ & \\
\hline Interno & 5 & 33,3 & 14 & 6,7 & $\begin{array}{l}\boldsymbol{x}^{2}=9,66 \\
\boldsymbol{p}=\mathbf{0 , 0 0 1}\end{array}$ \\
\hline Externo & 5 & 33,3 & 74 & 35,2 & $\begin{array}{l}\boldsymbol{x}^{2}=0,02 \\
\boldsymbol{p}>\mathbf{0 , 0 5}\end{array}$ \\
\hline
\end{tabular}


Capítulo 6

Discussão 


\section{HOMENS USUÁRIOS DO CSEBF-Av: QUEM SÃo ELES?}

Os homens usuários do CSEBF-AV entrevistados para essa pesquisa mostraram-se, predominantemente, pertencentes aos estratos sociais D e C com tendência de transição aos estratos sociais D e E, o que corresponde às alterações sócio-demográficas ocorridas na região da Barra Funda e seus arredores ao longo dos últimos anos: a mudança de uma população imigrante estrangeira autônoma para uma população imigrante estrangeira que trabalha em regime de semi-escravidão e vive em precárias condições de moradia (ANDRADE, 2003), indicando o baixo poder aquisitivo dessa população; e o surgimento de uma população migrante de baixo estrato socioeconômico que procura concentrar-se na região central do município de São Paulo, onde é maior a oferta de empregos. Pertencendo a uma população em processo de transição socioeconômica, os homens entrevistados concentraram-se ainda em grupos com cinco a onze anos de estudo, o que corresponde aos dados encontrados no Município de São Paulo para o ano de 2000: 46,6\% dos homens entre 20 e 59 anos apresentaram 4 a 10 anos de estudo (IBGE - SIDRA). Além disso, os homens entrevistados eram predominantemente trabalhadores com carteira assinada, fato que corresponde à concentração de fábricas e empresas de serviços na região (SILVEIRA, 1999; ANDRADE, 2003).

A população usuária da unidade refletiu a população da área abrangida pelo serviço, havendo predomínio de homens e mulheres no grupo etário de 25 a 44 anos (homens: 49,5\% e mulheres: 49,6\%, na área abrangida; homens: 54,1\% e mulheres: 56,4\%, no CSEBF-AV) bem como o predomínio de mulheres entre os indivíduos com 18 anos ou mais (57,6\% na área abrangida; 59,2\% no CSEBF-AV). Por outro lado, enquanto na área de abrangência do CSEBF-AV predominavam mulheres nos grupos etários a partir dos 35 anos, observamos que entre a população usuária do serviço as mulheres predominaram em todos os grupos etários, indicando a pouca frequiência no CSEBF-AV dos homens jovens, que estariam presentes na comunidade mas sem chegar ao serviço. Essa observação foi corroborada pelos achados da presente pesquisa, onde observamos que a maioria dos homens entrevistados, usuários do CSEBF-AV, concentrou-se em grupo etário mais elevado, 35 a 54 anos $(54 \%, N=237)$. Estudos sobre o uso de serviços de atenção primária à 
saúde mostram, de fato, que a população feminina é predominante entre os usuários desse tipo de serviço (LaurentTi, 1998; Courtenay, 2000; PinHEIro et al., 2002), conforme apontam os achados de PITTMAN (1999).

A maioria dos homens entrevistados $(\mathrm{N}=237)$ morava em casa/ apartamento, pertencia aos estratos sociais $\mathrm{C}$ ou $\mathrm{D}$, estava trabalhando e tinha de cinco a onze anos de estudo no momento da entrevista, porém, os homens entrevistados que pertenciam ao grupo em situação de exclusão predominaram entre aqueles que viviam em moradia "com risco social", pertenciam aos estratos sociais D e E, estavam desempregados e tinham baixa escolaridade ( $\mathrm{p}<0,05$ para todas as variáveis). Conforme Courtenay (2000), Pinheiro et al. (2002) e Wood et al. (2002), esses fatores prejudicam o tipo e quanta atenção os homens têm com sua saúde, o que permitiu identificar os homens em situação de exclusão como população de risco para adoecimento no presente estudo. Esses achados concordam com ANDRADE (2003), que em seu estudo, no caso, com mulheres, usuárias do CSEBF-AV, observou que as usuárias identificadas como "mulheres em situação de exclusão", ao que a autora denominou usuárias com discriminação positiva ${ }^{40}$ para entrada no serviço, apresentavam condições sócio-demográficas muito semelhantes às dos homens em situação de exclusão na presente pesquisa, ao observarmos o grupo de mulheres moradoras de rua. A autora apontou que esse grupo de mulheres predominou entre aquelas com baixa escolaridade e baixa condição socioeconômica (resultados estatisticamente significativos), e também predominou entre mulheres sem parceiro no momento da entrevista e que viviam em moradias "com risco social". Na presente pesquisa, os homens em situação de exclusão também predominaram entre os homens que não tinham parceira e viviam sozinhos $(\mathrm{p}<0,05$ para ambos), o que também é um fator de risco para adoecimento, uma vez que "ser casado", como apontam BANKS (2004), WHITE \& CASH (2004) e BARTLETT (2004), é considerado fator de proteção para a saúde dos homens. Os presentes achados concordam com o estudo de VIEIRA et al. (1992), que demonstram que a população que vive em situação de exclusão e é moradora de rua dificilmente se vincula a algum tipo estável de moradia, fazendo uso esporadicamente de albergues, apenas quando é necessário (quando faz muito frio, para alimentação e para higiene) e que

\footnotetext{
${ }^{40}$ Mulheres moradoras de rua, de favela e profissionais do sexo.
} 
são indivíduos que vivem predominantemente sozinhos, sobretudo os homens. Vale ressaltar que a condição "situação de exclusão" é, por si, conforme apontado anteriormente, um fator de risco à saúde e bastante presente na área do CSEBF-AV. Em relação às companheiras dos homens entrevistados é interessante ressaltar, em relação à variável idade, a diferença de dez anos a menos para as mulheres em relação aos seus companheiros e, apesar disso, observar que a maioria delas encontrava-se entre mulheres que são "do lar", com exceção das companheiras dos homens seguidos pela VE, que trabalhavam como domésticas em sua maioria e, curiosamente, nessa amostra de homens, nenhuma das parceiras era "do lar". Porém, ao observarmos a porcentagem de mulheres que trabalhavam fora, sem atentar para as categorias de tipo de emprego, observamos a tendência a uma mudança nesse perfil de "mulheres que ficam em casa" (mulheres ocupando o espaço privado - o lar). Notamos que, incluídas as mulheres que estavam à procura de emprego, quase $50 \%$ das companheiras dos homens entrevistados, moradores e trabalhadores, trabalhavam fora e, no caso das companheiras dos homens seguidos pela VE, quase 90\% delas trabalhavam fora. O grupo de homens seguidos pela VE destacou-se ainda pelo menor tempo de relacionamento estável e pelo menor número de filhos, em sua maioria, o que seria esperado uma vez que esses homens concentraram-se no grupo etário de 18 a 34 anos.

Observamos que 90,3\% ( $\mathrm{N}=237)$ dos homens entrevistados usuários do CSEBF-AV tiveram sua primeira relação sexual na faixa etária de 10 a 20 anos, sendo curioso observar que entre os homens seguidos pela VE, mais jovens, $75 \%$ $(n=12)$ deles tiveram sua primeira relação sexual mais tardiamente, isto é, entre $15 \mathrm{e}$ 20 anos, diferentemente do que se esperaria atualmente, uma vez que homens e mulheres estão constantemente mais expostos a estímulos sensuais e sexuais e conseqüentemente estariam propensos a iniciar sua vida sexual mais precocemente. Em relação à primeira parceira sexual, 41,4\% (N=237) dos homens entrevistados usuários do CSEBF-AV referiram ter sido uma amiga/ conhecida, sendo que o grupo de homens seguidos pela VE mais uma vez chamou a atenção uma vez que, na amostra entrevistada, nenhum deles teve sua iniciação sexual com uma profissional do sexo, ao contrário do que costumava ocorrer antigamente, quando "a maioria dos meninos eram iniciados sexualmente por mulheres 'experientes' - as prostitutas". 
Essas observações poderiam estar relacionadas a alguns fatores: 1. por ser uma "tradição antiga", estes homens, mais jovens, não adotariam o mesmo costume para sua iniciação sexual; 2. após os anos 70, a liberação sexual feminina mudou o comportamento de homens e mulheres em relação às práticas sexuais; 3 . as mudanças que os homens vêm passando nos últimos anos, entre as quais está incluída a valorização da afetividade na escolha das parceiras para atividade sexual (Giffin \& Cavalcanti, 1999; Pittman, 1999; GifFin, 2002). Porém, seria necessária uma amostra maior de homens mais jovens, no caso, seguidos pela VE, para uma avaliação mais precisa desse tipo de situação.

Outra observação que destacou os homens seguidos pela VE relacionou-se ao método anticoncepcional (MAC) adotado pelos casais, sendo que esse grupo de homens predominou entre aqueles que faziam uso do preservativo masculino (50\%, $\mathrm{n}=8$ ). Porém, o uso de métodos mais dependentes de uma atitude da parceira (DIU, anticoncepcional oral, diafragma/ espermicida, injeção, laqueadura) predominou entre todos os homens entrevistados com parceiras no momento da entrevista $(69,1 \%, n=134)$, o que poderia ser explicado entre os casais que mantêm relacionamento estável por alguns anos e que ainda pensam em ter filhos, uma vez que os métodos contraceptivos que dependem mais incisivamente de uma atitude do homem (ou pelo menos há necessidade que o homem também concorde com o método) são o uso do preservativo masculino (pouco adotado por casais estáveis) e a vasectomia. Assim, as observações sobre o MAC não permitiram concluir se os homens entrevistados estariam ou não sensibilizados com a questão do planejamento familiar, porém, em relação ao uso de preservativo masculino contra IST os homens entrevistados mostraram-se predominantemente conscientizados, com exceção dos homens em situação de exclusão.

\section{Homens uSuários do CSEbF-Av: Quais SÃo aS SUAS NECESSIDADES E PERCEPÇÕES EM SAÚDE?}

\section{II.1. Necessidades e percepções em saúde sexual}

Apesar das mulheres perceberem mais que os homens alguma deficiência em seu estado de saúde, a partir dos 50 anos os homens tendem também a perceber mais 
alguma deficiência em seu estado de saúde, segundo foi observado por PINHEIRO et al. (2002). Contrariamente a estes achados, o presente estudo mostrou que os homens seguidos pela VE, concentrados no grupo etário de 18 a 34 anos, foram os que mais apresentaram percepção (demanda auto-referida), dos sintomas gênito-urinários investigados, próxima do que foi detectado em seus prontuários (demanda diagnosticada), o que poderia indicar, já que são mais jovens, certa mudança nos tradicionais hábitos masculinos de negação, no caso, do adoecimento (CONNELL, 1997; CeCCARELli, 1998a; GARCIA, 1998; FONSECA, 1999; DAVIES et al., 2000; SiLVA SG da, 2000; White \& CASH, 2004; GIFFIN, 2005). Porém, não podemos deixar de considerar que, além da vinda espontânea desses homens ao serviço, conseqüente à auto-percepção de seus sintomas, esse grupo de homens também pode ter chegado ao serviço por consequiência da presença de alguma IST em suas parceiras, o que automaticamente leva à convocação desses homens à unidade, podendo a convocação ter despertado a atenção desses homens para um sintoma até então não percebido ou desvalorizado. Da mesma forma, os moradores e trabalhadores entrevistados perceberam alguma perturbação de sua saúde (demanda auto-referida) relacionada aos sintomas gênito-urinários porém, superior ao que foi encontrado em seus prontuários (demanda diagnosticada). Os resultados encontrados para moradores e trabalhadores poderiam ser conseqüentes à freqüência mais regular ao serviço que esses dois grupos de homens apresentaram, próxima à frequiência das mulheres aos serviços de atenção primária à saúde, que são usuárias predominantes desse tipo de serviço (Laurentti, 1998; Pittman, 1999; Courtenay, 2000; Pinheiro et al., 2002), sugerindo que estar mais presente na UBS contribuiria para melhor percepção e talvez até percepção aumentada de problemas de saúde, denotando maior atenção a si próprio. A presença regular desses homens no serviço (concentrados no grupo etário de 35 a 54 anos), que se aproxima da presença das mulheres, se justificaria pelo fato de que mulheres e homens, geralmente a partir dos 40 anos, passariam a apresentar problemas de saúde (muitas vezes crônicos), freqüentando mais os serviços de saúde, estando, portanto, mais expostos às ações de promoção e educação em saúde, o que contribuiria para melhor percepção de prejuízos à saúde; exposição essa que também ocorreria com as mulheres mais jovens, regularmente presentes nos serviços de atenção primária à saúde: acompanham filhos e parentes nas consultas, 
realizam exames preventivos de rotina, além do pré-natal. Porém, tais considerações necessitariam um estudo mais aprofundado nessas questões para que possamos obter melhor avaliação. Os homens em situação de exclusão demonstraram praticamente nenhuma percepção dos sintomas investigados, negando todos os sintomas na entrevista (demanda auto-referida), enquanto que em seus prontuários tais questões de saúde se fizeram presentes. Poderíamos entender que esse grupo de homens ou não perceberia alguma alteração existente como problema ou não consideraria tais alterações como uma questão importante para sua saúde, apontando mais uma vez para a maior vulnerabilidade desse grupo a processos de adoecimento.

\section{II.2. Necessidades e percepções em saúde geral}

Levantamentos e revisões sobre mortalidade entre homens apontam como principais causas de óbito, entre outras, aquelas relacionadas a doenças do sistema cardiovascular (LAURENTI, 1998; SCHOFIELD et al., 2000), ao câncer de pulmão conseqüente ao tabagismo (LAURENTI, 1998; SCHOFIELD et al., 2000), ao câncer gástrico (LAURENTI, 1998) e a causas relacionadas a problemas hepáticos consequientes ao etilismo (LAURENTI, 1998; PINHEIRO et al., 2002). Em relação às morbidades mais frequientes entre os homens, diversos estudos apontam problemas como tabagismo e doenças cardiovasculares (LAURENTI, 1998; SCHOFIELD et al., 2000; BAnKs, 2004; StweART, 2004) e etilismo (LAURENTI, 1998; DAVIES et al., 2000; SCHOFIELD et al., 2000; PinHeIRo et al., 2002; BANKS, 2004), o que é corroborado pelos achados de WHITE \& CASH (2004) e por dados estatísticos da World Health Organization (WHO) ${ }^{41}$, conforme aponta RUTZ (2004).

Porém, é necessário atentarmos para o fato de que, entre os poucos estudos sobre morbidade entre os homens, muitos trazem as morbidades mais encontradas entre homens internados em hospitais. Assim, esses achados não seriam, necessariamente, semelhantes aos achados que podemos encontrar entre morbidades mais freqüentes em um serviço de atenção primária à saúde, uma vez que nesse tipo de serviço o homem traz "queixas iniciais" de uma patologia que poderá ou não se

41 World Health Organization, Regional Office for Europe. Health for All (HFA) Database, Copenhagen, 2003. 
instalar, enquanto que as morbidades diagnosticadas em hospitais geralmente se relacionarão às patologias já instaladas. A partir dessas considerações, podemos dizer que um estudo populacional, que investigasse quais as morbidades mais freqüentes entre os homens, poderia apresentar dados mais semelhantes àqueles encontrados em um estudo com a mesma temática realizado em serviços de atenção primária, pois ambos considerariam a demanda espontânea do homem investigado (entrevistado no estudo populacional e perguntado sobre sua queixa na anamnese médica). Dessa forma, é possível compreender a presença de mais similaridades entre a presente pesquisa e o estudo de PINHEIRO et al. (2002) e de menos similaridades entre a presente pesquisa e os outros estudos pesquisados, conforme será discutido a seguir.

Assim, a população pesquisada no presente estudo apresentou algumas discordâncias em relação ao que encontramos na literatura, mostrando que a principal queixa apresentada pelos homens entrevistados $(\mathrm{N}=237)$ esteve relacionada a queixas gerais $(43,5 \%)$, com destaque para as cefaléias. Os homens em situação de exclusão foram os que mais apresentaram esse tipo de queixa. As morbidades relacionadas ao sistema cardiovascular, freqüentes entre a população masculina, conforme mencionado acima, e relacionadas às principais causas de mortalidade entre os homens (LAURENTI, 1998; SCHOFIELD et al., 2000), apareceram como demanda diagnosticada em $27,4 \%$ dos homens entrevistados, com destaque para hipertensão arterial que, conforme achados de PINHEIRO et al. (2002), apareceu como segunda doença crônica mais referida entre os homens então pesquisados. $\mathrm{Na}$ presente pesquisa, das patologias do sistema cardiovascular, a hipertensão arterial foi a doença, diagnosticada em prontuário, mais freqüente entre moradores e trabalhadores da área, o que condiz com o grupo etário no qual esses homens se concentraram nessa pesquisa ( 35 a 54 anos), já que é uma doença cujo aparecimento está associado ao aumento da idade. Entre os homens seguidos pela VE, que predominaram entre 18 e 34 anos, a hipertensão arterial foi pouco freqüente, assim como patologias do sistema cardiovascular. Os trabalhadores foram os que mais apresentaram queixas do sistema cardiovascular. O estudo realizado por PINHEIRO et al. (2002) encontrou como primeira doença crônica mais referida, entre os homens então pesquisados, aquelas relacionadas à coluna. Na presente pesquisa, as queixas osteomusculares apareceram como terceira principal demanda diagnosticada entre os 
homens entrevistados $(32,5 \%)$, porém as queixas de maior destaque nesse sistema foram aquelas relacionadas aos membros inferiores, sendo que as queixas relacionadas à coluna apareceram em segundo lugar. Os homens seguidos pela VE foram os que mais apresentaram queixas do sistema osteomuscular.

O tabagismo, bastante apontado na literatura como sendo um hábito mais freqüente entre homens que em mulheres e muito relacionado à mortalidade por câncer de pulmão na população masculina (LAURENTI, 1998; SCHOFIELD et al., 2000), apareceu como demanda diagnosticada em 15,6\% dos homens entrevistados e como demanda auto-referida em 30,8\%, tendo sido um hábito mais freqüente entre homens em situação de exclusão, tanto como demanda auto-referida como demanda diagnosticada, com $\mathrm{p}<0,05$ nos dois casos.

O etilismo, também apontado na literatura como um hábito mais freqüente entre homens que em mulheres, é muitas vezes responsável por doenças hepáticas que, eventualmente, contribuem para elevar as taxas de mortalidade entre os homens (LAURENTI, 1998; PinHEIRO et al., 2002), além de outras doenças conseqüentes ao etilismo que também podem ser fatais. Na presente pesquisa esse hábito apareceu em $6 \%$ dos casos diagnosticados em prontuários e em $62,4 \%$ dos casos como demanda auto-referida.

Os achados para demanda auto-referida sobre o uso de bebida alcoólica chamaram a atenção por vários motivos. Primeiro, pela maior frequiência desse hábito entre os homens seguidos pela VE, que são os mais jovens; segundo, especialmente em relação aos homens que vivem em situação de exclusão, pois a maioria deles negou o uso de bebida alcoólica na vida (demanda auto-referida), o que contradiz a literatura (VIEIRA et al., 1999) e os dados encontrados nos prontuários desses usuários $(\mathrm{p}=0,056)$, pois o etilismo apareceu como segundo motivo mais freqüente de uso do serviço social no CSEBF-AV por esses usuários; terceiro, quanto aos moradores, trabalhadores e também aos homens seguidos pela VE, o fato da demanda auto-referida sobre o uso de bebida alcoólica mostrar uma frequiência de uso superior à demanda diagnosticada levantaria a possibilidade de que os homens não identificam tal hábito como prejudiciais à saúde, sendo que não referem ou até negam "uso demasiado" nas consultas com profissionais de saúde. Porém, também caberia investigar se os profissionais de saúde questionam sobre o uso de bebida 
alcoólica e se registram em prontuário uma resposta negativa. Outra questão que deve ser considerada é se o uso freqüente do álcool por moradores, trabalhadores e homens seguidos pela VE não estaria encobrindo situações difíceis e de estresse na vida desses homens. Ainda, não temos como saber se a ingestão diária de álcool por esses três grupos de homens não estaria dentro da dose considerada de baixo risco pela OMS (até duas doses para os homens). Em relação ao tabagismo observamos a mesma situação, sendo a demanda referida maior que diagnosticada, cabendo as mesmas considerações em relação à sua investigação pelos profissionais de saúde. Contudo, essas suposições são apenas especulações, sendo necessário um estudo mais aprofundado e direcionado a esses assuntos específicos.

Ainda, problemas relacionados à saúde mental dos homens, especialmente depressão e estresse, relacionados predominantemente a problemas familiares, divórcios e desemprego, têm aparecido de forma importante entre as queixas dos homens (Rowe, 2000; WoOds et al., 2002). Segundo os achados de WoOds et al. (2002), corroborados pelo estudo da $\mathrm{WHO}^{42}$, apontado por RUTZ (2004), essas questões têm aumentado a procura por consultas de saúde mental pelos homens. Os resultados destas pesquisas merecem especial atenção, uma vez que sintomas como depressão podem ocasionar o suicídio, uma importante causa de mortalidade entre os homens (SCHOFIELD et al., 2000). O presente estudo também encontrou presença considerável de questões relacionadas à saúde mental nos prontuários dos homens entrevistados (19,8\%), com destaque para ansiedade, seguida por insônia e depressão, tendo sido encontrado o registro de um caso de tentativa de suicídio. Os homens seguidos pela VE foram os que mais apresentaram queixas psicológicas.

Além disso, Woods et al. (2002), em sua pesquisa com profissionais de saúde de serviços de atenção primária à saúde, apontaram que os profissionais identificavam como problemas de saúde nos homens usuários de seus serviços questões como etilismo, diabetes mellitus, estilo de vida não saudável e depressão. Os dados estatísticos da $\mathrm{WHO}^{43}$, apontados por RUTZ (2004), corroboram esses achados, sendo que LAURENTI (1998), COURTENAY (2000), DAVIES et al. (2000) e

\footnotetext{
${ }^{42}$ World Health Organization Regional Committee for Europe. Mental health in WHO's European region. Copenhagen: WHO Regional Office for Europe; 2003.

${ }_{43}$ World Health Organization, Regional Office for Europe. Health for All (HFA) Database, Copenhagen, 2003.
} 
ROWE (2000) concordam que o estilo de vida não saudável adotado pelos homens contribui sobremaneira para elevar a morbidade e a mortalidade entre os homens. Também questões como impotência e relacionadas à próstata (LAURENTI, 1998), a maior freqüência de infecções sexualmente transmissíveis (ISTs) em homens que em mulheres (SCHOFIELD et al., 2000) e doenças crônicas em geral (COURTENAY, 2000; PINHEIRO et al., 2002) são apontadas como questões de saúde freqüentes entre os homens. Os achados da presente pesquisa apontaram um estilo de vida pouco saudável entre os homens entrevistados quando observamos os dados relacionados ao tabagismo e ao etilismo e quando observamos que queixas relacionadas ao sistema digestivo aparecem como segunda causa mais freqüente, como demanda diagnosticada, entre os homens entrevistados $(37,1 \%)$, com destaque para epigastralgia, o que poderia ser conseqüente à má alimentação. LAURENTI (1998) aponta que o câncer gástrico é uma patologia freqüente entre os homens e que contribui para elevar as taxas de mortalidade masculina. Os trabalhadores foram os que mais apresentaram queixas do sistema digestivo. Em relação à prática de atividades físicas, hábito reconhecidamente benéfico a várias questões de saúde ${ }^{44} \mathrm{e}$ que promove bem-estar físico, mental e social (ROWE, 2000; CIOLAC \& GUIMARÃES, 2004), os homens entrevistados mostraram-se ativos, com 54,9\% praticando algum tipo de atividade física duas vezes por semana ou mais, segundo demanda autoreferida.

Em relação às outras queixas investigadas, acreditamos que a maior frequiência de sintomas gênito-urinários entre os homens seguidos pela VE $(p<0,05)$ poderia estar relacionada às IST, que poderiam ter sido o motivo da entrada desse grupo no serviço, tanto por demanda espontânea como por demanda ativa, ou seja, convocação pelo CSEBF-AV devido ao diagnóstico de alguma IST nas parceiras desses homens. Ainda, conforme se esperava, os homens em situação de exclusão foram os que mais apresentaram queixas sociais ( $p<0,001)$, com destaque para problemas relacionados ao tabagismo e ao etilismo. O predomínio de sintomas respiratórios $(\mathrm{p}<0,05)$ e de alguns sintomas sugestivos de tuberculose $(\mathrm{p}<0,05)$ entre os homens em situação de exclusão poderia ser conseqüente à maior exposição desse grupo às condições climáticas, como frio e chuva, à uma alimentação precária

\footnotetext{
${ }^{44}$ Hipertensão arterial, diabetes mellitus tipo II, dislipidemias, estresse e preocupações, entre outros.
} 
e à poluição do ar, entre outros. Porém, não encontramos, nessa amostra de homens em situação de exclusão, casos de tuberculose diagnosticada em prontuário, o que ocorreu em 16,7\% $(n=12)$ dos homens seguidos pela VE, o que seria esperado para esse grupo.

\section{Homens uSuÁrios do CSEBF-Av: COMO INTERAGEM COM OS SERVIÇOS DE SAÚDE?}

\section{III.1. A busca pelos serviços de saúde}

Em relação ao uso dos serviços de saúde, a primeira opção para o tipo de serviço procurado pelos homens entrevistados $(\mathrm{N}=237)$ quando estes necessitavam foi um centro de saúde próximo $(57,8 \%)$, seguido por farmácia $(13,1 \%)$, convênio $(11,4 \%)$, pronto-socorro/ hospital $(7,6 \%)$ e uso de remédios caseiros $(4,2 \%)$, o que nos mostra presença importante dos homens em unidades básicas de saúde. Porém devemos lembrar que a amostra de homens entrevistados é usuária do CSEBF-AV, onde a pesquisa foi realizada. Ao observar os homens de amostra de domicílios, que foi representativa de cada estado da federação, PINHEIRO et al. (2002) encontraram que o serviço de saúde mais procurado pelos homens foi o consultório particular (30,6\%), seguido por posto ou centro de saúde $(28,3 \%)$ e hospital $(19,0)$, mostrando, de certa forma, um uso importante das UBS. Não podemos inferir se encontraríamos resultados semelhantes ou não aos de PINHEIRO et al. (2002) caso a amostra fosse maior e constituída por homens que vivem na área de abrangência do CSEBF-AV (o que incluiria também os homens mais jovens, que fazem pouco uso do serviço). A respeito das dificuldades apontadas pelos homens entrevistados para o uso dos serviços de saúde observamos que alguns dos problemas encontrados no presente estudo também foram apontados no estudo de PINHEIRO et al. (2002), como falta de vaga (dificuldade que mais apareceu, na pesquisa atual e nos achados de PINHEIRO et al., 2002) e demora em ser atendido. Ainda, o estudo citado encontrou como dificuldades apontadas pelos homens então entrevistados a falta de médico, a falta de serviço de saúde e a falta de recursos financeiros. 
O predomínio de moradores e trabalhadores em consultas programadas em relação aos homens em situação de exclusão e a maior presença desses nas consultas de pronto atendimento em relação aos moradores e trabalhadores eram resultados esperados, uma vez que os homens em situação de exclusão dificilmente se adaptam ao fluxo das unidades básicas de saúde de agendamento de consultas e espera para o atendimento (CARBONE, 2000), pois buscam soluções imediatas para seus problemas (PinHEIRO et al., 2002; WoOds et al., 2002; FiguEIREDO, 2005). Os homens seguidos pela VE freqüentaram igualmente consultas agendadas e de pronto atendimento, o que provavelmente se explica pelo fato de que muitos freqüentem a unidade por um período de tempo relacionado, geralmente, ao tratamento da patologia que causou sua inclusão no serviço e, justamente por terem essa entrada na unidade fazem uso diferenciado das consultas programadas, ou seja, freqüentam essas consultas para seguimento da patologia em tratamento, com retornos mais freqüentes, até sua alta da VE, e não por uma atenção voltada espontaneamente à sua saúde em geral. Vale ressaltar que esse tipo de usuário, caso deseje continuar seguimento clínico na unidade, pode fazer uso da matrícula que obteve por motivo de vigilância epidemiológica, situação característica do CSEBF-AV, unidade de atenção primária que prima pelo atendimento integral do indivíduo. Em relação às consultas de pronto atendimento os homens seguidos pela VE muitas vezes utilizam essa assistência por terem sido convocados, e não por necessidade sentida, aumentando sua freqüência nesse tipo de consulta.

Em relação ao atendimento de enfermagem observamos o predomínio dos homens em situação de exclusão nesse tipo de atividade, porém não houve significância estatística. Acreditamos que isso ocorreu pois a assistência de enfermagem inclui diversas ações, desde atividades de curativo, onde esperamos predominar indivíduos em situação de exclusão, até atividades de aferição de pressão arterial, controle de glicemia capilar e realização de eletrocardiograma, exame que é agendado e realizado pela equipe de enfermagem, atividades que acreditamos serem mais freqüentadas por usuários moradores e trabalhadores da área do CSEBF-AV, uma vez que esses usuários fazem uso rotineiro do serviço e essas atividades fazem parte da rotina de seguimento para hipertensão arterial e diabetes mellitus. 
Os homens em situação de exclusão, em relação aos moradores e trabalhadores, predominaram no uso do Serviço Social $(\mathrm{p}<0,05)$, conforme era esperado, uma vez que esse grupo de homens faz uso constante desse tipo de assistência em busca de encaminhamentos para albergues, orientações para segunda via de documentos, solicitação de roupas, entre outros. Chamou atenção a frequiência elevada dos homens seguidos pela VE nesse tipo de atendimento, superando a freqüência de uso dos homens em situação de exclusão, porém, não tivemos como avaliar o por quê dessa freqüência.

Os homens em situação de exclusão destacaram-se ainda pelo uso predominante e significativo da assistência em saúde mental $(\mathrm{p}<0,05)$, situação que ANDRADE (2003) também encontrou entre as mulheres moradoras de rua participantes de seu estudo. Consideramos que esse resultado poderia ser consequiente a alguns fatores: indivíduos em situação de exclusão são alcoolistas e têm mais chances de se envolver com o uso de drogas, ambos provocando, a longo prazo, prejuízos à saúde mental, entre outros; além disso, por não manterem vínculo com a sociedade, podem não ter "preconceito" quanto à necessidade de freqüentar consultas com psicólogos e psiquiatras e, ainda, esses indivíduos também sofrem preconceito, o que pode ocasionar encaminhamentos ao serviço de saúde mental além do que é realmente necessário; entre outros fatores, como aponta (CARBONE, 2000), em que a presença de um processo de doença mental no indivíduo pode resultar no seu abandono pelos familiares, sendo que muitas vezes esse indivíduo passa a viver nas ruas. Apesar dessas suposições, a pesquisa não investigou essas questões e, pelo descrito em relação ao uso de bebidas alcoólicas e drogas pelos homens em situação de exclusão entrevistados, tanto dados obtidos dos prontuários como informações advindas do questionário mostram que poucos deles fazem uso dessas substâncias, sendo a significância observada resultado não esperado e que levanta novas questões.

Em relação aos encaminhamentos solicitados, os homens em situação de exclusão foram os que mais receberam encaminhamentos internos (trânsito do usuário nos serviços de saúde mental e/ou serviço social e/ou atendimento de enfermagem) $(\mathrm{p}<0,05)$. Acreditamos que esses resultados se devam ao fato de que os usuários de rotina do serviço (moradores e trabalhadores) necessitem mais 
encaminhamentos externos justamente porque fazem seguimento rotineiro, o que faz surgir questões tanto de outras especialidades como questões que necessitam de determinados especialistas para controle de complicações de algumas patologias (hipertensão arterial e diabetes mellitus, por exemplo). Os homens que chegam ao serviço por uma questão especial, ou seja, situação de vigilância epidemiológica, também acabam necessitando mais encaminhamentos externos, pois muitas vezes sua questão de saúde requer avaliação de especialistas. Quanto aos homens que vivem em situação de exclusão, acreditamos que por apresentarem, muitas vezes, demandas que vão além de questões clínicas, acabem necessitando o encaminhamento interno tanto quanto o externo.

\section{CONSIDERAÇõES FINAIS}

A identificação de quem são os homens que fazem uso do CSEBF-AV, o por quê desse uso e como esse uso é feito mostrou resultados que suscitam novos questionamentos para serem investigados e que são importantes para o planejamento de ações voltadas à saúde do homem no serviço. Porém, consideramos que se não houvesse a perda de $25 \%$ dos prontuários dos homens entrevistados alguns dos resultados encontrados poderiam ser diferentes, a depender do tipo de entrada que esses homens tiveram no serviço, mas alterações que poderiam apontar novas questões merecedoras de atenção na organização do serviço para o atendimento da população masculina.

Apesar dessa perda, a amostra final $(\mathrm{N}=237)$ permitiu obter estimativas com intervalo de confiança $95 \%$ e precisão de $6,5 \%$, sendo adequado para um estudo descritivo.

Consideramos ainda que o resultado obtido em relação à prática de atividade física possa ter sofrido viés informação: pela possibilidade dos homens entrevistados terem superestimado a freqüência com que praticam atividade física e também porque o resultado obtido pode ter sido elevado pelos homens em situação de exclusão (grupo que predominou entre os homens que praticavam atividade física diariamente), que por caminharem muito e diariamente, podem ter considerado essa atividade como prática de atividade física. CiOlaC \& GUIMARÃES (2004) apontam 
que a atividade física deve ser praticada regularmente e seguir quatro princípios básicos para que haja benefícios à saúde: sobrecarga maior daquela à qual se está habituado, especificidade, individualidade e reversibilidade (a interrupção da atividade física faz o organismo retornar ao estado original pré-treinamento).

Ainda, frente aos resultados obtidos cabe destacar a organização atual da equipe de saúde do adulto como uma oportunidade para a elaboração de atividades que incluam os homens sob o aspecto de gênero e sob as diversidades de cada grupo de homens, porém, como apontam (WoODs et al., 2002; BANKS, 2004; FIGUEIREDO, 2005), possibilitando a esses profissionais uma aproximação com a noção de gênero para se pensar tanto a saúde do homem como a saúde da mulher.

Fica ainda o questionamento de como atrair os homens mais jovens e, nesse caso, incluir também os meninos adolescentes para atividades de promoção da saúde e de prevenção, tanto na unidade como na comunidade, sendo a experiência abordada por FIGUEIREDO (2005) uma importante sugestão para interagir com esse grupo de homens.

Os resultados obtidos na presente pesquisa provocaram muitos questionamentos e apontaram novas formas de análise para se pensar novos trabalhos com essa temática. Minha sugestão para iniciar a continuidade de meu trabalho é procurar observar, entre os homens como um todo e por tipo de entrada no serviço, como suas demandas e a forma como utilizam os serviços de saúde poderiam estar relacionadas com algumas características sócio-demográficas: grupo etário, escolaridade, estrato social e ocupação que, segundo os achados de WoODS et al. (2002), assinalados também por vários autores (LAURENTI, 1998; COURTENAY, 2000; ROWE, 2000; PINHEIRO et al.,2002; LAURENTI et al., 2005), são fatores relacionados à forma como os homens percebem e cuidam de sua saúde e, com base nas masculinidades e no ideal de masculinidade hegemônica, a depender dessas características o prejuízo à saúde pode ser maior ou menor ou até mesmo nem existir. 


\section{Capítulo 7 Conclusões}


A presente pesquisa permitiu conhecer um pouco sobre homens usuários de um serviço de atenção primária à saúde localizado na região central do Município de São Paulo, o Centro de Saúde Escola Barra Funda "Dr. Alexandre Vranjac" (CSEBF-AV).

Ao considerarmos esses usuários segundo sua porta de entrada no serviço, moradores e trabalhadores da área de abrangência, homens em situação de exclusão e homens acompanhados pela vigilância epidemiológica (VE), pudemos conhecer semelhanças e diferenças em relação à atenção que esses diferentes grupos de homens dão à sua saúde e quais são suas demandas sentidas.

O estudo mostrou que os homens estão na atenção primária, principalmente os mais velhos, e estão inseridos na rotina do serviço para acompanhamento de doenças crônicas ou prevenção de doenças, apesar de predominarem em serviços de pronto socorro e hospitais (PINHEIRO et al., 2002; WoODS et al., 2002; FIGUEIREDO, 2005). A maioria dos homens entrevistados apresentou relacionamento afetivo estável, o que é um fator de proteção à saúde (BANKS, 2004; WHITE \& CASH, 2004; BARTLETT, 2004). Suas principais demandas de saúde foram as queixas gerais, digestivas e osteomuscular. Além disso, esses homens, predominantemente, autoreferem uso de bebida alcoólica superior aos dados encontrados em prontuários, sendo a mesma situação observada em relação ao tabagismo. Este fato pode sugerir que os homens teriam dificuldade em relatar tais práticas, ou tenderiam a não identificar o uso que fazem dessas substancias como fator prejudicial à sua saúde, não referindo o hábito em consulta por não acharem necessário ou, ainda, seriam praticas pouco exploradas nas consultas com profissionais de saúde.

Os homens em situação de exclusão mostraram-se mais vulneráveis aos fatores de risco para adoecimento por diversos motivos: a maioria deles não tinha parceira, viviam sozinhos e predominaram entre aqueles com baixa escolaridade, baixo estrato socioeconômico e entre os desempregados. LAURENTI (1998), Courtenay (2000), Rowe (2000), PinheIro et al. (2002), WoOds et al. (2002) e LAURENTI et al. (2005) apontam que essas características contribuiriam para a pouca atenção à saúde e, de fato, os homens em situação de exclusão fumavam mais, faziam mais uso de bebida alcoólica e faziam pouco uso do preservativo masculino para a prevenção das IST, o que os torna mais expostos a situações de risco para a 
saúde. Além disso, esses homens apresentaram baixa percepção de deficiência do estado de saúde, em relação às queixas gênito-urinárias investigadas na entrevista, quando comparado aos outros grupos. A despeito disso, quando estudadas as demandas diagnosticadas em prontuários, o grupo dos homens em situação de exclusão foi o que apresentou taxas mais elevadas de queixas diagnosticadas para a maioria dos sistemas investigados, apresentando mais queixas respiratórias e sintomas sugestivos de tuberculose e apresentando mais queixas sociais. Ainda, demonstraram uso do serviço de forma que é considerada pouco adequado pela unidade, predominando em consultas de pronto atendimento, não realizando, dessa forma, seguimento às suas patologias.

O estudo realizado sugere que os homens usuários do CSEBF-AV estão imersos num contexto social com fortes pressões em termos de mudança de relacionamento entre os gêneros. Por um lado, suas companheiras, predominantemente, trabalhavam fora, o que aponta para uma transformação no padrão "usual" das relações afetivo-familiares, cujo provento material era de responsabilidade do homem. Segundo CASTELls (2001), as transformações socialmente vividas atualmente implicam na diversificação da composição e arranjo familiar e na mudança em seu sistema de relações de poder, havendo uma (re)construção do modelo familiar tradicional, o que acarretaria maior possibilidade de igualitarismo nas relações entre os gêneros e as gerações no âmbito das famílias. Entretanto, muitos homens ainda estariam 'incomodados' e 'indecisos' frente a tais mudanças. Os dados do estudo apontam, por exemplo, que ainda predominaram os métodos de contracepção mais dependentes de uma atitude das mulheres, apesar de aparecer, entre os homens seguidos pela VE, mais jovens, o predomínio do uso do preservativo masculino. De fato, esses homens apresentaram uma série de características (primeira relação sexual mais tardiamente e com parceira conhecida, parceiras que trabalham fora, uso do preservativo masculino) que poderiam sugerir que estes homens estariam mais "sintonizados" com os novos padrões de masculinidade que, entre outras coisas, apontam para uma co-responsabilização das decisões reprodutivas do casal. Entretanto, tais considerações são apenas 'apostas' de quem atua e pesquisa (n)a atenção primária e tem no cotidiano fonte de inspiração para novas descobertas. 
Acreditamos que os homens usuários do CSEBF-AV têm certa visibilidade no serviço e, com base nos resultados apresentados, o serviço deve se organizar a fim de dar visibilidade aos diferentes grupos de homens que o utilizam, atentando para as necessidades comuns e específicas de cada um desses grupos. Além disso, é preciso atentar para a maior vulnerabilidade dos homens em situação de exclusão, o que foi claramente apontado pelos achados do presente estudo.

$\mathrm{O}$ desenvolvimento de ações e estratégias efetivas que tragam o homem às unidades básicas de saúde depende de uma organização dos serviços de saúde baseada nas relações de gênero, abordando a saúde do homem e a saúde da mulher de forma relacionada e integrada (COURTENAY, 2000; SCHOFIELD, 2000; STWEART, 2004; Couto \& SCHRAIBER, 2005; Figueiredo, 2005), para que os serviços de saúde e suas equipes estejam preparados para trabalhar na perspectiva da pluralidade. 
Anexos 


\section{TERMO DE CONSENTIMENTO}

$\mathrm{Eu}$, abaixo assinado, concordo em conceder entrevista para esta pesquisa que trata do assunto Homens, Conflitos Familiares e Saúde. Fui informado que o objetivo da pesquisa é conhecer as características dos usuários do serviço; a presença de conflitos na família e em outras relações interpessoais, afetivas, no trabalho, no lazer, etc., e como essas relações afetam a saúde. Fui informado também que responderei um questionário aplicado por pesquisador do sexo masculino e em local privativo, e posteriormente serão lidos os meus registros médicos existentes no serviço. Entendo que o nome e os dados que me identifiquem serão mantidos em sigilo pelos pesquisadores. Compreendo que minha participação é inteiramente voluntária e que posso interromper as informações a qualquer momento. Fui informado que minha participação não acarretará nenhum prejuízo ou vantagem quanto ao uso que faço deste serviço e que receberei orientação quando solicitar assistências adicionais. Entendo que minhas respostas serão importantes para ajudar outros homens e a desenvolver serviços melhores na assistência à saúde do homem.

São Paulo, de de 200

Assinatura do Entrevistado

Assinatura do Entrevistador

OBS. Se você tiver dúvidas sobre esta pesquisa ou desejar informações adicionais, sinta-se à vontade para perguntar agora ou à coordenação (Profa. Dra. Lilia Blima Schraiber e/ou Dra. Márcia Thereza Couto, telefone 1130667444 r. 42). 


\section{Anexo C InSTRumentos: AneXo C.1}

\section{QUESTIONÁRIO}

1. Serviço

$\mathrm{n}^{\circ}$

2. Data da aplicação:

3. Hora de início:

4. Número de matrícula no serviço:

4a iniciais da entrevistado:

4b. Usuário:

1. $\square$ em uso

2. $\square$ acompanhante

5. Data do nascimento: I

6. Escolaridade:

6a. Sabe ler e escrever?

1. $\square \operatorname{sim}$

2. $\square$ não

6b. Você já freqüentou a escola?

$1 . \square \operatorname{sim}$

2. $\square$ não

[ir para q. 7]

6c. Até que série/ ano você estudou? Primeiro grau

Segundo grau/técnico

Universitário ano

ano

7a. Qual a sua cor de sua pele?
1. $\square$ branco
4. $\square$ mulato/pardo
2. $\square$ negro
5. $\square$ outras mestiços
3. $\square$ amarelo
6. $\square$ outras

\section{7b. Entrevistador:}
1. $\square$ branco
4. $\square$ mulato/pardo
2. $\square$ negro
5. $\square$ outras mestiços
3.
$\square$ amarelo
6. $\square$ outras

8. Qual é a sua prática religiosa? (resposta múltipla)

1. $\square$ católica

6. $\square$ espírita kardecista

2. $\square$ judaica

7. $\square$ umbanda

3. $\square$ muçulmana

8. $\square$ candomblé

4. $\square$ evangélica histórica

9. $\square$ outras

5. $\square$ evangélica pentecostal $10 . \square$ sem prática religiosa [ir p/ q10]

9. Qual a frequência de sua principal prática religiosa?

1. $\square$ diária

2. $\square$ semanal

3. $\square$ quinzenal

4. $\square$ mensal

5. $\square$ esporádica

10. Onde você nasceu? 10a. Estado:

Se o entrevistado nasceu no estado de são paulo, pergunte:

10b. 1. $\square$ capital

2. $\square$ grande são paulo

3. $\square$ outras localidades

10c. $1 . \square$ rural $2 . \square$ urbana

11. Há quanto tempo você está em são paulo? anos

12. Você diria que mora em: nunca saiu da grande são paulo: 95

1. $\square$ casa/apartamento

2. $\square$ quintal comum/cortiço

3. $\square$ pensão/quarto

4. $\square$ barraco
1.

2.

3.

4. -----

4 b.

5.

6 a.

$6 \mathrm{~b}$.

$6 \mathrm{c}$.

7 a.

7 b.

8 a.

8 b.

9 a.

10 a.

$10 \mathrm{~b}$.

$10 \mathrm{c}$.

11.

12. 


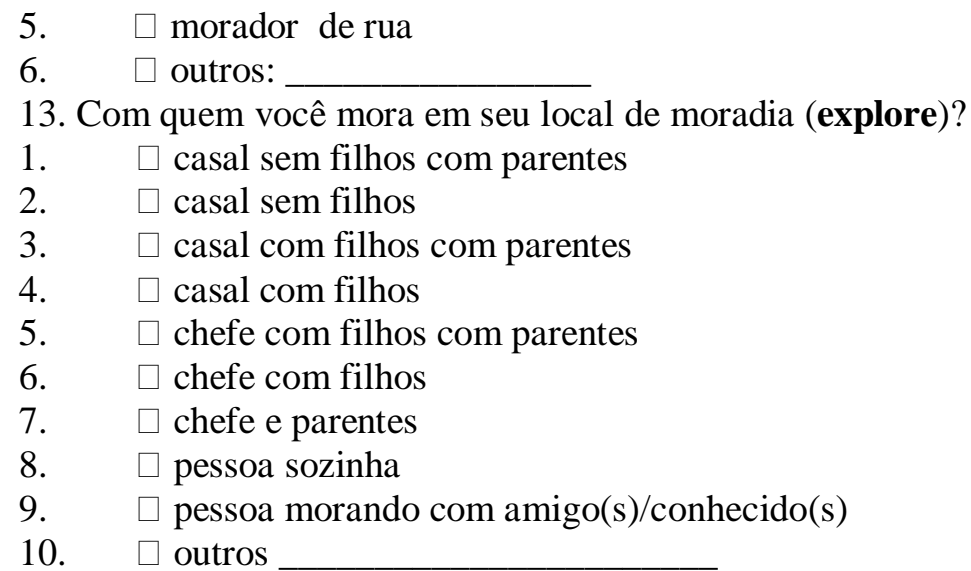

13.

13.

Atenção - para os moradores de rua, ou quem mora em pensão/quarto a próxima questão se refere a quantos dos itens ele possui. Para os outros a questão se refere a quantos destes itens a casa da entrevistado possui.

14. Você possui quantos destes ítens/serviços?

\begin{tabular}{|c|c|}
\hline & ] televisão colorida \\
\hline $\mathrm{b}$ & ] vídeo cassete/dvd \\
\hline $\mathrm{c}$ & ] rádio \\
\hline $\mathrm{d}$ & ] banheiro \\
\hline e & ] automóvel de passeio \\
\hline$t$ & ] empregada mensalista \\
\hline g & ] aspirador de pó \\
\hline$h$ & ] máquina de lavar roupa \\
\hline & ] geladeira \\
\hline & ] freezer (isolado ou geladeira duplex) \\
\hline
\end{tabular}

15. Qual a sua ocupação? (resposta múltipla):

1. $\square$ estudante

2. $\square$ trabalhador de empresa

3. $\square$ trabalhador autônomo

4. $\square$ trabalhador esporádico

5. $\square$ desempregado

6. $\square$ aposentado/pensionista

7. $\square$ outros

16. Você está casado ou tem um relacionamento íntimo, atualmente?

1. $\square$ casado/ vivendo com uma companheira/ amigado

2. $\square$ casado/ vivendo com um companheiro/ amigado

3. $\square$ tem uma parceira/ namorada (com relação sexual), mas não vive junto

4. $\square$ tem parceiro/ namorado (com relação sexual), mas não vive junto

5. $\square$ tem uma parceira/ namorada, sem relação sexual.

6. $\square$ tem um parceiro/ namorado, sem relação sexual.

7. $\square$ não está casado, nem vivendo com alguém, nem namorando [ir p/ q23]

17. Há quanto tempo está com a(o) atual companheira(o)? anos $\mathrm{m}$

$\overline{18}$. Qual a idade da(o) companheira(o):

19.escolaridade do companheiro(a):

19 a. Ela(e) sabe ler e escrever?

19 b. Ela(e) já freqüentou a escola?
1. $\square \operatorname{sim}$
2. $\square$ não [ir para q. 20]

anos

não sabe : 99

17.

16.

15 a.

$15 \mathrm{~b}$.

14 a.

$14 \mathrm{~b}$.

$14 \mathrm{c}$.

$14 d$.

14 e.

$14 \mathrm{f}$.

$14 \mathrm{~g}$.

$14 \mathrm{~h}$.

14 i.

$14 \mathrm{j}$.

18.

19 a.

$19 \mathrm{~b}$.

19 c.

19 c. Até que série/ ano ela(e) estudou? Primeiro grau ano ano 
Universitário ano

não sabe : 99

20. Qual é a prática religiosa de sua companheira? (resposta múltipla)

\begin{tabular}{|c|c|c|c|}
\hline 1. & $\square$ católica & 6. & $\square$ espírita kardecista \\
\hline 2. & $\square$ judaica & 7. & $\square$ umbanda \\
\hline 3. & $\square$ muçulmana & 8. & $\square$ candomblé \\
\hline 4. & $\square$ evangélica histórica & 9. & $\square$ outras \\
\hline 5. & $\square$ evangélica pentecostal & $\begin{array}{l}10 . \\
99 .\end{array}$ & $\begin{array}{l}\square \text { sem prática religiosa } \\
\square \text { não sabe }\end{array}$ \\
\hline
\end{tabular}

20 a.

20 b.

1. $\square$ do lar

2. $\square$ doméstica(o)[cozinheira(o),copeira(o),faxineira(o),jardineira(o),etc]

3. $\square$ estudante

4. $\square$ trabalhadora(or) de empresa

5. $\square$ trabalhadora(or) autônoma(o)

6. $\square$ trabalhadora(or) esporádica(o)

7. $\square$ desempregada $(0)$

8. $\square \operatorname{aposentada(o)}$

9. $\square$ outros

99. $\square$ não sabe

22. Você manteve relações sexuais com mais alguém, além de sua atual ou mais recente companheira(o) no último ano?

1. $\square \operatorname{sim} 2 . \square$ não [ir para q. 23]

22a. Com que freqüência?

1. $\square$ muitas vezes 2 . $\square$ poucas vezes 3 . $\square$ raras vezes

23. Com que idade foi sua primeira relação sexual?: [se virgem $=00$, ir para q.29] não lembra/não sabe: 99

23a. Com quem foi sua primeira relação sexual?

1. $\square$ namorada

4. $\square$ familiar

2. $\square$ amiga/ conhecida

5. $\square$ outros

3. $\square$ garota de programa/ prostituta

8. $\square$ não quis responder

9. $\square$ não sabe/não lembra

24. Você tem filhos? $1 . \square \operatorname{sim}$

2. $\square$ não [ir para q.25]

24a. Quantos filhos?

atual/ último relacionamento?

$24 \mathrm{c}$ quantos são de outros relacionamentos?

24d. Quantos nasceram com baixo peso (abaixo de $2,5 \mathrm{~kg}$ )? não sabe/não lembra: 99

24e. Sobre seu último filho, você diria que: $1 . \square$ queria

$$
\begin{aligned}
& \text { 2. } \square \text { queria esperar } \\
& \text { 3. } \square \text { não queria } \\
& \text { 4. } \square \text { não fazia diferença }
\end{aligned}
$$

25. Sua atual companheira tem filhos de outros relacionamentos?
$1 . \square \operatorname{sim}$
2. $\square$ não [ir para q.26]
3. $\square$ não se aplica

25a. Quantos?

3.

26. Você e/ou sua parceira atual fazem uso de algum método para evitar gravidez? Qual? (resposta múltipla)

$1 \square$ não usa método

$2 \square$ ela está grávida

$3 \square$ diu

$4 \square$ pílula

$5 \square$ diafragma/geléia espermecida

$6 \square$ injeção

21 a.

21 b.

22.

22 a.

23.

23 a.

24 .

24 a.

24 b.

24 c.

$24 \mathrm{~d}$.

24 e.

25.

25 a.

26 a.

$26 \mathrm{~b}$. 
$7 \square$ laqueadura

$8 \square$ vasectomia

$9 \square$ condom/ camisinha

$10 \square$ métodos naturais (tabelinha, coito interrompido, lavagem, ducha, abstinência sexual)

$11 \square$ não se aplica (mulher na menopausa, sem parceira, mulher histerectomizada, homens que fazem sexo com homens)

$12 \square$ não sabe se a parceira usa

$13 \square$ usa, mas não sabe qual

$14 \square$ outros (ela está amamentando ou outros métodos)

27. Você alguma vez usou camisinha com sua(seu) parceira(o) mais

27 . recente/ atual para se proteger de alguma doença?

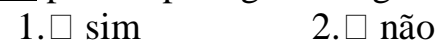

27a. Alguma vez você já se recusou a usar camisinha embora sua

27 a. parceira(o) atual/recente tivesse solicitado?
1. $\square \operatorname{sim}$
2. $\square$ não
3. $\square$ ela não solicitou

28. Nos últimos 12 meses, você teve

A . Dor na relação sexual

B. Ardor ao urinar

Sim Não

C. Secreção no pênis

D. Ferida e ou verruga no pênis/região genital

12

$\begin{array}{ll}1 & 2 \\ 1 & 2\end{array}$

28 a.

28 b.

28 c.

29. Você, alguma vez, já fez o teste para o hiv ou aids? Não queremos

28 d. saber o resultado, apenas saber se você já fez o teste.
1. $\square \operatorname{sim}$
2. $\square$ não
9. $\square$ não sabe

30. Quando você tem algum problema de saúde, geralmente, o que você faz (múltipla resposta)?
$1 \square$ não faz nada
$2 \square$ procura o centro/posto de saúde próximo
$3 \square$ procura o pronto-socorro/hospital público
$4 \square$ procura médico ou hospital conveniado
$5 \square$ vai à farmácia
$6 \square$ toma remédios caseiros (chá, ervas, etc.)
$7 \quad \square$ outros

31. Na última vez que você precisou ou quis procurar um serviço de saúde, você teve alguma dificuldade? (múltipla resposta). Explore:

1.

2.

$\square$ não precisei ou não quis

$\square$ não tive dificuldade

3. $\square$ distância do serviço de saúde

4. $\quad \square$ falta de dinheiro

5. $\square$ longo período de espera para ser atendido

6. $\quad \square$ não tinha vaga/longo período para conseguir uma vaga

7. $\square$ não tenho tempo para ir pois trabalho o dia todo

8. $\quad \square$ não tem horário de consulta fora do período do meu

trabalho

9.

não tem ninguém para marcar uma consulta para mim

10. $\square$ não sabia aonde ir

$11 . \quad \square$ outros

32. Com que frequência você faz atividade física?

31 a.

31 b.

31 c.

31 d.

$30 \mathrm{~b}$.

30 c.
1.
$\square$ todos ou quase todos os dias
2. $\quad \square$ uma ou duas vezes por semana
3. $\square 1-3$ vezes por mês
4. $\square$ raramente 
5. nunca

33. Atualmente você fuma.... 1. $\square$ diariamente [ir para q. 34]

33.

2. $\square$ ocasionalmente [ir para q. 34]

3. $\square$ de modo algum

33 a. Você já fumou alguma vez em sua vida? Você fumava...

33 a.

1. $\square$ diariamente

2. $\square$ ocasionalmente

3. $\square$ de modo algum

34. Com que freqüência você ingere bebida alcoólica?

34.
1. $\quad \square$ todos ou quase todos os dias
2. $\square$ uma ou duas vezes por semana
3 . $\square 1-3$ vezes por mês
4. $\square$ raramente
5. $\square$ parou de beber há um ano ou menos
$6 . \quad \square$ nunca (ir para q.36)

35. Nos últimos 12 meses você teve algum dos seguintes $\quad$ Sim Não problemas relacionados com a bebida?

35a. Problemas com dinheiro

35b. Problemas de saúde

35c. Conflitos familiares ou com amigos

35d. Problemas no bar

35e. Problemas com autoridades

35f. Problemas no trabalho

$\begin{array}{ll}1 & 2 \\ 1 & 2 \\ 1 & 2 \\ 1 & 2 \\ 1 & 2 \\ 1 & 2 \\ 1 & 2\end{array}$

35g. Outros

36. Atualmente você usa drogas (ilícitas)? Com que freqüência?

1. $\square$ todos ou quase todos os dias [ir para q. 37]

2. $\square$ uma ou duas vezes por semana [ir para q. 37]

3. $\square 1-3$ vezes por mês [ir para q.37]

4. $\quad \square$ raramente [ir para q.37]

$5 . \quad \square$ não usa

36 a. Você já usou drogas (ilícitas) alguma vez na vida? Com que frequiência?
1. $\square$ todos ou quase todos os dias
2. $\square$ uma ou duas vezes por semana
3. $\square 1-3$ vezes por mês
4. $\square$ apenas experimentou
$5 . \quad \square$ não usou

37. Na casa em que você foi criado você presenciou brigas e/ou discussões entre seus pais e/ou outros familiares?

$1 . \quad \square$ poucas vezes

2. $\square$ muitas vezes

3. $\square$ nunca

38. Quando você era criança, sua mãe era agredida fisicamente pelo seu pai ou marido/companheiro dela?
$1 . \square \operatorname{sim}$
2. $\square$ não
3. $\square$ não se aplica (não morava
com os pais)

"os assuntos que se seguem acontecem com muitas pessoas em relações pessoais, familiares e profissionais. Fique à vontade para responder, ou não, as perguntas que seguem."

39. Alguma vez, alguém (na rua, no bar, no trabalho ou em sua casa) já lhe $\mathbf{3 9}$. insultou, depreciou ou fez com que você se sentisse desvalorizado?

1. $\square \operatorname{sim}$

2. $\square$ não [ir para q. 40] 
8. $\square$ não quis responder [ir para q. 40]

\begin{tabular}{|c|c|c|c|c|c|c|c|}
\hline \multirow[t]{2}{*}{39 a. Quem?(explore) } & \multicolumn{4}{|c|}{$\begin{array}{l}39 \text { b. Quantos anos você tinha? } \\
\text { (explore) }\end{array}$} & \multicolumn{3}{|c|}{$\begin{array}{l}39 \text { c. Quantas vezes } \\
\text { isso aconteceu? }\end{array}$} \\
\hline & $\begin{array}{c}\text { Antes dos } \\
12\end{array}$ & $12-18$ & 19-39 & $\begin{array}{c}40 \mathrm{ou} \\
\text { mais }\end{array}$ & Uma & $\begin{array}{c}\text { Pouc } \\
\text { as }\end{array}$ & $\begin{array}{c}\text { Muita } \\
\text { s }\end{array}$ \\
\hline a) Esposa/namorada & 1 & 2 & 3 & 4 & 1 & 2 & 3 \\
\hline b) Filhos & 1 & 2 & 3 & 4 & 1 & 2 & 3 \\
\hline c) Mãe/mãe adotiva & 1 & 2 & 3 & 4 & 1 & 2 & 3 \\
\hline d) Pai/pai adotivo & 1 & 2 & 3 & 4 & 1 & 2 & 3 \\
\hline e) $\operatorname{Irmão(ã)(s)~}$ & 1 & 2 & 3 & 4 & 1 & 2 & 3 \\
\hline f) Outros familiares & 1 & 2 & 3 & 4 & 1 & 2 & 3 \\
\hline g) Vizinhos & 1 & 2 & 3 & 4 & 1 & 2 & 3 \\
\hline h) Colega/amigo(a)(s) & 1 & 2 & 3 & 4 & 1 & 2 & 3 \\
\hline i) Colegas/pessoas do trabalho & 1 & 2 & 3 & 4 & 1 & 2 & 3 \\
\hline j) Patrão/chefe & 1 & 2 & 3 & 4 & 1 & 2 & 3 \\
\hline k) Polícia & 1 & 2 & 3 & 4 & 1 & 2 & 3 \\
\hline 1) Estranhos & 1 & 2 & 3 & 4 & 1 & 2 & 3 \\
\hline m) Ex-esposa/ex-namorada & 1 & 2 & 3 & 4 & 1 & 2 & 3 \\
\hline n) Outros_ & 1 & 2 & 3 & 4 & 1 & 2 & 3 \\
\hline
\end{tabular}

40. Alguma vez, alguém (na rua, no bar, no trabalho ou em sua casa) já lhe $\mathbf{4 0}$. agrediu fisicamente (com tapas, empurrões, socos, chutes, etc)?
1. $\square \operatorname{sim}$
2. $\square$ não [ir para q.41]
8. $\square$ não quis responder [ir para q. 41]

\begin{tabular}{|c|c|c|c|c|c|c|c|c|}
\hline \multirow{2}{*}{\multicolumn{2}{|c|}{$\begin{array}{l}40 \text { a. Quem? } \\
\text { (explore) }\end{array}$}} & \multicolumn{4}{|c|}{$\begin{array}{l}40 \text { b. Quantos anos você tinha? } \\
\text { (explore) }\end{array}$} & \multicolumn{3}{|c|}{$\begin{array}{l}40 \text { c. Quantas vezes } \\
\text { isso aconteceu? }\end{array}$} \\
\hline & & $\begin{array}{l}\text { Antes dos } \\
\quad 12\end{array}$ & $12-18$ & 19-39 & $\begin{array}{l}40 \text { ou } \\
\text { mais }\end{array}$ & Uma & $\begin{array}{l}\text { Pou } \\
\text { cas }\end{array}$ & $\begin{array}{c}\text { Muit } \\
\text { as }\end{array}$ \\
\hline a) & Esposa/namorada & 1 & 2 & 3 & 4 & 1 & 2 & 3 \\
\hline b) & Filhos & 1 & 2 & 3 & 4 & 1 & 2 & 3 \\
\hline c) & Mãe/mãe adotiva & 1 & 2 & 3 & 4 & 1 & 2 & 3 \\
\hline d) & Pai/pai adotivo & 1 & 2 & 3 & 4 & 1 & 2 & 3 \\
\hline e) & Irmão(ã)(s) & 1 & 2 & 3 & 4 & 1 & 2 & 3 \\
\hline f) & Outros familiares & 1 & 2 & 3 & 4 & 1 & 2 & 3 \\
\hline g) & Vizinhos & 1 & 2 & 3 & 4 & 1 & 2 & 3 \\
\hline h) & Colega/amigo(a)(s) & 1 & 2 & 3 & 4 & 1 & 2 & 3 \\
\hline i) & Colegas/pessoas do trabalho & 1 & 2 & 3 & 4 & 1 & 2 & 3 \\
\hline j) & Patrão/chefe & 1 & 2 & 3 & 4 & 1 & 2 & 3 \\
\hline k) & Polícia & 1 & 2 & 3 & 4 & 1 & 2 & 3 \\
\hline 1) & Estranhos & 1 & 2 & 3 & 4 & 1 & 2 & 3 \\
\hline & Ex-esposa/ex-namorada & 1 & 2 & 3 & 4 & 1 & 2 & 3 \\
\hline n) & Outros & 1 & 2 & 3 & 4 & 1 & 2 & 3 \\
\hline
\end{tabular}

41. Alguma vez, alguém já lhe forçou a ter relação sexual contra sua

41. vontade?

1. $\square \operatorname{sim}$

2. $\square$ não [ir para q. 42]

8. $\square$ não quis responder [ir para q. 42]

\begin{tabular}{|c|c|c|c|c|c|c|c|}
\hline $\begin{array}{l}41 \text { a. Quem? } \\
\text { (explore) }\end{array}$ & \multicolumn{4}{|c|}{$\begin{array}{l}41 \text { b. Quantos anos você tinha? } \\
\text { (explore) }\end{array}$} & \multicolumn{3}{|c|}{$\begin{array}{l}41 \text { c. Quantas vezes } \\
\text { isso aconteceu? }\end{array}$} \\
\hline \multirow[b]{2}{*}{ a) Esposa/namorada } & $\begin{array}{l}\text { Antes dos } \\
12\end{array}$ & $12-18$ & $19-39$ & $\begin{array}{l}40 \text { ou } \\
\text { mais }\end{array}$ & Uma & $\begin{array}{l}\text { Pou } \\
\text { cas }\end{array}$ & $\begin{array}{c}\text { Muit } \\
\text { as }\end{array}$ \\
\hline & 1 & 2 & 3 & 4 & 1 & 2 & 3 \\
\hline
\end{tabular}




\begin{tabular}{|c|c|c|c|c|c|c|}
\hline b) Filhos & 1 & 2 & 3 & 4 & 1 & \\
\hline c) Mãe/mãe adotiva & 1 & 2 & 3 & 4 & 1 & \\
\hline d) Pai/pai adotivo & 1 & 2 & 3 & 4 & 1 & \\
\hline e) $\operatorname{Irmão}(\tilde{a})(s)$ & 1 & 2 & 3 & 4 & 1 & \\
\hline f) Outros familiares & 1 & 2 & 3 & 4 & 1 & \\
\hline g) Vizinhos & 1 & 2 & 3 & 4 & 1 & \\
\hline h) Colega/amigo(a)(s) & 1 & 2 & 3 & 4 & 1 & \\
\hline i) Colegas/pessoas do trabalho & 1 & 2 & 3 & 4 & 1 & \\
\hline j) Patrão/chefe & 1 & 2 & 3 & 4 & 1 & \\
\hline k) Polícia & 1 & 2 & 3 & 4 & 1 & \\
\hline 1) Estranhos & 1 & 2 & 3 & 4 & 1 & \\
\hline m) Ex-esposa/ex-namorada & 1 & 2 & 3 & 4 & 1 & \\
\hline n) Outros & & & & 4 & 1 & \\
\hline
\end{tabular}

Atenção entrevistador

As questões que seguem referem-se a homens que estão casados, moram com a (o) companheira (o) ou têm namorada (o), ou que alguma vez na vida tiveram relacionamentos deste tipo. Se VIRGEM, VÁ PARA A QUESTÃo 47

42. No seu relacionamento atual ou mais recente com sua companheira ou

42. namorada, com que frequência você diria que vocês brigam ou discutem?
1. $\square$ nunca (ir para q.43)
2. $\quad \square$ raramente
3. $\square$ algumas vezes
4. $\square$ frequentemente

42a. E quando isso ocorre, na maioria das vezes, quem inicia a discussão ou a

42 a. briga?

1. $\quad \square$ o entrevistado

2. $\square$ esposa/companheira

3 . $\quad \square$ os dois

42b. Existem situações particulares que levam vocês dois a brigarem ou

discutirem? (explore) (múltipla resposta)

42 b 1.

1. $\square$ sem motivos

2. $\square$ problemas com a bebida

3. $\square$ problemas com dinheiro

4. $\quad \square$ problemas com os filhos

5. $\square$ problemas com outros familiares

6. $\square$ dificuldades no meu trabalho

7. $\square$ quando estou desempregado

8. $\square$ quando saio para beber com os amigos

9. $\square$ durante a gravidez de minha esposa/companheira

42 b 2.

42 b 3.

42 b 4.

42 b 5.

10. $\square$ ciúmes em relação a mim

11. $\square$ ciúmes em relação à ela

12. $\square$ quando minha esposa/companheira se recusa a ter relações sexuais

13. $\square$ quando ela me desobedece ou não me escuta

14. $\square$ quando ela não pára de falar

15. $\square$ outras 


\begin{tabular}{|c|c|c|c|c|c|c|c|c|c|c|}
\hline $\begin{array}{l}\text { 43. O senhor } \\
\text { poderia me dizer } \\
\text { se alguma vez } \\
\text { tratou a sua atual } \\
\text { esposa/companhei } \\
\text { ra(o), ou qualquer } \\
\text { outra } \\
\text { companheira ou } \\
\text { namorada (o) }\end{array}$ & \multicolumn{2}{|c|}{$\begin{array}{l}\text { A) } \\
\text { (se sim, } \\
\text { continue } \\
\text { em b. Se } \\
\text { não, vá } \\
\text { para o } \\
\text { próximo } \\
\text { item) }\end{array}$} & \multicolumn{2}{|c|}{$\begin{array}{l}\text { B) } \\
\text { Isto aconteceu } \\
\text { nos últimos } 12 \\
\text { meses? } \\
\text { (se sim, } \\
\text { pergunte } \\
\text { somente a c. } \\
\text { Se não, } \\
\text { somente a d) }\end{array}$} & \multicolumn{3}{|c|}{$\begin{array}{l}\text { C) } \\
\text { Nos últimos } 12 \\
\text { meses você diria } \\
\text { que isso aconteceu } \\
\text { uma, poucas ou } \\
\text { muitas vezes? } \\
\text { (depois de } \\
\text { responder a c, pule } \\
\text { o d) }\end{array}$} & \multicolumn{3}{|c|}{$\begin{array}{l}\text { D) } \\
\text { Antes dos últimos } 12 \\
\text { meses você diria que } \\
\text { isso aconteceu uma, } \\
\text { poucas ou muitas } \\
\text { vezes? }\end{array}$} \\
\hline 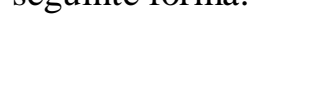 & Sim & Não & Sim & Não & $\begin{array}{c}\mathbf{U m} \\
\mathbf{a}\end{array}$ & $\begin{array}{c}\text { Pouc } \\
\text { as }\end{array}$ & $\begin{array}{c}\text { Muit } \\
\text { as }\end{array}$ & $\begin{array}{c}\text { Um } \\
\mathbf{a}\end{array}$ & Poucas & $\begin{array}{c}\text { Muit } \\
\text { as }\end{array}$ \\
\hline $\begin{array}{l}\text { a) Insultou, } \\
\text { depreciou, } \\
\text { humilhou ou fez } \\
\text { com que ela (e) se } \\
\text { sentisse mal }\end{array}$ & 1 & 2 & 1 & 2 & 1 & 2 & 3 & 1 & 2 & 3 \\
\hline $\begin{array}{l}44 . \\
\text { a) Deu-lhe um } \\
\text { tapa ou jogou algo } \\
\text { que poderia } \\
\text { machucá-la? }\end{array}$ & 1 & 2 & 1 & 2 & 1 & 2 & 3 & 1 & 2 & 3 \\
\hline $\begin{array}{l}\text { b) Empurrou-a ou } \\
\text { deu-lhe um tranco/ } \\
\text { chacoalhão? }\end{array}$ & 1 & 2 & 1 & 2 & 1 & 2 & 3 & 1 & 2 & 3 \\
\hline $\begin{array}{l}\text { c) Machucou-a } \\
\text { com um soco ou } \\
\text { com algum objeto? }\end{array}$ & 1 & 2 & 1 & 2 & 1 & 2 & 3 & 1 & 2 & 3 \\
\hline $\begin{array}{l}\text { d) Deu-lhe um } \\
\text { chute, arrastou-a ou } \\
\text { surrou-a? }\end{array}$ & 1 & 2 & 1 & 2 & 1 & 2 & 3 & 1 & 2 & 3 \\
\hline $\begin{array}{l}\text { e) Estrangulou-a } \\
\text { ou queimou-a de } \\
\text { propósito? }\end{array}$ & 1 & 2 & 1 & 2 & 1 & 2 & 3 & 1 & 2 & 3 \\
\hline $\begin{array}{l}\text { f) Ameaçou usar } \\
\text { ou realmente usou } \\
\text { arma de fogo, faca } \\
\text { ou outro tipo de } \\
\text { arma contra ela? }\end{array}$ & 1 & 2 & 1 & 2 & 1 & 2 & 3 & 1 & 2 & 3 \\
\hline $\begin{array}{l}45 . \\
\text { a) Obrigou sua } \\
\text { parceira a ter } \\
\text { relações sexuais } \\
\text { quando ela não } \\
\text { queria? }\end{array}$ & 1 & 2 & 1 & 2 & 1 & 2 & 3 & 1 & 2 & 3 \\
\hline $\begin{array}{l}\text { b) Obrigou sua } \\
\text { parceira a fazer } \\
\text { certas práticas } \\
\text { sexuais de que ela } \\
\text { não gostasse? }\end{array}$ & 1 & 2 & 1 & 2 & 1 & 2 & 3 & 1 & 2 & 3 \\
\hline
\end{tabular}

46. Alguma destas vezes ela estava grávida?
1. $\square \operatorname{sim}$
2. $\square$ não 9. $\square$ não sabe/não lembra

47. Após os seus 18 anos, você alguma vez já bateu ou agrediu fisicamente

46.

47 . 
alguém que não a sua companheira? 1. $\square \operatorname{sim} \quad$ 2. $\square$ não [ir para q. 48] 47a. Em quem? (resposta múltipla)
1. $\square$ filhos
7. $\square$ vizinhos
2. $\square$ mãe/mãe adotiva
8. $\square$ amigo/conhecido(a) (s)
3. $\square$ pai/pai adotivo
9. $\square$ colegas/pessoas do trabalho
4. $\square$ irmão (ã) (s)
10. $\square$ pessoas em bar (conhecidas ou não)
5. $\square$ familiares
11. $\square$ estranhos
consangüíneos
12. $\square$ outros

47 a 1.

47 b 2.

47 c 3.

$47 \mathrm{~d} 4$.

47 d 5.

6. $\square$ familiares afins

48. Você considera que sofreu violência por alguma pessoa na vida? 1 . $\square$ sim

2. $\square$ não

49. Você considera que já foi violento com alguém na vida? $1 . \square$ sim

2. $\square 49$.

não

50. Agora eu farei duas questões e gostaria que você anotasse suas respostas no cartão que vou the dar. Neste cartão há espaços para você marcar um "x" na alternativa sim ou não. Você não é obrigado a responder, mas isso lhe garantirá o anonimato, ou seja, ninguém saberá de sua resposta. Depois de marcar o cartão, por favor dobre-o e coloque-o nesta urna, junto com os cartões de outros homens. Pois bem, as perguntas são:

50a. Antes dos 12 anos, alguma vez você já foi forçado a algum ato sexual contra sua vontade ? 1. $\square$ respondeu

2. $\square$ não quis responder

50 a.

50b. Você já forçou ou obrigou alguém a ter relação sexual quando esta pessoa não queria?

1. $\square$ respondeu

2.

não quis responder

51. Entrevistador:

52. Hora de término:

51.

Observações do entrevistador:

50 b. 
Anexo C Instrumentos: AneXo C.2

\section{FICHA DE LEITURA DE PRONTUÁRIOS MÉDICOS}

\section{FICHA DE LEITURA DE PRONTUÁRIOS MÉDICOS - ficha 1}

1. Serviço $n^{o}$ questionário

1.

2. $\mathrm{N}^{\mathrm{o}}$ do Prontuário

2 .

Iniciais do usuário

3. Modalidade: 1. $\square$ Em uso

2. $\square$ Acompanhante

3.

4. Data de nascimento:

5. Data da aplicação questionário:

6. Data de inscrição no serviço:

_L___ (a partir de 12 anos)

4.

5.

6.

7. Uso de serviço no último ano (referência: data da entrevista $\mathrm{p} /$ em uso e data da ultima consulta p/ acompanhante):

\begin{tabular}{|l|l|l|}
\hline \multicolumn{1}{|c|}{ Atividade de Atendimento } & \multicolumn{2}{c|}{$\mathbf{N}^{\mathbf{0}}$ de vezes que passou por cada atividade } \\
\hline 7.a Caso Novo, P A, Encaixe & & \\
\hline 7.b Segmento, Retorno & & \\
\hline 7.c Atendimento enfermagem & & \\
\hline 7.d Grupos & & \\
\hline 7.e Entrev. Dinâmica/Triagem, Consulta S & & \\
M (Médico) & & \\
\hline 7.f Terapia Individual (Psicólogo) & & \\
\hline 7.g Grupos Saúde Mental & & \\
\hline 7.h Assistente Social & & \\
\hline 7. i Visita Domiciliar & & \\
\hline 7.j Outras Atividades & & \\
\hline 7. $\mathrm{k} \mathrm{n}$ comparecimento & & \\
\hline 7. Faltas em atividades agendadas & & \\
\hline
\end{tabular}

8. Uso de serviço na vida: (desde entrada na Saúde do Adulto)

\begin{tabular}{|l|l|l|l|l|}
\hline \multicolumn{1}{|c|}{ Atividade de Atendimento } & \multicolumn{3}{c|}{ Registro de Violência } & \multicolumn{1}{c|}{$\begin{array}{c}\mathbf{N}^{\mathbf{0}} \text { de vezes que } \\
\text { passou por cada } \\
\text { atividade }\end{array}$} \\
\hline 8.a Caso Novo, Pronto Atendimento & & & & \\
\hline 8.b Segmento, retorno & & & & \\
\hline 8.c Atendimento enfermagem & & & & \\
\hline 8.d Grupos & & & & \\
\hline $\begin{array}{l}\text { 8. e Entrevista Dinâmica/Triagem e } \\
\text { Consulta Saúde Mental (Médico) }\end{array}$ & & & & \\
\hline 8.f Terapia Individual (Psi.) & & & & \\
\hline 8.g Grupos Saúde Mental & & & & \\
\hline 8.h Assistente Social & & & & \\
\hline 8.i Visita Domiciliar & & & & \\
\hline 8.j n comparecimento & & & & \\
\hline 8.k Faltas em atividades agendadas & & & & \\
\hline
\end{tabular}

9. Relato espontâneo de violência sofrida na Vida (se pelo menos 1 relato, assinalar SIM): 
9.
0. não ( )
1. $\operatorname{sim}(\quad)$

10. Relato espontâneo de violência praticada na Vida (se pelo menos 1 relato, assinalar SIM):
0. não ( )
1. Contra Mulheres ( )
2. Contra Outros ( )
10.

11. Relato de violência Sofrida (questionário) (a ser preenchido na codificação):

0. não ( ) 1. $\operatorname{sim}($ )

11.

12. Relato de violência Perpetrada (questionário) (a ser preenchido na codificação):

0. não ( ) 1. Contra Mulheres ( ) 2. Contra Outros ( )

13. Data da avaliação do prontuário: I

13.

14. Avaliador do prontuário

14.

\section{FICHA DE LEITURA DE PRONTUÁRIOS MÉDICOS - ficha 2}

1. Serviço questionário

2. $\mathrm{N}^{\mathrm{o}}$ do Prontuário

3. Data do Atendimento

4. Tipo de Atendimento

1.Caso Novo/Pronto Atendimento

2.Retorno, segmento

3.Atendimento enfermagem

4.Grupos

5.Entrev. Dinâmica/Triagem e Consulta SM (Médica)
1.

2.

3. -1

4.

6.Terapia Individual (Psicólogo) 7.Grupo Saúde Mental

8.Assistência Social

9. Visita domiciliar 10.Outras Atividades 


\section{Queixas/ Diagnóstico}

\section{queixas gerais}

1. Dor geral ou inespecífica

2. $\square$ Calafrios

3. $\square$ Sudorese

4. $\square$ Febre

5. $\square$ Fraqueza/Cansaço

6. $\square$ Dor no peito

7. $\square$ Queixas genéricas/vagas

8. $\square$ Dor de cabeça/cefaléia

9. $\square$ Vertigem/tontura/ desmaio/síncope

10. $\square$ Inchaço/edema

11. $\square$ Perda de apetite/perda de peso

Osteo-muscular

12. $\square$ Queixas (dor) nas

costas/lombar/ombros

13. $\square$ Queixas (dor) em MMSS

14. $\square$ Queixas (dor) em MMII

15. $\square$ Queixas (dor) nos pés

16. $\square$ Dor muscular

17. $\square$ Hematoma/fratura/lesão

18. $\square$ Outras queixas osteomusculares

Aparelho digestivo

19. $\square$ Dor abdominal/cólicas gerais

20. $\square$ Dor epigástrica/dor de

estômago

21. $\square$ Dispepsia/indigestão

22. $\square$ Náusea/azia

23. $\square$ Vômito

24. $\square$ Diarréia

25. $\square$ Constipação

26. $\square$ Sangramento retal

27. $\square$ Dificuldade para engolir

28. $\square$ Massas abdominais

29. $\square$ Vermes

30. $\square$ Distensão abdominal

31. $\square$ Outros sintomas/queixas

digestivas

\section{Cárdio-circulatório}

32. $\square$ Dor no coração/angina

33. $\square$ Hipertensão e/ou aumento PA

34 $\square$ Varizes

35. $\square$ Outros sintomas/queixas cardio-

circulatório

\section{Olhos e Ouvidos}

36. 37. $\square$ Dor de Ouvido/otalgia

37. $\square$ Queixas de audição

38. $\square$ Queixas de visão

Respiratório

39. $\square$ Dispnéia/estado ofegante
40. $\square$ Tosse

41. $\square$ Gripe/resfriado/sinusite/coriza

42. $\square$ Queixas e sintomas na garganta

43. $\square$ Asma/bronquite

44. $\square$ Pneumonia

45. $\square$ Tuberculose

46. $\square$ Outros sintomas/ queixas respiratórias

\section{Dermato}

47. $\square$ Prurido/ coceira

48. $\square$ Abrasão/arranhões/bolhas pele

49. $\square$ Manchas e erupção cutânea

50. $\square$ Dermatofitose/frieira

51. $\square$ Urticária

52. $\square$ Outras queixas de pele

Neurológico

53. $\square$ Convulsão

54. $\square$ Epilepsia

55. $\square$ Nevralgia

56. $\square$ Outras queixas/sintomas neurológicos

Metabólico

57. $\square$ Obesidade ou sobrepeso

58. $\square$ Dislipidemias

59. $\square$ Colesterol aumentado

60. $\square$ Diabetes

61. $\square$ Distúrbios metabólicos

\section{Genito-urinário}

62. $\square$ Disúria/ardor ao urinar

63. $\square$ Frequência/Urgência urinária

64. $\square$ Incontinência urinária

65. $\square$ Uretrite

66. $\square$ Impotência

67. $\square$ Ejaculação Precoce

68. $\square$ Ferida, verruga, coceira no pênis e região genital

69. $\square$ Dor na relação sexual

70. $\square$ Sexo desprotegido, parceria múltipla

71. $\square$ Outras queixas genito-urinárias 
Psicológico

$72 \square$ Depressão

$73 \square$ Raiva/irritabilidade alta

$74 \square$ Nervosismo/ansiedade

$75 \square$ Insônia/Distúrbio de sono

$76 \square$ Tentativa de suicídio

$77 \square$ Problemas de memória/confusão mental

Social

$780 \square$ Problemas no trabalho

$79 \square$ Desemprego

$80 \square$ Problemas relacionamento c/ família

$81 \square$ Problemas relacionamento c/ conhecidos/vizinhos

$82 \square$ Viol. física contra o Usuário na casa

$83 \square$ Viol. física contra o Usuário por outros

$84 \square$ Viol. sexual contra o usuário

$85 \square$ Violência contra o usuário não especificada

$86 \square$ Viol. física do usuário contra a mulher

$87 \square$ Viol. sexual do usuário contra a mulher

$88 \square$ Violência do usuário contra mulher não especificada

5.A

$5 . \mathrm{B}$

5.C

5.D

5.E
6. Conduta:
1. $\square \operatorname{sim}$
2. $\square$ não

6. Encaminhamento:

Interno ao serviço

1. $\square$ Saúde Mental

2. $\square$ Outros

$7 \mathrm{~A}$

Externo

3. $\square$ Saúde Mental

4. $\square$ Outros

$7 \mathrm{~B}$

5.Não houve

$7 \mathrm{C}$

6. Ilegível

$7 \mathrm{D}$ 


\section{Referências Bibliográficas}


ADDIS ME, MAHALIK JR. Men, masculinity, and the contexts of help seeking. American Psychologist. 2003;58(1):5-14.

ANDRADE MC. Violência contra a mulher e exclusão social: estudo entre subgrupos de populações usuárias do Centro de Saúde Escola Barra Funda Dr. Alexandre Vranjac [dissertação]. São Paulo: Faculdade de Medicina, Universidade de São Paulo; 2003.

ARANA MJ. Mujeres en la Historia [on-line]. Mujeres en red; 2005. Available from: http://www.nodo50.org/mujeresred/historia-mj_arana.html

ARILHA M. O masculino em conferências e programas das Nações Unidas: para uma crítica do discurso de gênero [tese]. São Paulo: Faculdade de Saúde Publica, Universidade de São Paulo; 2005.

BAllarín P, Birriel M, MARTinez C, Ortíz T. Las mujeres en la historia de Europa. In: Mujeres en Europa: convergencias y diversidades [on-line]. Universidad de Granada; 1998. Available from: www.helsinki.fi/science/xantippa/wee/wee1.html

BANDEIRA L. Relações de gênero, corpo e sexualidade. In: GALVÃo L, Díaz J. Saúde sexual e reprodutiva no Brasil. São Paulo: Hucitec-Population Council; 1999. p. 180-97.

BANKS I. New models for providing men with health care [editorial]. The Journal of Men's Health and Gender. 2004;1(2-3):155-8.

BARTLETT EE. The effects of fatherhood on the health of men: a review of the literature. The Journal of Men's Health and Gender. 2004;1(2-3):159-69.

BESSIS S. Cien años de feminismo [on-line]. UNESCO: United Nations Educational Scientific and Cultural Organization; 2000. Available from: http://www.unesco.org/courier/2000_06/sp/doss11.htm

CARbone MH. Tísica e rua: os dados da vida e seu jogo [tese] [on-line]. Rio de Janeiro: Escola Nacional de Saúde Pública, Ministério da Saúde - Fundação Oswaldo Cruz; $2000 . \quad$ Disponível em: http://portalteses.cict.fiocruz.br/pdf/FIOCRUZ/2000/carbonemhm/capa.pdf 
Carneiro Junior N, Lesher AD, Grojcer B, Bedoian G, AZEvedo, LM, Silva LN da, PERnAmbuCo MCA. Crianças em situação de risco social: limites $e$ necessidades da atuação do profissional de saúde. São Paulo: G. Bedoian Comunicação; 2004. 74p.

CARNeIRo Junior N, SiLveIRA C. Organização das práticas de atenção primária em saúde no contexto dos processos de exclusão/inclusão social. Cad. Saúde Pública. 2003;19(6):1827-35.

CASTElls M. O fim do patriarcalismo: movimentos sociais, família e sexualidade na era da informação. In: $O$ poder da identidade: a era da informação, economia, sociedade e cultura. $3^{\mathrm{a}}$ ed. Paz e Terra; 2001. cap.4.

CecCARelli PR. A construção da masculinidade [on-line]. Percurso. 1998a;19:4956.

Disponível

em:

http://www.ceccarelli.psc.br/artigos/portugues/html/aconstrucao.htm

CECCARELLI PR. A masculinidade e seus avatares [on-line]. Catharsis. 1998b;19:101. em: http://www.ceccarelli.psc.br/artigos/portugues/html/amasculinidade.htm

Chaves LC. Getúlio Dornelles Vargas 1883 - 1954 [on-line]. 2004. Disponível em: http://www.culturabrasil.org.br/vargas.htm

CONNEll RW. La organización social de la masculinidad. In: VladÉs T, OlaVARIA J. Masculinidades - Poder Y Crisis. Chile: Ediciones de las mujeres; 1997. p.31-48.

CONNELL RW. Understanding men: gender sociology and the new international research on masculinities. In: Clark Lecture; 2000, Kansas.

CONSTITUIÇÃo 1934 [on-line]. Disponível em: https://www.planalto.gov.br/ccivil_03/Constituicao/Constituicao34.htm

Costa AAA. O movimento feminista no Brasil: dinâmicas de uma intervenção política. Labrys - Estudos Feministas [on-line]. 2005. Disponível em: http://www.unb.br/ih/his/gefem/labrys7/liberdade/anaalice.htm 
COURTENAY WH. Constructions of masculinity and their influence on men's wellbeing: a theory of gender and health. Social Science \& Medicine. 2000;50:13851401.

Courtenay WH., KeELing RP. Men, gender, and health: toward an interdisciplinary approach [editorial]. Journal of American College Health. 2000;48:243-46.

COUTO MT, ScHRAIBER LB. Homens, saúde e violência: novas questões de gênero no campo da Saúde Coletiva. In: Minayo MCS, CoIMBra Junior, CEA. Críticas e atuantes: ciências sociais e humanas em saúde na América Latina. Rio de Janeiro: Fiocruz; 2005. p.687-706.

COUTO MT. Homens, violência e saúde: uma contribuição para o campo de pesquisa e intervenção em gênero, violência doméstica e saúde [tese]. São Paulo: Faculdade De Medicina, Universidade de São Paulo; 2002.

D'Oliveira AFPL, Senna DM. Saúde da mulher. In: Schraiber LB, Neme MIB, Mendes-GonçAlves RB. Saúde do adulto - programas e ações na unidade básica. São Paulo: Hucitec; 1996. p.86-108.

Datasus. Ministério DA SAÚde, BRASIL [on-line]. Disponível em: http://w3.datasus.gov.br/datasus/datasus.php

DAVIES J, MCCRAE BP, FrAnK J et al. Identifying male college students' perceived health needs, barriers to seeking help, and recommendations to help men adopt healthier lifestyles. Journal of American College Health. 2000;48:259-67.

DINIZ SG. Gênero e prevenção das DST. Coletivo Feminista Sexualidade e Saúde. 2001 [on-line]. Disponível em: http://www.mulheres.org.br/fiqueamigadela/arquivocompleto.pdf

DuARTE CL. Feminismo e literatura no Brasil. Estud. av. 2003;17(49): p.151-72. [on-line]. Disponível em: http://www.scielo.br/pdf/ea/v17n49/18402.pdf

ESQUEMA CRONOLÓGICO DO SISTEMA ELEITORAL [on-line]. Disponível em: http://www.ucam.edu.br/leex/Inter/Cronolog1.htm

FARIA N, NoBre M. Gênero e desigualdade. São Paulo: SOF; 1997. 52p.

FERREIRA M. Feminismo e ciências sociais. Estudos Feministas. 2005;13(3):756-74. 
FigueIREDO W. Assistência à saúde dos homens: um desafio para os serviços de atenção primária. Ciências \& Saúde Coletiva - Saúde do Homem: Alerta e Relevância. 2005;10(1):105-9.

FONSECA AJMS da. A teoria da masculinidade. In: A identidade masculina segundo Robert Bly: o paradoxo entre o real e o imaginado [dissertação] [on-line]. Lisboa: Universidade Aberta; 1999. Available from:

Formiga Filho JFN. Políticas de saúde reprodutiva no Brasil: uma análise do PAISM. In: Galvão D, DiAZ J. Saúde sexual e reprodutiva no Brasil. São Paulo: Hucitec-Population Council; 1999. p.151-62.

Gadelha M. Cinqüentenário da morte de Getulio Vargas e o Brasil moderno - o cinqüentenário de um estadista [on-line]. 2004. Disponível em: http://www.getulio50.org.br/textos/gvap1.htm

GARCIA SM. Conhecer os homens a partir do gênero e para além do gênero. In: ARILHA M, RIDENT SGU, MEDRADO B. Homens e masculinidade - outras palavras. São Paulo: ECOS/EDITORA 34; 1998. p.31-50.

GifFin K, Cavalcanti C. Homens e reprodução. Revista Estudos Feministas. 1999; 7(1-2):53-71.

GIFFIN K. A inserção dos homens nos estudos de gênero: contribuições de um sujeito histórico. Ciências \& Saúde Coletiva - Saúde do Homem: Alerta e Relevância. 2005;10(1):47-57.

GIFFIN K. Pobreza, desigualdade e equidade em saúde: considerações a partir de uma perspectiva de gênero transversal. Cad. Saúde Pública. 2002;18(suplemento): 103112.

GIFFIN K. Violência de gênero, sexualidade e saúde. Cad. Saúde Pública. 1994;10(1):146-55.

Gomes R, NAscimento EF do. A produção do conhecimento da saúde publica sobre a relação homem-saúde: uma revisão bibliográfica. Cad. Saúde Pública. 2006;22(5):901-11. 
Gomes R, Schraiber LB, Couto MT. O homem como foco da Saúde Pública [editorial]. Ciências \& Saúde Coletiva - Saúde do Homem: Alerta e Relevância. 2005;10(1):4.

GRUMBACH MM. To an understanding of the biology of sex and gender differences: "an idea whose time has come" [editorial]. The Journal of Men's Health and Gender. 2004;1(1):12-9.

HEISE L. Gender based abuse: the global epidemic. Cad. Saúde Pública. 1994;10(1):135-45.

HERnÁNDEZ A. ¿Masculinidad o masculinidades?. La tarea. 1996;8: [on-line]. Available from: http://www.latarea.com.mx/articu/articu8/hernandez8.htm

HISTÓRIA DO VOTO [on-line]. Disponível em: http://www.direitoshumanos.rj.gov.br/docs/dh_brasil/historia_voto_br.htm

ibGE - Instituto Brasileiro de Geografia e Estatística. Sidra, censo. BRASIL; 2000 [on-line]. Disponível em: http://www.sidra.ibge.gov.br/

JONES WK. Men's health as a public health issue [editorial]. The Journal of Men's Health and Gender. 2004;1(2-3):147-9.

KORIN D. Adolescência Latinoamericana - Nuevas perspectivas de género en salud. Adolesc. Latinoam. 2001;2(2):67-79 [on-line]. Available from: http://raladolec.bvs.br/pdf/ral/v2n2/p03v2n2.pdf

Laurenti R, Jorge MHPM, Gotlieb SLD. Perfil epidemiológico da morbimortalidade masculina. Ciências \& Saúde Coletiva - Saúde do Homem: Alerta e Relevância. 2005;10(1):35-46.

LAURENTI R. Perfil epidemiológico da saúde masculina nas regiões das Américas: uma contribuição para o enfoque de gênero. Faculdade de Saúde Pública/USP,São Paulo, 1998.

LeOnardo PX, Marmo AC. Adolpho Gordo e Bertha Lutz: a luta pelo voto feminino [on-line]; $2005 . \quad$ Disponível em: http://www.centrodememoria.unicamp.br/arqhist/votofem.pdf 
MACHADO V. As várias dimensões do masculino: traçando itinerários possíveis. Revista Estudos Feministas. 2005;13(1):196-99. [on-line]. Disponível em:

Medrado B, Lyra J, Galvão K, NAscimento P. Homens por quê? Uma leitura da masculinidade a partir de um enfoque de gênero [on-line]. Disponível em: http://www.papai.org.br/homens_porque.htm

MeRCADANTE OA. O centro de saúde como local de estagio de saúde pública para estudantes de medicina [dissertação]. São Paulo: Faculdade de Saúde Publica, Universidade de São Paulo; 1970.

MERYN S. Gender Quo Vadis: 21 the first female century? The Journal of Men's Health and Gender. 2004;1(1):3-7.

NicOlaU J. A participação eleitoral no Brasil. Working Paper Series. University of Oxford Centre for Brazilian Studies. Instituto Universitário de Pesquisas do Rio de Janeiro (IUPERJ) [on-line]; 2002. 50p. Disponível em: http://www.brazil.ox.ac.uk/workingpapers/Nicolau26.pdf

Pinheiro RS, Viacava F, Travassos C, Brito AS. Gênero, morbidade, acesso e utilização de serviços de saúde no Brasil. Ciências \& Saúde Coletiva. 2002;7(4):687707.

PITTMAN PM. Gendered experiences of health care. Iternacional Journal for Quality in Health Care. 1999;II(5):397-405.

RAGO M. Os feminismos no Brasil: dos "anos de chumbo" à era global. Labrys Estudos feministas. 2003;3: [on-line]. Disponível em: http://www.unb.br/ih/his/gefem/labrys3/web/bras/marga1.htm

RIBEIRO AS. A Mulher e o Voto [on-line]. Disponível em: http://www.al.sp.gov.br/eleicao/mulher_voto.htm

RowE J. Men's health promotion in general practice: a review oh the literature. Literature Review; 2000.

RUTZ W. Men's health on the European WHO agenda [editorial]. The Journal of Men's Health and Gender. 2004;1(1):22-5. 
SABO D. Understanding Men's Health: A Relational and Gender Sensitive Approach. Harvard Center for Population and Development Studies Working Paper Series. 1999;99.14: [on-line]. Available from: http://www.hsph.harvard.edu/Organizations/healthnet/HUpapers/gender/sabo.html

SCHOFIELD T, CONNELl RW, WALKER L, et al. Understanding men's health and illness: a gender-relations approach to policy, research, practice. Journal of American College Health. 2000;48:247-56.

SCHRAIBER LB. Ocorrência de casos de violência doméstica e sexual nos serviços de saúde em São Paulo e desenvolvimento de tecnologia de atendimento para o programa de saúde da mulher/FAPESP [mimeo]. Linha Políticas Públicas, São Paulo; 1999.

Schraiber LB \& D' OliveIRA AF. WHO Multi-Country Study on Women's Health and Domestic Violence Against Women. Projeto de Pesquisa. São Paulo, 1998.

SCHRAIBER LB, D' OLIVEIRA AF, FRANÇA-JUNIOR I et al. Violência contra a mulher: estudo em uma unidade de atenção primária à saúde. Rev. Saúde Pública. 2002; 36(4):470-7.

SCHRAIBER LB, GOMES R, COUTO MT. Homens e saúde na pauta da saúde Coletiva Ciências \& Saúde Coletiva - Saúde do Homem: Alerta e Relevância. 2005;10(1):717.

Schraiber LB, MENDES-GonÇALVES RB. Necessidades de saúde e atenção primária. In: SCHRAIBER LB, NEME MIB, MENDES-GONÇALVES RB. Saúde do adulto - programas e ações na unidade básica. São Paulo: Hucitec; 1996. p.29-47.

Sempla - Departamento de Estatística e Produção de InformaÇão Dipro. Secretaria Municipal de Planejamento - Município de São Paulo [on-line]. Disponível em: http://www.vitruvius.com.br/entrevista/wilheim/wilheim_06.jpg

Secretaria Municipal de Saúde de São Paulo - Centro de Controle de DOENÇAS (SMS-CCD). Disponível em: http://ww2.prefeitura.sp.gov.br//arquivos/secretarias/saude/vigilancia_saude/doenca_ agravo/0014/stuac_tuberculose.pdf 
SILVA SG da. Masculinidade na história: a construção cultural da diferença entre os sexos. Psicol. Cienc. Prof. 2000a;20(3):8-15. [on-line]. Disponível em: http://scielo.bvs-psi.org.br/pdf/pcp/v20n3/v20n3a03.pdf

SILVA SV da. Os estudos de gênero no Brasil: algumas considerações. Revista Bibliográfica de Geografía y Ciencias Sociales. 2000b;262 [on-line]. Universidad de Barcelona. Disponível em: http://www.ub.es/geocrit/b3w-262.htm

SilveIRA C. O significado da prática profissional e do ensino em unidade básica de saúde: um estudo de cultura organizacional no Centro de Saúde Escola Barra Funda [tese]. São Paulo: Faculdade de Saúde Pública, Universidade de São Paulo; 1999.

Simon UM. O Centro de Saúde Experimental da Barra Funda [dissertação]. São Paulo: Faculdade de Saúde Pública, Universidade de São Paulo; 1970.

SOIHET R. História das mulheres e relações de gênero: debatendo algumas questões. ComCiência [on-line]. 2003. Disponível em: http://www.comciencia.br/reportagem/mulheres/16.shtm/

STEWART DE. What about men's health? A chair of women's health perspective [editorial]. The Journal of Men's Health and Gender. 2004;1(1):20-1.

Tabnet de Mortalidade [on-line]. São Paulo (Município). Disponível em: http://ww2.prefeitura.sp.gov.br//cgi/deftohtm.exe?secretarias/saude/TABNET/SIM/o bito.def

TAYLOR B. Exploring the perspectives of men who self-harm. Learning in Health and Social Care. 2003;2(2):83-91.

VIEIRA MAC, Bezerra EMR, Rosa CMM. População de rua: quem é, como vive, como é vista. São Paulo: Hucitec; 1992. 181p.

Villela W. Gênero, saúde dos homens e masculinidades. Ciências \& Saúde Coletiva - Saúde do Homem: Alerta e Relevância. 2005;10(1):29-32.

WhitE A, CASH K. The state of men's health in Western Europe. The Journal of Men's Health and Gender. 2004;1(1):60-6. 
Woods M, Macdonald J, CAMPBELl M. General practioners and men's health perceptions and practicalities [on-line]. 2002. Available from: http://menshealth.uws.edu.au/documents/GP\%20Conf\%20Paper.pdf 


\section{Bibliografia Consultada}


ABIPEME. Disponível em: http://www.abipeme.org.br/

AMERICAN MEN's STUdiES ASSOCIATION (AMSA). Available from:

www.mensstudies.org/

ANTROPOLOGIA, GÊNERO E MASCULINIDADE. Disponível em:

http://www.artnet.com.br/ marko/firstp.html

ÉPOCA. Eternamente jovem: como os homens de hoje podem viver mais, melhor e com mais saúde que seus pais. E aproveitar a vida até os 80 anos. São Paulo: Globo, 280:84-91;2003.

ESTUdos E COMUNICAÇÃO EM SEXUALIDAdE E REPRODUÇÃO HuMANA (ECOS), GRUPO DE ESTUdOS SOBRE SEXUALIDADE MASCULINA E PATERNIDADE (GESMAP). Disponível em: http://www.ecos.org.br/index2.asp

HISTÓRIA DO 8 DE MARÇO. Disponível em: http://www.suapesquisa.com/dia_internacional_da_mulher.htm

INSTITUTO PAPAI. Disponível em: www.papai.org.br/

INTERNATIONAL SOCIETY FOR MEN'S HEALTH \& GENDER (ISMH). Available from: www.ismh.org/

MeN’s Health. São Paulo: Abril; desde 2006.

MENS HEALTH FoRUM. Available from:

http://www.menshealthforum.org.uk/userpage1.cfm?item_id=291

MeN'S HEALTH JOURNAL: http://www.bmj.com/cgi/content/full/323/7326/1432

MEN'S HEALTH. Disponível em: menshealth.abril.com.br/

MEN's STUDIES PRESS. Available from: www.mensstudies.com/

ORGANIZAÇÃo DAS NAÇÕES UNIDAS. BRASIL. Disponível em: http://www.onubrasil.org.br/

ORgANiZAÇÃo Mundial DE SAÚde (OMS) - World HEALth ORGANIZATION (WHO). http://www.who.int/en/ 
PEREIRA MG. Mortalidade. In: PEREIRA MG. Epidemiologia: teoria e prática. Rio de Janeiro: Guanabara-Koogan S.A.; 1995. p.105-43.

REVISTA DA FolHA. Homens apaixonados. São Paulo: Plural Editora e Gráfica, ano:12(583):8-12;2003.

ReVista DA FOlHA. Papo de homem [especial saúde do homem]. São Paulo: Plural Editora e Gráfica; 2003.19p.

REVISTA VoGUE. Disponível em: http://www.voguebrasil.com.br/site/

The Journal Of Men's Health \& Gender. Available from: jmhg:www.jmhg.org

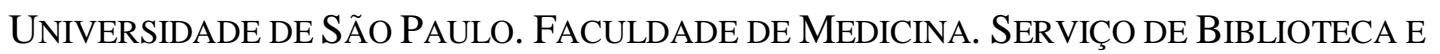
DOCUMENTAÇÃO. Guia de Apresentação de dissertações, teses e monografias da FMUSP. Elaborado por Annelise Carneiro da Cunha, Maria Júlia A. L. Freddi, Maria F. Crestana, Marinalva de S. Aragão, Suely C. Cardoso, Valéria Vilhena. 2a . ed. São Paulo: Serviço de Biblioteca e Documentação; 2005.

VEJA. Homem [edição especial]. São Paulo: Abril, ano:36(27);2003. 86p.

VEJA. Homem: o homem em seu novo papel [edição especial]. São Paulo: Abril, ano:37(34);2004. 74p.

VEJA. O novo homem. O homem em nova pele. São Paulo: Abril, ano:36(39):6272;2003.

Vogue HomeM. São Paulo: Carta Editorial; desde 2004. 